DOCUMENT OF

THE WORLD BANK GROUP

FOR OFFICIAL USE ONLY

\title{
Serbia Systematic Country Diagnostic
}

April 2015

Europe and Central Asia Region

This document has a restricted distribution and may be used by recipients only in the performance of their official duties. Its contents may not otherwise be disclosed without World Bank authorization. 


\section{CURRENCY EQUIVALENTS}

Exchange Rate Effective May 15, 2015

Currency Unit: RSD

RSD 106.075=US $\$ 1$

Fiscal Year

[January 1 - December 31]

\section{ABBREVIATIONS AND ACRONYMS}

\begin{tabular}{|c|c|c|c|}
\hline ALMPs & Alternative Labor Market Policies & NES & National Employment Service \\
\hline BEEPs & $\begin{array}{l}\text { Business Environment and Enterprise } \\
\text { Surveys }\end{array}$ & NHS & National Health Survey \\
\hline CAD & Current Account Deficit & NBS & National Bank of Serbia \\
\hline CEVES & Center for Advanced Economic Studies & NCDs & Non-communicable Diseases \\
\hline CeSID & $\begin{array}{l}\text { Center for Free Elections and } \\
\text { Democracy }\end{array}$ & NEET & $\begin{array}{l}\text { Not in Education, Employment or } \\
\text { Training }\end{array}$ \\
\hline $\mathrm{CoS}$ & Corridors of Serbia & NPLs & Nonperforming Loans \\
\hline $\mathrm{CPF}$ & Country Partnership Framework & OECD & $\begin{array}{l}\text { Organisation for Economic Co-operation } \\
\text { and Development }\end{array}$ \\
\hline CPIA & $\begin{array}{l}\text { Country Policy and Institutional } \\
\text { Assessment }\end{array}$ & OTE & $\begin{array}{l}\text { Hellenic Telecommunications } \\
\text { Organization }\end{array}$ \\
\hline CESEE & $\begin{array}{l}\text { Central, Eastern and South Eastern } \\
\text { Europe }\end{array}$ & PA & Privatization Agency \\
\hline DAAD & $\begin{array}{l}\text { German Academic Exchange Service } \\
\text { Deutscher Akademischer Austausch } \\
\text { Dienst }\end{array}$ & PERS & Public Enterprise Roads of Serbia \\
\hline DaLA & Damage and Loss Assessment & PIFC & Public Internal Financial Control \\
\hline DIA & Deposit Insurance Agency & PPO & Public Procurement Office \\
\hline $\mathrm{EC}$ & European Commission & RCA & Revealed Comparative Advantage \\
\hline ECA & Europe and Central Asia & RSD & Serbian Dinar \\
\hline ECD & Early Childhood Development & SAA & Stabilization and Association Agreement \\
\hline EMS & Enterprise Elektromreza Srbije & SAI & State Audit Institution \\
\hline EPS & Elektroprivreda Srbije & SCD & Systematic Country Diagnostic \\
\hline EU & European Union & SEE & South East Europe \\
\hline FDI & Foreign Direct investment & SILC & Survey on Income and Living Conditions \\
\hline FMC & Financial Management and Control & SMEs & Small, and Medium Enterprises \\
\hline FSA & Financial Social Assistance & SOEs & State-Owned Enterprises \\
\hline GDP & Gross Domestic Product & TEN-T & Trans-European Networks \\
\hline HBS & Household Budget Survey & TFP & Total Factor Productivity \\
\hline
\end{tabular}




\begin{tabular}{|c|c|c|c|}
\hline HR & Human Resources & TI & Transparency International \\
\hline IBRD & $\begin{array}{l}\text { International Bank for Reconstruction } \\
\text { and Development }\end{array}$ & TIMSS & $\begin{array}{l}\text { Trends in International Mathematics and } \\
\text { Science Study }\end{array}$ \\
\hline ICT & $\begin{array}{l}\text { Information and Communications } \\
\text { Technology }\end{array}$ & TPES & Total Primary Energy Supply \\
\hline IFC & International Finance Corporation & TVET & $\begin{array}{l}\text { Technical and Vocational Education and } \\
\text { Training }\end{array}$ \\
\hline LFS & Labor Force Surveys & UAE & United Arab Emirates \\
\hline LITS & Life in Transition Surveys & UNDP & $\begin{array}{l}\text { United Nations Development } \\
\text { Programme }\end{array}$ \\
\hline LSMS & Living Standards Measurement Survey & UNECE & $\begin{array}{l}\text { United Nations Economic Commission } \\
\text { for Europe }\end{array}$ \\
\hline MICS & Multiple Indicator Cluster Survey & UNESCO & $\begin{array}{l}\text { United Nations Educational, Scientific } \\
\text { and Cultural Organization }\end{array}$ \\
\hline MIGA & $\begin{array}{l}\text { Multilateral Investment Guarantee } \\
\text { Agency }\end{array}$ & UNICEF & United Nations Children's Fund \\
\hline MINT & $\begin{array}{l}\text { Mathematics, Informatics, Natural } \\
\text { Sciences, and Technology }\end{array}$ & VAT & Value Added Tax \\
\hline MoE & Ministry of Economy & WB & World Bank \\
\hline $\mathrm{MoF}$ & Ministry of Finance & WTO & World Trade Organization \\
\hline MoT & Ministry of Transport & & \\
\hline
\end{tabular}

Regional Vice President: Laura Tuck

Country Director: Ellen Goldstein

Senior Director: Marcelo Giugale/Ana Revenga

Practice Manager: Ivailo Izvorski/ Carolina Sanchez

Task Team Leader: Abebe Adugna/ Trang Nguyen 


\section{Serbia Systematic Country Diagnostic (SCD) Table of Contents}

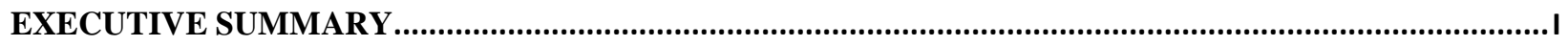



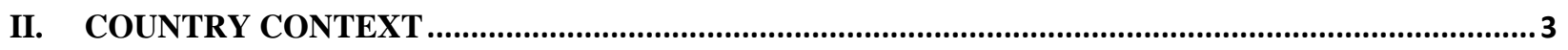

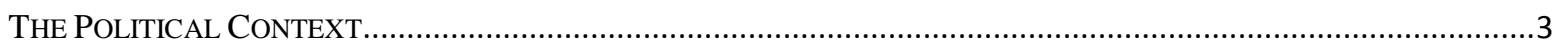

ECONOMIC GROWTH, POVERTY REDUCTION, AND SHARED PROSPERITY .....................................................

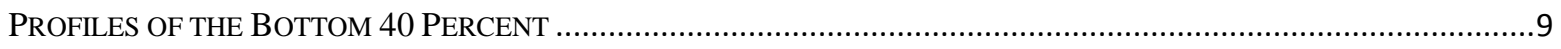

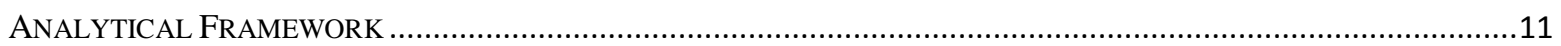

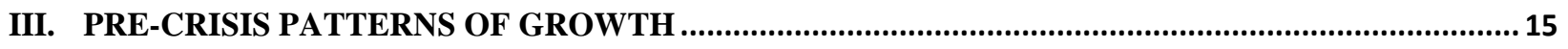

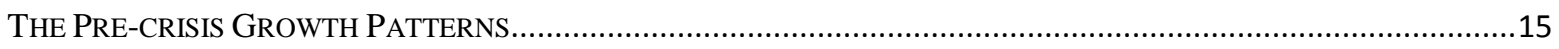

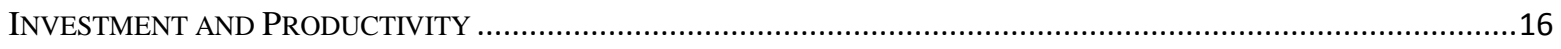

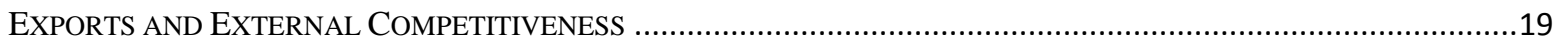

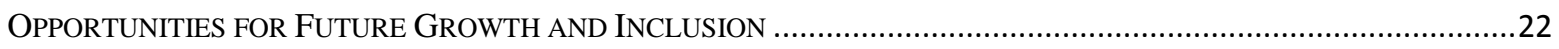



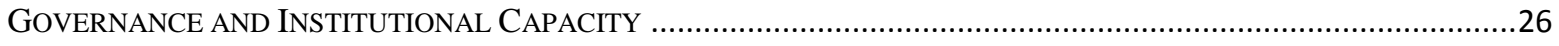

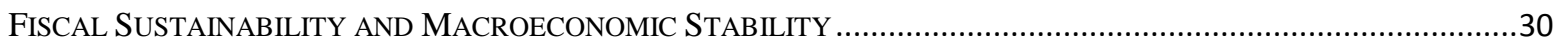

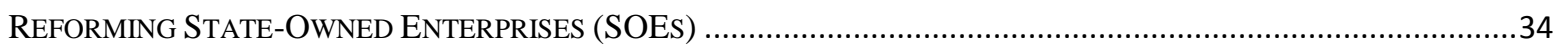

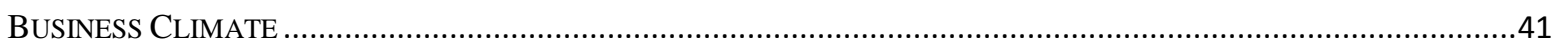

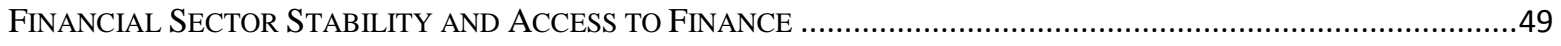

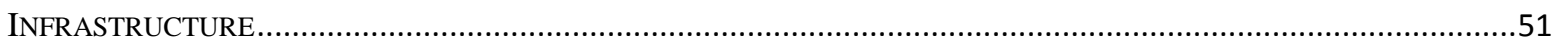

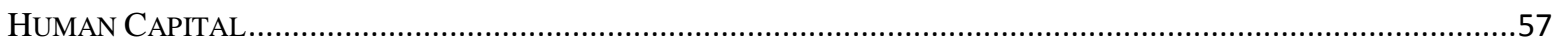

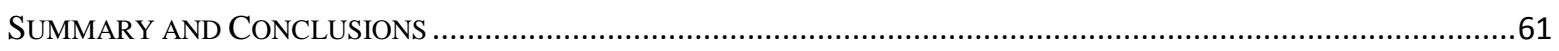

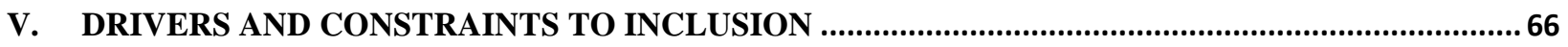

EQUITABLE AND SUSTAINABLE OPPORTUNITIES TO BUILD CRITICAL ASSETS .................................................67

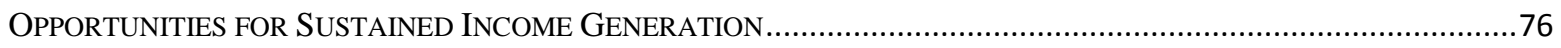

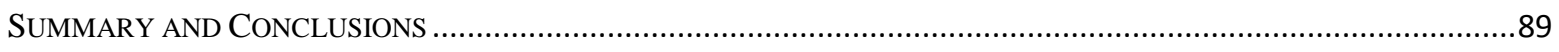

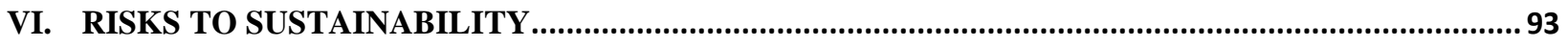

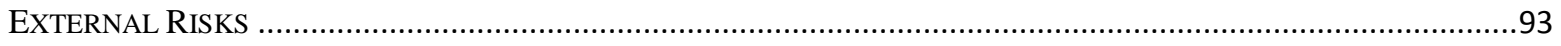

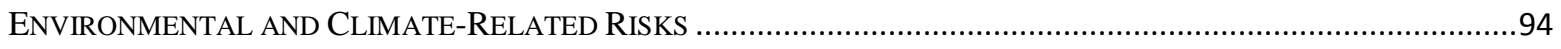

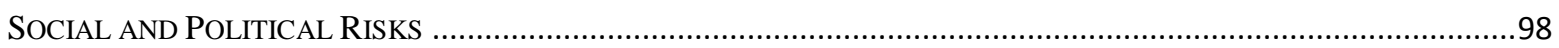

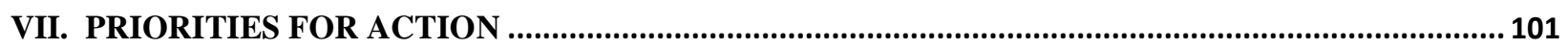

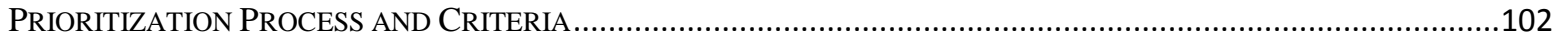

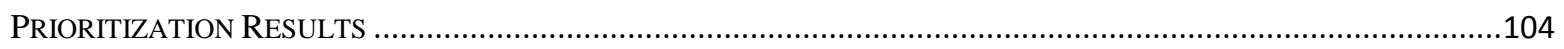

SEQUENCING OF REFORMS AND OVERALL IMPACT ON THE TWIN GOALS.................................................112

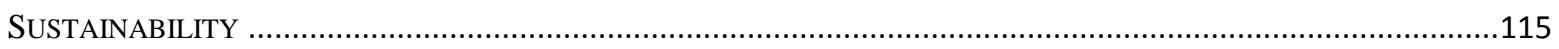

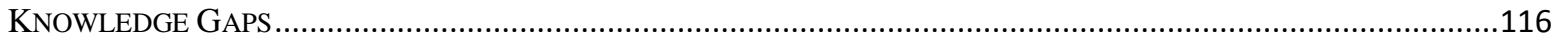

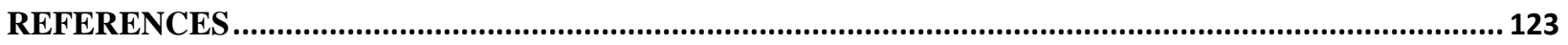


ANNEX 2: SERBIA: PUBLIC FINANCIAL MANAGEMENT CHALLENGES .......................................... 129

ANNEX 3: SERBIA GROWTH ACCOUNTING, 1990-2011 ..................................................................... 131

ANNEX 4: SERBIA GOVERNANCE BENCHMARKING VIS-À-VIS EU MEMBER STATES.................. 137

ANNEX 5: SERBIA: KEY MACROECONOMIC INDICATORS AND PROJECTIONS............................ 139

ANNEX 6: PUBLIC CONSULTATIONS AND CITIZEN ENGAGEMENT AROUND THE SCD............... 140

\section{TABLES}

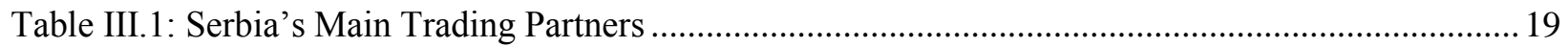

Table IV.1: Serbia Governance and Institutional Capacity Benchmarking a/ ...........................................2 28

Table IV.2: Method of Privatization for Companies in the Privatization Agency Portfolio........................ 35

Table IV.3: Logistics Performance Index and Subcomponent Rankings ................................................ 48

Table IV.4: Serbia: Rate of Returns of Education, Percent (per year in each level)..................................59

Table VI.1: Serbia: Select Comparative Environmental Sustainability Indicators ..................................95

Table VII.1: Serbia: Key Constraints and Desired Medium-Term Policy Goals.................................... 102

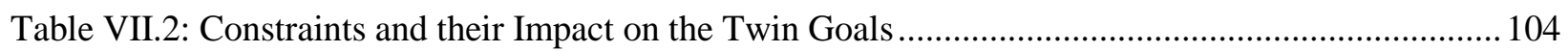

Table VII.3: Five Top Priorities with the Highest Impact on the Twin Goals........................................ 106

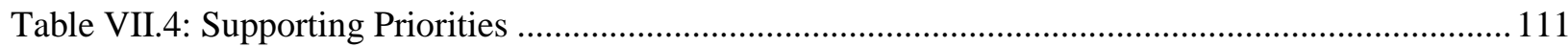

Table VII.5: Serbia SCD Prioritization: Principal Constraints and their Impact on Twin Goals (Based on

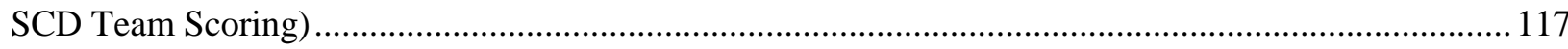

\section{FIGURES}

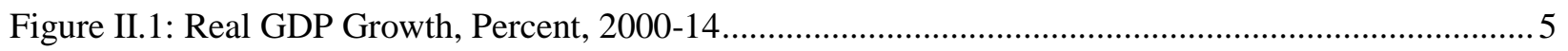

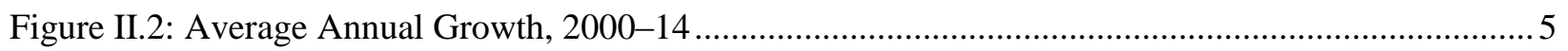

Figure II.3: Poverty Headcount (Percent) and Real GDP per Capita..................................................... 6

Figure II.4: Poverty Rates, Serbia and EU-CESEE (Central, Eastern and South Eastern Europe), 2012

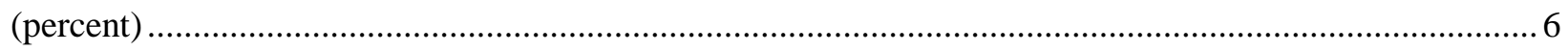

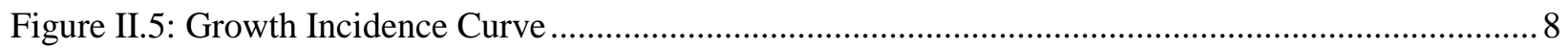

Figure II.6: National Consumption Aggregate-based Shared Prosperity Indicator .................................. 8

Figure II.7: Annualized Growth of the Bottom 40 Percent, ECA Countries ............................................ 8

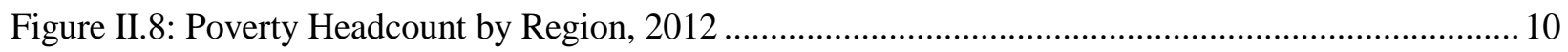

Figure II.9: Age-Gender Pyramid and Those at Risk of Poverty, Percent .............................................. 10

Figure II.10: Employment by Occupation, Percent .............................................................................. 11

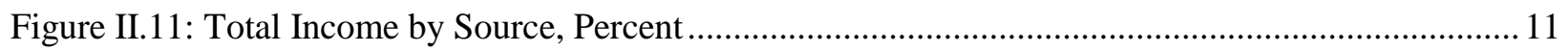

Figure II.12: Elements of Sustainable Poverty Reduction ................................................................ 12

Figure II.13: Summary: The context for Serbia's poverty and shared prosperity challenge ...................... 13

Figure III.1: Demand Composition of Growth, 2004-13 …............................................................ 15

Figure III.2: Current Account Deficit, Percent of GDP, 2002-2013 …................................................ 15

Figure III.3. Private and Public Investment, Pre- and Post-Crisis, Percent of GDP ................................ 16 
Figure III.4. FDI and Remittances, Pre- and Post-Crisis, Percent of GDP ............................................ 16

Figure III.5: Real Capital Stock and Human Capital Adjusted Employment, 1990-2011 _....................... 17

Figure III.6: Growth Accounting, 1991-11 ...................................................................................... 17

Figure III.7: (Real) Apparent Labor Productivity in Manufacturing, 2012 ........................................... 17

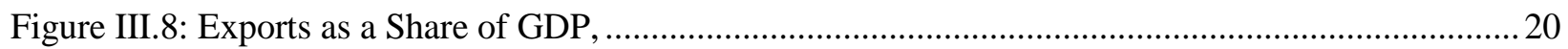

Figure III.9: Exports in Comparison to Regional Peers, 1991-2013 …................................................. 20

Figure III.10: Labor Productivity and Real Earnings, 2002-13 ......................................................... 20

Figure III.11: The Relationship of Labor Productivity to Employment, 2003-13 ..................................20

Figure III.12: Share of Components in Manufactured Exports, 2002-12 ...........................................2

Figure III.13: Share of ICT Services in Total Service Exports, Serbia and Comparators, 2008-12 .........21

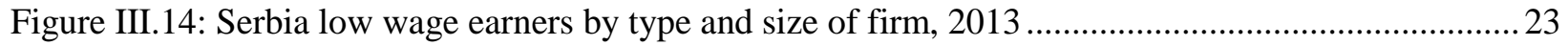

Figure III.15: Serbia low wage earners by sector, 2012, percent share ...............................................23

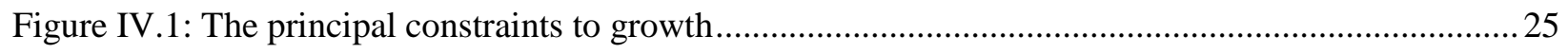

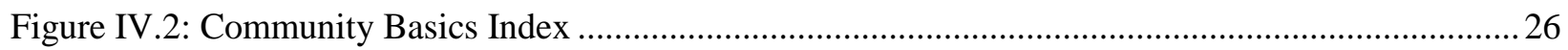



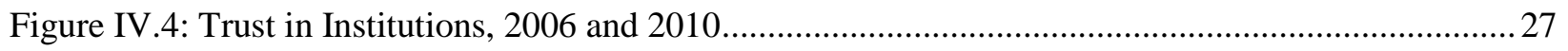

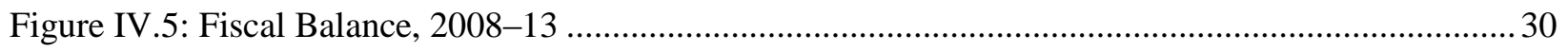

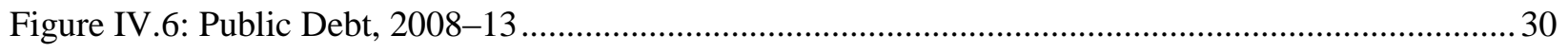

Figure IV.7: Serbia: Public Debt Sustainability 1, 2 ..................................................................... 33

Figure IV.8: Electricity Prices for Domestic Consumers, Europe and South East Europe........................ 38

Figure IV.9: Serbia's 2014 Doing Business Position ................................................................... 41

Figure IV.10: Most Problematic Business Regulations in Serbia, Doing Business Rankings................... 41

Figure IV.11: Biggest Investment Climate Constraints in Serbia .........................................................43

Figure IV.12: Business Perceptions of Corruption in Serbia, 2013 ….................................................. 44

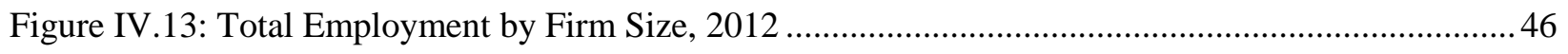

Figure IV.14: Job Creation by Firm Size, 2010-12 …...................................................................... 46

Figure IV.15: Main Business Climate Constraints on SMEs.............................................................4 47

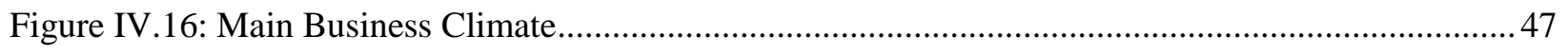

Figure IV.17: Top Five Obstacles for Exporters.......................................................................... 47

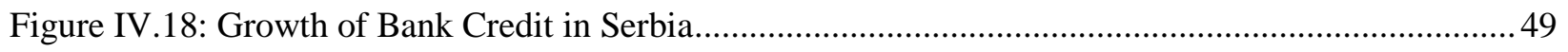

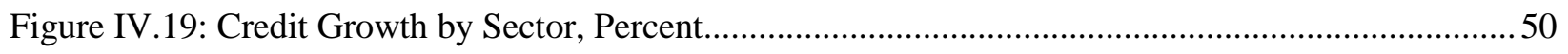

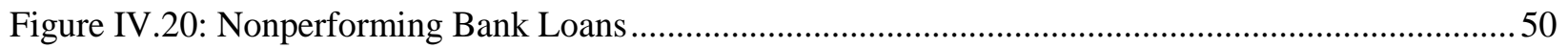

Figure IV.21: Transport Infrastructure Quality Rankings, 2014-15 ...................................................52

Figure IV.22: Cost of Routine Maintenance (Euros per km) .............................................................53

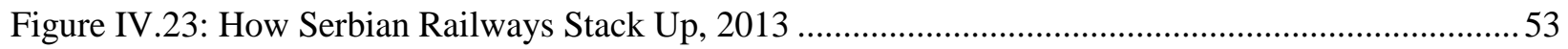

Figure IV.24: Energy Intensity, Selected Countries, 2011, 2013 ......................................................55

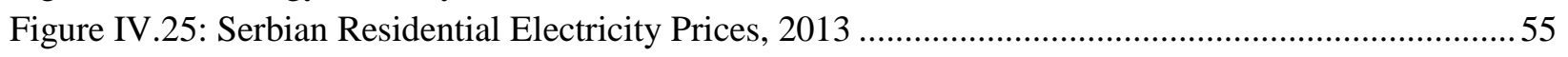

Figure IV.26: Fixed and Mobile Broadband Penetration, 2013 ….....................................................56

Figure IV.27: International Internet Connectivity, Kbps, 2013 .........................................................56

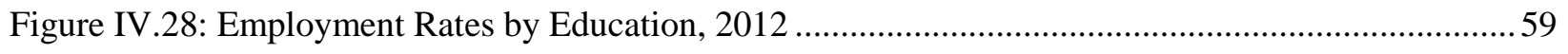

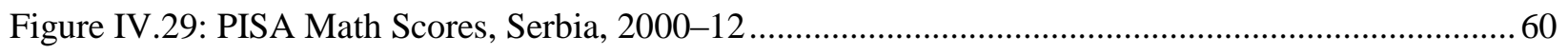

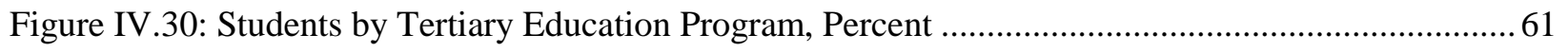

Figure IV.31: The critical constraints on Serbia's growth performance .................................................64

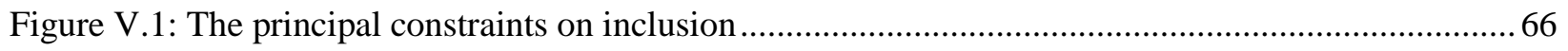




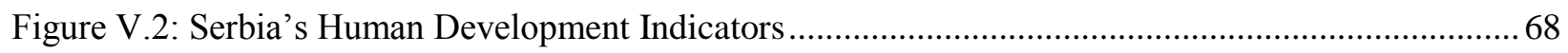

Figure V.3: Access to the Internet by Income Group and Urban-Rural Location ....................................6 68

Figure V.4: Early Education ECD Participation by Welfare Quintile ....................................................69

Figure V.5: Educational Attainment By Income Group ….............................................................. 70

Figure V.6: Nutrition Outcomes of Poor and Roma Children under 5, Percent ....................................... 71

Figure V.7: Child Immunization and Antenatal Care, by Welfare Quintile* .......................................... 72

Figure V.8: Unmet Medical Needs and Insurance Coverage, by Income Quintile .................................. 72

Figure V.9: Self-reported Adult Hypertension by Income Quintile....................................................... 72

Figure V.10: Non-communicable Disease Incidence, 2000-13 …...................................................... 72

Figure V.11: Social Assistance Coverage of the Poor, Percent ............................................................ 75

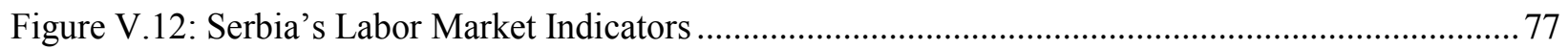

Figure V.13: Net Employment Losses by Sector, 2008-14 .............................................................. 77

Figure V.14: Structure of Net Job Creation, by Type and Age of Worker, 10/2012-9/2014 ...................78

Figure V.15: Contribution to Job Creation by Firm Size and Age ...................................................... 79

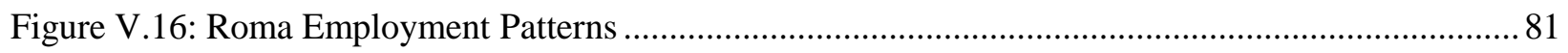

Figure V.17: Employment Rates by Age, Percent …....................................................................... 81

Figure V.18: Accounts at Financial Institutions by Income (Percent) ................................................. 85

Figure V.19: Employment Breakdown by Sector, Percent ............................................................. 86

Figure V.20: Crop Yields, Serbia, FYR Macedonia, Turkey, and the EU (100 kg/ha, 2010-2012 average)

Figure V.21: Agricultural Labor Productivity, Serbia and EU, 2004-12, €/person Employed, ................ 87

Figure V.22: The critical constraints on the sharing of Serbia's prosperity ........................................... 92

Figure VI.1: The principal risks to sustainability …....................................................................... 93

Figure VI.2: Composition of Serbia's Natural Capital, 2010 .............................................................. 95

\section{BOXES}

Box II.I: Measuring Poverty and Shared Prosperity in Serbia: Data and Methodology ............................. 7

Box III.I: Serbia's Aging Population and its Consequences............................................................... 18

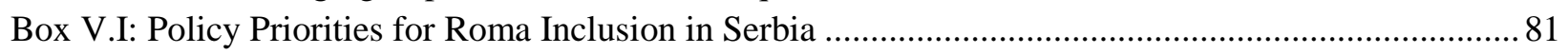

Box VI.1I: Climate Change Scenarios for Serbia: Heat Waves, Droughts, and Floods ........................... 97

Box VII.I: Prioritization method and Team Scoring of Priorities......................................................... 103 


\section{Acknowledgements}

This report was prepared by a World Bank Group team led by Abebe Adugna and Trang Van Nguyen, and consisting of: Olivera Jordanovic, Bekzod Shamsiev (agriculture); Craig Meisner, Philippe Ambrosi (climate change); Nina Arnhold, Katia Herrera (education); Claudia Suarez, Salvador Rivera (energy and extractives); Nikola Ille, Craig Meisner, Kseniya Lvovsky (environment and natural resources); Rinku Chandra and Elena Kantarovich (finance and markets); Marijana Jasarevic and Ana Maria Munoz Boudet (gender); Zachary Mills, Srdjan Svircev, Klaus Decker, Aleksandar Crnomarkovic (governance); Ana Holt, Patrick Eozenou, Timothy Johnston (health, nutrition, and population); Anita Schwartz, Johannes Koettl, Marijana Jasarevic, Marina Petrovic, Sandor Karacsony (social protection and labor); Lazar Sestovic, Ashley Taylor, Gallina Vincelette (macroeconomics and fiscal management), Trang Nguyen, Cesar Cancho, Maria Davalos (poverty), Wolfgang Fengler, Dusko Vasiljevic, Igor Matijevic, Michael Ferrantino, Claire Hollweg (trade and competitiveness); Baher El-Hefnawy, Natalija Gelvanovska, Svetlana Vukanovic, Raymond Bourdeaux (transport and ICT); Naima Hasci, Tomoko Unaki, Toshiaki Keicho, (urban, rural, and social development); David Malcolm Lord (water); George Konda, Thomas Lubeck, Nebojsa Arsenijevic, Violane Konar-Leacy, Aleksandra Krstic, Lisa Kaestner, Patrick Luternauer (all IFC). The team is grateful for the excellent data analysis support provided by Anil Onal and Cesar Cancho.

The report was prepared under the overall guidance of Ellen Goldstein (country director), Ivailo Izvorski (current practice manager), Carolina Sanchez (practice manager, poverty), Tony Verheijen (country manager) and Albert Zeufack (former practice manager). The team would like to also thank Ana Revenga (Senior Director, GPVDR), Satu Kahkonen (Director, GMFDR), Ambar Narayan, and Andras Horvai for their advice to the team throughout the preparation of the report.

The team is grateful for comments received from the peer reviewers, Peter Sanfey (EBRD), Marina Wes, and Emmanuel Skoufias. The report was enriched by several rounds of discussions held within the Serbia country team as well as in-country consultations with government, think-tanks, donors, and CSOs - and the team is grateful for the discussions. Finally, the team would like to thank Mismake Galatis, Indiana Fonseca Leiva, Hermina Vukovic Tasic, Amanda Schneider, Nejme Kotere, and Valentina Martinovic for their support in preparation of the report. 



\section{EXECUTIVE SUMMARY}

After a difficult decade of conflict associated with the breakup of the Socialist Federal Republic of Yugoslavia and of economic mismanagement in the 1990s, Serbia resumed its transition in 2001. Between 2001and 2008, supported by a favorable global economy and sustained implementation of reforms, Serbia made considerable progress in terms of both growth and poverty reduction. Real GDP growth averaged 5.0 percent annually, and the poverty headcount declined from 14.0 percent in 2002 to 6.6 percent in 2007. Poverty went down among those employed in agriculture, mining, and construction; to a lesser extent among those employed in services; and even among those without steady employment.

Since 2008 economic growth has sharply deteriorated, and progress on poverty reduction and shared prosperity has reversed. Average annual real GDP growth dropped to below zero, with the economy experiencing economic contractions in 2009, 2012, and in 2014, partly because of adverse external environment and weather shocks to agriculture (drought in 2012, floods in 2014). Although pre-crisis growth had particularly benefitted the bottom 40 percent of the population (B40), with annual growth of consumption higher than the average, the crisis hit them disproportionately. Data on recent trends of poverty and shared prosperity are not comparable to the earlier period because in 2012 Serbia changed its statistical methodology; however, the data available show that poverty climbed from 6.1 percent in 2008 to 9.2 percent in 2010 and annual B40 consumption fell by 3.8 percent annually while the national average consumption declined by 2.9 percent. Poverty went up among those employed in almost all sectors-agriculture, mining and construction, trade and services, and to a lesser extent industry - as well as among those not employed. Decomposition by income component suggests that losses in employment and labor income have contributed the most to the deterioration in shared prosperity and increased poverty since the onset of the crisis. $^{1}$

Rural poverty and losses in employment and labor incomes were the main reason for the decline in B40 welfare after 2008. Not only are poverty rates higher in rural areas but national trends closely track what happens there. Rural poverty after the crisis climbed from 7.5 percent in 2008 to 13.6 percent in 2010, accounting for 85 percent of the national rise. Similarly, labor market opportunities significantly worsened between 2008 and 2012 for all Serbians but particularly low-income earners. Private and informal employment was hit hard, resulting in a larger decline in B40 welfare than the national average. Decomposition by income component suggests that for 2008-10 a fall in the share of employed adults and in off-farm labor income contributed the most to the rise in poverty and the decline in B40 welfare.

\footnotetext{
${ }^{1}$ Using a different methodology to measure relative poverty as the fraction of the population living below 60 percent of the median income (a standard EU measure), Serbia was found to have 24.6 percent relative poverty rate in 2012higher than all EU members.
} 


\section{Pre-crisis growth patterns and opportunities for future growth}

As in many countries in emerging Europe, Serbia's growth was driven by high domestic demand and significant capital inflows before the global crisis. Consumption, both private and government, contributed significantly to growth. About three-quarters of foreign direct investment (FDI) went to nontradable sectors of the economy, fueling domestic demand and adding to exchange rate appreciation pressures. The pre-crisis growth model was associated with high external imbalances: the current account deficit reached over 20 percent of GDP in 2008, although it has dropped significantly since.

This consumption-fuelled growth proved unsustainable. Since 2008 the contribution of domestic demand to growth has remained negative. For higher and sustainable growth in the future, Serbia will need to rely more on increased capital accumulation, enhanced productivity and improved competitiveness. By investing more, becoming more export-oriented, and raising economy-wide productivity, Serbia could achieve more balanced and sustainable growth. Domestic demand may well contribute, but reliance on external demand is likely to be more sustainable.

Strong and sustainable growth will require higher levels of investment. At 3.4 percent of Serbian GDP, FDI is 2 percentage points lower than before the crisis. Total investment at 18-19 percent of GDP is still below the 21-22 percent pre-crisis level and the 25 percent of GDP recommended by the Growth Commission as the threshold that countries should strive to meet to attain robust growth. While a quick return to the pre-crisis level is unlikely given the adverse external environment, Serbia can grow through higher investment. Attracting higher FDI will be a considerable part of restoring and sustaining higher growth.

The contribution of total factor productivity (TFP) has perceptibly deteriorated since 2008. A growth accounting reveals that the contribution of TFP to Serbian growth since 2008 has only been one-fourth of what it was before the crisis. The contribution of capital to growth has been mildly positive, but the contribution of human capital has been highly negative, especially in recent years. With Serbia's aging population and projected declines in labor force, maintaining a positive contribution to growth requires boosting labor productivity and innovation, increasing labor market participation (including for excluded groups), and keeping workers in the labor force until retirement age and beyond.

While exports have been driving growth since the crisis, there is considerable room to expand them. Though they have been growing steadily, exports are still relatively low in comparison to regional peers. Opportunities for growth lie in traditional exports, such as agricultural and food products, metals, automobiles (mainly parts and components), and services. Information and communications technology (ICT) comprise 51 percent of services exports, a higher share than in comparator countries in South East Europe; however, as measured by unit values, Serbian exports are typically of lower quality with less valueadded. They are also more volatile, suggesting problems with the capacity and consistency of export production. Proximity to and the prospect of full integration into the EU offer Serbia a solid opportunity to expand exports and diversify its economy.

A critical question for Serbia is whether export-led growth can support inclusion by providing adequate employment and labor income opportunities for the B40. In Serbia today only 40 percent of 
the adult population has a job; even fewer have a formal job, and fewer still a private-sector formal job. No country can sustainably grow with so little employment and participation. Not surprisingly, the B40 constitute the bulk of the jobless, where the lack of labor income is a major deterrent to escaping poverty. They mostly represent two groups in Serbia: (a) the pre-transition generation, aged 40 or more, who either lost their jobs during the transition and never found a proper new job, or entered the labor market as the transition was beginning and never gained a firm foothold; and (b) groups, especially minorities like the Roma but also women generally, who have never been strongly attached to the labor market. These groups now live either on public and private transfers or subsistence farming and are largely excluded from labor markets, especially formal jobs.

For export-led growth-i.e. growth that exposes large parts of the Serbia economy to international competition--to support inclusion, it will be essential to raise skills and productivity of those at the bottom of the ladder. Chapter 5 demonstrates that many of the B40 do not have the skills required to benefit from the types of jobs that export-led growth could create. While agricultural products have some potential, most low-wage earners in Serbia work in the service and hence the non-tradable sector; they work for micro and small enterprises; and many of them are in fact self-employed. To boost employment for the B40 and excluded groups, in addition to promoting export-led growth, policy should be directed to removing barriers for small and medium enterprises (SMEs) and self-employment and attracting investments in agriculture and services.

\section{Drivers and Constraints to Growth}

To generate broad-based and sustainable growth, Serbia will need to tackle numerous constraints. These include improving governance and institutional capacity, restoring fiscal sustainability and ensuring macroeconomic stability, completing the large agenda of first-generation reforms of state-owned enterprises (SOEs), making the business climate more attractive, and removing infrastructure and skills constraints to productivity and competitiveness. As a cross-cutting issue, Serbia needs to better manage disaster and climate-related risks. Agriculture, a vital component of the Serbian economy, is already most vulnerable to weather hazards and climate change, with repercussions for growth, fiscal sustainability, shared prosperity and poverty reduction. Recent weather shocks have directly affected both people and infrastructure and caused serious damage to the economy and the well-being of vulnerable population (see Sustainability section below).

Inadequate governance and institutional capacity raise questions about Serbia's ability to lay a foundation for sustained and inclusive economic growth. The Serbian public administration lacks robust accountability for results and suffers from limited technical capacity and a high turnover in senior staff and advisors during frequent changes in government, which have led to a loss of continuity and institutional memory. The growing number of politically-based appointments has exacerbated clogged decision making throughout the system. Policy coordination and management are inadequate; many decisions are being pushed up to ministerial levels, and those at the top are overloaded with relatively trivial issues. This poor governance undermines implementation of reforms even when political will is sufficient.

If Serbia is to restore growth and fiscal sustainability, completing first-generation SOE reforms is crucial. This will enable Serbia to restore growth; reduce fiscal pressures on the state budget; level the playing field for the private sector; improve resource reallocation and efficiency; and increase productivity. 
These gains, however, are not costless. Between 30,000 and 50,000 workers could be made redundant, and cushioning the social impacts of labor retrenchment - through well-designed severance packages, employment services, and active labor market policies to support transition to new jobs-is critical for success of the reforms. This will require determined political commitment to see through reforms.

Serbia needs to do much more to promote private-sector-led growth and employment creation. The investment climate must be improved to retain current investment, attract more, and expand private sector participation in the economy. All types and sizes of firms would benefit from (a) reducing the time it takes to obtain permits in general and construction permits in particular; (b) making policy and regulation more predictable, and consistently enforcing regulations through better administrative coordination and supervision; (c) continuing to restructure SOEs and reduce informal competition with formal businesses; and (d) improving contract enforcement and insolvency mechanisms. SMEs need special attention to access to finance, in particular long-term finance; facilitating customs and trade is a priority for large and exporting enterprises.

Further investment and institutional reforms in infrastructure networks could enhance connectivity, competitiveness and access to services. Rail passenger services are neither reliable nor comfortable. Not only is investment in maintaining the Serbian roads network (an estimated 9,500 km) low, but the per-km cost is among the highest in the region. That could be reduced through competitive bidding and performance contracts. Investment is also needed to upgrade the energy infrastructure to reliably meet demand, create a power exchange market, and establish a transparent price signal and facilitate regional power trade. Beyond investment, a significant part of the agenda for improving the quality of infrastructure, particularly in transport and energy, relates to institutional and financial reforms to make large public utilities more efficient - another illustration that SOE reforms are central to the growth and competitiveness agenda. In ICT, providing a supportive environment (e.g. through training, venture capital, incubation) can boost innovation and maintain Serbia's comparative advantage in ICT service exports. Public Private Partnerships (PPPs) should be explored as a means of generating new investments and improving efficiency in operations and maintenance of the infrastructure.

Given the current high unemployment rate, education and skill gaps are not yet binding constraints on growth but may become so if the economy recovers. Firms in Serbia consider an inadequately educated workforce to be a constraint on doing business but it is not among the top five (although it is among the top 10). Other indicators suggest that the type and quality of skills students acquire may not be relevant to the modern economy: the education system produces a large share of functionally illiterate youth; technical and vocational education and training (TVET) curricula are obsolete; and most college students major in social sciences even though market demand is in such areas as agribusiness, manufacturing, and ICT services. Reforming the training and education systems in the short to medium term can help address future skill needs.

\section{Drivers and Constraints to Inclusion}

Asset accumulation is reasonably good in Serbia, although concerns remain about both socioeconomic and geographic disparities and the quality of human capital. Serbia's human development indicators and access to basic services are generally good across the country and compared to 
other countries with similar income levels. Participation in education in Serbia is high for all levels, but socioeconomic differences in schooling are stark at the preprimary level: only 8.6 percent of children aged 36-59 months in the poorest quintile and 6 percent of Roma children participate in early childhood development programs, compared to 82 percent of children in the wealthiest quintile. Similar disparities persist through elementary and secondary education, and in learning outcomes, especially according to school location, size, and parental education. Serbia's key health outcomes, including life expectancy and infant and maternal mortality rates, are good for its income level. However, the B40, and particularly excluded groups such as the Roma, have worse health and nutrition outcomes. Infant mortality rates are twice as high for Roma as for the overall population. 94 percent of the population has health insurance coverage, but lower-income groups tend to have slightly higher unmet medical needs and lower insurance coverage. Inefficient health spending, the poor quality of primary care, service rationing, and corruption make it harder to improve the health of disadvantaged groups and address non-communicable diseases.

While the targeting of social safety nets to the poorest quintile is respectable, coverage of the poor, particularly by the last-resort social assistance program, is small. Serbia's last-resort means-tested social assistance program, Financial Social Assistance (FSA), is well targeted to the poor, with 75 percent of the benefit going to the poorest quintile. However, the FSA covers only 5.7 percent of the population in the poorest quintile. Although existing built-in work disincentives in the FSA design might not constitute the largest barrier for formal employment, given the small generosity of the benefit, efforts to expand targeted social assistance need to go hand-in-hand with improvement of the benefit design to incentivize transition to formal work.

Serbia runs the risk of losing another generation of workers. Many Serbians are not active in the labor market, unemployment is high, and formal employment is low. As of 2014, the activity rate stood at 50 percent, the employment rate at 40 percent, and unemployment at 17 percent. At close to 50 percent, youth unemployment is more than twice that of the working age population. About 22 percent of young people are neither in employment nor training or education, one of the highest rates in the world. Currently about 21 percent of all jobs are informal; this means that in 2013 a mere 1.8 million people worked in the formal economy, 700,000 of them in the public sector. The private sector is not generating many formal jobs, and public employment still accounts for more than one-third of formal employment. Among the 1.1 million formal private workers, more than 200,000 are sole proprietors. Informal employment is more likely to be part-time - an estimated 30-40 percent of all informal employment - and is particularly high among women.

Most jobs created recently have been informal. Between October 2012 and the third quarter of 2014 the Serbian economy created about 176,000 jobs. While formal full-time jobs actually decreased by about 18,000 , informal full-time jobs expanded by about 65,000 . The loss of formal full-time jobs was almost entirely borne by those aged 40 and older. The younger generation actually experienced a slight expansion, which suggests that younger workers were replacing older. The trend toward irregular employment, either part-time formal or entirely informal, is clear. The largest group of jobs created, about 79,000, was parttime and informal, mostly in agriculture but also in construction and services. These are certainly not the best jobs, but a shift in policy to acknowledge this source of job creation - and an effort to bring workers into the formal sector-is likely to improve the impact on household welfare. 
Numerous factors account for Serbia's sluggish labor market. On the demand side, weak or even negative economic growth and limited private job creation have reduced income-generating opportunities for all Serbians but especially for the B40. On the supply side, while human development indicators are generally good, issues remain on the quality and on the types of skills the education and TVET systems produce. Ineffective labor institutions also make it difficult to match labor and jobs efficiently. Until a 2014 reform, labor regulations restricted part-time work. A number of other constraints - ranging from poor public employment services to a high tax wedge for low-wage workers and to work disincentives in social welfare-also constrain labor market performance.

The need to re-embark on privatization and SOE reforms adds urgency to addressing the sluggish labor market. At present the labor market could not absorb the 30,000-50,000 SOE workers expected to be released, who would mostly be older and unskilled. If they find work at all, it is likely to be informal, low-skilled, low-paid, casual, and part-time. The challenge for the government is to manage the short-term social impact of SOE reform by providing adequate compensation for redundant workers while creating a labor and social protection system that can mitigate the long-term impacts.

In tackling these problems, policy must focus on both promoting growth and building up labor market policies and institutions. Addressing barriers to broad-based growth and private-sector-led job creation is clearly important. Beyond growth, however, it is also vital to improve the functioning and inclusiveness of labor market institutions. Here the priorities are to remove barriers to low-skills jobs through flexible work arrangements; reform the minimum social security contribution; redesign the social benefit system to make it incentive-compatible; reform labor market institutions like the National Employment Service (NES) to support efficient match making between job-seekers and employers; and dismantle financial barriers for SMEs. These reforms would constitute the crucial first step to engaging those not currently in the Serbian labor market. For women, whose contribution will be important, additional measures like providing care facilities for children and the elderly might be necessary to help them reconcile care duties with career goals.

National poverty and shared prosperity trends in Serbia track what happens in agriculture. According to recent data, 36 percent of the B40 and 46 percent of those at risk of poverty are employed in agriculture and mining. Geographically, (semi-)subsistence farmers are concentrated in the South, where poverty is also higher, a smaller portion of income comes from the sale of food, and a higher proportion is direct consumption. At least in the short term, agricultural growth and higher productivity could have a sizable impact on reducing the poverty of those employed in agriculture.

What can be done to raise agricultural productivity and rural incomes? Land fragmentation, skewed incentives due to subsidies, and broad policy and institutional unpredictability constrain agricultural productivity in Serbia. Among priorities for raising rural productivity and incomes are: (a) Reduce distortions in the design of subsidies, such as the area-based payment, and make eligibility conditional on initiatives to invest, improve product quality, and adopt sustainable environmental practices. (b) Make policy and institutional support more predictable: budget support to agriculture has been volatile; individual support programs change often; and even within programs, within a single season eligibility criteria and the amount of support can change more than once. More predictable policy would create a more favorable environment for farm investment and production. (c) Improve incentives for farmers to raise productivity 
and on-farm investment: rebalancing public support between direct payments and investment or structural support could shift the dominance from direct subsidies to productivity-enhancing support in terms of extension services, diversification of farm income, irrigation and improvements of infrastructure, and technology transfer. Disaster risk management and adaptation measures (e.g., expanding the share of winter crops, improving on-farm water management and water storage capacity, etc.) are particularly important in agriculture not only to support productivity and growth but to protect and promote the welfare of the B40.

While inclusion policies are desirable on their own, they also can contribute to sustainable growth, creating a virtuous cycle. Early childhood development (ECD) interventions, especially for groups like the Roma who lag behind in accumulating human capital, are critical not only for inclusion but to build the skills and competencies that are critical for lifelong learning and future competitiveness and sustained growth. Conversely, the costs to Serbia of continuing to exclude people who are over 40, women, and Roma are high in terms of both fiscal costs and transfers and foregone income and economic growth. For example, , an estimate shows that the income loss associated with gender gaps in labor force participation for wage earners, employers, and self-employed in Serbia is a significant $16 \%$ of income per capita (Cuberes and Teignier 2014). Over the medium to long term, Serbia's aging population and declining workforce will make it ever more urgent that the Roma and other excluded groups be equipped with the skills tomorrow's work force will need.

\section{Priorities for Action}

This report analyzes in detail a number of areas that constrain growth, shared prosperity, and poverty reduction in Serbia. Some of these areas-governance and institutional capacity, fiscal sustainability and macroeconomic stability, SOEs, the business climate, financial sector stability and access to finance, infrastructure, and human capital - are constraints to growth. A second set - education, health, social protection, the labor market, and self-employment and agriculture - are constraints to making growth inclusive. From these broad areas, the SCD has identified 11 distinct priorities for accelerating economic growth, reducing poverty and increasing shared prosperity as outlined in Table ES.1.

Prioritization relied on a thorough review of the evidence, a process of team discussion and scoring of priorities, and engagement with local stakeholders to identify the most critical barriers to sustainable achievement of the twin goals in Serbia. While the main criterion is the impact of removing constraints to achieving the twin goals, among other considerations are whether a constraint is an enabler of other reforms ("foundational"); whether it is cross-cutting and its removal has multiple benefits or impacts; and how quickly its removal would spur growth, shared prosperity, and poverty reduction. After a systematic review of the evidence and the SCD team's scoring of the relative impact of the priority areas, two were seen as foundational, enabling other reforms, five were seen as high impact for achieving the twin goals and four were seen as supporting priorities, which have either indirect or long-term impact on growth, poverty and prosperity. 
Table ES.1: Most Binding Constraints to Progress toward the Twin Goals in Serbia

\begin{tabular}{|c|c|}
\hline Constraints/Medium Term Policy Objective & $\begin{array}{l}\text { Impact on Twin } \\
\text { Goals }\end{array}$ \\
\hline \multicolumn{2}{|l|}{ Foundational Priorities } \\
\hline $\begin{array}{l}\text { Fiscal sustainability, financial and macro stability: Restore debt } \\
\text { sustainability and maintain macro and financial stability. }\end{array}$ & - High \\
\hline $\begin{array}{l}\text { Governance and institutional capacity: Create an effective institutional } \\
\text { mechanism within government to coordinate, implement, and monitor reforms. }\end{array}$ & - High \\
\hline \multicolumn{2}{|l|}{ Priorities with Highest Impact on Twin Goals } \\
\hline $\begin{array}{l}\text { SOE reform: Reduce the state's footprint in the economy and make the public } \\
\text { sector more efficient by privatizing commercially oriented enterprises, } \\
\text { restructuring large public utilities, and rightsizing the public sector. }\end{array}$ & - High \\
\hline $\begin{array}{l}\text { Business climate reform: Create an environment conductive to private sector- } \\
\text { led investment, growth, and job creation. }\end{array}$ & - High \\
\hline $\begin{array}{l}\text { Labor market institutions: Strengthen these institutions to facilitate formal } \\
\text { employment, create earnings opportunities for the less well-off, and help } \\
\text { mitigate the negative consequences of SOE reforms. }\end{array}$ & - High \\
\hline $\begin{array}{l}\text { Agriculture, self-employment: Support higher agricultural productivity and } \\
\text { rural incomes to improve the welfare of the B } 40 \text { and reduce poverty. }\end{array}$ & - High \\
\hline $\begin{array}{l}\text { Infrastructure: Enhance the quality of public infrastructure to better support } \\
\text { international, regional and domestic connectivity. }\end{array}$ & - Medium-High \\
\hline \multicolumn{2}{|l|}{ Other Supporting Priorities } \\
\hline $\begin{array}{l}\text { Water and sanitation: Enhance Serbia's water resource management, } \\
\text { wastewater treatment, and environmental sustainability }\end{array}$ & - Medium \\
\hline $\begin{array}{l}\text { Education and skills: Expand access to and the quality of education for all, in } \\
\text { particular marginalized groups; reduce inequity and increase workforce } \\
\text { productivity by improving skills and learning outcomes. }\end{array}$ & - Medium \\
\hline $\begin{array}{l}\text { Health: Expand access to care for marginalized groups, reduce disparities and } \\
\text { improve the quality of care and health outcomes, and reduce the fiscal risks } \\
\text { related to personal spending on health. }\end{array}$ & - Medium \\
\hline $\begin{array}{l}\text { Social protection: Improve the coverage, equity, efficiency, and fiscal } \\
\text { sustainability of pensions and the social assistance program. }\end{array}$ & - Medium \\
\hline
\end{tabular}

\section{Risks to Sustainability}

For sustainable progress toward the twin goals, Serbia needs to manage three principal risks: external, environmental, and sociopolitical. While all are important, of special importance is better management of disaster and climate-related risks. Not only has Serbia in recent years been subject to a wide variety of natural hazards - floods, landslides, droughts, earthquakes, and wildfires - but these shocks directly affect both people and infrastructure and have caused serious damage to the economy and the wellbeing of vulnerable populations. Serbia experienced significant floods in 1999, 2001, 2002, 2005, 2006, 
2007, 2009, 2010, and - the biggest so far- in 2014. These caused loss of lives, resettlements, severe damage to infrastructure, and adverse impacts on agriculture, energy, and other productive sectors.

Agriculture, already on the frontline of the Serbian economy, is most vulnerable to weather hazards and climate change, with repercussions for growth (value-added and exports) and shared prosperity (B40 welfare). Increasingly frequent and intensive droughts in the past two decades have deeply damaged Serbian agriculture: it is estimated that droughts can reduce average crop yield by over 40 percent, which could worsen as the climate continues to change. While floods and landslides are the biggest threats, earthquakes and wildfires have also inflicted serious damage. Climate change is expected to increase the intensity and frequency of such disasters, with more droughts in the summer and more floods in the winter and spring. That will have serious implications for agriculture, infrastructure, and the security of the population. Addressing these environmental risks will require a significant shift from emergency response to a more comprehensive approach based on resilience and risk management, including: adaptation measures to reduce risks (e.g., expand the share of winter crops, improve on-farm water management and water storage capacity); integrate climate change considerations and adaptation into the agriculture sector development plan; pilot insurance schemes; build more knowledge and capacity (e.g., raise awareness of climate-smart practices by agro-ecological zone and heighten the related skills); and mitigation measures, in particular energy efficiency, clean energy, and waste management and pollution control.

The large reform agenda also carries substantial social and political risks, associated especially with significant employment retrenchment and adverse impacts on B40 welfare, which need to be managed well. Serbia's macroeconomic outlook is precarious and the economy is facing very serious challenges. Public debt levels are high and rising. Addressing public debt will require tackling stubborn spending pressures, which in turn will force wide-ranging and deep structural reforms that won't be easy to implement. The SOE and public sector reforms involve significant layoffs--potentially between 30,000 and 50,000 workers -- which are politically unpopular. If, as the public sector sheds employment in the short to medium term, private sector investment and job creation do not kick in fast enough to offset immediate public sector losses and/or other social mitigations measures are not put in place, unemployment and shared prosperity could worsen and the government could lose socio-political support for reforms. Cushioning and managing the social impacts of such layoffs and labor retrenchment - through appropriate severance packages, employment services, active labor market policies, social safety nets, and a return to growth -are all therefore critical to support transition and assure the success of the reforms.

Finally, the SCD identifies four principal knowledge gaps for future work: (1) Labor demand: the need for better firm-level data and analysis to understand the dynamics of labor demand, the impacts on labor market outcomes, and whether labor supply responds effectively. (2) Roma issues: The agenda to enhance inclusion is not simple; continuing to experiment, evaluate, and learn is necessary to find out what works best. (3) Skills: the extent to which skills gaps will constrain business and productivity in a growing Serbian economy is not well understood; and (4) the need for further study to generate knowledge on a fiscallyviable way of reducing the high minimum social security contributions, currently a strong disincentive to accepting formal part-time work in Serbia. While the authorities recognize this hinders formal employment, there is concern about the under-reporting of wages, implications for the health and pension funds and the fiscal sustainability of the reform overall. The study could build the evidence base to support this important reform. 


\section{INTRODUCTION}

1.1. After a difficult decade of conflict associated with the breakup of the Socialist Federal Republic of Yugoslavia and of economic mismanagement in the 1990s, Serbia resumed its transition in 2001. Between 2001 and 2008, the country, supported by a favorable global economic environment, made considerable progress in terms of both growth and poverty reduction. Real GDP growth averaged 5.0 percent a year. Relatively high growth in combination with social transfers helped to reduce poverty from 14 percent of the population in 2002 to 6.6 percent in 2007, according to the Living Standards Measurement Survey (LSMS) data. Decomposition analysis indicates that between 2006 and 2008 poverty fell mainly among people employed in agriculture, mining, and construction, to a lesser extent in services, and to some extent even among those without steady employment.

1.2. Since the global financial crisis, economic growth has stalled and progress on poverty reduction and shared prosperity has reversed. The decline in welfare fell disproportionately on the bottom two income quintiles due to losses of employment and labor income. Average annual real GDP growth after the crisis dropped to almost zero, and recession hit Serbia in 2009, 2012 and again in 2014. Not only has overall growth been negligible but inequality has somewhat worsened, reducing shared prosperity. Data for more recent trends of poverty and shared prosperity is not comparable to earlier period as Serbia changed in 2012 its methodology from a consumption-based, absolute poverty method of measurement (using the Household Budget Survey [HBS]) to an income-based, relative poverty method (using the Survey on Income and Living Conditions [SILC]); however, from the data available, it seems that the poverty rate climbed from 6.1 percent in 2008 to 9.2 percent in 2010, the latest year for which comparable data are available. The bottom 40 percent (B40) have been disproportionately hurt since the crisis: their annual consumption has fallen by 3.8 percent compared to an average drop of 2.9 percent for all Serbians. Poverty went up among those employed in almost all sectors-agriculture, mining and construction, trade and services, and to a lesser extent industry - as well as among those not employed. Decomposition by income component suggests that losses in employment and labor income have contributed the most to poverty and inequity since the crisis. Serbia faces significant challenges in generating income opportunities for those at the bottom of the distribution and excluded groups.

1.3. Serbia has in recent years made progress in overcoming its troubled European history and advancing toward European Union (EU) accession. Dialogue with the EU on membership began in November 2007. Serbia's accession negotiations formally started on January 21, 2014, and are now well underway.

1.4. This Systematic Country Diagnostic (SCD) aims to identify the major constraints on and opportunities for sustaining poverty reduction and shared prosperity ${ }^{2}$ in Serbia. The SCD serves as the analytic foundation on which the World Bank Group and the Government of Serbia will define a new

\footnotetext{
${ }^{2}$ These goals interpreted in a particular country context refer primarily to the national notion of poverty and the welfare particularly of those in the bottom two quintiles of the income distribution.
} 
Country Partnership Framework (CPF) for FY16-20. It is based on the best possible analysis, drawing on available evidence, and not limited to areas where the World Bank Group is currently engaged.

1.5. The SCD is structured as follows: Chapter II presents the political and economic context. The economic context describes recent trends in growth, shared prosperity, and poverty reduction and briefly discusses factors behind them. Chapter III discusses pre-crisis patterns of growth and opportunities for future growth and inclusion in Serbia. Chapter IV presents drivers of economic growth in Serbia and the principal constraints on growth and competitiveness. Chapter V discusses drivers of and constraints to economic inclusion. Chapter VI outlines risks to sustainable shared prosperity and poverty reduction. Chapter VII presents priorities for action. 


\section{COUnTry CONTEXT}

\section{The Political Context}

2.1. The fall of the Berlin Wall in 1989 and the monumental changes that followed in Eastern Europe was accompanied by the disintegration of the Socialist Federal Republic of Yugoslavia. Conflicts ensued first in Slovenia, then Croatia, Bosnia and Herzegovina, and finally Kosovo in 1999. As formerly constituent states declared independence, Serbia, together with Montenegro, remained as the successor state of the Federal Republic of Yugoslavia (FRY) until 2006, when Montenegro declared its own independence.

2.2. The 1990s was a lost decade for Serbia. The FRY economy suffered not only directly from the conflicts but also from economic mismanagement and loss of the Yugoslav and international markets due to UN trade sanctions. In 1993, output fell by more than 30 percent, and FRY experienced one of the most acute hyperinflations in world history. The conflicts also resulted in Serbia hosting a considerable number of refugees, over a million by some estimates, from the other former Yugoslav republics. A stabilization package introduced in 1994 brought inflation down below 20 percent, and a moderate economic recovery ensued from 1994 to 1999. However, in 1999, the conflict with NATO over Kosovo led to a decline in real GDP of 18 percent and a revival of inflation. The overall results of the decade were steep drops in output and trade and high to very high inflation; severe deterioration in conditions in the enterprise, financial, and infrastructure sectors; and worsened social indicators and higher poverty and inequality.

2.3. Serbia's political transition effectively began in 2001, when the coalition government led by Prime Minister Zoran Djindjic took office. At that point, real GDP per capita was less than half of its 1989 level. In 2001, the new government launched an ambitious reform program for rapid transition to a more market-oriented economy ${ }^{3}$, normalization of relations with foreign creditors, and integration with regional, EU, and world markets. After a decade of being ostracized, Serbia sought to reintegrate with Europe and the broader international community, a process that has proven to be protracted and complex.

2.4. Serbia's political trajectory since 2001 has been characterized by two main features: domestic political fragmentation and efforts at international reintegration. Domestically, after Djindjic was assassinated in March 2003, it became much harder to form coherent political coalitions. A succession of short-lived governments lacked the coherence required to follow through on the ambitious reform efforts that had been initiated. After 2005, short-lived political coalitions and extreme fragmentation dominated politics, extending into the critical period after the global economic crisis in 2008.

\subsection{The fragmentation of domestic politics was in part driven by disagreements over Serbia's} most sensitive political challenge-its relationship with Kosovo. Kosovo declared independence in 2008, but Serbia has not recognized it as a sovereign state. Nonetheless, in recent years the two countries have signed several treaties that allowed Serbia to fulfill one of the conditions for eventual EU accession.

\footnotetext{
${ }^{3}$ Even before 1989, some of the elements of a market economy had existed in the Former Republic of Yugoslavia, including autonomous management and "competition" between enterprises and open trade, but the conflicts disrupted a potentially rapid transition.
} 
Another fault line in domestic politics has been the process of dismantling the dominant state- and sociallyowned enterprises. Initial privatization and transformation of ownership created a captive economy in which vested interests blocked or slowed reforms in order to retain control. The lack of decisive political action to dismantle these special interests prolonged the painful economic transition. Serbia's response to the economic crisis reflected its frozen political process: instead of engaging in structural reforms where political consensus was elusive, successive coalition governments attempted to spend their way out of recession. Not surprisingly, public debt has reached worrying levels.

2.6. In recent years, Serbia has made strides toward reintegration with European and international structures. In November 2007, Serbia initialed a Stabilization and Association Agreement (SAA) with the European Union. In 2008, a European partnership for Serbia was adopted, setting out priorities for its membership application. In 2009, Serbia formally applied for EU membership and in March 2012 was granted EU candidate status. In September 2013, the SAA entered into force. In June 2013, the European Council decided to open accession negotiations with Serbia and in December 2013 adopted the negotiating plan and agreed to hold the 1st Intergovernmental Conference. On January 21, 2014, the 1st Intergovernmental Conference took place, signaling the formal start of Serbia's accession negotiations.

2.7. Serbia has also been rebuilding relations with historical partners from the "nonaligned movement"4 and expanding relations with other partners looking for investment opportunities in Europe. In recent years, this approach has proven beneficial, and inflows from nontraditional partners have become increasingly important, as exemplified by partnership with the United Arab Emirates (UAE) in a number of areas. Serbia seeks to fulfill its obligations toward the EU while staying on good terms with strategic non-EU actors, especially Russia, China, and the UAE. It has maintained a cordial relationship with Russia, especially in such vital areas as energy. At a time of heightened tensions on the European continent, how well Serbia can manage the obligations of its EU membership ambitions and maintain a productive relationship with Russia will be a decisive influence on the country's medium-term trajectory.

2.8. The March 2014 parliamentary elections gave Serbia a rare opportunity to reduce the political fragmentation that has characterized the past and build a new momentum for long overdue economic reforms. The Serbian Progressive Party (SNS), headed by Prime Minister Vucic, won a solid 48 percent of the votes and an absolute majority of 158 of the 250 assembly seats. The new coalition government has stated its intention to transform the state administration, public finances, and the economy, in pursuit of EU accession. A clear majority government,, combined with the ongoing EU integration process, creates the most favorable political conditions for economic reform and development in a decade. At the same time, the legacy of political and institutional fragmentation and deep domestic economic and social reform challenges, coupled with the sluggish Eurozone performance and conflict in Ukraine, will continue to raise complex issues even for a government supported by a large majority in Parliament.

\section{Economic Growth, Poverty Reduction, and Shared Prosperity}

2.9. Until the global economic crisis, the Serbian economy was performing reasonably well, but growth has since stalled (Figures II.1 and II.2). Economic growth averaged 5.0 percent annually for 200108, but in 2009 real GDP fell by 3.5 percent, driven by an abrupt contraction in real domestic demand (-

\footnotetext{
${ }^{4}$ A group of states which are not formally aligned with or against any major power bloc.
} 
7.5 percent). Recovery was sluggish in 2010, when GDP grew 1.0 percent, and in 2011, when it was up only 1.6 percent. Recession returned in 2012, when the economy contracted by 1.5 percent, driven by severe weather conditions that deeply depressed agriculture yields; spillovers from the Eurozone crisis; and closure of the largest exporter, US Steel. In 2013, the economy recovered, with real GDP growth of 2.5 percent, supported by the exports of the large Italian carmaker FIAT and rising agricultural and energy production. Overall since 2008, average annual real GDP growth has stalled at about zero.

\subsection{Devastating floods in May 2014 have pushed the already wobbling economy into recession} again in 2014, underscoring generally how vulnerable Serbia's economy is to weather and climatic shocks (see chapter V). Record high rainfall in-mid May 2014 led to severe flooding and damaged vital economic sectors such as energy, mining, and agriculture and transport infrastructure (roads, bridges, and railways). ${ }^{5}$ The floods are estimated to have lowered real GDP growth by 1 percentage point relative to the pre-floods scenario. ${ }^{6}$ Using data from the 2013 SILC and estimated employment loss, it is estimated that the floods increased the poverty headcount nationally by 1.7 percentage points, equivalent to 125,000 people.

Figure II.1: Real GDP Growth, Percent, 2000- Figure II.2: Average Annual Growth, 2000-14 14

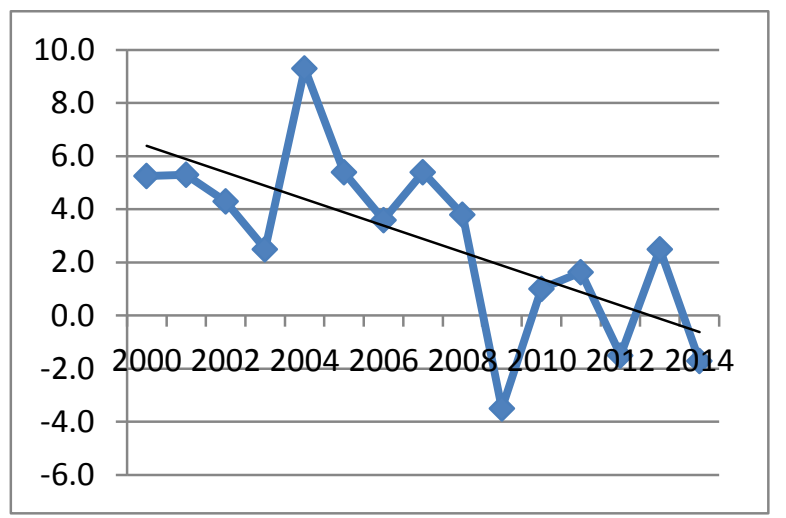

Source: NBS, MOF, World Bank staff.

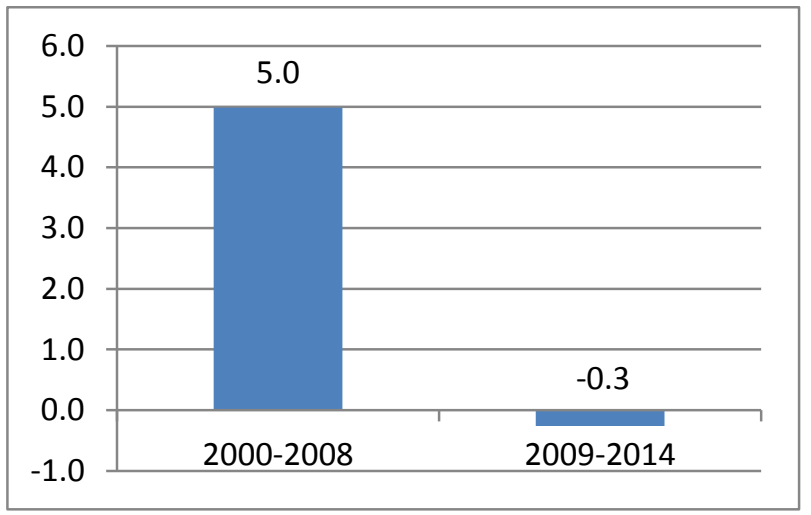

Source: NBS, MOF, World Bank staff.

\footnotetext{
5 The human toll of the floods was significant: 51 persons died and over 30,000 people were evacuated from their homes. While the vast majority of evacuees found shelter with relatives, about 5,000 persons were accommodated in temporary shelters established by the Serbian Red Cross.

${ }^{6}$ The growth impact estimates of the floods are principally based on a production-side national accounts growth model that considers the detailed sectoral Damage and Loss Assessment (DaLA) in terms of overall impact on the economy.
} 
Figure II.3: Poverty Headcount (Percent) and Real GDP per Capita

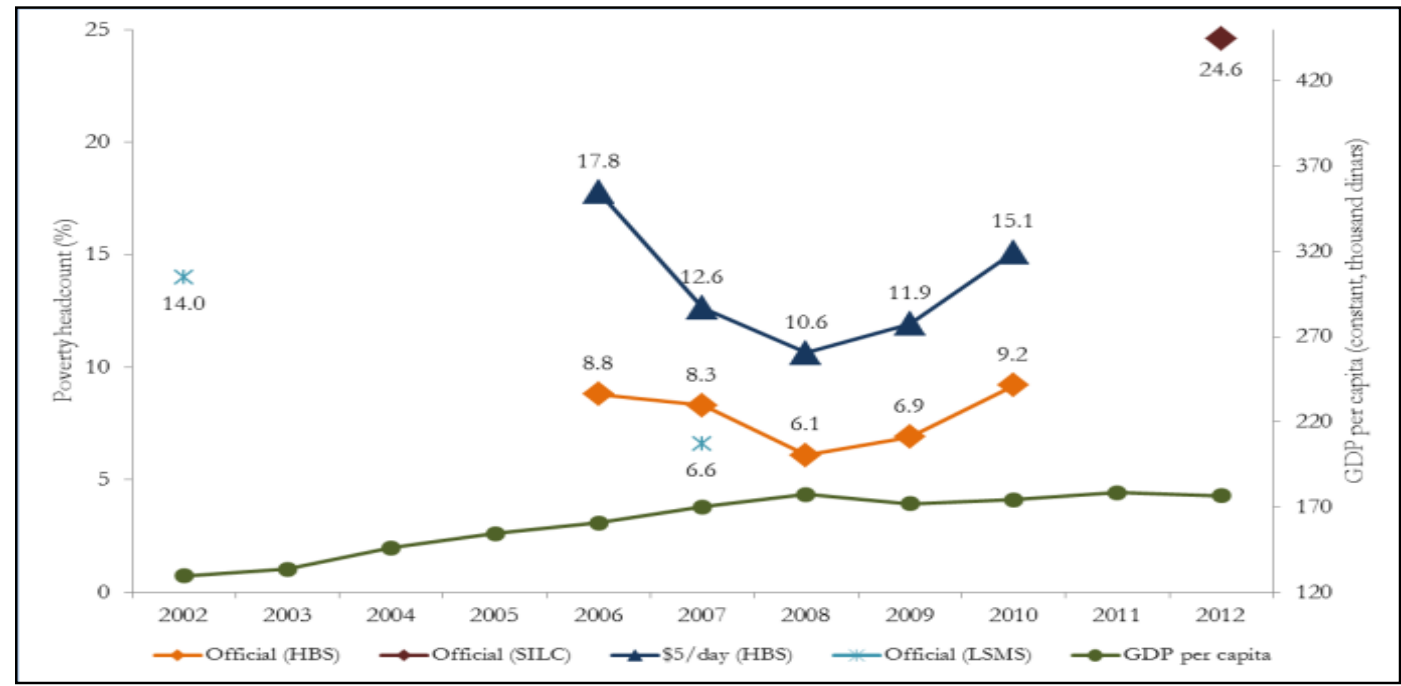

Source: Statistical Office of Republic of Serbia; ECAPOV data portal; WDI.

Note: Official poverty estimate in 2012 is based on income (EU-SILC data). Previous year estimates are based on consumption (LSMS and HBS data). Estimates based on these different survey instruments are not strictly comparable. See Box 2 for data and methodology.

Figure II.4: Poverty Rates, Serbia and EU-CESEE (Central, Eastern and South Eastern Europe), 2012 (percent)

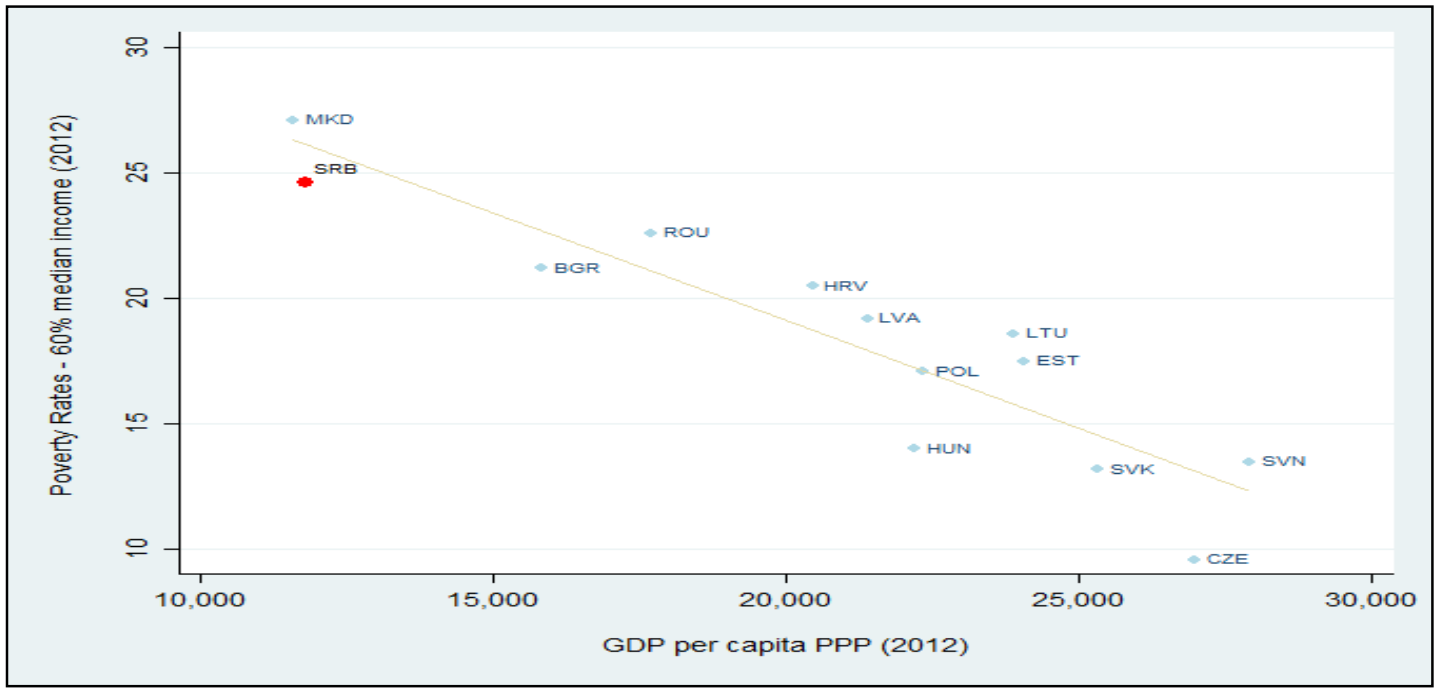

Source: EuroStat. For FYR Macedonia, World Bank staff calculations based on 2011 SILC data. Note: Below 60 percent median income.

\subsection{Economic growth before the crisis helped to reduce poverty and expand shared prosperity}

(Figure II.3). Measurement of poverty for the earlier part of the last decade relies on LSMS data, according to which the poverty headcount fell by more than half, from 14 percent in 2002 to 6.6 percent in 2007. Considerable and sustained economic growth and the growth of pensions, other social transfers, and international remittances brought poverty down substantially. Decomposition of poverty changes in 20062008 by occupation of the household head suggests that poverty went down especially among those 
employed in agriculture, mining, and construction; to a lesser extent among those employed in services; and even among those not employed.

Box II.I: Measuring Poverty and Shared Prosperity in Serbia: Data and Methodology

Analysis of poverty and the characteristics of groups within the welfare distribution requires data from households and individuals. Three types of such surveys have been used in Serbia since 2002; however, inferring long-term trends is difficult because data from these survey instruments are not strictly comparable:

1. The LSMS surveys of 2002 and 2007 provide a trend in poverty based on consumption aggregate measures and an absolute poverty line.

2. Official poverty monitoring during 2006-10 was based on comparable annual Household Budget Survey data, and used per adult equivalent consumption aggregate and an absolute poverty line.

3. Starting in 2012, poverty in Serbia is measured using annual data from the Survey on Income and Living Conditions (SILC) and uses an income-based welfare aggregate (on a modified OECD equivalence scale) and a relative poverty line ( 60 percent of the median national per adult equivalent income). The relative poverty line provides a measure of the population at risk of poverty, which differs from the absolute poverty line usually constructed to reflect the cost of basic needs. This methodology is consistent with the methodology in place for EU countries that follow the Europe 2020 strategy. The SILC is considered to have better data than previous surveys because of higher response rates and a larger effective sample size. Official poverty indicators now also report severe material deprivation and very-low work intensity, two nonmonetary indicators designed to capture vulnerability and social exclusion. The SILC, conducted in 2013, and sometimes referred to as the 2013 SILC, in fact asked for 2012 data, which is the last currently available; the second round is now in the field.

2.12. The downward trend in poverty reversed with the onset of the global financial crisis. Given data availability, the focus of subsequent analyses is on 2006-2012, often separating the trends before and after 2008. Measuring poverty and welfare in Serbia more recently relies on the HBS, with the latest year measure based on the SILC. Box II.1 details the data sources and methodologies used. Figure II.3 shows national and US\$5/day poverty rates based on the HBS between 2006 and 2010, with the lowest having been in $2008 .^{7}$ The sensitivity of poverty rates suggests there is a substantial vulnerable population slightly above the poverty line, and poverty reduction gains flipped immediately when the economy stopped growing or went into recession. Tracking longer and more recent time trends of poverty and shared prosperity is difficult since Serbia changed its official poverty measurement in 2012 (see Box II.1), adopting the EU relative poverty measure - the fraction of the population living below 60 percent of the median income - as the official poverty rate. The first EU-SILC survey for Serbia measured this indicator of relative poverty at 24.6 percent in 2012, higher than for all the EU-11 countries (Figure II.4). The change in survey instrument and methodology makes it difficult to monitor welfare and assess policy impacts consistently over time.

\subsection{Although pre-crisis growth particularly benefitted the B40, they were disproportionately} hurt during the recent economic slowdown and recession. As shown in the growth incidence curves in Figure II.5, the bottom of the welfare distribution experienced higher than average growth just before the

\footnotetext{
${ }^{7}$ During this period the depth of poverty — the poverty gap — followed the same trend as the poverty headcount, though the gap was already small (below 2\%). Extreme poverty as measured by US\$1.25 a day is virtually non-existent in Serbia.
} 
crisis. Between 2008 and 2010, however, the lack of economic growth and to a lesser extent the somewhat worsening inequality worked against the poor, as is confirmed by the growth incidence curve and decomposition of growth redistribution. The Gini slightly worsened between 2008 and 2010, hovering at 26-27 percent. $^{8}$ The decline in consumption in Serbia in this period was larger for the B40-3.8 percent a year-than for the average population (2.9 percent) (Figure II.6). Between 2005 and 2010, the negative consumption growth of the bottom 40 percent in Serbia was among the lowest in ECA (Figure II.5).

Figure II.5: Growth Incidence Curve
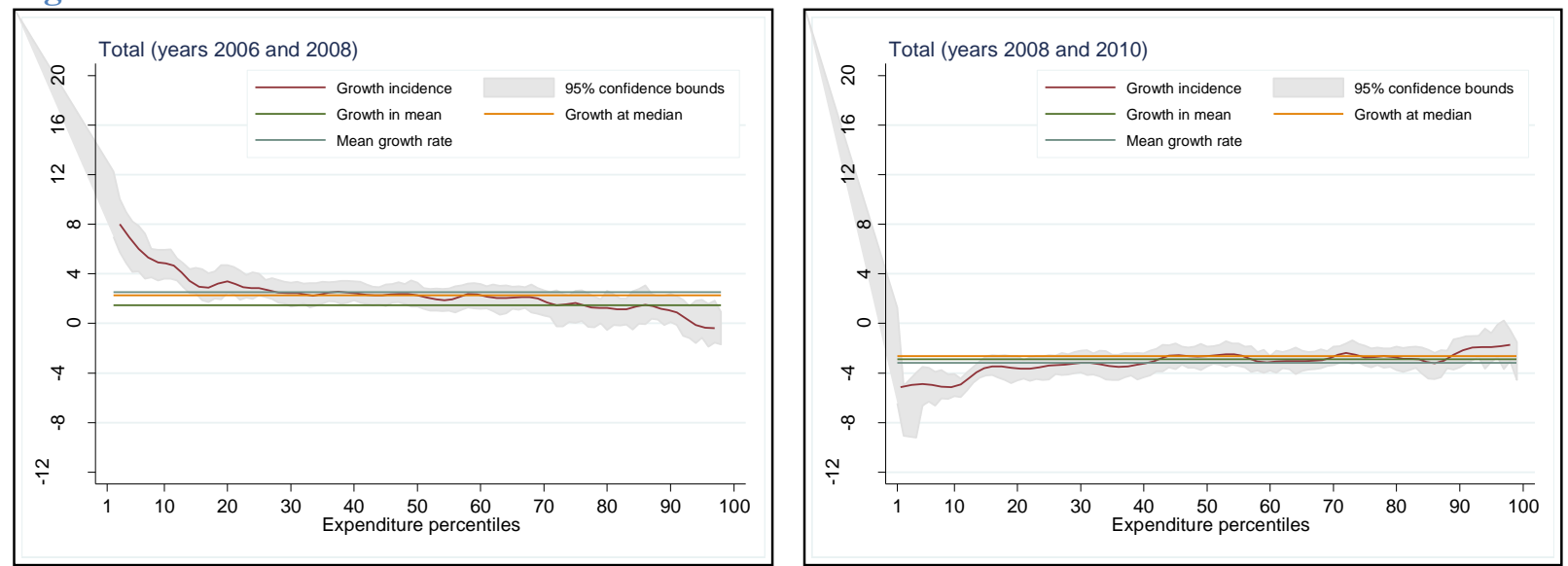

Source: Estimates based on Statistical Office of Republic of Serbia's HBS data.

Figure II.6: National Consumption Aggregate-based Shared Prosperity Indicator

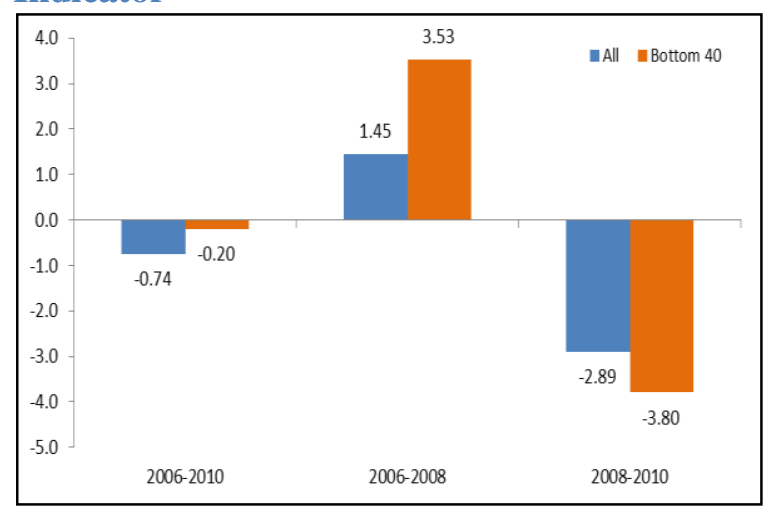

Source: Estimates based on Statistical Office of Republic of Serbia's HBS data.
Figure II.7: Annualized Growth of the Bottom 40 Percent, ECA Countries

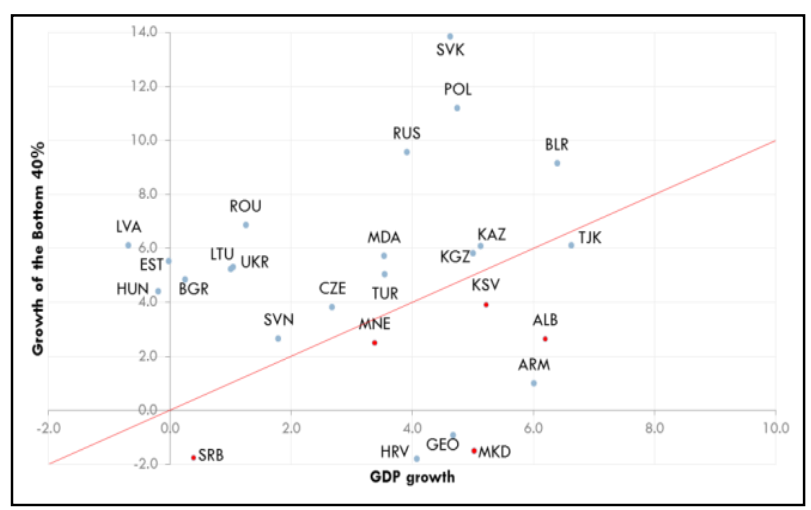

Source: SEE Regular Economic Report Note: Growth circa 2005-2010 (Serbia 2007-2010), based on the ECAPOV harmonized consumption aggregate.

\subsection{The welfare dynamics of those at the bottom are associated with heightened rural poverty} and losses in employment and labor income. Poverty rates are higher in rural areas (see Profile discussion below and Annex 1), and poverty trends in Serbia closely track what happened in rural areas. The increase in poverty after the crisis was particularly stark there, climbing from 7.5 percent in 2008 to 13.6 percent in

\footnotetext{
${ }^{8}$ Inequality measures based on income tend to be higher as consumption is usually smoothed out. The 2012 Gini for Serbia based on an income aggregate from the SILC is 38 percent, higher than in all EU-CESEE countries.
} 
2010. When poverty changes are decomposed by urban-rural-population shifts, changes in rural poverty account for the most - 93 percent of the reduction in national poverty in 2006-08 and 85 percent of the rise in 2008-10. Chapter IV discusses the dynamics in agriculture income and employment that influence rural welfare.

2.15. Losses in employment and labor income were the main reason for the rise in poverty and the decline in welfare of the $\mathbf{B 4 0}$ after 2008. Labor market opportunities significantly worsened between 2008 and 2012 for all Serbians, but particularly for low-income earners. The majority of wage employment losses for workers younger than 55 between April 2008 and April 2013 were in private firms. From 2008 to 2010 , households where the head was unemployed, employed in the private sector, or self-employed had higher poverty rates and registered the greatest increases in poverty. Informal workers were also hit hard. From April 2012 through 2013, informal workers were significantly more likely to move into unemployment or inactivity than those formally employed. The worsening declines in the employment prospects of low-income earners since the crisis are consistent with the larger decline in welfare visible at the bottom of the distribution. Decomposition by occupation of household head reveals that heightened poverty among those employed in almost all sectors - agriculture, mining and construction, trade and services, and to a lesser extent industry - as well as among those not employed contributed to the general rise in poverty. Decomposition by income component suggests that a fall in the share of employed adults and falling off-farm labor income contributed the most to the rise in poverty and the decline in the B40 welfare from 2008 to 2010 (Annex 1). Changes in pensions partially offset this negative impact, although the contribution of social assistance to changes in income was very small. As Serbia restructures SOEs and downsizes the public sector, further contraction in public employment could worsen poverty.

\section{Profiles of the Bottom 40 Percent}

2.16. Clear spatial differences persist in the poverty profile, with the $\mathbf{B} 40$ more likely to reside in rural and thinly populated areas. In 2012, 36 percent of the population in thinly populated areas and 24 percent in other low-density areas were considered at risk of poverty, compared to 13.8 percent in the densely populated urban areas. In the B40, 49 percent live in thinly populated, 27 percent in intermediate, and 24 percent in densely populated areas. The at-risk-of-poverty rate - the share of the population who have less than 60 percent of the median income - was highest in the southern and eastern regions and lowest in Belgrade (Figure II.8). All of Serbia's regions, particularly Vojvodina and Central Serbia (the southern and eastern regions), made strides in shared prosperity in 2006-08, but growth in B40 consumption became negative across all regions between 2008 and 2010. 
Figure II.8: Poverty Headcount by Region, 2012

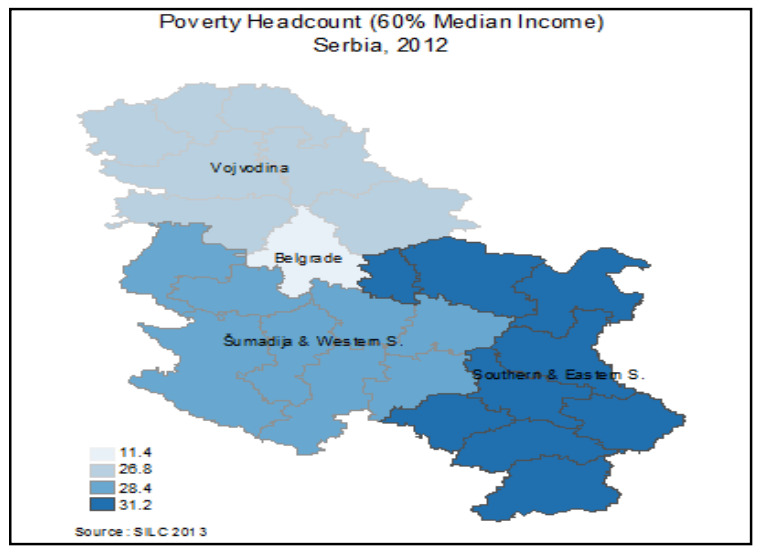

Source: Based on Statistical Office of Republic of Serbia's SILC data.
Figure II.9: Age-Gender Pyramid and Those at Risk of Poverty, Percent

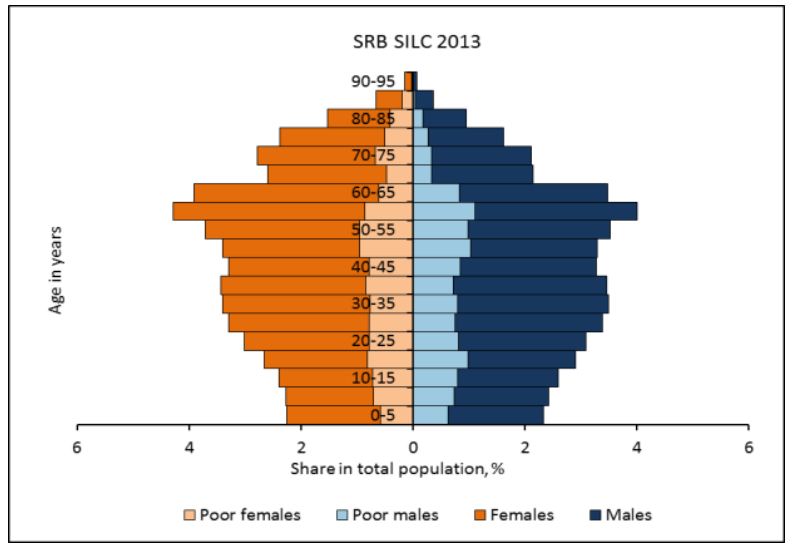

Source: Based on Statistical Office of Republic of Serbia's SILC data.

Note: "Poor" refers to at-risk-of-poverty population (below 60 percent median income).

2.17. Larger households with more children and those with less education are more likely to be at the bottom of the welfare distribution. The age-gender pyramid (Figure II.9) shows that in Serbia's aging society, the at-risk-of-poverty incidence is higher among children (e.g., 28.4 percent for children under 10) than among adults (e.g., 22.5 percent for adults aged 30-40). Among all Serbs aged 18 or above, 9.9 percent (15.9 percent) have primary or less education (tertiary education) while the rate among the B40 is 15.7 percent (5.0 percent).

2.18. The B40 have worse labor market outcomes than the rest of the population and rely heavily on social transfers. Overall, participation in the Serbian labor force is low, structural unemployment is above 20 percent, and 21 percent of workers are employed informally. The B40, in particular, are concentrated among those inactive, unemployed, or working in agriculture and lower-skill occupations (Figure II.10 and Annex 1). Among the unemployed are 37 percent of the B40 compared to 13 percent of the top 60 . Only 17 percent of the B40 are salaried, compared to 50 percent of the top 60 percent. The B40 employment rate is 34.2 percent versus 58.7 percent for the top three quintiles, and the self-employment rate is 49.3 percent versus 15.4 percent. Not surprisingly, on average the B40 rely more on non-labor income (pensions, social assistance, and private transfers/remittances) than those further up the welfare distribution (Figure II.11). Those residing in thinly populated rural areas also rely more on non-labor income. Since for them both labor income and total income are both relatively low, those at risk of poverty and in the B40 derive more of their total income from social assistance (last-resort program, child and family benefits, veterans benefits, disability benefits and others).

2.19. The Roma population- the most vulnerable minority group--has a much higher poverty rate, much less education, and poorer labor market outcomes than non-Roma. According to the 2011 Population Census, 147,607 Roma were living in Serbia, constituting 2 percent of the total population. This number reflects the lower bound of estimates, because many Roma choose not to report their ethnicity in surveys. A 2010 Council of Europe estimate suggested that the number of Roma in Serbia ranges from 400,000 to 800,000 , corresponding to 5.5-11.1 percent of the population. According to a World 
Bank/UNDP/EC 2011 survey, 30 percent of Roma face absolute income-based poverty (living on less than US $\$ 4.30 \mathrm{PPP}$ a day), compared to only 8 percent among non-Roma living in areas with a high concentration of Roma populations,. School enrollment rates and educational achievements are lower for Roma children, as are health outcomes. About 49 percent of Roma are unemployed, compared to 27 percent of the nonRoma population.

Figure II.10: Employment by Occupation, Percent

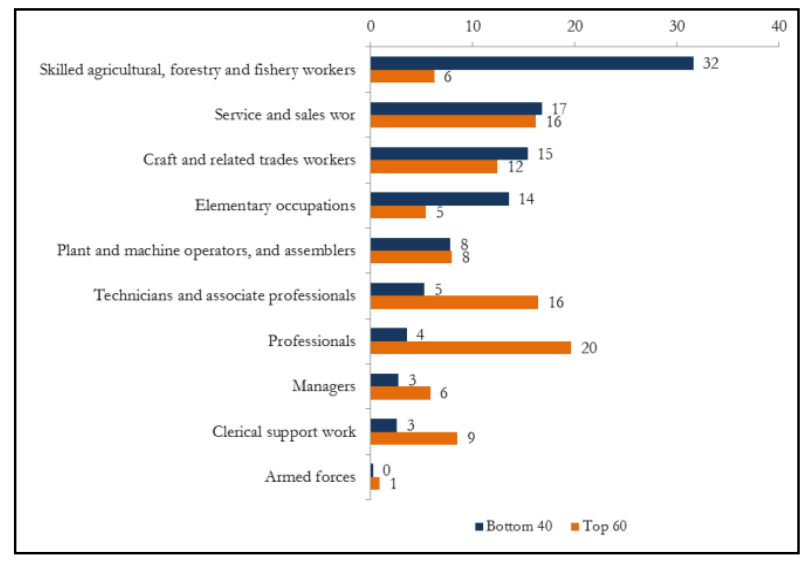

Source: Based on Statistical Office of Republic of Serbia's SILC data.
Figure II.11: Total Income by Source, Percent

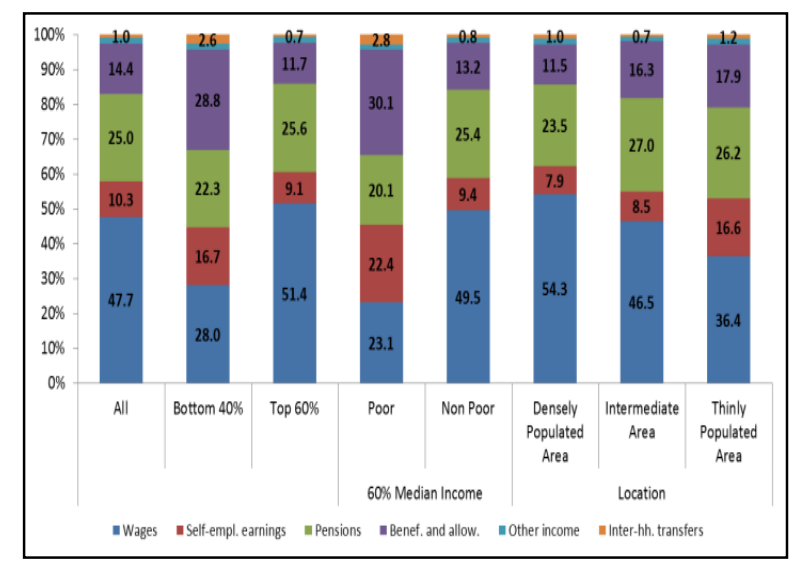

Source: Based on Statistical Office of Republic of Serbia's SILC data.

Note: "Poor" refers to at-risk-of-poverty population (below 60 percent median income).

\section{Analytical Framework}

2.20. As the SCD turns to deeper investigation of causes and constraints, it uses a three-part framework to organize the analysis. Given that poverty reduction and shared prosperity in Serbia has closely tracked economic growth, accelerating growth and making it inclusive is critical. To do that, Serbia must dismantle binding constraints to growth, address barriers to improving outcomes for the poor and less well-off so that economic gains are shared, and manage risks to sustainability. Therefore, the SCD analysis will be organized around diagnosing major constraints to growth, inclusion, and sustainability (Figure II.12). Cross-cutting issues like governance and institutions will be discussed throughout as they affect drivers of growth, inclusion, and sustainability.

\subsection{The three interrelated building blocks of this analytical framework combine both macro and} micro approaches to identifying constraints on the welfare of those at the bottom of the income distribution. Welfare gains for the B40 depend on both economic gains across the economy and the participation in and sharing of those gains by most Serbians. The framework offers macro perspectives by analyzing what constrains the capacity to generate broad-based economic gains. This analysis of drivers of growth covers governance and institutional issues, such as those of the public sector and the business environment, and extensively discussed in Chapter 4 . The framework also offers micro perspectives related to opportunities for individuals and households to generate income by analyzing what makes it difficult for them to accumulate assets and use them to earn returns through interactions with markets and institutions. Critical assets like human, physical, and natural capital and financial and social capital influence the 
productive capacity and income-generating opportunities of individuals in the labor market, agriculture, self-employment, and entrepreneurship. Micro economic gains shape macro gains. Analysis of constraints to inclusion will cover those related to factors that can enable income generation, such as public service delivery in health and education, provision of public goods, social protection, institutions, government interventions, and market regulations. With assets as an important basis for analysis, the framework for the Serbia SCD is consistent with the shared prosperity framework developed by Bussolo and Lopez-Calva (2014).

\section{Figure II.12: Elements of Sustainable Poverty Reduction}

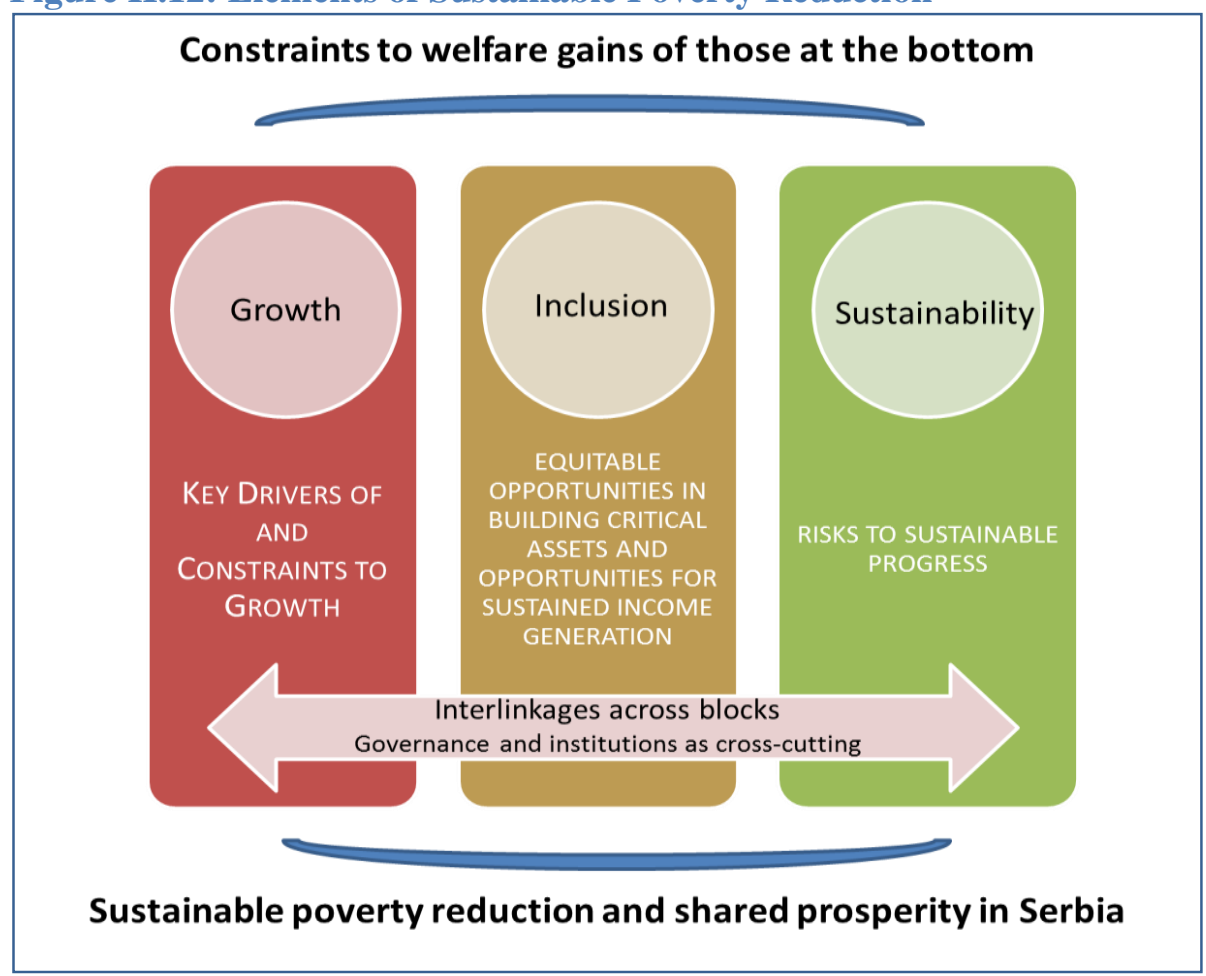

2.22. To make progress on the shared prosperity and poverty reduction, Serbia will need both a growing economy and an inclusive one. Economic growth is necessary to sustainably reduce poverty and boost shared prosperity. However, it is not sufficient to make progress toward inclusion and poverty reduction. Making growth inclusive would require complementary policies aimed at increasing household investment in health, education and skills; increasing the returns on those assets to generate income, particularly in the labor market; addressing a number of disparities across social groups and regions in Serbia; improving rural welfare, especially through agriculture; and making service delivery more efficient —issues which will be extensively discussed under "inclusion" in Chapter 5.

2.23. The analysis of sustainability is concerned with the risks to sustainable growth, shared prosperity and poverty reduction, which principally relate to the external environment, environmental and climate-related risks, and social and political risks. These risks need to be managed carefully. This general framework guides the analysis in the next four sections of the SCD, with 
attention to inter-related factors that affect growth, inclusion, and sustainability. For example, the delayed transition has impacts on growth, welfare of those at the bottom, and sustainability of the development model. Another critical inter-linkage in the distributional impacts of reforms and implications for social and political sustainability will also be discussed.

Figure II.13: Summary: The context for Serbia's poverty and shared prosperity challenge

Growth in Serbia has stalled since the global financial crisis...

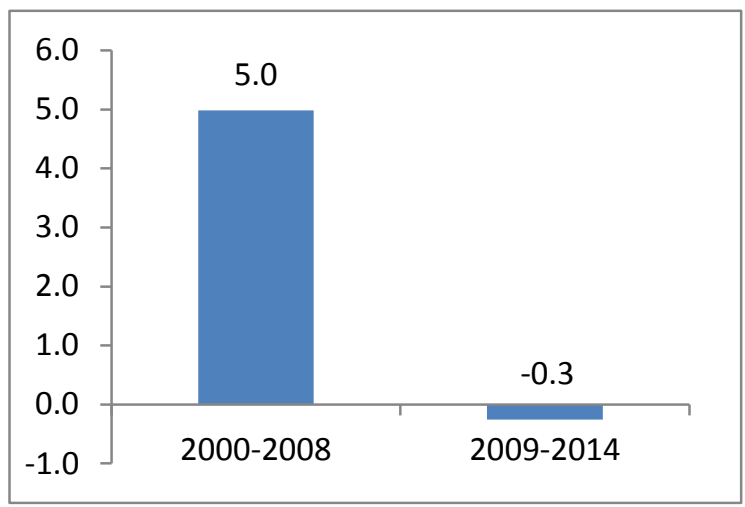

The consumption of the bottom 40 percent has been heavily impacted by the crisis...

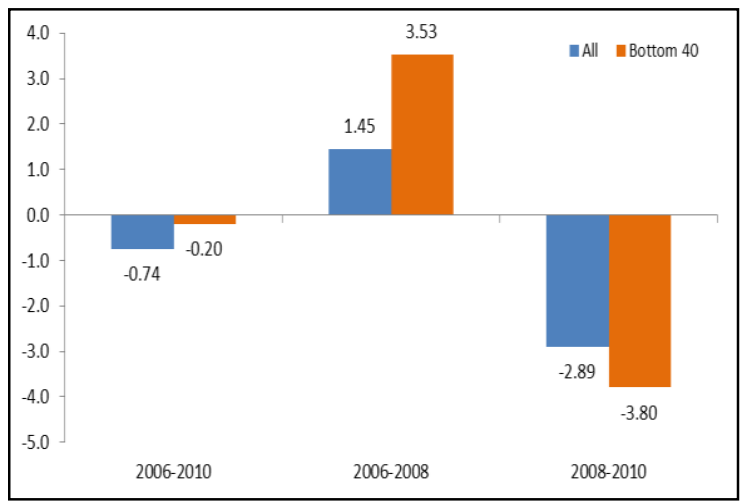

Employment in the bottom 40 percent is concentrated in lower-skill occupations...
... contributing to a rise in poverty, reversing previous gains

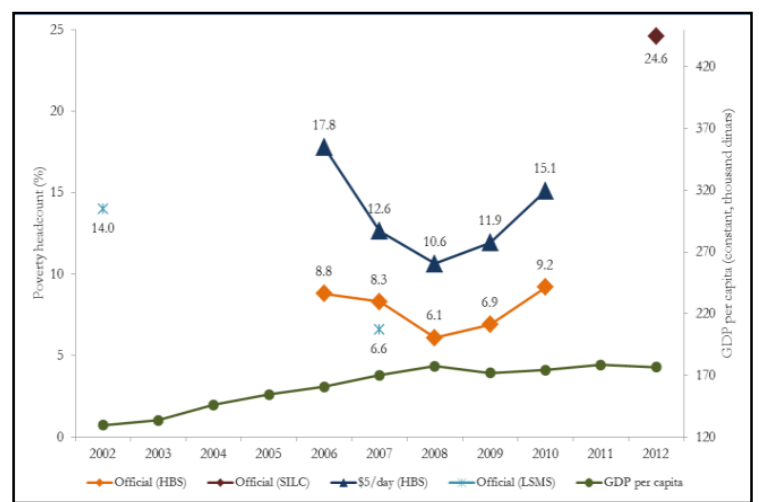

... with loss in jobs or labor income the main contributor to the rise in poverty

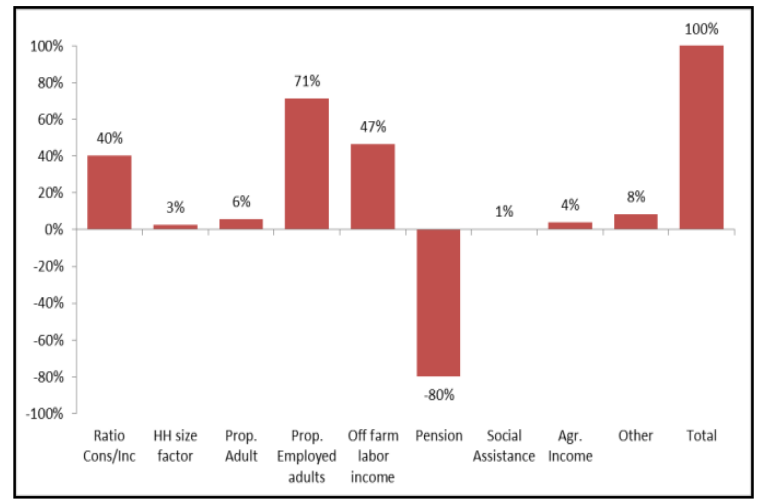

... and pensions, social assistance and other transfers account for most of their incomes 

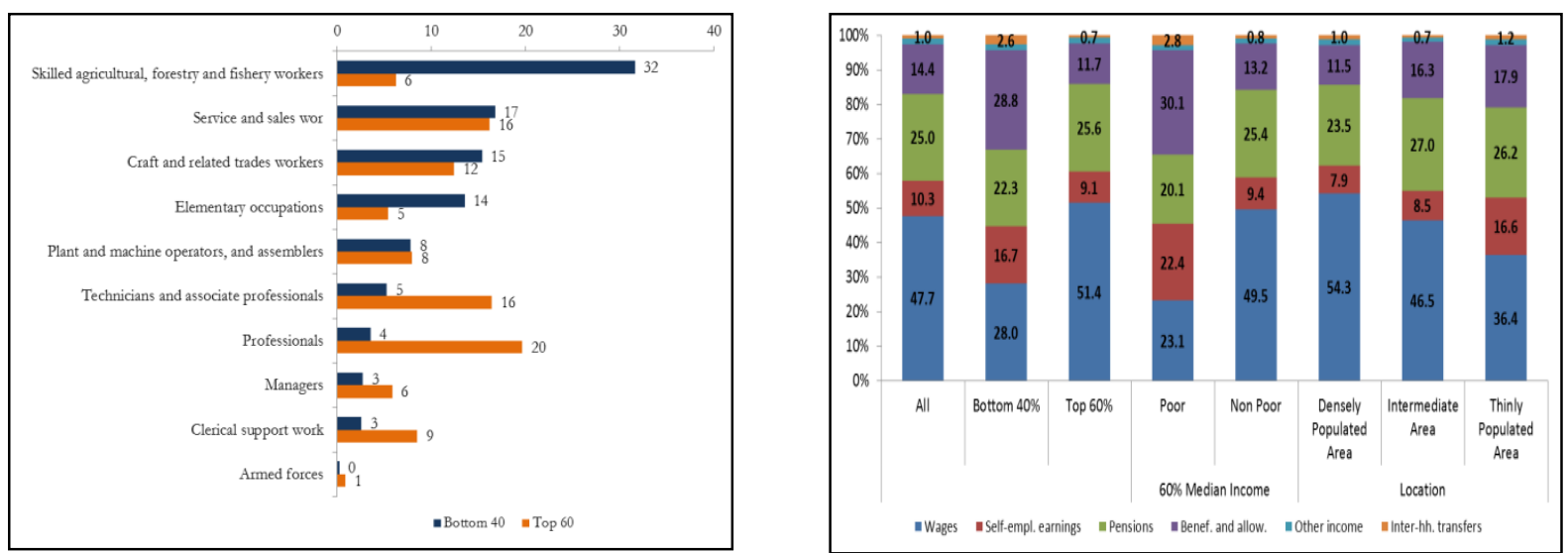

Source: Statistical Office of Republic of Serbia, ECAPOV data portal, WDI. Official 2012 poverty estimate based on income (EU-SILC data), previous years on consumption (LSMS and HBS data). Estimates based on different survey instruments not strictly comparable. Bottom 40 percent consumption based on HBS data. Income data based on Serbia's SILC data where "Poor" refers to at-risk-of-poverty population (below 60 percent median income). 


\section{Pre-Crisis Patterns of Growth}

3.1. Given that poverty reduction and shared prosperity in Serbia have closely tracked economic growth, it is essential that Serbia restore higher and sustainable growth. Economic growth, particularly growth that promotes private sector-led job creation and employment opportunities for broad segments of the population, is necessary to sustainably reduce poverty and boost shared prosperity. This section discusses pre- and post-crisis sources of growth; post-crisis trends in investment, productivity, and competitiveness; and constraints that must be addressed to get the economy back on the path of higher and sustainable growth.

\section{The Pre-crisis Growth Patterns}

\subsection{Serbia's pre-crisis growth was driven by high domestic demand linked to significant capital}

inflows. Consumption, both private and government, had contributed significantly to growth rates up to 2008, but since then the contribution of domestic demand to growth has been mostly negative (Figure III.1). About three-quarters of Serbia's FDI went to non-tradable sectors of the economy, fueling domestic demand and adding to exchange rate appreciation pressures. Since the crisis, however, growth has been driven principally by exports and to a lesser extent by investment.

Figure III.1: Demand Composition of Growth, 2004-13

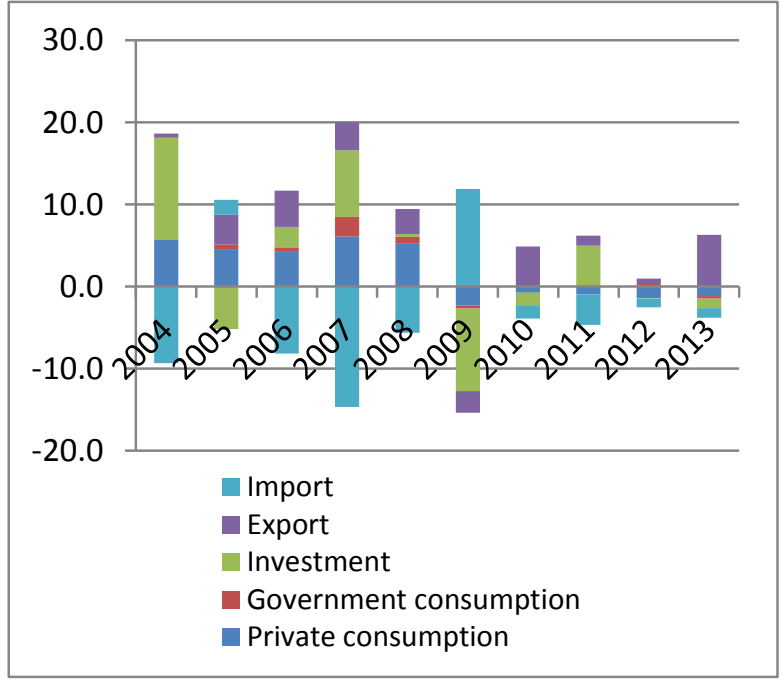

Source: MOF, NBS, World Bank staff.
Figure III.2: Current Account Deficit, Percent of GDP, 2002-2013

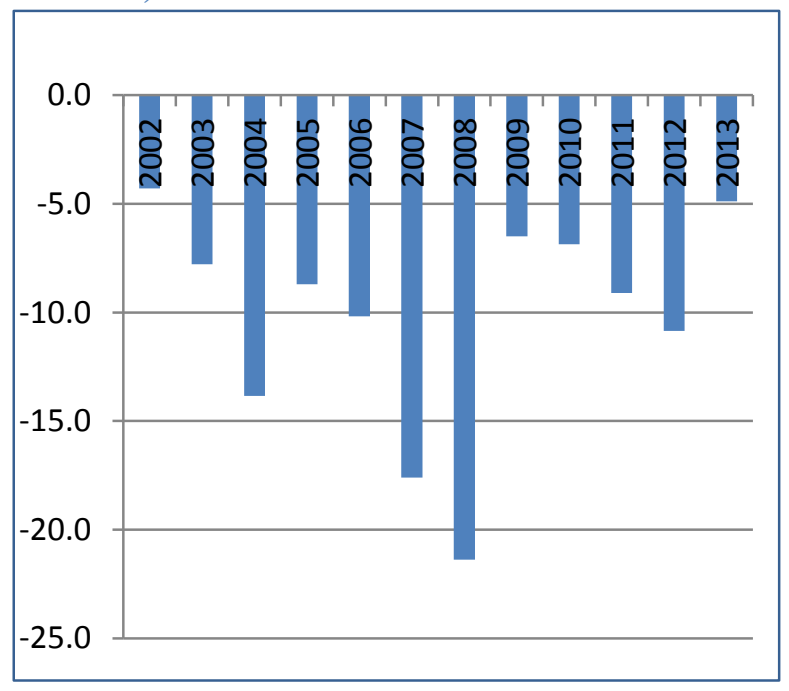

3.3. As in other countries in South East Europe (SEE), the pre-crisis growth model resulted in high external imbalances (Figure III.2). In 2008 the current account deficit (CAD) reached over 20 percent of GDP. The current account has since adjusted downward, supported by faster growth in exports and weaker domestic demand and imports; it fell from 10.6 percent of GDP in 2012 to about 5 percent in 2013. Most of the CAD has been financed by FDI (which has declined since the crisis) and long-term borrowing. 


\section{Investment and Productivity}

3.4. In Serbia post-crisis total investment at 18-19 percent of GDP is still below the pre-crisis level of 21-22 percent. At 3.4 percent of GDP, FDI is 2 percentage points lower than before the crisis (Figure III.4). While a quick return to the pre-crisis level is unlikely given the adverse external environment, Serbia can grow through higher investment. Attracting higher FDI will have to be a considerable part of restoring and sustaining higher growth.

Figure III.3. Private and Public Investment, Preand Post-Crisis, Percent of GDP

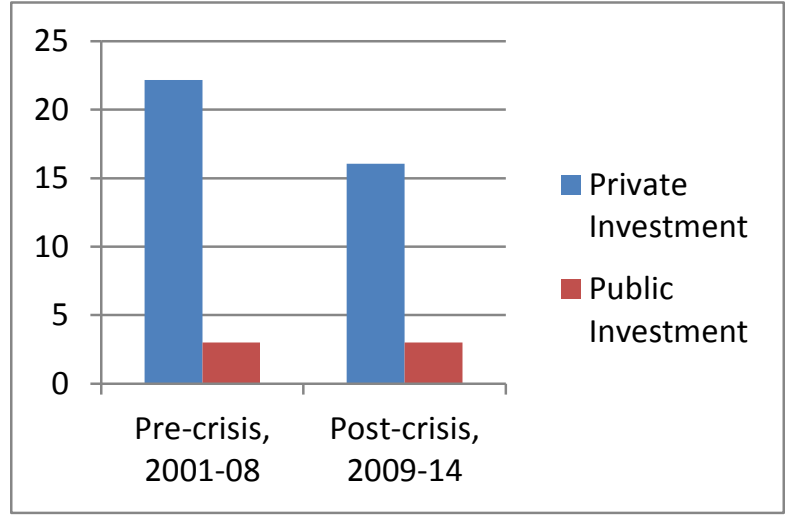

Source: MOF, NBS, World Bank staff.
Figure III.4. FDI and Remittances, Pre- and Post-Crisis, Percent of GDP

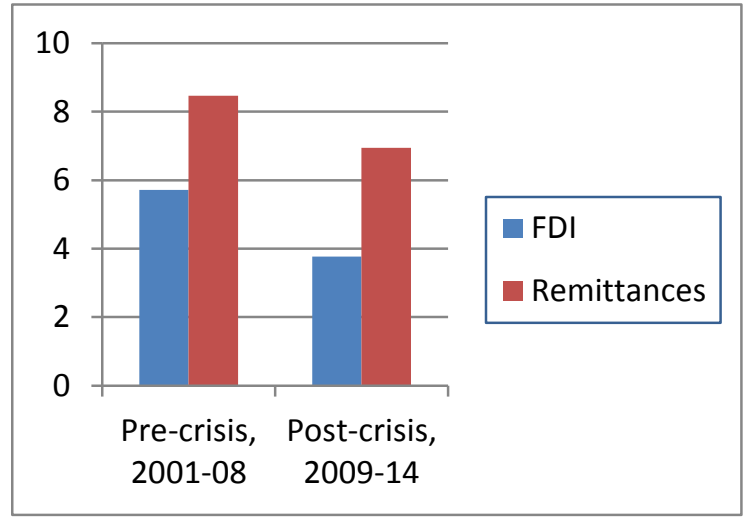

3.5. While total factor productivity (TFP) has been the main driver of Serbia's economic growth since early in the transition, its contribution to growth has perceptibly deteriorated since 2008. A growth accounting analysis ${ }^{9}$ for Serbia shows that real capital stock, after having plunged until 2003, has risen quickly since (Figure III.5). On the other hand, human capital-adjusted labor input and employment have both steadily declined since the early 1990s, except for a small spike just before the global economic crisis (Figure III.5). TFP, estimated as the difference between the growth rate of output and the weighted growth rates of factor inputs, ${ }^{10}$ has been the main driver of growth since the early 2000s (Figure III.6). On the other hand, the contribution of human capital to growth has on the whole been negative, with that effect more pronounced since the global financial crisis. The contribution of capital to growth has remained mildly positive, but the combined positive contribution to growth from TFP and capital since the crisis (2009-11) has nearly been offset by the negative contribution from labor. With Serbia's aging population and projected declines in labor force (see Box III.1), maintaining a positive labor contribution to growth requires boosting (labor) productivity and keeping workers in the labor force until retirement.

3.6. The negative contribution of human capital to growth is in part explained by Serbia's late start of transition and its incomplete structural reforms. As the experience of many advanced reformers during the 1990s shows, unproductive jobs are typically destroyed at the start of a transition through a process of restructuring and labor shedding. After 5 to 10 years, however, this process of labor shedding is typically followed by the creation of truly productive jobs. Serbia's reforms began to pay off around 2006,

\footnotetext{
${ }^{9}$ Serbia's data on real capital stock, employment, and average human capital per employed data are obtained from the Penn World Table 8.0. See Annex 3 for the methodology.

${ }^{10}$ Weights are the respective aggregate income shares of factor inputs.
} 
and for about three years, employment rates increased but the momentum was then disrupted by the global financial crisis. The fact that many of the fundamental reforms, including the privatization and restructuring of many large SOEs, remain incomplete limits the opportunities for labor reallocation and higher productivity.

Figure III.5: Real Capital Stock and Human Capital Adjusted Employment, 1990-2011

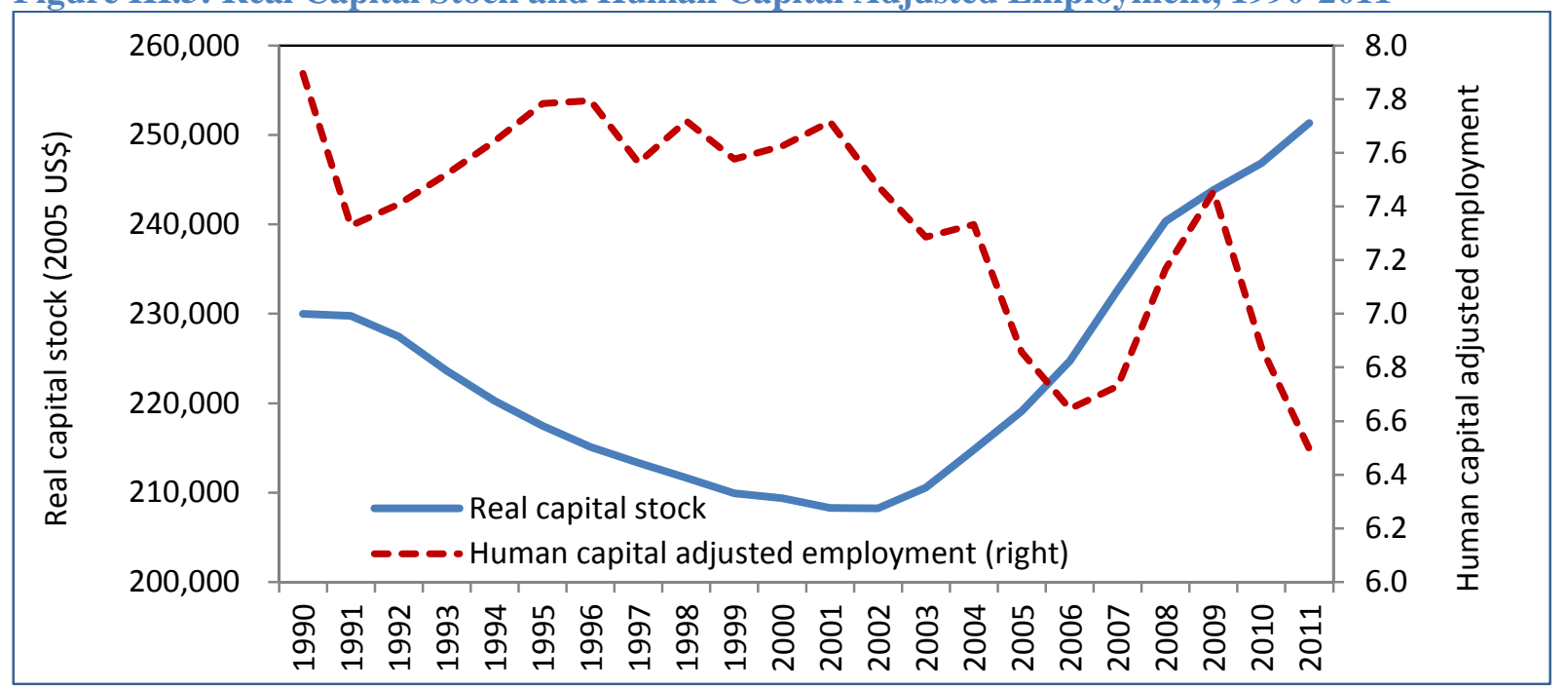

Source: World Bank staff calculations based on Penn World Table 8.0.

Figure III.6: Growth Accounting, 1991-11 (contribution to total growth, percent)

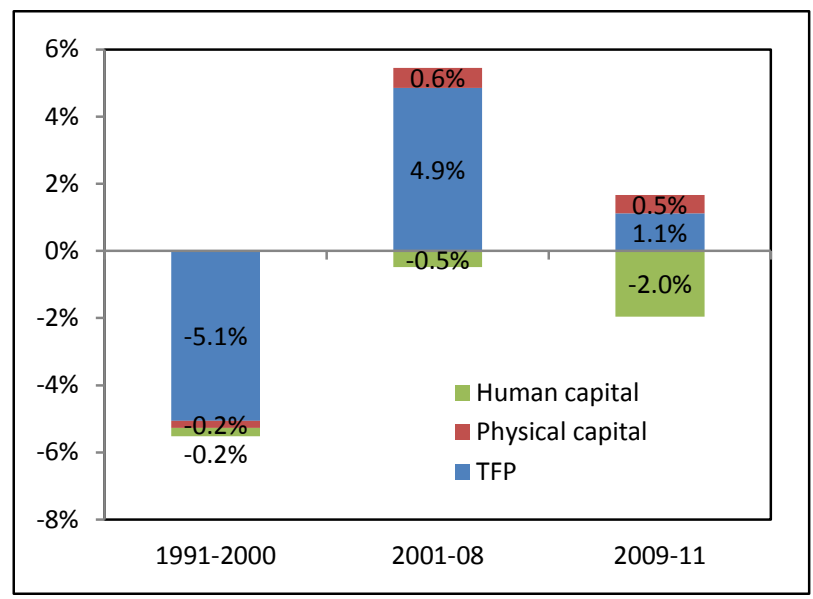

Source: World Bank calculations based on Penn World Table 8.0.
Figure III.7: (Real) Apparent Labor Productivity in Manufacturing, 2012 (value added at factor cost per employee at 2005 Euro)



Source: World Bank, Serbia Competitiveness Policy Note.

3.7. Serbia's productivity in manufacturing, the main tradable sector, is well below that of regional peers (Figure III.7). Manufacturing was devastated during the 1990s and recovery since has been slow. Since 2000 it has grown by less than 1 percent annually; today it constitutes less than 20 percent of GDP. The steep drop in output during the 1990s was not followed by a similar drop in employment, leading 
until recently to a large productivity gap. Movement of labor across sectors has not been productivityenhancing. Decomposition of labor productivity using Serbian SBS data (which do not cover agriculture) suggests that the contribution of labor reallocation to growth in labor productivity in 2007-12 was at best small and at worst negative (see World Bank Serbia Competitiveness Policy Note).).

\section{Box III.I: Serbia's Aging Population and its Consequences}

As Serbia's society is aging, the working age population is projected to decline over time. Relative to 2013 , the working age population (defined as age 15-64) is projected to fall by 8 percent by 2020, by 16 percent by 2030 , and by 23 percent by 2040. Maintaining GDP growth in the face of a declining working age population puts more pressure on increasing labor productivity and on keeping workers in the labor force until retirement age and beyond. Currently, Serbia experiences a high rate of early withdrawal from the labor force which, if continued, would cause even sharper declines in the future labor force.



Note: Vertical axis - Age; Blue-Male; Red-Female

Source: World Bank staff projections

The projected demographics directly affect pension systems, with the beneficiary-to-contributor ratio expected to jump to 1:1 from the current 0.6:1. The ratio of beneficiaries to contributors is important in a pension system since contributions from those of working age are used to support pensions for the elderly. If the ratio becomes 1:1, the benefit that is affordable as a percentage of average wage becomes equal to the contribution rate as a percentage of average wage. Thus, today's 24 percent contribution rate would translate into an affordable benefit of 24 percent of average wage, far lower than the current benefit of about 60 percent of average wage.

Children from low-income and Roma households will represent a growing percentage of the future workforce. The total fertility rate for the Serbian population as a whole is 1.6 children per mother, well below replacement rate. Low income households tend to have higher fertility rates, however; specifically for Roma, the total fertility rate was 3.1 in 2014 (MICS 2014). Using best available estimates of the Roma population (between 400,000 to 800,000), preliminary estimates suggest that in the next 15-20 years new labor market entrants of Roma descent may represent between 14 percent to 29 percent of total new labor market entrants in Serbia. Even when using the official census estimates (which underestimate the Roma population), Roma would still represent at least 5 percent of new labor market entrants. As such, future economic growth and sustainability of the pensions system will depend increasingly on children from today's low-income and disadvantaged households.

The projected demographics will also affect health spending, as health needs increase with age, as well as the need for long-term care which tends to be highly labor-intensive. Health spending also tends to increase as older individuals deal with the management of non-communicable diseases, even if the acute spending only occurs in the very last years of life. Long-term care, which is highly labor-intensive, is also likely to present a challenge 
as the labor force available to provide the care shrinks and the needs for care increase. Even education, which might be expected to shrink given the reduced number of children, might face upward pressure from the need to raise productivity and keep individuals highly skilled.

Source: World Bank staff projections.

\section{Exports and External Competitiveness}

3.8. As a small open economy, Serbia could have higher and more sustainable growth by relying on higher and diversified exports. Exports grew steadily grown since the crisis, reaching about 34 percent of GDP in 2013, driven mainly by FIAT exports. Nonetheless, they are still far below those of regional peers ${ }^{11}$ (Figures III.8 and III.9). The prospect of full integration into the EU offers an additional opportunity for Serbia to expand its exports and diversify its economy.

\subsection{More than 60 percent of Serbia's total external trade- both exports and imports-- is with}

the EU (Table III.1). While the EU is the dominant trading partner, Serbia's trade with its regional partners--both the Central European Free Trade Agreement (CEFTA) and the former Yugoslavia-remains significant, with Serbia running a trade surplus with these partners. Serbia's exports to Russia and other members of the CIS, as well as East Asia, grew at a double-digit rate over 2007-2012, although from a relatively low base.

\section{Table III.1: Serbia's Main Trading Partners}

\begin{tabular}{lcccc}
\hline & \multicolumn{2}{c}{ Share } & \multicolumn{2}{c}{ Annual growth rate, 2007-12 } \\
\hline & Exports & Imports & Exports & Imports \\
EU28 & 60.6 & 61.0 & 6.9 & 1.5 \\
CEFTA* & 21.7 & 5.3 & -0.4 & 0.4 \\
CIS** & 9.9 & 14.9 & 12.4 & -2.2 \\
East Asia & 0.6 & 10.2 & 36.1 & -0.5 \\
Rest of World & 7.2 & 8.6 & 2.1 & -0.3 \\
Total & 100 & 100 & 5.2 & 0.5 \\
Memo: & & & & -1.4 \\
Former Yugoslavia & 28.1 & 10.7 & 0.1 & \\
Total Value (US\$ m) & 11353 & 19013 & & \\
\hline
\end{tabular}

*CEFTA (the Central European Free Trade Agreement) is a grouping of countries which enjoy preferential trade access with each other. The current membership of CEFTA consists of Albania, Bosnia and Herzegovina, FYR Macedonia, Moldova, Montenegro, Serbia, and Kosovo. When a country joins the EU, as did Slovenia in 2004 and Croatia in 2013, it leaves CEFTA, causing some duties in agricultural products with its CEFTA partners to increase.

**Not including Moldova, which is in CEFTA.

Source: UN COMTRADE.

\footnotetext{
${ }^{11}$ See: World Bank, "Serbia Competitiveness Policy Note", 2014.
} 
Figure III.8: Exports as a Share of GDP, 2002- 13

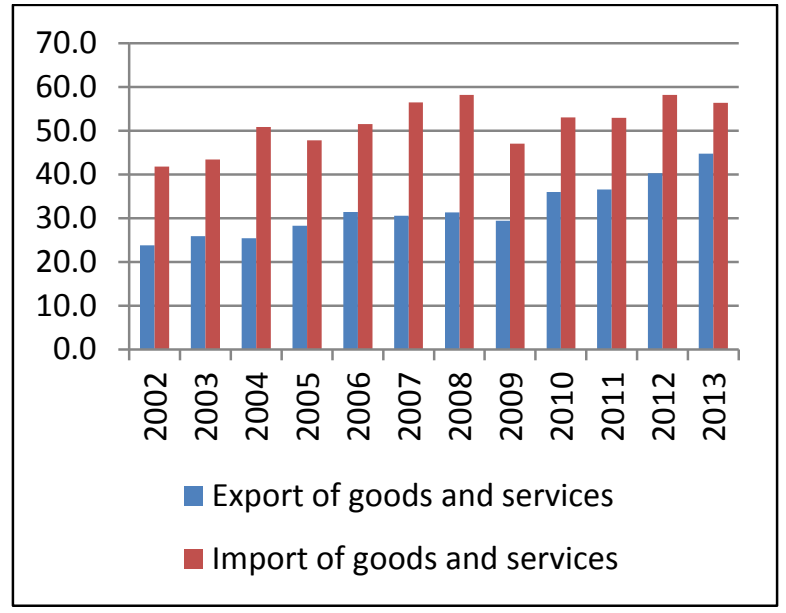

Source: NBS, World Bank staff.
Figure III.9: Exports in Comparison to Regional Peers, 1991-2013

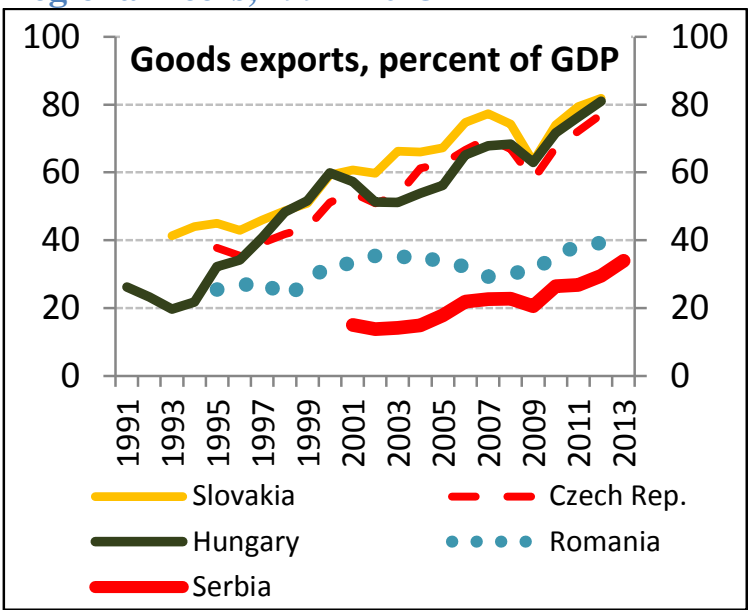

Source: World Bank staff estimates based on Statistical Office data.

3.10. After rising until 2008, Serbia's unit labor cost, an indicator of competitiveness, has fallen in recent years. While earnings grew faster than productivity before the global financial crisis, this trend has since been reversed. During 2008-13, labor productivity grew faster than real earnings, making Serbia's real unit labor cost fall and improve export competitiveness (Figure III.10). While the moderation of earnings growth has contributed to this trend, a large driver of the dynamic seems to be a persistent decline in employment (Figure III.11). In other words, the improved unit labor cost is driven more by substantial declines in employment than by moderated earnings, especially until 2012, underscoring the importance both of increasing employment and flexible wage setting mechanisms in Serbia.

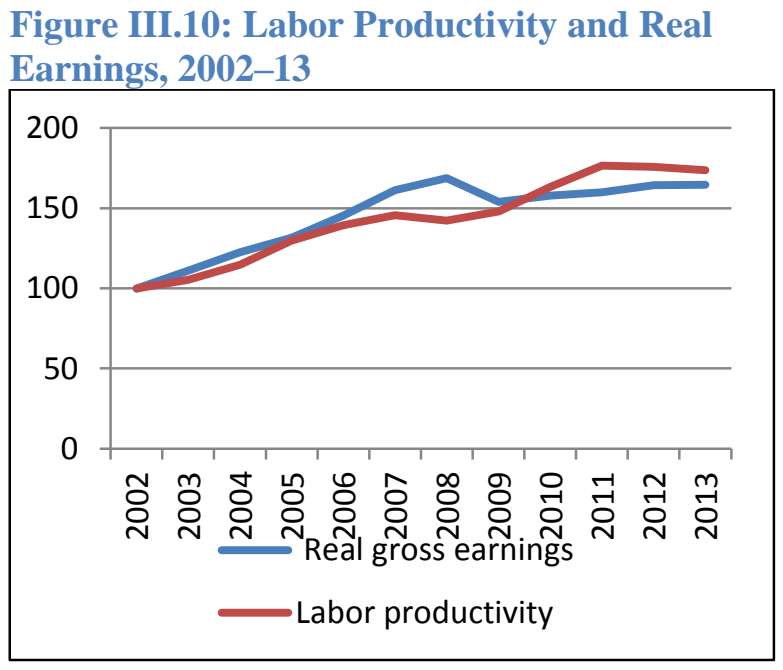

Source: SORS.
Figure III.11: The Relationship of Labor Productivity to Employment, 2003-13

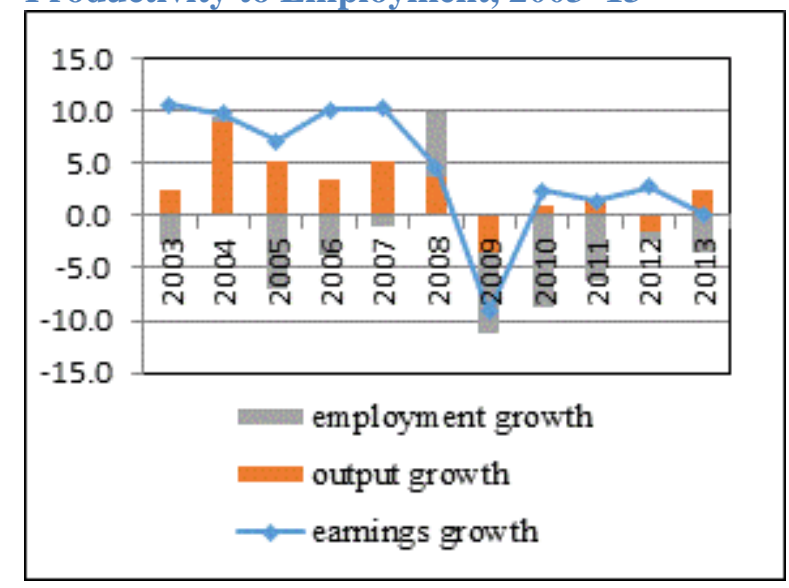

3.11. While the exchange rate plays a critical role in supporting external competitiveness, Serbia's exchange rate is broadly aligned with fundamentals, with no evidence of overvaluation. The National Bank of Serbia has pursued inflation targeting and a flexible exchange rate regime, which remain appropriate for Serbia to, respectively, anchor inflation expectations and provide buffer against external 
shocks. NBS' foreign exchange interventions will need to be limited to smoothing excessive exchange rate volatility without targeting a specific level or path for the exchange rate, while considering the implications for financial sector stability and meeting the inflation target. Serbia's current level of gross international reserves is above the levels determined adequate by most reserve metrics, providing a much needed cushion against shocks.

\subsection{Opportunities for growth lie in traditional exports, such as agricultural and food products,} metals, automobiles, and services (in particular information and communications technology [ICT] services). A recent analysis ${ }^{12}$ identified sectors where Serbia has a revealed comparative advantage, ${ }^{13}$ with agriculture and food products at the top. These tend to be sectors in which privatization was mostly completed early. More recently, some evidence suggests Serbia may be improving its integration with global value chains related to exports of manufactured parts and components (Figure III.12) and ICT services (Figure III.13). With respect to the latter, it appears that Serbia has benefited from the continuing boom in software outsourcing driven by the quality of the services provided by highly skilled Serbian IT specialists and the relatively low cost of production. ICT services comprise 51 percent of services exports, a significant and higher share than in comparator countries in the South East Europe (SEE) region and equaled only by Hungary. ${ }^{14}$ Still, as measured by unit values, Serbia's exports are typically of lower quality with less value-added than in regional peers.

Figure III.12: Share of Components in Manufactured Exports, 2002-12



Source: UN COMTRADE and World Bank staff.
Figure III.13: Share of ICT Services in Total Service Exports, Serbia and Comparators, 2008-12

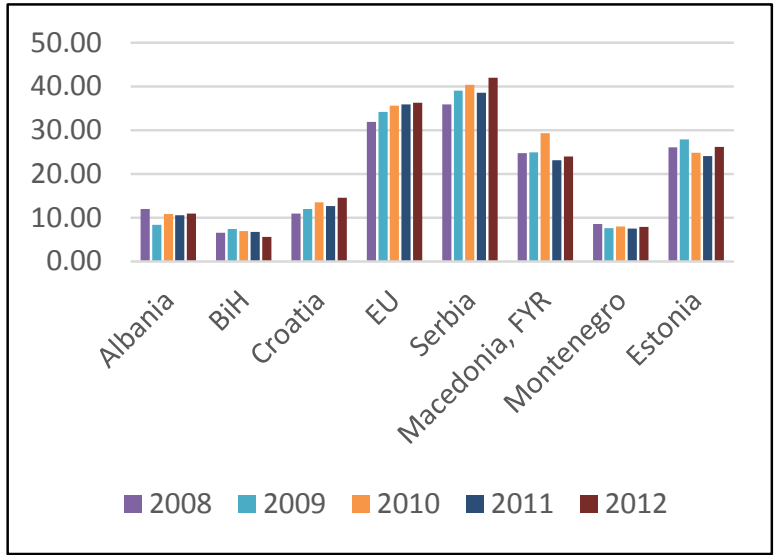

\footnotetext{
${ }^{12}$ See "Serbia Competitiveness Policy Note".

${ }^{13}$ A "revealed comparative advantage" (RCA) means that Serbia's share of world exports in that category exceeds Serbia's share of total world export.

${ }^{14}$ Source: "Rebalancing Serbia's Economy" (p. 22):

"http://www.worldbank.org/content/dam/Worldbank/document/eca/Serbia/rs-competitiveness-rebalancing-serbianeconomy.pdf.
} 


\section{Opportunities for Future Growth and Inclusion}

3.13. As a small open economy, Serbia will need to rebalance its growth model to one that relies more on productivity and competitiveness in order to achieve sustainably higher growth. The precrisis consumption-fuelled growth was unsustainable, and going forward, Serbia will need to pursue a more sustainable growth model, one that is based on external demand and increased productivity. While TFP has continued to contribute to growth, productivity has contributed only one-fourth of what it did before the crisis and the productivity of Serbian firms is particularly low compared to those in new EU member states. Notwithstanding the recent export growth, the ratio of Serbia's goods exports to GDP, at about 20 percent, is well below that of regional peers and significantly below some global leaders. ${ }^{15}$ The geographic proximity and the potentials of EU integration offer Serbia a unique opportunity to tap into the EU markets for exportled growth while dealing with the competitive pressures of open markets. By investing more, shifting to a greater export orientation, and enhancing economy-wide productivity, Serbia could achieve more balanced, sustainable, and broad-based growth. Domestic demand may well contribute to growth, but heavier reliance on external demand through export-led growth is likely to be more sustainable.

3.14. Serbia's low employment and participation rates are serious impediments to growth. In Serbia today only 40 percent of the adult population has a job; even fewer have a formal job, and even fewer still a private-sector formal job. No country can sustainably grow with so little employment and participation. Not surprisingly, the B40 mostly consists of the jobless, and the lack of labor income is a major deterrent to escaping poverty. In other words, bringing these people back into jobs is the key to both economic growth and inclusion. They mostly represent two groups: (a) the pre-transition generation, aged 40 or more, who either lost their jobs during the transition and never found a proper new job, or entered the labor market as the transition was beginning and never gained a firm foothold; and (b) groups, especially minorities like the Roma and also women generally, who have never been strongly attached to the labor market. These groups now live either on public and private transfers or subsistence farming and are largely excluded from labor markets, especially formal jobs.

\subsection{While export-led growth could broadly support inclusion in Serbia, given past experience} that growth has been mostly good for the poor, it may well fall short in generating enough jobs for the low-skilled and low productivity workers. As the analysis in Chapter 5 demonstrates, many of the B40 do not have the skills to benefit from high-productivity jobs that could be created from export-led growth. While there could be some potential in agricultural products, especially the fresh vegetables and fruits that are labor-intensive to harvest but require relatively little skill, the analysis finds that most lowwage earners in Serbia work in the service and hence the non-tradable sector; they work for micro and small enterprises (Figure III.14); they work in services and agriculture (Figure III.15); and many of them are in fact self-employed.

\footnotetext{
${ }^{15}$ See: World Bank, "Serbia Competitiveness Policy Note", 2014.
} 
Figure III.14: Serbia low wage earners by type and size of firm, 2013

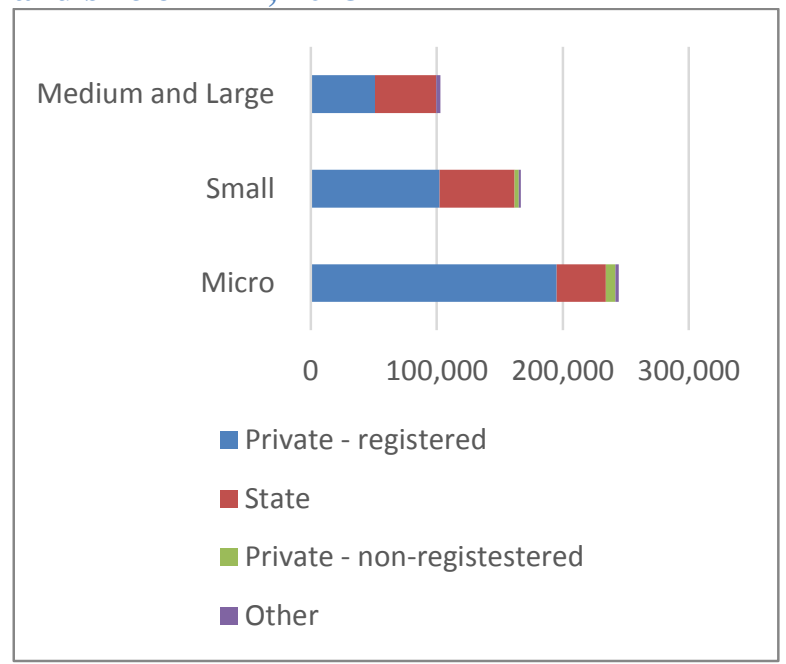

Source: LFS, April 2013.

Note: Wage employees earning RSD 25000 or less. Does not include self-employed. Micro: up to 11 employees; small 11-49 employees; medium and large above 50 employees.
Figure III.15: Serbia low wage earners by sector, 2012, percent share

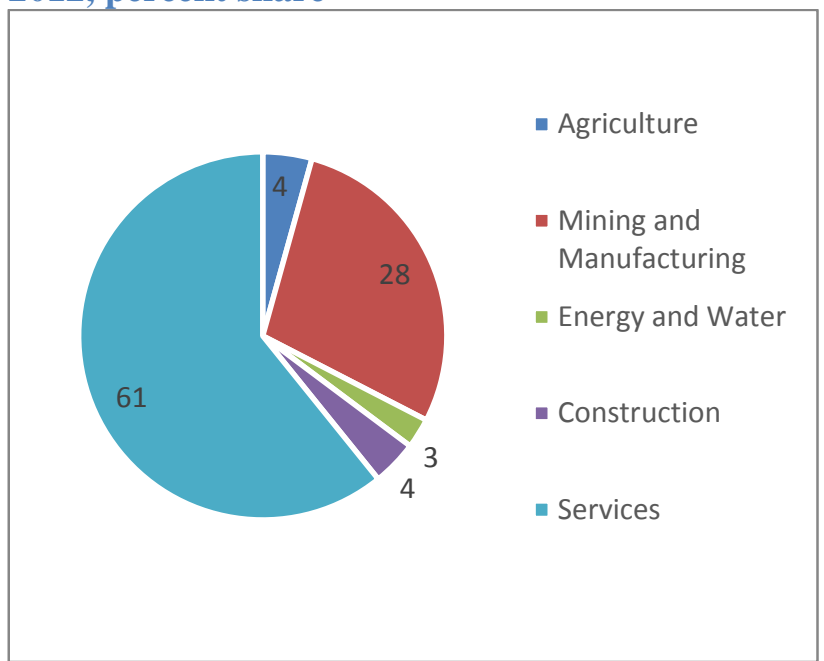

Source: LFS, April 2013.

Note: Wage employees earning RSD 25000 or less. Does not include self-employed.

3.16. To boost employment for the B40 and excluded groups, in addition to export-led growth, policy should be directed to removing barriers for SMEs and self-employment and attracting investments in agriculture and the non-tradable service sector. As discussed in Chapter 5, this principally means removing barriers to low-productivity jobs through flexible work arrangements; reforming the minimum social security contribution; redesigning the social benefit system to make it incentive-compatible; reforming labor market institutions like the National Employment Service (NES) to support efficient matchmaking between job-seekers and employers; and dismantling financial barriers in the SME sector. For women, whose contribution will be important, additional measures like providing care facilities for children and the elderly might be necessary to help them reconcile care duties with career goals.

\subsection{Over the medium to long term, Serbia's aging population and declining workforce make it} all the more important that the Roma and other excluded groups become more active in the labor force. In the medium term, the Serbian labor force is projected to shrink significantly due to demographic contraction (Box III.1). As it shrinks, it will be imperative that the labor force become more productive, not only to sustain growth but to finance such social services as health care and pensions for the old. Serbia can partly mitigate the adverse impact of demography by active policies that would offer incentives for labor force participation and employment (e.g., through training unemployed and inactive workers) among both the general population and excluded groups (see Chapter 5). The costs of continuing to exclude those aged 40 and above, the Roma, and women are high both in terms of lost growth, fiscal transfers and foregone fiscal revenues. 
3.18. Broad-based and sustainable growth, however, is unlikely to happen without dismantling critical constraints to growth. A slowly improving external environment, particularly in the Eurozone, will help, but solid and sustained growth will hinge on domestic policies and structural reforms that improve governance and institutional capacity, keep the economy stable, finish the incomplete SOE reforms, improve the business climate, and remove other impediments to exports and competitiveness. Domestic demand may well contribute to growth as it did in the past, but heavier reliance on external demand through export-led growth is likely to allow for faster and more sustainable growth and job creation. 


\section{DRIVERS AND CONSTRAINTS TO ECONOMIC GROWTH}

4.1. To achieve broad-based economic growth that is anchored in higher investment, productivity, and external competitiveness, Serbia will have to tackle a broad range of governance, macroeconomic, and structural constraints. It especially needs to improve its governance and institutional capacity to implement reforms; tackle the large unfinished agenda of restructuring and privatization of SOEs; make its regulatory and business environment more predictable and friendly; ensure that fiscal policy is sustainable; improve access to finance, including to long-term finance; and invest in infrastructure and skills. Key elements of restoring strong economic growth in Serbia are providing a more conducive environment for the private sector while curbing the large role of the state in the economy and completing the largely unfinished first-generation reform agenda for an efficient public sector. The figure below provides an overview of the structure of the discussion of these constraints on growth in the rest of this Chapter.

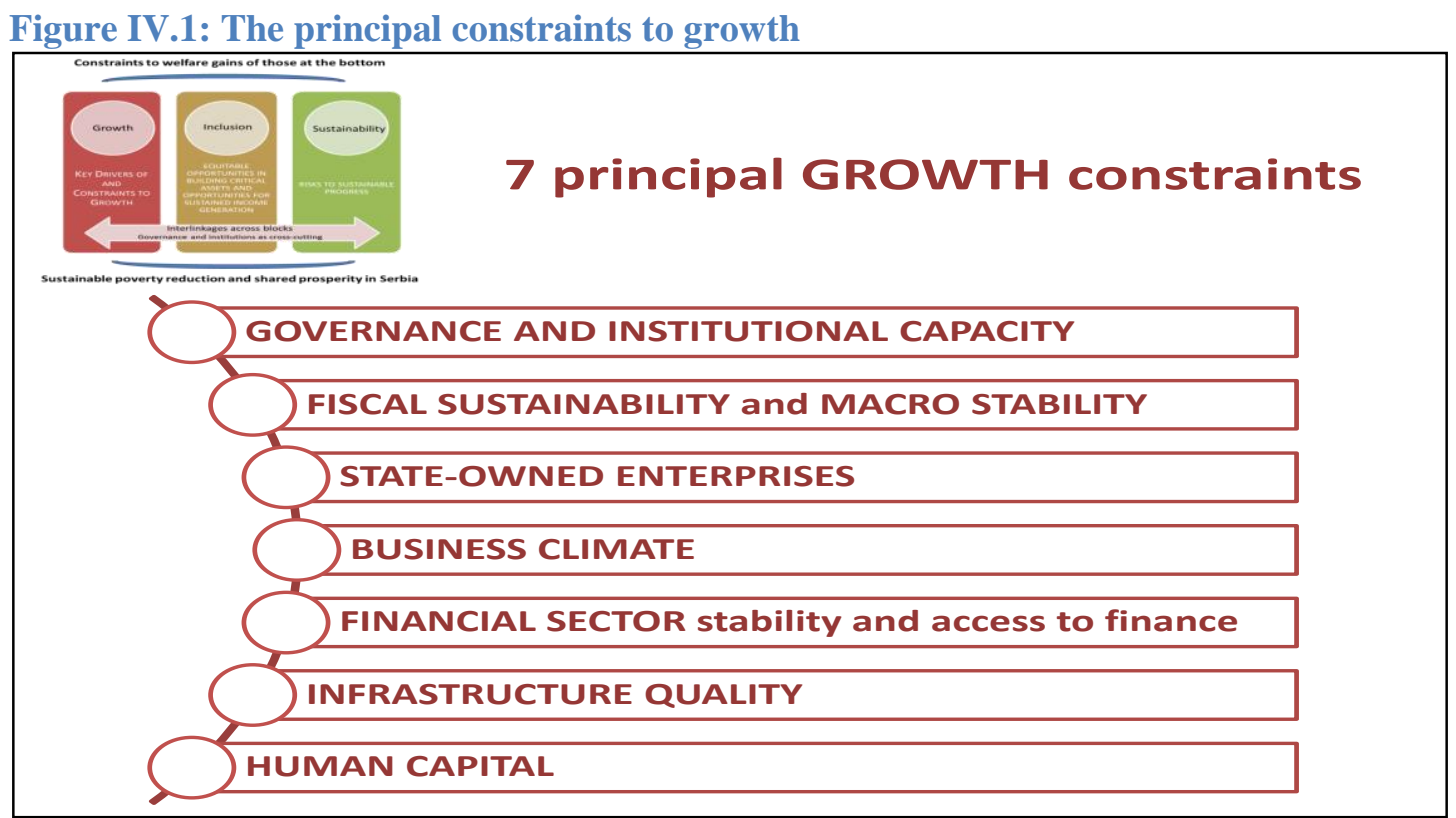

Source: World Bank staff.

4.2. The pro-growth reforms-including fiscal consolidation, SOE reforms-will have distributional implications for the $\mathbf{B 4 0}$. Some of the effects of reforms could be indirect as some of the households affected by, for example, fiscal consolidation and SOE measures may have relatively high income and consumption levels. However, some others may impact the welfare of the B40, where particular attention is needed to protect those at the bottom of the welfare distribution. In the short term, fiscal consolidation and structural reform imperatives combined with the recent adverse impact of floods on growth could negatively impact especially the B40. Furthermore, as the public sector sheds employment in the short to medium term, private sector investment and job creation may not kick in fast enough to offset immediate public sector losses, in which case unemployment and shared prosperity could worsen before 
improving. How quickly the B40 can start to benefit from the pro-growth reforms thus depends on the pace of both public sector reform and private sector response, in particular response in terms of investment. Given the potential for adverse effects on the poor, it will be important to have in place complementary policies (e.g. a well-targeted social assistance program, supportive employment services) that will mitigate the distributional consequences -an issue extensively discussed in Chapter 5.

\section{Governance and Institutional Capacity}

4.3. Serbia's ability to create the conditions for sustained and inclusive economic growth is undermined by insufficient institutional capacity to implement reforms. The country not only lacks a robust accountability framework for results, it also suffers from limited technical capacity and high turnover of technical advisors during changes in government. Government officials are not held accountable for results. Performance targets are not clearly defined or monitored, and day-to-day activities are typically not directed to meeting goals. Neither organizations nor ministers are subject to robust performance assessment, and the annual performance appraisal system for public employees is not widely used. Getting things done is also complicated by shortages of technically skilled staff. Although the public sector workforce is high relative to the population, the government finds it difficult to mobilize staff with the needed skills. Furthermore, the high turnover in technical advisors to ministers caused by constant changes in government carries a loss of institutional memory and high risks that reforms in progress will not be carried forward. Institutional quality in the public sector is also hampered by recruitment policies that are often based on patronage and connections rather than merit.

4.4. As a result of these deficiencies, citizens have little satisfaction with or trust in public service delivery and government institutions. For example, Serbia scores lowest in the SEE region on the Gallup World Poll Community Basics Index, which measures satisfaction with such aspects of everyday life as education, the environment, health care, housing, and infrastructure (Figures IV.2 and IV.3). Satisfaction has in fact been trending downward since 2010.

\section{Figure IV.2: Community Basics Index}

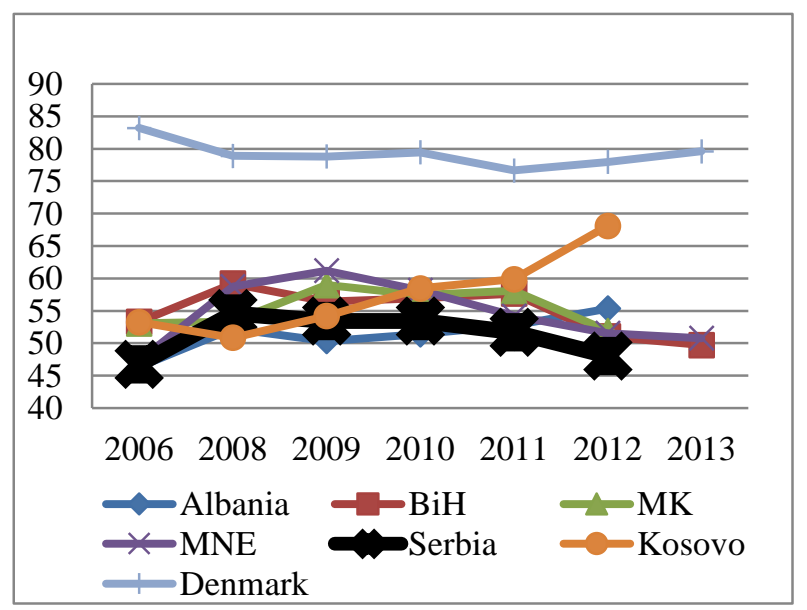

Source: Gallup World Poll data.
Figure IV.3: Satisfaction with Public Services, 2012

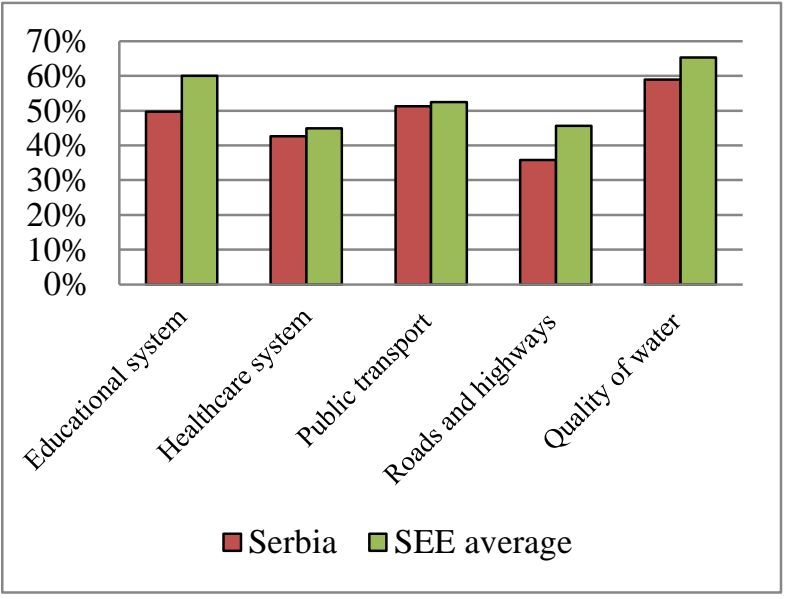




\subsection{Life in Transition Surveys (LiTS) also found a decline in trust in all types of institution} between 2006 and 2010 (Figure IV.4). The LITS data reveal that trust levels are highest in the armed forces and religious institutions and lowest in the courts, government, parliament, and political parties. With the exception of trust in religious institutions, foreign investors, and banks and the financial system, Serbia also has significantly lower trust levels compared to Western EU averages.

\section{Figure IV.4: Trust in Institutions, 2006 and 2010}

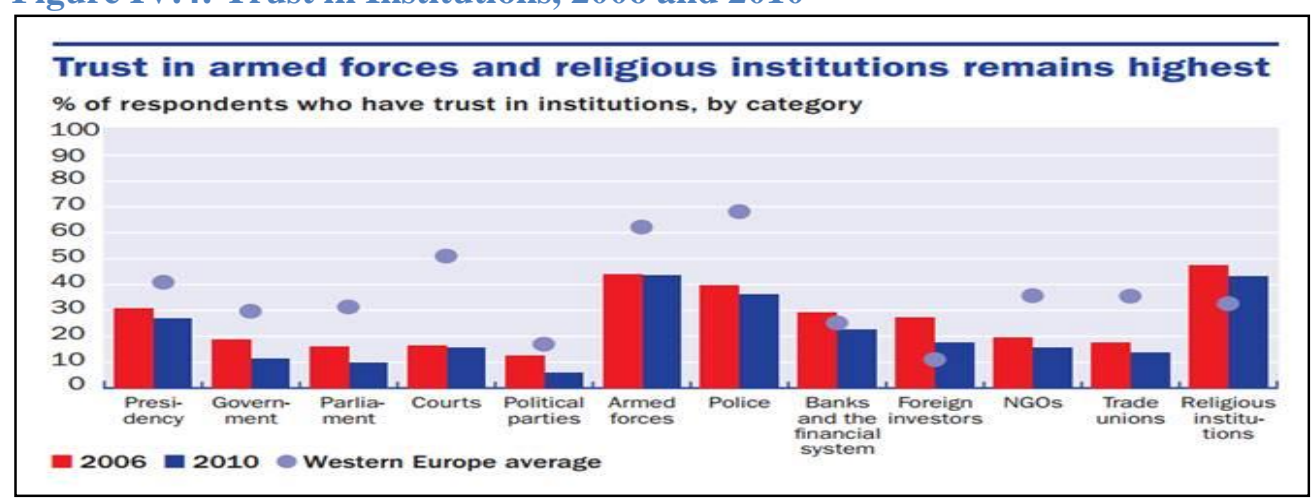

Source: Life in Transition Surveys 2006 and 2010.

4.6. Serbia's institutional capacity and EU readiness are low. A comparison of Serbia's public sector performance and institutional capacity today with the EU's new member states back in 2006 illustrates the challenges that Serbia has to confront to bridge the huge gaps in performance and institutional capacity (see Annex 5). ${ }^{16}$ Five areas stand out as the most important gaps in terms of Serbia's ability to design and implement effective economic reform policies and manage the process of EU accession: public sector performance, strategic planning, policy coordination, effective human resources and career management, and management of the political-administrative interface.

4.7. Public sector performance is poor. Serbia scores comparatively low on areas critical for building assets (such as education), the business environment and competitiveness, program delivery related to labor market issues, and health. Yet the country spends significant resources on public sector wages and other costs in these areas. If one applies the Common Assessment Framework (CAF), a European bottom-up approach of measuring the quality of public administration, Serbia would rate 0.5 , which would place it among the weakest performers when the New Member States assessment was completed. Although Serbia is planning to adopt a public administration reform strategy and action plan, it has yet to be designed. A consensus has not yet been established on what a performance framework would look like and who will report on public sector performance. It is significantly more difficult to hold officials accountable without clear performance criteria and standards. The progress made by Poland, for example, demonstrates that it is possible to make quick advances but it takes a determined and concerted effort.

\footnotetext{
16 This comparative assessment is based on the evidence based tracking systems and methodologies applied to the EU's new member states in 2006 but the EU accession process has since changed significantly, with the EU accession requirements for institutional systems and technical capacity being more rigorous now, so the institutional challenges are going to be even greater.
} 
Table IV.1: Serbia Governance and Institutional Capacity Benchmarking a/

\begin{tabular}{|c|c|c|c|c|c|c|c|c|}
\hline Area of Study & & POLICY & & & PEO & & & E-GOV \\
\hline Aspect of Study & $\begin{array}{l}\text { Performance } \\
\text { Management }\end{array}$ & $\begin{array}{l}\text { Strategic } \\
\text { Planning }\end{array}$ & $\begin{array}{c}\text { Policy } \\
\text { Coordination }\end{array}$ & $\begin{array}{c}\text { HR } \\
\text { Legislation }\end{array}$ & $\begin{array}{c}\text { HR } \\
\text { Horizontal } \\
\text { Management }\end{array}$ & $\begin{array}{l}\text { Political- } \\
\text { Admin } \\
\text { Relations }\end{array}$ & Incentives & E-Gov \\
\hline Scoring System & $\mathrm{CAF}$ & $\mathrm{CAF}$ & Metcalfe & SIGMA & SIGMA & SIGMA & SIGMA & \\
\hline Scoring Range & $0-5$ & $0-5$ & $1-9$ & $1-7$ & $1-7$ & $1-7$ & $1-7$ & $1-4$ \\
\hline Poland & 0.5 & 0.5 & 4 & $6 / 7$ & $6 / 7$ & 7 & 5 & 1 \\
\hline Hungary & 1 & 1.5 & 5 & 5 & 5 & 5 & -- & 1 \\
\hline Czech Republic & 1 & 1.5 & 3 & $6 / 7$ & $6 / 7$ & -- & -- & 2 \\
\hline Slovakia & 1 & 1.5 & 3 & $6 / 7$ & $6 / 7$ & 7 & -- & 2 \\
\hline Slovenia & 1 & 1.5 & -- & 5 & 5 & -- & -- & 1 \\
\hline Lithuania & 3 & 4 & 8 & 5 & 5 & 2 & 3 & 1 \\
\hline Latvia & 3 & 3.5 & 7 & 5 & 5 & 3 & 2 & 2 \\
\hline Estonia & 1 & 1.5 & -- & 5 & 5 & -- & -- & 4 \\
\hline Serbia & 0.5 & 0.5 & 2 & 2 & 6 & 6 & 6 & 1 \\
\hline
\end{tabular}

Source: World Bank (2007), EU-8 Administrative Capacity in the New Member States: The Limits of Innovation?

Note: a/ See Annex 5 for more details on the rating methods.

4.8. Serbia lacks strategic planning. A robust strategic planning system is critical for a country with ambitions to both overhaul its management of the economy and negotiate EU accession. Little attention is given to output and outcomes, and strategies are rarely based on analytical work. Moreover, the public has little opportunity to comment on the proposed strategies and public debates are inadequate. At best, Serbia would get a 0.5 rating on the CAF-related scale, the lowest point for the new EU Member States back in 2006. Strategic planning requires a decision-making system that draws on specific structures to review, consult on, and vet policy proposals for their quality and alignment with strategy. Lithuania's strategic planning process, set up after its 1998 economic crisis, is one of the best examples of such an approach; the process has not only survived numerous changes of government but also supported Lithuania's successful fiscal consolidation and EU accession processes and its strong performance upon entry into the EU (see Evans and Evans 2001). It took Lithuania about a year and a half to draft its strategic planning process and put it into operation.

4.9. Policy coordination is perhaps the weakest point for Serbia. The General Secretariat is overly bureaucratic, is concerned with form rather than substance, and has been ineffective in policy coordination. Inter-ministerial coordination processes are ad hoc; take place at the regular meetings of the government instead of being prioritized and filtered by lower-level coordination structures; and are more a formality than a forum for debate. Rethinking how policy is managed should be an urgent priority if Serbia's ambitious fiscal consolidation and structural reform program is to succeed. On current evidence Serbia would rate no higher than 2 on the Metcalfe $\operatorname{scale}^{17}$ (a policy coordination measurement scale developed by Les Metcalfe, see Annex 4), while the consensus is that at least a 4, preferably a 5, is needed for effective functioning in the EU system. Critical first steps would be both overhaul of procedures and establishment of a qualitative filter at the Office of the Government.

4.10. Poor management of public services generally has led to a growing number of politicallybased appointments and clogged decision making throughout the system. As a result, the civil service

\footnotetext{
${ }^{17}$ Metcalfe, Les (1994), 'International Policy Co-ordination and Public Management Reform', International Review of Administrative Sciences, Sage, London, Thousand Oaks and New Delhi, Vol. 60, 271-290.
} 
has become seriously overstaffed without enhancing service delivery. Analysis of local government staffing and the public wage system has highlighted the inadequacy of both central and local hiring control systems and persistent violation of staffing norms and rules, juxtaposed with disappointing service delivery outcomes. Until early 2014 the Serbian government did not know how many staff it paid. Along with overstaffing and a lack of professional human resource management, decision-making processes have become equally clogged. In effect the system of arbitration and coordination of policy management has collapsed, all decisions are pushed up to ministerial levels, and government sessions have become overloaded with trivialities.

4.11. Serbia's human resources (HR) legislation and horizontal management performance are mixed. HR legislation for the core civil service is relatively strong, though laws related to broader public service are not. Brought to successful conclusion, current efforts would put Serbia in position to meet standards on this aspect and move towards a 2 rating on the Metcalfe scale. HR horizontal management procedures, however, are ineffective, as shown by how difficult it is to reallocate staff across the administration. The HR database serves merely to know where staff are placed; no operative sourcing and HR management system exist. As the situation stands, EU entry standard (a rating of 6) is not likely to be achieved in the medium term. The clear implication is that Serbia needs to build a public service that can meet the demands of EU membership.

4.12. As noted, Serbia's institutional capacity has been eroded by political fragmentation, which has in turn undermined formulation and implementation of economic policies. Although Serbia inherited a relatively well-established civil and public service system and a set of government institutions capable of supporting effective political decision-making and tracking of policy actions, growing politicization and fragmented coalition politics have eroded those systems and institutions. Although formally there is protection from politically motivated transfers or dismissals, it is ineffective. As in other SEE countries, there is high turnover in the administration after each change of minister, which is accompanied by delays or reversals in policy and program implementation.

4.13. Public sector management problems affect economic governance in two ways. First, an overloaded and clogged political decision-making process reduces the ability of government to act strategically and opens up opportunities for undue influence through access to decision-makers. Second, the lack of effective filtering of decisions means that the sheer volume of government decisions that must be made at a high level makes effective tracking of implementation impossible.

\subsection{Significant effort will be needed if Serbia is to reach at least the minimum levels required for it to meet the multiple challenges of both economic reform and EU accession. Recent government initiatives to reestablish a system of strategic decision-making and track implementation are encouraging but will take time and effort to have an impact. Efforts to reassert establishment control systems and create a more strategic staffing process are similarly encouraging. While building functioning public service management systems will take longer in Serbia, given heavy politicization and deep-seated issues of fragmentation in career management, the Baltic States and Hungary have demonstrated that strategic planning, performance management, and coordination of results can be achieved quickly when there is clear political commitment. The current efforts to overhaul at least the legal structure are a good starting point but realistically will take several years of conscientious effort for results to materialize. At this point, rapid}


investment in establishing strategic planning and performance management processes, along with overhaul of outdated and largely dysfunctional coordination mechanisms, deserve critical priority.

\section{Fiscal Sustainability and Macroeconomic Stability}

4.15. As the economy slowed, in particular since 2008, the fiscal position of the government has deteriorated (Figure IV.6). Revenues fell in 2008-11 but have since recovered, in part due to increases in the value added tax (VAT) rate. Expenditures have been growing steadily. The result has been steady deterioration in the general government fiscal deficit, from about 2.6 percent of GDP in 2008 to a peak of about 7.2 percent in 2012, although it then subsided to 5.6 percent in 2013 due to cuts in capital spending and subsidies and the introduction of new rules for indexation of public salaries and pensions. The 2014 fiscal deficit is estimated at a high 7.9 percent of GDP as expenditures have continued to rise (e.g., in the first 11 months spending on goods was up by 5.9 percent and on subsidies by 4.8 percent).

\subsection{As a result, Serbia's public debt, including guarantees, has more than doubled in recent years,} from 32.4 percent of GDP in 2008 to over 70 percent at the end of 2014 (Figure IV.6). Contributing significantly to this surge were guarantees issued on behalf of public enterprises and local governments, which stood at close to 9.9 percent of GDP at the end of 2013. Guarantees, issued principally to SOEs, more than tripled, from 2.8 percent of GDP in 2008 to 9.9 percent at yearend-2013. From 2008 through 2014, domestic public debt grew from about 10 percent of GDP to about 30 percent, and external public debt from about 17 percent of GDP to 37 percent. At year-end 2014 it is estimated that the stock of public debt exceeded 70 percent of GDP.

Figure IV.5: Fiscal Balance, 2008-13 (after grants and incl. guarantees, \%GDP)

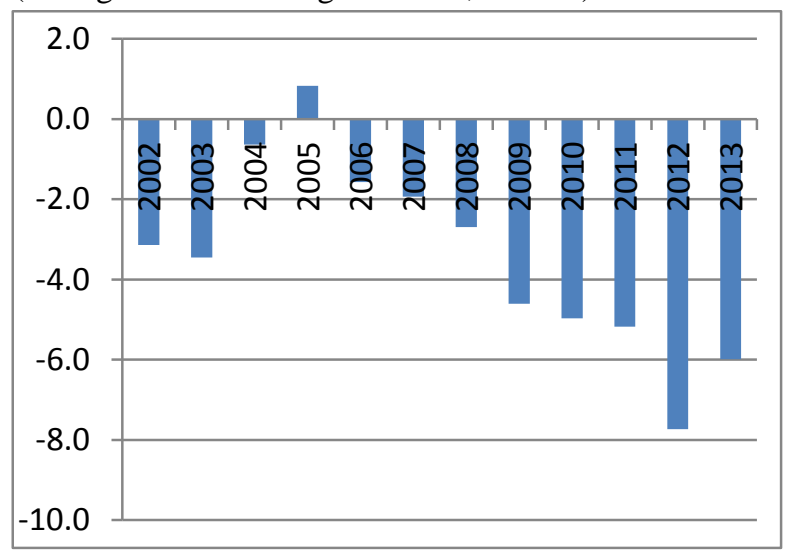

Source: MOF, NBS, World Bank staff.

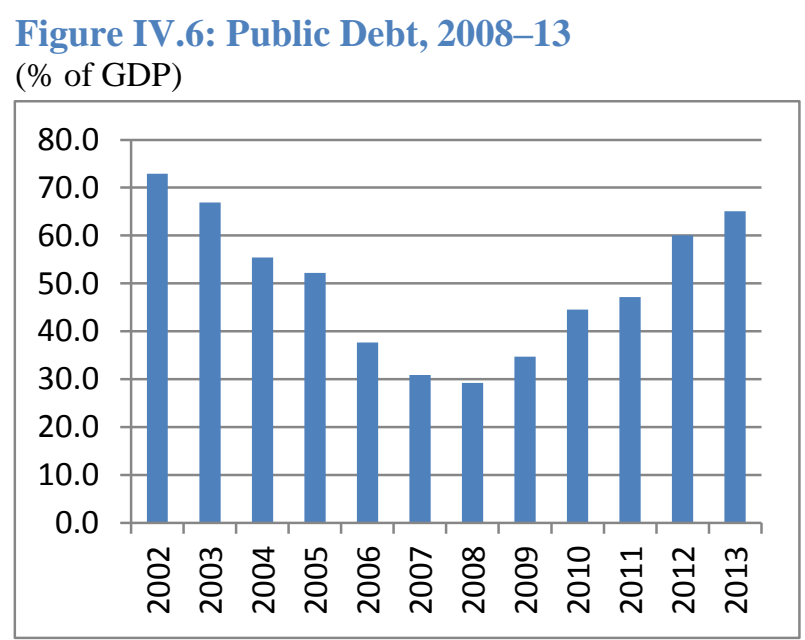

Source: MOF, NBS, World Bank staff.

4.17. Debt service not only absorbs a significant amount of resources that could be used for productive purposes, it also carries significant roll-over risk. From a mere 5 percent in 2008, debt service grew to 40 percent of total revenues (16 percent of GDP) in 2014. With fiscal consolidation partial or delayed, the problem has grown over time.

4.18. A comprehensive fiscal consolidation program is urgently needed to reduce the deficit and keep debt sustainable over the medium term. Opportunities for fiscal adjustment lie mostly on the 
spending side though some will come from more rigorous revenue administration. Serbia already collects significant revenues and the potential for collecting more by raising tax rates is limited. ${ }^{18}$ The country on average collects about 41 percent of GDP in public revenues, about 6 percentage points above the SEE average. Several tax rates went up in 2014: the lower VAT rate from 8 to 10 percent, the corporate income tax from 10 to 15 percent; and some excise taxes also went up. Although improved management within the tax administration and customs could yield additional revenues, ${ }^{19}$ the priorities for fiscal adjustment lie on the expenditure side, which reached a heavy 47 percent of GDP in 2013. Expenditure reduction can be achieved through restructuring the SOEs (including state-owned banks), reform of public administration and the wage bill, pensions, subsidies - all of which are needed to encourage efficiency and provide the necessary fiscal savings as an impetus for growth.

4.19. An unaffordable public sector wage bill is a pressing problem. The general government wage bill, which has grown significantly in recent years, now accounts for almost 11 percent of GDP. Structural weaknesses in wage and control systems have resulted in a bloated public sector, characterized by more than 780,000 employees, 2,200 job titles, 71 different remuneration structures, 16 different base salaries, 900 different job coefficients, 19 laws, and a plethora of by-laws that regulate salary levels in 11,000 budget institutions. Overstaffing or staffing imbalances are most evident in health (the nonmedical cadre is overstaffed) and police and security forces. Many public agencies and public enterprises are budgetdependent but not subject to public salary rules or establishment control, and staffing is not accompanied by the corresponding level of accountability. [See "Wage Bill and Public Employment Note."]

\subsection{Curbing the considerable spending on pensions is also essential to fiscal adjustment; at more} than 14 percent of GDP, pension spending in Serbia is the second-highest in Europe. The spending is driven both by high benefit levels and large numbers of beneficiaries. While not necessarily high in absolute terms, benefits are high relative to average wages and to GDP per capita. Pension spending per beneficiary is 66 percent of GDP per capita; within the EU that is topped only by Cyprus' 69 percent. Germany, Sweden, Poland, and even Croatia have benefit levels in the range of 39-47 percent of GDP per capita. Also, almost a third of old-age beneficiaries in Serbia are not yet 65 . The imbalance between contributions (24 percent of average wage) and benefits (average pension is 70 percent of average wage) and the high dependency ratio lead to deficits that have to be financed from the general budget, which then leads to inequities because general revenue, broadly collected, is used to finance high pensions for higher-income retirees. Early retirement and the absence of actuarial reductions in benefits have also contributed to the fiscal pressure.

\subsection{A new pension law passed in July 2014 gradually introduces actuarial reductions for early} retirement as well as reduces benefits for those who earn higher pensions. However, a significant number of potentially early retirees are exempted from the early retirement reforms, and even for those impacted, the downward adjustment for early retirement is only fully phased in by 2031 and consists of a 4 percent reduction in benefit per year of early retirement. Actuarial fairness suggests that there should be a 6 percent reduction in benefits per year of early retirement. On the reduction in benefits to higher pension earners, a temporary tax was introduced in November 2014, valid only until 2017, on pension incomes above RSD 25,000 per month but its sustainability will need to be strengthened. At the same time, the huge

\footnotetext{
${ }^{18}$ A recent World Bank study (Khwaja 2014) shows that the country is in fact collecting above its economic capacity.

${ }^{19}$ Recent studies on the informal sector show (e.g. USAID, 2013) some limited potential for raising additional revenues from better coverage of the informal sector-estimated to be in the range $0.3-0.5$ percent of GDP annually.
} 
overall reduction in benefits that will come about in the next 15 years from the peculiar indexation that is already in the pension law will need to be revisited to ensure a more controlled reduction over time so pension reforms are not undone by political pressures.

4.22. Over the last five years direct subsidies have grown to an average of 3.1 percent of GDP. Subsidies have remained high principally because there are a significant number of SOEs in the real sector, public utilities are inefficient, and agriculture continues to rely on regular state support. The central government provides two-thirds of all subsidies and local governments the other one-third. In 2013, of total subsidies of RSD 84 billion about 45 percent went to agriculture, 18 percent to economy (including energy) and 16 percent to the railways; together the three account for almost 80 percent of total subsidies. Subsidies to the railroad company and the coal mining company, JP Resavica, have been rising. As a result, 2013 subsidies reached about 4.8 percent of GDP, a record high.

4.23. Increasingly important, and costly, is the support in the form of government guarantees for loans to SOEs. SOEs often fail to service the guaranteed loans, causing significant contingent liabilities for the budget. In recent years, the cost to the central budget of this debt service has shot up from $€ 72$ million in 2010 to an expected $€ 431$ million in 2014. This type of state support has primarily been extended to struggling utilities like Srbijagas, which has accumulated over $€ 700$ million of guaranteed debt—with another $€ 200$ million in loans approved but still not drawn. In previous years, Government provided this type of support to SOEs in commercial sectors, like the steel smelter Zelezara Smederevo, which has accumulated about $€ 110$ million of guaranteed debt, and the pharmaceutical company Galenika, about $€ 85$ million.

4.24. In an effort to deal with its fiscal challenges, the government has adopted an ambitious fiscal consolidation and structural reform $\operatorname{program}^{20}$ to halt the rise in public debt and put it on a downward trajectory by 2017. Fiscal consolidation will be pursued by reducing public sector wage bills, pension costs, and fiscal support to public enterprises, in conjunction with broad-ranging structural reforms. The 2014 supplemental budget laid out the first steps in the program of across-the-board cuts in wages and pensions: there will be (a) no indexation of wages as of October (the legal obligation was an increase of 1 percent in April and October), and (b) nominal reduction of wages of 10 percent as of November 2014. In parallel the parliament approved the Law on Temporary Reduction of Pensions, also effective as of November 2014, that envisages reduction of pensions above RSD 25,000 by 22 percent and above RSD 40,000 by 25 percent. The primary structural components of the program are restructuring large public enterprises and improving the investment climate. The former includes long-delayed reforms in such vital areas as energy, railways, and road enterprises (see the next section for details). Success of the fiscal consolidation program hinges crucially on reducing the fiscal drain from the SOEs as well as addressing the public financial management challenges. Annex 4 describes the key public financial management challenges. Annex 5 provides projections of the macroeconomic outlook for Serbia, including the fiscal targets for 2015-17 which reflect the government's fiscal consolidation program.

4.25. A debt sustainability analysis shows that in the baseline scenario, public debt-to-GDP will reach 79.6 percent in 2016, after which it will begin to decline (Figure IV.7). This scenario assumes

${ }^{20}$ This reform program is supported by a new 3-year IMF precautionary stand-by program. 
that real GDP growth will continue to average about 1.5 percent through 2017 and that the fiscal consolidation strategy operates as planned, with the primary deficit declining from 4.9 percent of GDP in 2014 to 0.8 percent by 2016 and thereafter moving into a small primary surplus. Over the near term gross government financing needs will remain significant, though declining from 14 percent of GDP in 2014 to 12 percent in 2016 as the primary deficit narrows.

Figure IV.7: Serbia: Public Debt Sustainability 1, 2
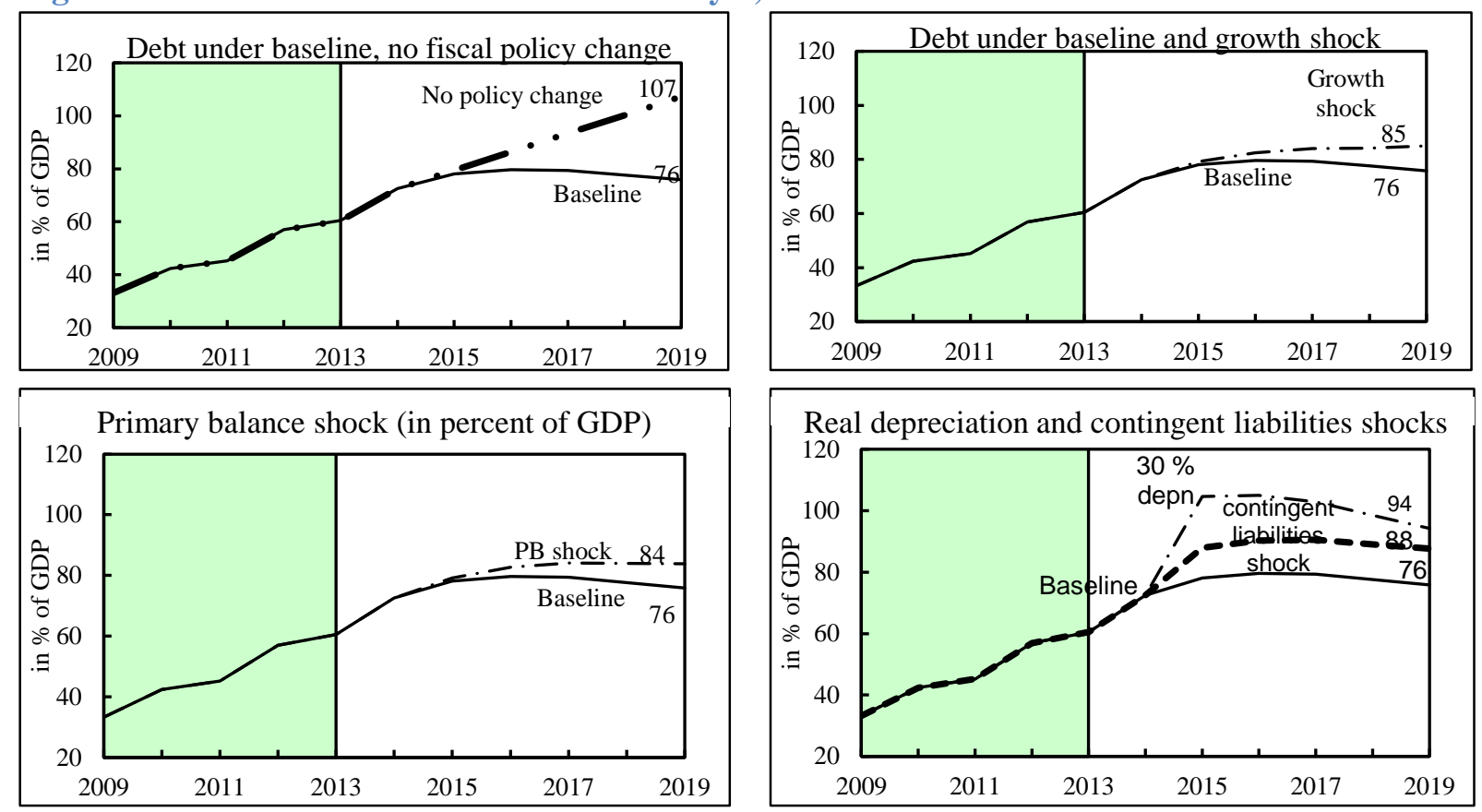

Source: Serbia Ministry of Finance and Economy, IMF, World Bank staff projections.

${ }^{1}$ Shaded areas represent actual data. Individual shocks (growth, primary balance) are permanent one-half standard deviation shocks from historical ten-year average from 2015.

${ }^{2}$ One-time real depreciation of 30 percent and 10 percent of GDP shock to contingent liabilities occur in 2015 , with real depreciation defined as nominal depreciation (measured by percentage fall in dollar value of local currency) minus domestic inflation (based on GDP deflator).

4.26. The projected public debt path, however, is highly sensitive to slippages in the fiscal consolidation plan, unexpectedly poor growth, or a negative real exchange rate shock. Indeed, both unexpectedly low GDP growth and a primary deficit that is half a standard deviation higher than the baseline would push Serbia's debt ratio to about 85 percent by 2017 (and still rising if growth is weakening). Similarly, a one-off real depreciation of 30 percent or a one-off realization of 10 percent of GDP in contingent liabilities will push the public debt ratio up to 88-94 percent of GDP. Even a more moderate real depreciation of 10 percent in 2015 would move the debt ratio up to 85 percent in 2015 and 2016-6-7 percentage points above the baseline — while a combination of smaller slippages could lead to the debt ratio continuing to rise throughout the projection period.

4.27. Serbia's macroeconomic outlook faces significant risks, both external and internal. External risks relate to worse than expected economic recovery in the Eurozone, which would have an adverse effect on Serbia's economic outlook through exports, remittances, and capital flows since the EU countries are Serbia's largest trading partners. Adverse shocks to capital inflows, for example, because of normalization 
of US interest rates, or negative spillovers from other emerging economies, could also pose risks given Serbia's refinancing needs and foreign currency debt burden. A deterioration of the financial situation of foreign parent banks could similarly jeopardize credit recovery and undermine growth. On the upside, given Serbia's sizeable dependence on oil and fuel imports, stabilization of oil prices at their current low levels could reduce imports and support current account adjustment. Internally, the main risks are that the government will be unable to enforce the policy of "no new liquidity guarantees to public enterprises" and will fail to reduce subsidies as proposed. Without reforms that tackle public utilities such as the natural gas monopoly Srbijagas, stricter control of the issuance of new guarantees may prove politically difficult. If some of these fiscal risks were to come about, or if growth or the currency weakens, the government would need to undertake even greater fiscal consolidation efforts over the medium term to keep debt sustainable and the Serbian economy stable. These risks put an even higher premium on completing first-generation reforms of SOEs and public utilities in order to reduce fiscal pressures and enhance economic efficiency, a topic discussed in the next section.

4.28. Last but not least, Serbia's low level of employment, coupled with its aging population, adversely impacts fiscal sustainability over the long term. The incredibly low rate of formal private sector employment implies that the proportion of the population paying taxes to fund public services is low. Without increasing labor force participation and employment and bringing excluded groups into the formal economy, fiscal sustainability becomes harder to maintain over the long term; 20 years later, when most of these people are too old to work, but with no eligibility for a formal pension, the fiscal pressures from social protection and health care could increase considerably.

\section{Reforming State-Owned Enterprises (SOEs)}

4.29. The state looms too large in the economy. A widespread perception persists among the Serbian public that the state's role is to provide for individuals - a deeply held entitlement culture. This perception has been slow to change, preventing efforts to reduce the public sector and the role of the state in the economy. Yet Serbia's ability to generate growth and jobs is highly dependent on overcoming the anachronistic notions of the role of the state and shaping the size of the public sector accordingly to reduce its scope and inefficiency. Serbia's consolidated general government expenditure, a proxy for the state's role in the economy, has increased from about 44 percent of GDP before the crisis to about 47 percent now.

4.30. Much of the agenda for reform of the SOE has only recently begun. One of the major legacies of Serbia's transition is the presence of a large number of SOEs, which must be dealt with to assure the success of the general reform program. There are about 1,300 SOEs that employ about 16 percent $(270,000)$ of the formal Serbian workforce. While highly heterogeneous, they can be segmented into two groups: (a) state and socially-owned enterprises, and (b) municipally-owned enterprises. ${ }^{21}$ The first group can further be segmented into commercial companies in the Privatization Agency (PA) portfolio and public utilities. Privatization of socially-owned enterprises and restructuring of large inefficient public utilities need to be completed, and the state needs to deal with the magnitude of public sector employment and the wage bill as well as of social benefits and inefficient subsidies. These steps are necessary to better reallocate resources

${ }^{21}$ Municipal utility companies include several hundred companies of different types and sizes. For a detailed discussion of their operational and financial (in) efficiency, please see: "Serbia Municipal Public Finance Review II", 2014, World Bank. 
and restore sustainability to the public finances. Reform of large utilities also needs to be deepened through, among other measures, continuation of privatization and restructuring the workforce, operations, and debts of public utilities and professionalizing corporate management. While privatization and restructuring of SOEs (and public sector downsizing) will likely lead to further contraction in public employment, they are essential for Serbia to get back on the path of sustainable growth.

4.31. SOEs have net annual losses of an estimated 3-4 percent of GDP, or more than $€ 1$ billion, and require significant state support to stay afloat. Direct support consists of budget subsidies and soft loans. Indirect support takes such forms as unpaid taxes and contributions, guarantees for loans, and arrears to other state entities and public utilities. Across all categories of SOEs, yearly cash outflows and equivalents for both direct and indirect support amount to over 2.5 percent of GDP annually. In addition, the inability of creditors and suppliers, both private and state-owned, to collect for their services from companies being restructured is a major market distortion. Unpaid bills translate to direct losses for major utilities, making them much less attractive to investors. In total, companies being restructured have accumulated over $€ 4.5$ billion in debt. De facto wage policy in many SOEs, although in principle related to the public wage salary scale, is relatively liberal and further distorts the already high public/private wage ratio. Since SOEs have a major role in nearly every sector of the economy, private investment is crowded out and valuable labor, capital, and land are not allocated productively. SOE reform will contribute to medium-term fiscal consolidation efforts as well as economic recovery through greater economic efficiency and higher productivity.

\section{State-owned Enterprises to be Privatized}

4.32. There are about 502 companies in the PA portfolio, employing in total about 90,000 workers (Table IV.2). With the new Privatization Law approved in August 2014, the government has initiated restructuring procedures for these companies, which are expected to be resolved during 2015 or the first half of 2016. The Privatization Law envisages four possible models for resolving the companies in the PA portfolio: bankruptcy, equity sale, asset sale, and strategic partnership.

\begin{tabular}{|c|c|c|}
\hline Method of privatization & No. of companies & Total no. of employees \\
\hline Bankruptcy & 188 & 5,000 \\
\hline Equity sale & 139 & 25,000 \\
\hline Asset sale & 29 & 3,000 \\
\hline Equity-asset sale & 3 & 3,000 \\
\hline Strategic partnership & 22 & 24,000 \\
\hline Removed from privatization & 90 & 16,000 \\
\hline
\end{tabular}

Source: MoE, World Bank staff.

4.33. The privatization plan prepared by the PA and the Ministry of Economy (MoE) sets out the approach the PA will apply:

- Bankruptcies. A group of 188 companies employing about 5,000 workers will be sent to bankruptcy, most in the first quarter of 2015. 
- Sale of equity and assets. Most of the other companies in the PA portfolio are slated for privatization under the equity sale model (139 companies, with about 25,000 workers), the asset sale model (29 companies, with about 12,000 workers) or a mixed model (3 companies with about 3,000 workers). Initial steps (e.g., collecting the documentation necessary to prepare public tenders) have been completed for about half of these and are underway for the rest.

- Strategic partnerships. Strategic partnerships are envisaged for 22 companies with about 24,000 workers. These companies are in general large, and many are very important for the local economy. The schedule for resolving this group is not yet clear, though the authorities estimate that the process could start for three or four of the companies in early 2015.

- Companies that have been removed from the privatization process. Reasons for terminating these privatizations mostly relate to legal proceedings, but it will be important that once court cases are resolved the privatization process be reinitiated. For 90 companies with about 16,000 workers, the privatization procedure will be suspended or terminated. Among them are companies for which there is a clear case to tackle them separately-for example, companies employing disabled persons, local waterworks companies, companies based in Kosovo, and so on. However, the reasons for suspension of the privatization process are less clear in some cases (e.g., a large furniture making company and an aircraft maintenance company).

4.34. The transitional unemployment consequences of this reform are expected to be significant, as 30,000 to 50,000 workers could lose their jobs. Efforts to cushion the impact on workers include (a) ensuring adequate severance packages to mitigate the immediate impact (the 2015 budget allocates about $€ 135$ million for this); (b) ensuring that the National Employment Service (NES) gives priority to helping these workers with the transition; and (c) expanding the NES and designing and conducting better alternative labor market policies (ALMPs). These measures are discussed further below, and in Chapter V.

4.35. Privatization of these companies will encourage private investment. Some companies in the PA portfolio that were being restructured had been protected by law from creditors and bankruptcy. Amendments to the Privatization Law in May 2014 now provide that this protection effectively expires in March 2015. ${ }^{22}$ The inability of creditors and suppliers, both private and state-owned, to collect what these companies owe for their services has created a major market distortion. Companies in restructuring have together accumulated over $€ 4.5$ billion in debt, of which more than $€ 2$ billion is to commercial creditors. Because most companies being restructured have extremely weak balance sheets, realistically private creditors are likely to collect only a fraction of that amount. Still, elimination of the creditor and bankruptcy shield would help level the playing field and perhaps create brownfield opportunities that could attract private investment.

4.36. The fiscal impact of resolving these companies is significant. On average, between 2010 and 2012 direct support to these companies from the budget in the form of subsidies and soft loans ran at about $€ 90$ million annually, 0.3 percent of GDP, but this was significantly reduced in 2013 and 2014 as it became

\footnotetext{
${ }^{22}$ Early in Serbia's transition "restructuring" was intended to be applied to a select group of large debt-burdened SOEs with a large number of employees. At that time, it arguably made economic sense (and was politically beneficial) to postpone resolution of some of these and provide protection for a period to adjust to new conditions. However, "restructuring" is no longer effective; it is in fact being used to prolong resolution of unviable enterprises indefinitely.
} 
clear that these companies were going to be resolved. ${ }^{23}$ In 2015 , €135 million has been allocated for severance payments, and privatization revenues will likely be negligible. The indirect fiscal impact, in the form of unpaid taxes and contributions and unpaid bills to public utilities, is much more significant at over $€ 250$ million annually. ${ }^{24}$ Unpaid bills to utilities have a major spillover effect: for some, in particular Srbijagas, unpaid bills from these ailing SOEs has meant support from the state budget to offset the cost of outstanding accounts payable. Indeed, that is how much of Srbijagas's $€ 800$ million in debt that is guaranteed and serviced by the state was created. Some of these companies also have significant arrears to other public utilities, such as Serbia Railways and EPS, the power company, creating problems for them as well. Resolving the companies in the PA portfolio will ease the financial pressure on public utility companies and consequently reduce pressure on the state budget.

\section{Large Public Utilities}

\subsection{The large public utilities consist of four SOEs important in the energy and transport sectors:} Serbia Gas (Srbijagas), Serbia Electricity (Elektroprivreda Srbije, or EPS), Serbia Railways (Železnice Srbije), and Roads of Serbia (Putevi Serbije). While sector policy issues are discussed later under infrastructure, this section highlights the operational and financial challenges that these SOEs face in Serbia.

\section{EPS and Serbia Gas}

4.38. EPS is a fully publicly owned, vertically-integrated electricity holding company, which encompasses 13 legal entities. ${ }^{25}$ It employs over 38,000 people (about 15 percent of all SOE employees), and ranks first in assets and equity. Public Enterprise Elektromreza Srbije (EMS) is the country's only electricity transmission system operator. The Energy Law makes EMS responsible for organizing and administering the balancing market. For natural gas, the vertically integrated and 100 percent governmentowned Srbijagas manages all trade, supply, transmission, and distribution activities. It operates 95 percent of the Serbian gas transmission network and accounts for about 70 percent of gas sales.

\subsection{Serbia's power and gas sectors are still characterized by high losses, below-cost tariffs, and} lack of payment discipline. Energy intensity in Serbia is 1.89 times higher than the European average due partly to technical losses and obsolete infrastructure ${ }^{26}$ and partly due to very low household and industry efficiency. Power tariffs in Serbia are the lowest in the South East Region (Figure IV.8) and they are estimated to be about 30 percent below cost-recovery level. Below-cost tariffs undermine the financial sustainability of the sector. In the gas sector, the critical issue is lack of payment discipline, especially from other energy-intensive SOEs and other budgetary institutions.

\footnotetext{
${ }^{23}$ Exact data for 2013 and 2014 are not available, but annual support was likely reduced to $€ 20-30$ million.

${ }^{24}$ Tax Administration data show that in 2012 the gross increase in accumulated debt for unpaid taxes and contributions was about $€ 220$ million - an indirect subsidy to PA portfolio companies. The gross increase in unpaid bills to utilities in 2012 was about $€ 60$ million.

${ }^{25}$ Five of these entities are licensed to generate electricity. Coal production (open pit mining) is carried out by a separate EPS entity and also within one of its power generation companies. A new legal entity has recently been established to generate electricity from renewable sources.

${ }^{26}$ Only 25 percent of transmission lines and substations are in good condition; the average age of thermal plants is 30 years and of hydro plants 40 years.
} 
Figure IV.8: Electricity Prices for Domestic Consumers, Europe and South East Europe

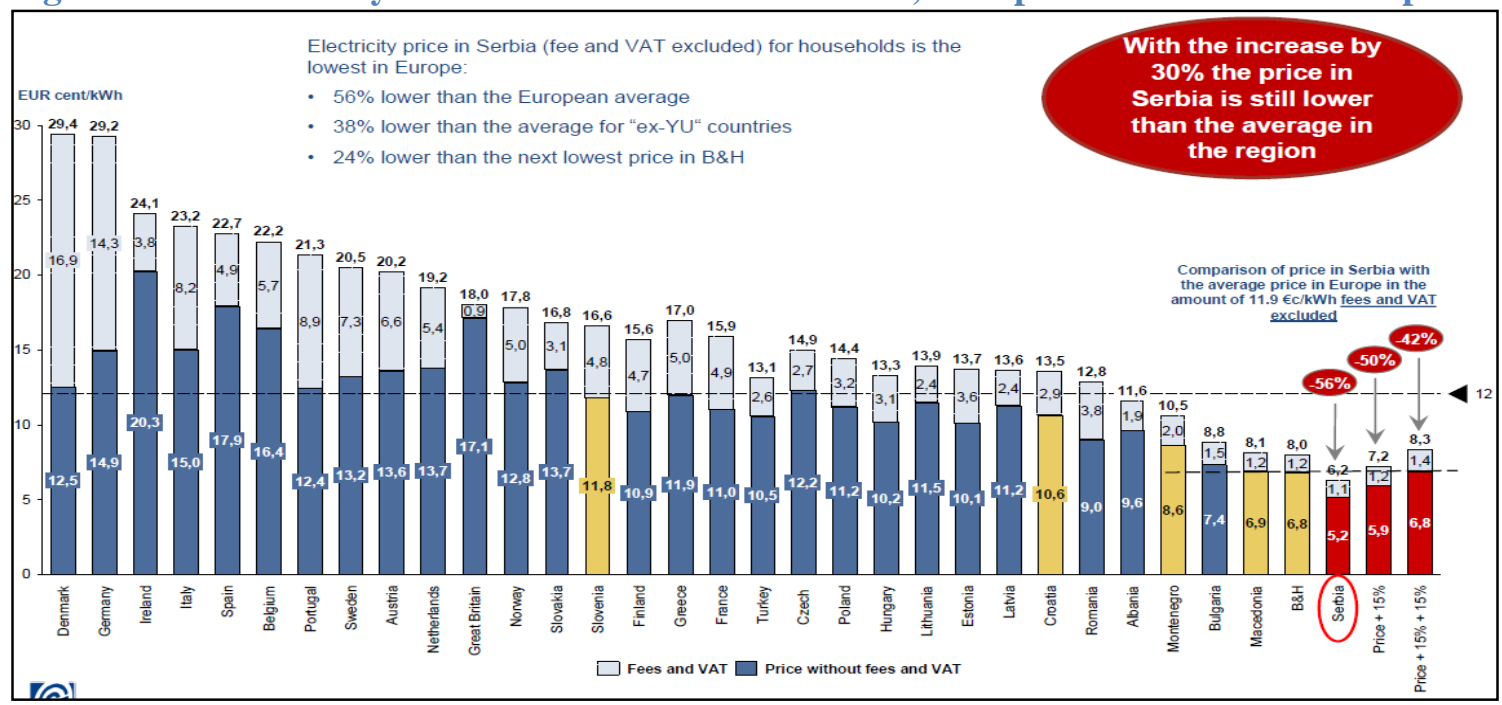

Source: EPS.

4.40. The financial situation of both EPS and Serbijagas is fragile, with significant contingent liabilities for the state budget. Aging assets, high technical losses, and operational inefficiencies are crippling EPS' financial standing, and in 2015 indebtedness is expected to become critical, with the company relying mostly on expensive short-term commercial lending. A failure of EPS to service its debt would call for significant resources from the state budget, thus directly increasing the fiscal deficit. Given the size of the company, this is a risk Serbia cannot afford. Similarly, Srbijagas is bankrupt. It has continued to incur large losses in 2012, 2013, and 2014. The losses result from extremely low collections (only 60 percent) from large consumers of energy (SOEs, district heating companies), substantial debt write-offs, and heavy spending to support loss-making subsidiaries. The cumulative losses exceed the value of the company's equity, which is now fully financed by state-guaranteed loans. In 2013 and 2014, the state budget had to pay called guaranteed loans that Srbijagas was unable to honor. Budget expenditures to cover guaranteed loans jumped from RSD 5 billion in 2013 to RSD 22.1 billion in 2014.

4.41. Recognizing the critical need to take action, at the end of 2014 the government approved a corporate restructuring plan for EPS and Srbijagas. The plan foresees the consolidation of EPS subsidiaries to improve efficiency and decrease costs. It also sets an ambitious timeline to convert EPS into a joint stock company by mid-2016 in the hope of attracting private sector participation. In the gas sector, the restructuring plan envisions consolidation of all subsidiaries under a holding company, and the government is drafting a detailed plan that will ensure that the legal and functional unbundling of transmission system operators for natural gas will be in full compliance with EU regulations.

4.42. Bold policy measures are now needed if Serbia is to stabilize and improve the financial viability of its energy sector. For Srbijagas the critical steps are (a) resolution of debts from large SOEs; (b) amendment of the RINO law to stop SOEs and budgetary institutions from accumulating new debt; (c) corporatization; and (d) financial consolidation, with priority given to working out debt with commercial banks and gas suppliers. For EPS, the main reforms should (a) facilitate collections from SOEs and budgetary institutions; (b) commercialize EPS, centering on a tariff adjustment; and (c) reinforce the 
independence of the supervisory board and put in place accountability mechanisms to monitor performance. As tariffs are adjusted, it would be important also to put in place social protection measures for the most vulnerable consumers.

\section{Serbia Railways and Roads of Serbia}

4.43. The two main transport SOEs are Železnice Srbije (Serbian Railways; ŽS) and Putevi Serbije (Public Enterprise Roads of Serbia; PERS). ŽS is vital both for Serbia's international and domestic trade and for regional passenger service, which is typically important for lower-income groups. However, ŽS is confronting both financial and operational difficulties. It is inefficient and in a difficult financial position: ŽS railway traffic intensity (the sum of passenger-km and ton- $\mathrm{km}$ divided by total route $\mathrm{km}$ ) is only about 30 percent of the EU-27 average. Passenger intensity is about 11 percent and freight intensity 54 percent of the EU-27 averages. ŽS labor productivity is also only about 30 percent of the EU-27 average. Operating subsidies to ŽS between 2008 and 2013 averaged 0.47 percent of GDP (range: 0.39 to 0.59 percent), not counting subsidies for electricity purchases or operating losses. When operating losses are included, total state support to operations over the same period averages 0.88 percent of GDP (range: 0.64 to 1.0 percent).

4.44. Transforming ŽS into an efficient and productive company will require difficult and sustained reforms, including: (a) a commercially-driven $\check{Z} S$ : An autonomous ŽS management free to make business decisions on new routes, staffing, service cuts, and route closures; (b) labor retrenchment on the order of about 50-60 percent of the current labor force of 17,000 to reach the average labor productivity of the EU-27; and, (c) line closure and asset disposal -closure of a number of lines, stations, and marshalling yards, and disposal of thousands of wagons, locomotives, and other assets. Given the sensitivity of these issues, it is essential that the necessary decisions are made at a senior government level and that the poor and vulnerable groups are protected. Since Serbia still has a number of years before it will join the EU, reforms of ŽS can be strategically phased in over a number of years to allow time for managing the social impacts of labor retrenchment and network reduction.

\subsection{Investment in roads, and capital investments more generally, suffer from two major problems in Serbia: (a) inclusion in the budget of projects that are not ready; and (b) delays and cost overruns, which can have significant effects on the state budget. The Public Investment Division of the Ministry of Finance (MoF) currently lacks the capacity to carry out rigorous checks for project readiness. As a result projects for which the preparatory work is incomplete are often incorporated into the budget. ${ }^{27}$ Delays and cost overruns are principally due to lack of political coordination of capital projects; no central monitoring of public investments; persistent procurement problems; and unresolved property issues.}

4.46. PERS is not functioning as a fully autonomous, accountable agency. International experience shows that separating road transport policy and regulatory functions from road planning, construction, and maintenance functions would minimize conflicts of interest and enable planning and execution to be carried out on a commercial and competitive basis. While the intention in setting PERS up as an enterprise was to achieve accountability and improve performance, it still resembles a "directorate" (a department within the

\footnotetext{
${ }^{27}$ Externally-funded capital projects also are not fully captured through the treasury system.
} 
Ministry of Transport [MoT]) because its funding is not secure, road investments are implemented through several channels, and the Serbian government as a whole has to approve its business plan.

4.47. Transforming PEPS into an autonomous, accountable agency will require three steps: (a) agreement on a monitorable service level agreement (SLA) between the MoT and PERS for maintenance of the national road network, with annual and five-year rolling targets defined and financing guaranteed; (b) modernizing maintenance by moving to competitive tendering of road maintenance contracts instead of the current practice of setting unit rates administratively; ${ }^{28}$ (c) avoiding creation of project implementation units outside PEPS, and transitioning Corridors of Serbia (CoS) into PEPS. ${ }^{29}$ Faster execution of road investments with fewer delay-related costs to the government can be facilitated by: (a) completion of land acquisition and expropriation before contracts are signed; strengthening the main design process in Serbia and holding designers accountable; and building up the public investment management system as a whole, such as strengthening the capacity of the MoF Public Investment Division to review and ensure the readiness of investment projects; avoiding delays in approval of the annual business plans of PEPS and $\mathrm{CoS}$; and establishing a formal intergovernmental committee with official oversight and responsibility for monitoring to speed up completion. PPP arrangements, whereby the responsibility for financing, design and construction is transferred to the private partner under an explicitly defined contract, should also be explored as part of the solution for tackling the issues of delays in implementation and cost overruns.

4.48. Overall, completing the first-generation SOE reforms-both through privatization and restructuring-- will have the multifaceted benefits for Serbia that have already been described, but the gains are not without cost. Resolution of companies in the PA portfolio through bankruptcies, privatizations, or strategic partnerships is envisaged for the next one to two years. ${ }^{30}$ For large public utilities, in particular four of the largest companies, ${ }^{31}$ the process will require major structural reforms that will take longer. In either case, the transition is not without costs as some 30,000 to 50,000 workers could be made redundant. Cushioning and managing the social impacts-through appropriate severance packages, employment services, ALMPs to support transition to new jobs, effective communication - is critical for reform success. These measures are discussed in detail in Chapter 5.

\subsection{Beyond transitional unemployment costs, according to Serbia's law, environmental liabilities} associated with privatization of SOEs rest with the state. Recognizing that strategic investors will be reluctant to invest or will heavily discount their offer prices if there are significant unassigned environmental liabilities, the Government in 2003 amended the Law on Privatization to state that liability for environmental damage caused by state-owned enterprise prior to its privatization rests with the state. In a few cases, when foreign investors were involved, the provision of the Privatization Law assigning past environmental liability to the State was included, albeit with specific case by case limits.

\footnotetext{
${ }^{28}$ Two competitively tendered contracts financed under a closed Bank project resulted in savings of more than 25 percent. However, competitive performance-based contracting is likely to reduce the labor force engaged in the road maintenance sector, the negative effects of which might need to be mitigated.

${ }^{29}$ The government has recently moved to merge CoS into PERS - a step in the right direction but one that has to be managed carefully to avoid disruptions to CoS projects.

30 This reform is supported by a World Bank SOE Development Policy Loan (DPL).

${ }^{31}$ Reforms of public utilities will be supported by a World Bank program and the IMF program.
} 
4.50. These arrangements raise concerns about the potentially unlimited financial liability that may arise for the state from past environmental and public health concerns associated with theSOEs. In 2014 the Government slated enterprises for production and processing of coal, oil, gas and oil derivatives, ferrous and non-ferrous metals, non-metallic minerals, and chemical products, yarn and fabrics, and food and beverages and building of machines, vehicles and ships - all of which are associated with significant environmental pollution. The effective handling of environment liabilities in the privatization process which relies on environment assessments, general provisions in the privatization agreements, and environmental action plans remains a concern. The review of past privatization deals also revealed inadequate follow-up of agreed environmental action plans. While divestiture of state owned assets will address poor operational and financial performance in the SOE sector, concerns remain of the unlimited financial liability for the state and its capacity to mobilize resources to implement programs for addressing past environmental and public health concerns associated with these SOEs.

\section{Business Climate}

4.51. Its business climate needs major work if Serbia is to boost private investment and improve competitiveness. Serbia ranks 93rd out of 189 economies in the 2014 Doing Business report, below such neighboring countries (Figure IV.9) as FYR Macedonia (25), Slovenia (33), Montenegro (44), Hungary (54), Bulgaria (58), Romania (73), Croatia (89), and Albania (90); in the region it is ahead only of Bosnia and Herzegovina (131). Furthermore, Serbia's ranking has slipped 6 points, from 87th place in 2013. The unfavorable business environment deters both creation of new businesses and day-to-day company operations and offers few incentives for long-term investments, including FDI, that are vital to creating jobs to offset the large numbers of jobs that the public sector may have to cut (Figure IV.10).

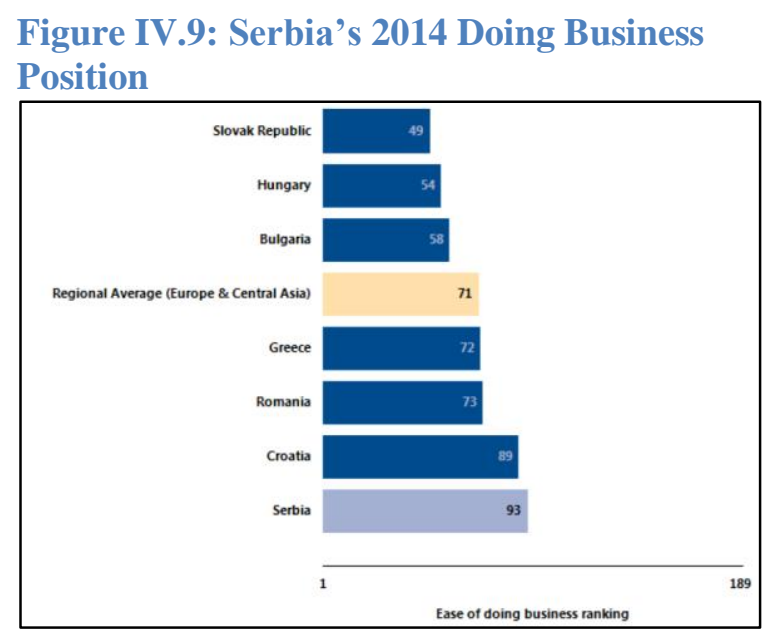

Source: Doing Business 2014.
Figure IV.10: Most Problematic Business Regulations in Serbia, Doing Business Rankings

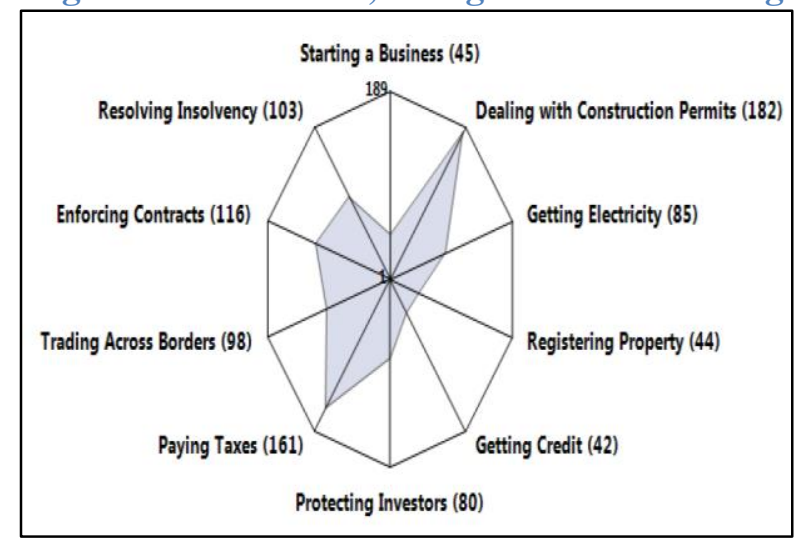

Source: Doing Business 2014.

4.52. The Doing Business indicators suggest that construction permits, paying taxes, and resolving insolvency and contract enforcement are serious problems (Figure IV.10). The government has in recent years implemented reforms to streamline procedures for starting and closing businesses, registering property, improving access to credit, and enforcing contracts. As a result, its rankings on getting credit (42), registering property (44), and starting a business (45) are relatively high. However, reform momentum in other areas has lagged, in particular in dealing with construction permits (182), paying taxes (161), 
resolving insolvency (103) and contract enforcement (116). More vigorous use of restructuring proceedings for viable companies would help retain jobs, and a swift bankruptcy process could help redeploy assets and human resources in the market for more effective use.

4.53. The process for getting permits is still opaque, lengthy, and heavy with red tape. ${ }^{32}$ Overall, there are numerous and overlapping licenses and permits requirements and para-fiscal fees at different levels of government, which add considerably to the costs of doing business. These could be streamlined, through for example, a publicly available single electronic register of licenses and permits and para-fiscal fees, so that businesses know the requirements. With regard to construction permits, there are deep structural issues in the management of land and property rights. Problems related to the poor quality of spatial plans, lack of general urban and regulatory plans, and frequent changes in the law add to the cost of undertaking a business venture or investment. Also contributing to delays are poor infrastructure, the bureaucratic difficulties of securing the necessary public utilities, problems with land ownership rights, and the fees to be paid for conversion of agricultural to development land before a location permit is secured. A new Law on Planning and Construction governing spatial planning, construction, and urban development was adopted in the Parliament on December 8, 2014, an important step toward implementation. Beyond this law, there is a need to facilitate conditions for the conversion of land use rights to ownership rights with paid compensation.

4.54. Businesses perceive paying taxes as time-consuming and difficult as measured by the number of hours spent per year to prepare, file returns and pay taxes, the tax liability as a percent of profit, and the number of tax payments per year. Doing Business shows that in Serbia both total hours spent (279) and tax liability as percent of profit (37 percent) are inordinately high.

4.55. A more effective mechanism for bankruptcy resolution and restructuring is a priority for restoring credit intermediation. The law and the responsible institutions do not adequately honor creditors' rights. Companies in financial distress are rarely restructured in Serbia-most are liquidated in piecemeal sales, with considerable loss of value for the Serbian economy. Adequate restructuring proceedings would help save jobs. Despite recent amendments to the laws, implementation is dilatory because institutional capacity is weak. Serbian NPLs are among the highest in the region at 23 percent of gross loans in the second half of 2014. Efficient debt resolution would allow stakeholders to collect on their claims and security faster, bringing predictability for lenders and other creditors. In turn, this could reduce the risk premium, raising lending capacity and access to credit - all of which can be expected to expand investments in Serbia. Reinforcing the legal framework, improving transparency, and building capacity for the main stakeholders would help increase creditor trust in the system.

4.56. Business investment and expansion are constrained by the inability of the justice system to enforce contract and property rights impartially, efficiently, and transparently and to mediate business disputes. Over 33 percent of businesses with recent experience in court consider the courts to be a major obstacle to basic business operations, and another 30 percent consider them to be a moderate obstacle [Serbia Judicial Functional Review, Multi-Donor Trust Fund for Justice Sector Support, World Bank, 2014, pp135-136]. Businesses also report that high court and attorney fees mean the courts are

\footnotetext{
${ }^{32}$ For a thorough annual assessment of this and other business environment constraints, see the Investors Council of Serbia "White Book," available at: http://www.fic.org.rs/cms/item/whitebook/en.html.
} 
increasingly inaccessible. Small businesses find it especially difficult to navigate the court system because of cumbersome processes, lengthy delays, inadequate enforcement, and constant changes in the law, in addition to the high costs. The courts are also clogged with millions of old enforcement cases that leave creditors unpaid. Furthermore, laws are not applied uniformly, courts are less accessible than in EU member states and neighboring countries, and alternative dispute resolution remains elusive after a series of failed reforms.

4.57. Other key measures that could help improve the investment climate in Serbia are: an inspection reform to reduce the burden of inspections and improve the business environment and predictability of laws and regulations; a progressive harmonization of Serbian legislation with the EU, especially in export oriented sectors like agribusiness and light manufacturing; amendments to the foreign exchange law to facilitate exports through internet sale and receive proceeds or refunds in foreign currency, which at the moment are practically impossible. Removal of forex barriers could open business opportunities for exports and stimulate growth.

\section{Business Environment and Enterprise Performance Surveys}

4.58. Analysis of the Business Environment and Enterprise Performance surveys (BEEPS) broadly reinforces the same conclusions. According to the latest survey (BEEPS 2013) the top three impediments to businesses of all sizes and ages are regulatory and political instability, tax rates, and competitors in the informal economy (Figure IV.11). Other major obstacles are corruption, access to finance, tax administration, the court system, crime, customs, and trade regulations.

\section{Figure IV.11: Biggest Investment Climate Constraints in Serbia}

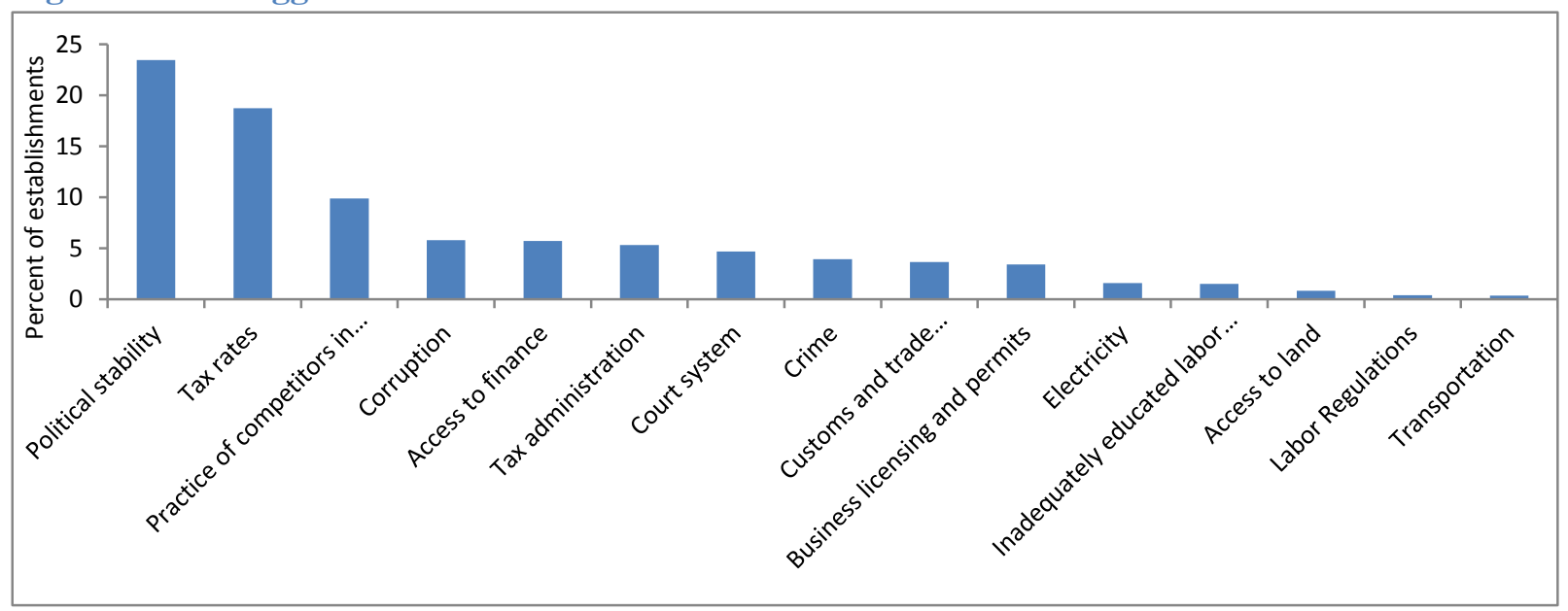

Source: EBRD-World Bank 2013, Enterprise Surveys (www.enterprisesurveys.org)

4.59. Businesses in Serbia seem to be most concerned about the instability of regulation and policy, which is seen as a major deterrent to both domestic and foreign investment. This concern is corroborated by other sources. For example, the National Alliance for Local Economic Development (NALED) tracks 30 laws important for businesses; in the last five years, these laws have been amended or completely changed 98 times. Further, there are currently 114 different strategic documents, with very little harmonization among them. According to the Public Policy Secretariat, only 16 percent of the targets of 
different strategies are mutually consistent. The laws not only lack predictability, they are not implemented consistently. Businesses are also concerned about high tax rates and poor tax administration, and about the unfair competition posed by informal firms that do not pay taxes.

\subsection{As measured by several international indices, perceptions of administrative corruption are} high in Serbia. In the 2014 Transparency International (TI) Corruption Perceptions Index it ranked 78 of 175 countries. Within Serbia, in the 2013 BEEPS one-quarter of firms identified corruption as a major constraint to doing business (Figure IV.12). Furthermore, 40 percent of firms stated that gifts are required to secure a government contract. The 2011 UNODC study on corruption in Serbia found that citizens rank it as the third most important problem facing the country after unemployment and poverty / low standard of living. Moreover, 45 percent of citizens surveyed thought it was on the rise, while only 10 percent thought it was decreasing.

4.61. Corruption is prevalent within the Serbian judiciary. Based on recent court user surveys, 9 percent of recent court users admit to using informal means to influence cases, and 6 percent of firms report that bribery is frequent in dealing with courts. These figures are likely to be significantly under-reported. ${ }^{33}$ The judiciary ranks second only to the health system as the institution perceived by citizens to be most affected by corruption. ${ }^{34}$ On a range of global indices measuring judicial corruption, Serbia trails both EUCESEE (Central, Eastern and Southeastern Europe) ${ }^{35}$ states and neighboring countries. ${ }^{36}$

\section{Figure IV.12: Business Perceptions of Corruption in Serbia, 2013}

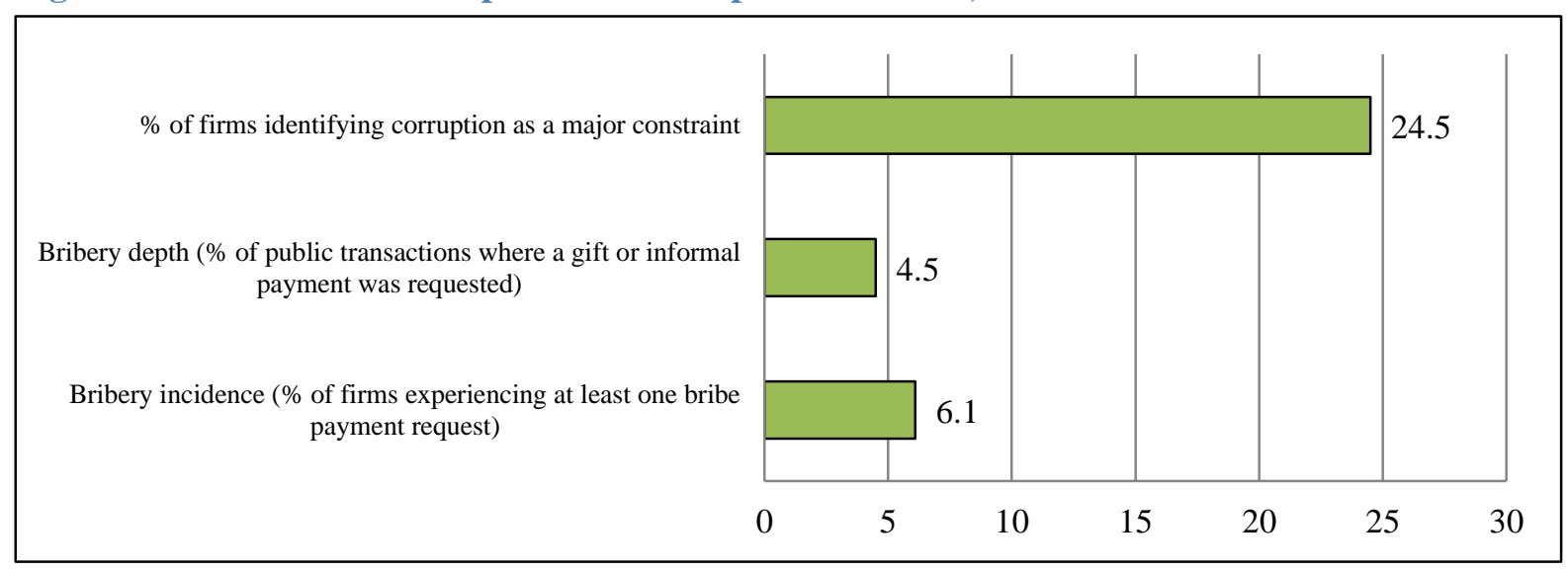

Source: EBRD-World Bank, BEEPS 2013.

\footnotetext{
${ }^{33}$ See Serbia Judicial Functional Review, pp.118-22 and sources cited there.

34 The share of citizens who report that corruption is present in judicial system fell from 58 percent in 2009 to 51 percent in 2013. Meanwhile, the percentage of those who report that corruption is present in the health care system went up from 53 percent to 59 percent. See Serbia Judicial Functional Review, pp.123-24.

${ }^{35}$ Also formerly known as EU11.

36 The Transparency International Global Corruption Barometer 2013 ranks Serbia 72nd out of 175 countries. Compared with the EU-CESEE, Serbia has the second highest rate of perceived corruption, behind only Bulgaria and on a par with Lithuania. Serbia's judiciary also ranks worst in the region. According to the World Justice Project Rule of Law Index 2014, in civil cases, Serbia scores 0.40, behind all EU-CESEE countries and second only to Albania as the worst in the region. In criminal cases, Serbia scores 0.41, second-last compared to the EU-CESEE, after Bulgaria, and second-last in the region, again only behind Albania.
} 
4.62. About 96 percent of enterprises in Serbia are SMEs that employ fewer than 99 people. BEEPs data suggest that about 45.5 percent of Serbian establishments have fewer than 10 employees (micro), 28.9 percent 10 to 19 (small); 21.6 percent 20 to 99 employees (medium); and only 4 percent 100 or more (large). Micro, small, and medium enterprises (SMEs) together constitute 96 percent.

\subsection{At 58.7 percent the contribution of SMEs to total formal employment in Serbia is higher than} that of larger firms (Figure IV.13); however, at 37 percent SMEs contribute less to job creation than large firms. Recent studies of the effects of SMEs on the economy suggest that their contribution to job creation across all country income groups is greater than that of larger firms, but comparative analysis of the 2013 enterprise surveys shows this is not the case for Serbia. ${ }^{37}$ While the SME contribution to total employment in Serbia is high relative to EU-CESEE ${ }^{38}$ (Central, Eastern and Southeastern Europe) and ECA, their contribution to Serbian job creation is low relative to EU-CESEE and ECA. Between 2010 and 2012 only 37.2 percent of jobs created in Serbia were in SMEs; the other 62.8 percent were in firms with at least 100 employees (Figure IV.14). Similarly, at 49.1 percent old and large firms created almost half (49.1 percent) of the jobs in Serbia and young firms created only a very modest 11.7 percent, in sharp contrast to what has been observed elsewhere in Europe.

Figure IV.13: Total Employment by Firm Size, 2012

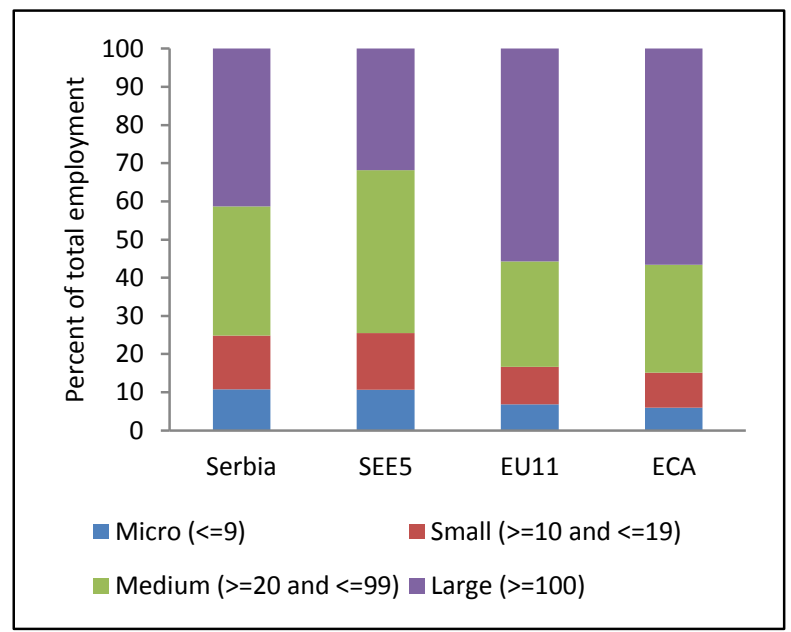

Figure IV.14: Job Creation by Firm Size, 201012

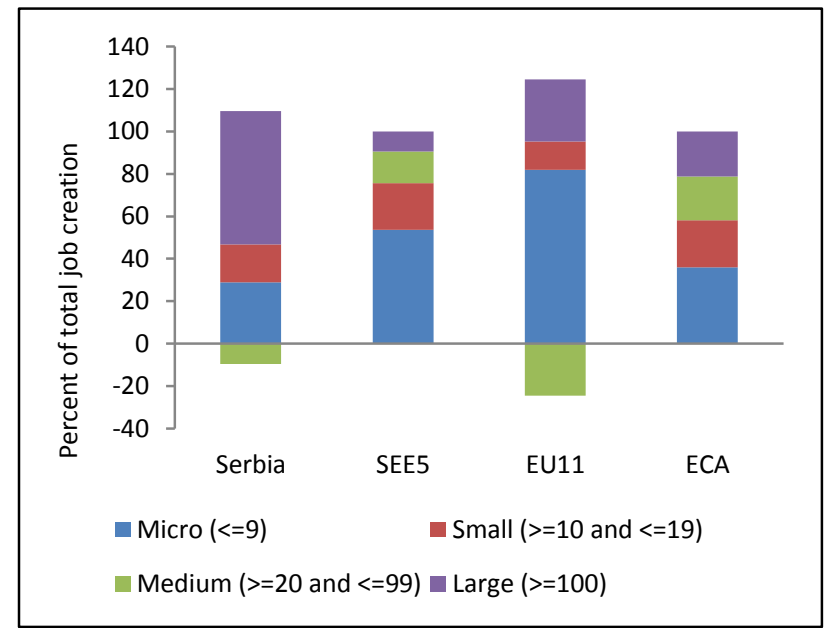

Source: World Bank calculations based on the latest enterprise surveys, which are dated 2013 for all countries but Russia. The latest enterprise survey for Russia is from 2012.

\footnotetext{
${ }^{37}$ The analysis covers ECA countries and are based on the latest enterprise surveys-2013 in all countries except Russia, where the last survey was done in 2012.

${ }^{38}$ Also formerly referred to as EU11.
} 


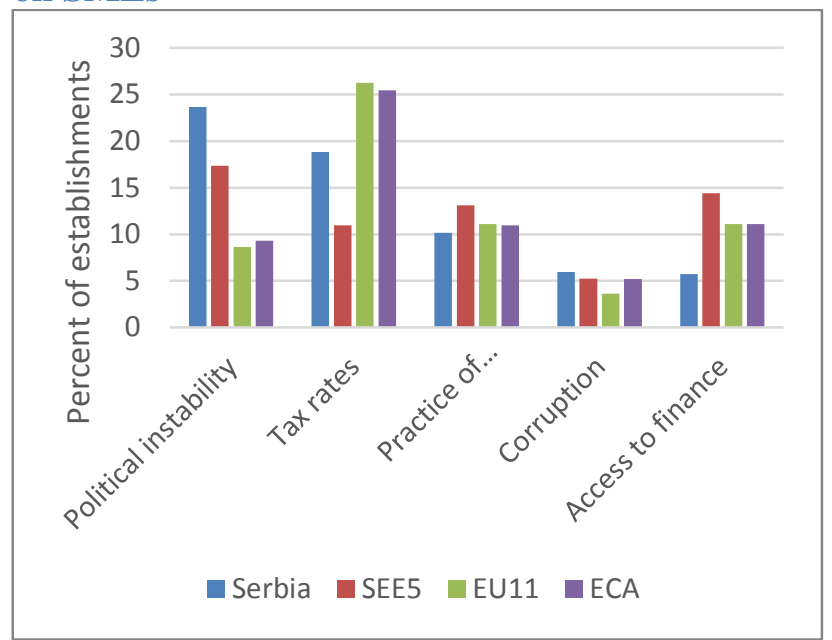

\section{Figure IV.16: Main Business Climate}

Constraints on Large Firms

Source: World Bank calculations based on the latest enterprise surveys, which are dated 2013 for all countries but Russia. The latest enterprise survey for Russia is from 2012.

\subsection{A comparison of the top five constraints for SMEs (Figure IV.17) and for large firms (Figure} III.27) shows that the practices of the informal economy, access to finance, and corruption are particularly important for SMEs. Political instability, taxes, and tax administration are perceived as constraints by both groups, but SMEs are also concerned about access to finance (including long-term finance) and corruption, constraints that do not have high importance for large firms, which are more concerned about tax administration, customs and trade regulations, and labor regulations.

\subsection{SMEs have been hit} heavily by tightened bank credit standards and a lack of willingness to lend in Serbia. The BEEPs found that while more than 95 percent of SMEs surveyed have a checking or savings account, only 54 percent have a loan from a bank. The share of firms obtaining bank financing dropped from 29 percent in 2008 to 15 percent in 2013, and the share using trade credit from suppliers went up from 7 to 18 percent. Asked about

Figure IV.17: Top Five Obstacles for Exporters

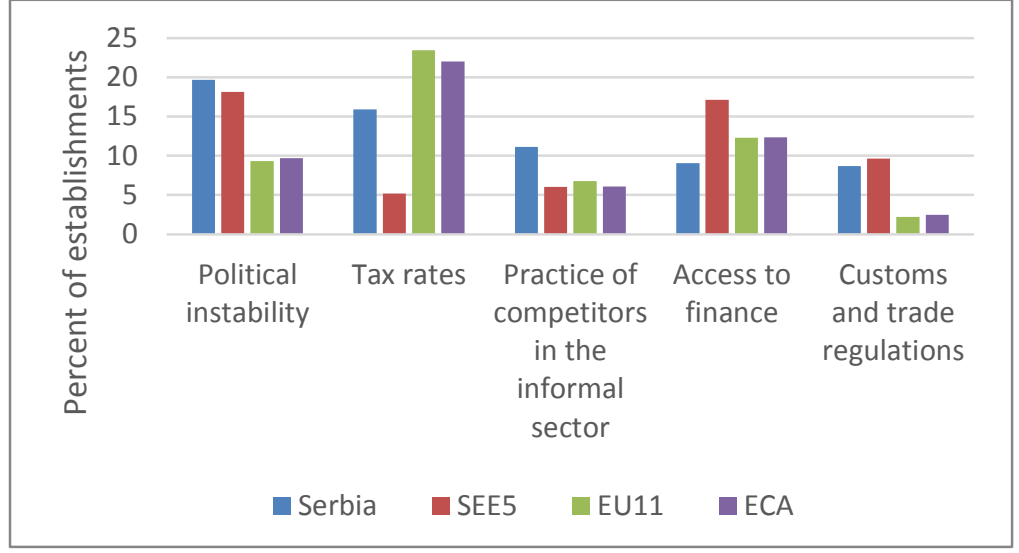

Source: World Bank calculations based on the latest enterprise surveys, which are dated 2013 for all countries but Russia. The latest enterprise survey for Russia is from 2012.

the major contraint to obtaining a loan, 34 percent cited unfavorable interest rates, followed by 5 percent that cited complex application procedures. The share of SME loans in total business was 21.4 percent in 2007 and only 21.2 percent in 2012. Long-term loans account for most lending to SMEs, having gone up from 64.5 percent in 2007 to 72 percent in 2012. Nevertheless, the amount of loans, collateral requirements, and maturities remains unfavorable. Banks are reluctant to expand credit to the economy for fear of weaker 
economic performance, difficulties in recovering losses by selling collateral, and inability to collect receivables.

\section{Constraints on Exporters}

4.66. Large exporters perceive customs and trade regulations to be larger impediments in Serbia than elsewhere (Figure IV.18). An estimated 22 percent of Serbian enterprises get at least 10 percent of their revenues from foreign markets. About 73 percent of Serbian exporters have fewer than 19 employees - higher than in comparator countries. While exporters share many of the top constraints to businesses in Serbia, for these firms customs and trade regulations constitute significantly larger impediments.

\subsection{It is not surprising that efficient customs and logistics services are of particular importance} for exporting firms in landlocked countries like Serbia. According to the World Bank Logistics Performance Index (LPI) ${ }^{39}$ for 2014, Serbia now ranks 63rd out of 160 countries, a marked improvement from its 83rd ranking in 2010. Still, its overall LPI ranking is lower than that of comparator countries, suggesting that improvements are needed (Table IV.3).

Table IV.3: Logistics Performance Index and Subcomponent Rankings

\begin{tabular}{llllllll}
\hline \multirow{2}{*}{ Country } & LPI & \multicolumn{2}{l}{ LPI Sub-indices } & & & \\
\cline { 3 - 8 } & & customs & Infrastructure & $\begin{array}{l}\text { International } \\
\text { shipments }\end{array}$ & $\begin{array}{l}\text { Logistics } \\
\text { Competence }\end{array}$ & $\begin{array}{l}\text { Tracking } \\
\text { \& Tracing }\end{array}$ & Timeliness \\
\hline Czech Republic & 32 & 33 & 36 & 13 & 29 & 25 & 39 \\
Hungary & 33 & 48 & 40 & 32 & 37 & 15 & 20 \\
Serbia & $\mathbf{6 3}$ & $\mathbf{1 1 3}$ & $\mathbf{6 6}$ & $\mathbf{5 4}$ & $\mathbf{5 3}$ & $\mathbf{6 9}$ & $\mathbf{4 8}$ \\
Slovak Republic & 43 & 52 & 37 & 38 & 46 & 63 & 30 \\
Poland & 31 & 32 & 46 & 24 & 33 & 27 & 15 \\
\hline
\end{tabular}

Source: World Bank, Connecting to Compete: Trade Logistics in the Global Economy-The Logistics

Performance Index and Its Indicators, 2014.

\subsection{Serbia's lowest ranking is in customs (113th) because of excessive border crossing times and}

costs. While the laws governing customs procedures in Serbia (Customs Law, Customs Tariff Law, related bylaws, and free trade agreements) are in line with good international practice, their application is uneven, characterized by delays, discretionary decisions, and general unpredictability. Serbia could improve customs clearance and create a predictable environment for trade and investment at the border if it had an efficient customs information system that would simplify procedures and automate clearances; simplified export clearance for shipments; and trained customs personnel to ensure consistent application of the laws, reduce discretionary decisions, and assign accountability if a consignment is held or inspected without good reason. Serbia can also improve its border inspection by setting uniform rules on sanitary and phyto-sanitary border inspection procedures for the food, beverage, cosmetics, and tobacco industries; consistently apply inspection procedures; and reduce arbitrary interpretations.

\footnotetext{
${ }^{39}$ In 2007 the World Bank launched the Logistics Performance Index (LPI), which measures performance along the logistics supply chain within a country. Based on a worldwide survey of freight forwarders and express carriers, the LPI helps identify challenges and opportunities along the supply chain. Using a 5-point scale, the LPI looks at customs, infrastructure, international shipments, logistics competence, tracking and tracing, and timeliness.
} 
4.69. Serbia has recently taken major legislative steps to improve the business climate. There are new labor and bankruptcy laws, and as discussed above the processes for privatization of SOEs have been restarted. The Labor Law introduced major changes: it reduced severance pay, raised the maximum duration for term employment, abolished obligations to pay higher salaries for shift work, and changed provisions related to extended application of collective agreements.

4.70. However, much more remains to be done to improve the business climate, attract investment, and support growth. Among reforms that will be important to all types and sizes of firms are (a) reducing the time it takes to obtain construction permits; (b) making policy and regulation more predictable, and consistently enforcing laws and regulations through better administrative coordination and supervision; (c) combating the informal economy and continuing to restructure SOEs; and (d) improving contract enforcement and insolvency mechanisms. For SMEs, BEEPs data suggest that special attention to access to finance is warranted. For large and exporting enterprises, facilitating customs and trade seems particularly critical. All these measures are vital for Serbia to secure current investments and attract more; create broad-based growth and job opportunities; and increase productivity, exports and competitiveness.

\section{Financial Sector Stability and Access to Finance}

4.71. The banking sector in Serbia is relatively stable, but weak credit growth hampers economic recovery and growth. Serbian banks are in general well-capitalized, with capital ratios that exceed 20 percent. They are also liquid, with the ratio of core liquid assets to total assets also over 20 percent. They are thus well positioned to deal with any shocks. The Serbian banking sector is dominated by subsidiaries of banks headquartered in the EU, which hold about 75 percent of the market. With support from parent banks, the foreign-owned banks have limited deleveraging and maintained their presence in Serbia.

\section{Figure IV.18: Growth of Bank Credit in Serbia}

(a) Private Sector Credit Growth, nominal, Percent

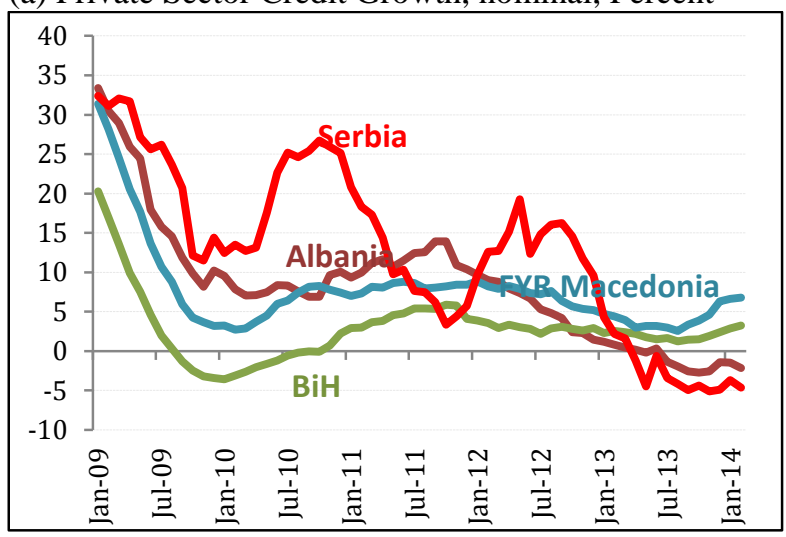

Source: National Bank of Serbia.

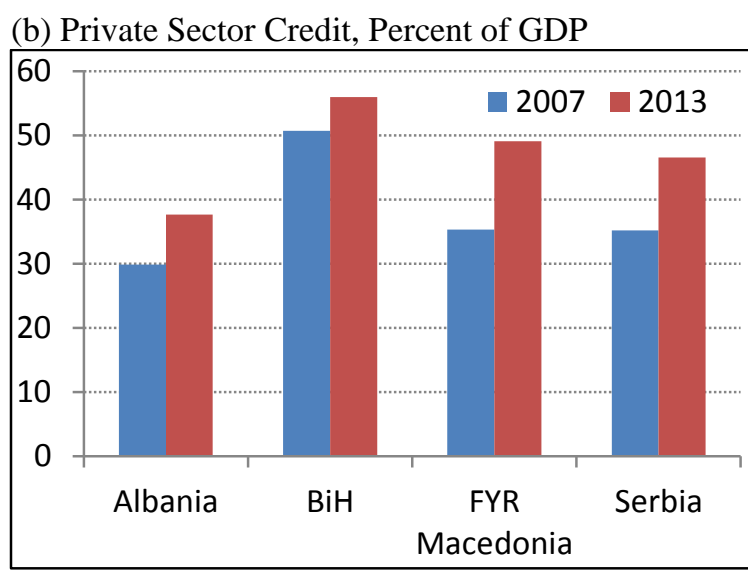


4.72. Although the system is relatively healthy, financial intermediation is low compared to the rest of the region and credit growth has stagnated since 2012. Financial intermediation in Serbia is lower than in most other countries in the Western Balkans, with the private sector credit-to-GDP ratio accounting for about 47 percent in 2013.

Bank lending to the private sector stagnated in 2012, then fell to negative numbers starting in April 2013 (Figure IV.19). The slowdown in credit growth has particularly hit corporations; growth to that sector is still negative and well below the levels seen in early 2012. Growth in household credit was only 5

Figure IV.19: Credit Growth by Sector, Percent

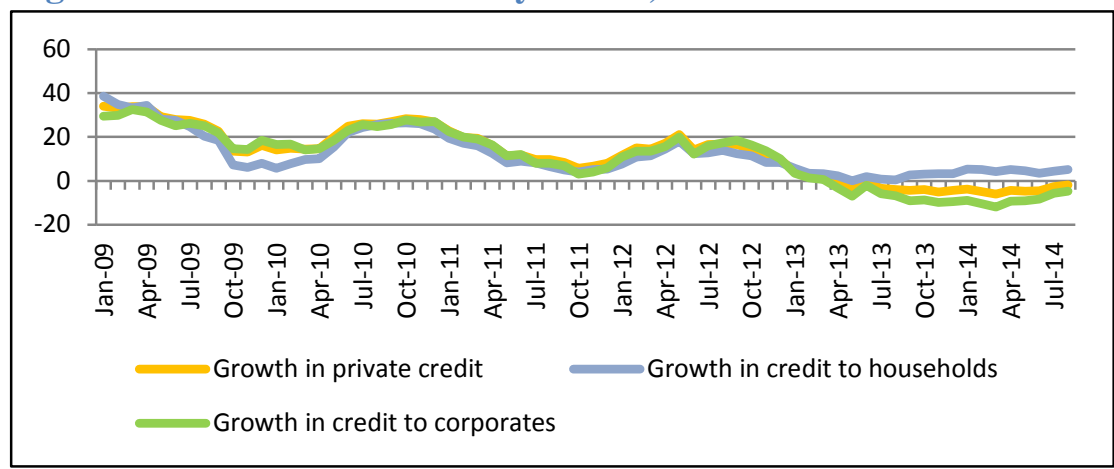

Source: National Bank of Serbia.

percent in August 2014 compared to about 14 percent in August 2012.

4.73. Banks are more cautious about lending because of poor profitability and high and rising levels of nonperforming loans (NPLs). Serbian banks have the second-highest level of NPLs in the Western Balkans; they were 20 percent of total loans at yearend-2013 (Figure IV.20). Currency risks are significant and a major driving force of NPLs as well as a serious credit risk for banks, because most borrowers are unhedged and about 70 percent of loans are denominated in a foreign currency. In addition, banking sector profitability, as measured by return on assets, has been declining since 2008 , reaching 0.1 percent in 2011 and improving only slightly in 2012. Poor profitability combined with high levels of NPLs and foreign exchange lending increase bank exposure to credit losses.

Figure IV.20: Nonperforming Bank Loans NPLs to Total Loans, Percent



Source: IMF FSI tables; National Bank of Serbia.

\section{Loan Loss Provisions, Percent}

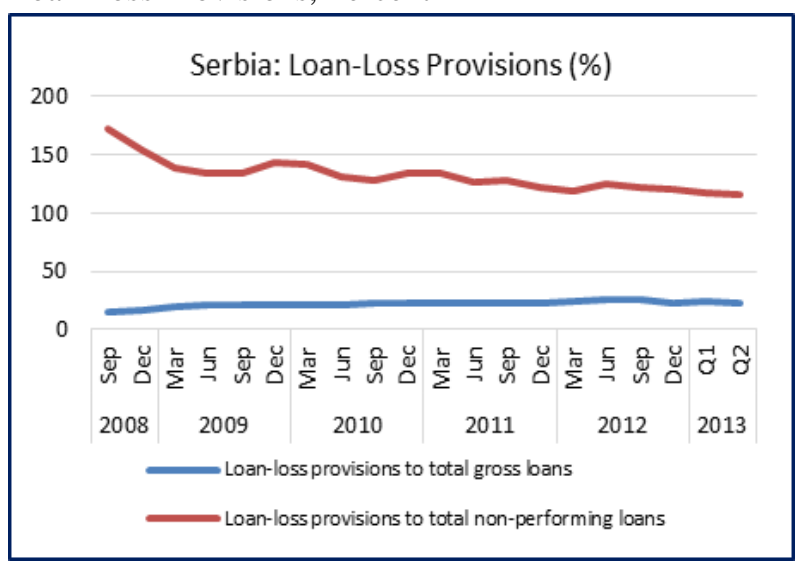


4.74. Interest rates are high due to high sovereign and credit risks. Serbian interest rates are relatively high compared to those in other Western Balkan countries. The main drivers are the significant credit risk that banks are facing as well as high NPLs and stricter prudential policies that have been put in place to maintain stability. As a result, access to credit for both corporations and households has further decreased.

4.75. Although the banking system is adequately capitalized as a whole, state-owned banks have not been in as good shape. In 2012 and 2013 three small banks in which the state had an ownership stake (Agrobanka, RBV, and PBB) and one private bank (Univerzal) failed, mainly because of governance weaknesses that led to significant deterioration in asset quality. The bank failures raised concernsparticularly about the quality of the assets in some other state-owned banks, the effectiveness of governance and oversight, and the bank resolution framework, including the limited resolution options and poor communication between the NBS and the entity responsible for bank resolution, the Deposit Insurance Agency (DIA) - all of which need to be systematically addressed.

4.76. The authorities have recently taken steps to significantly strengthen the bank resolution framework. The reform establishes a robust framework that will facilitate timely resolution of banks while minimizing fiscal risks. The new framework reflects international best practices and draws, as appropriate for Serbia's specific conditions, on the EU's Bank Resolution and Recovery Directive. The framework is based on the principle of loss allocation to private sector participants in line with creditor hierarchy. It expands the menu of resolution powers and tools to allow early and decisive intervention; improves transparency and predictability through legal and procedural clarity; and centralizes the resolution powers at the NBS, with safeguards to duly separate resolution and supervision functions. In parallel, the governance and operational capacity of the Deposit Insurance Agency is being strengthened.

\section{Infrastructure}

4.77. Effective infrastructure enables trade, investment, and connectivity to markets and social services, thereby supporting economic growth and shared prosperity. High quality and sustainable roads, energy, air transport, and communications infrastructure are essential for businesses to operate productively and compete externally. However, providing broad-based access to quality infrastructure requires not only major capital investments but also an effective institutional set up to deliver on them. A comparison of Serbia's quality of infrastructure - transport, energy, water, and ICT — with its neighbors' shows that while Serbia is doing well in some areas (e.g., ICT), there is room for improvement in others (e.g. railways). While part of the agenda for improving the quality of infrastructure no doubt relates to higher investment, a larger part has to do with improving the institutional set up of large and inefficient public utilities to strengthen operational efficiency and financial sustainability.

\section{Transport Infrastructure}

4.78. Serbia's quality of infrastructure lags behind the EU-CESEE states (Figure IV.21). The 201415 Global Competitiveness Index (GCI) ranks the quality of Serbia's infrastructure-which includes telecommunications and electricity as well as transport infrastructure-at 111th, lower than its overall competitiveness rank of 94th out of 144 countries. Road infrastructure is ranked 114th, rail infrastructure 83rd (out of 104), port infrastructure 127th, and air transport infrastructure 112th. There is considerable 
potential for the improvement in the quality of Serbia's transport infrastructure and services and in the efficiency of resource use and service delivery.

Figure IV.21: Transport Infrastructure Quality Rankings, 2014-15
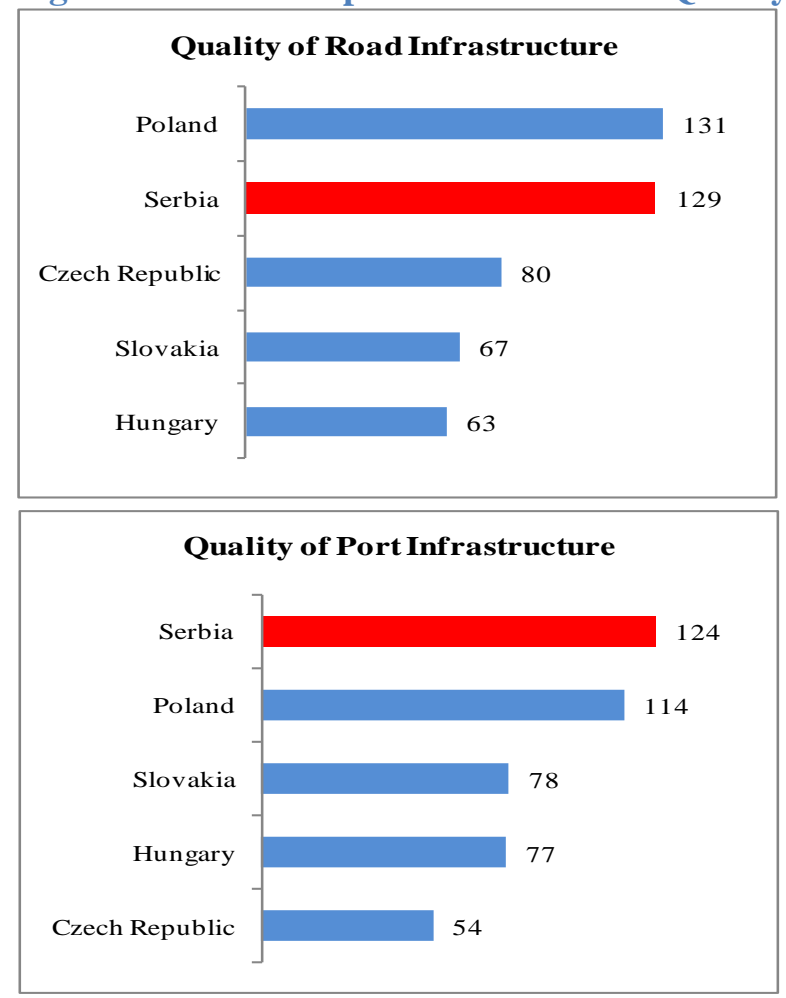
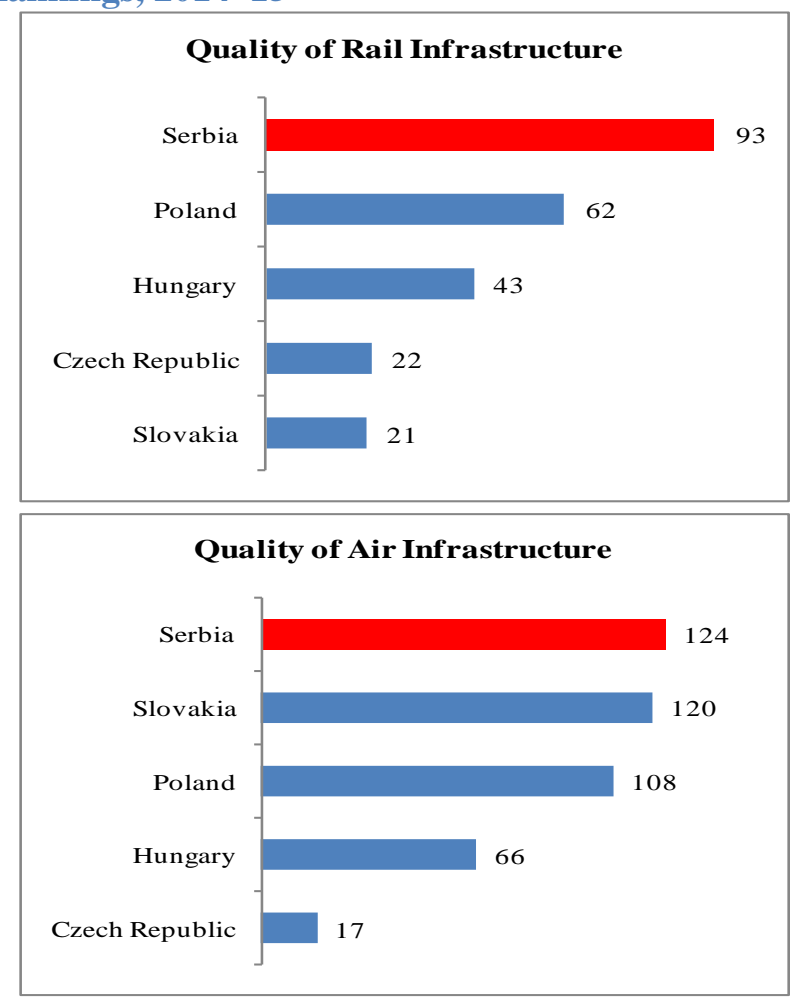

Source: World Economic Forum 2014, Global Competitiveness Report 2014/15.

\subsection{Completion of the Corridor $\mathbf{X}$ motorway-with its Belgrade-Budapest and Nis-Sofia} branches-is expected to enhance Serbia's connections to the region significantly, in particular to the Trans-European Networks (TEN-T) and European export markets. Many sections of Corridor X south of Belgrade (connecting Austria/Hungary, Slovenia/Croatia, through Serbia to Bulgaria/ FYR Macedonia/Greece) are now under construction and completion of the network in the next few years is expected to make a significantly contribution to regional connectivity, competitiveness, and growth.

\subsection{Little is invested in maintaining the national road network (estimated at about $9,500 \mathrm{~km}$ ) and} the local road network (estimated at $30,000 \mathrm{~km}$ ). Recurrent spending on national road network maintenance, after holding steady at about US\$380 million annually until 2012, has since dropped considerably. The current maintenance backlog is estimated at US\$700-900 million. Similarly, local road conditions need to be improved both to increase utilization of the national road network and for access to services and markets. Improving local road quality will require building road maintenance capacity at the local level and putting in place an information system on road conditions. While the number of road fatalities has been reduced in recent years, continued efforts are needed there as well.

\footnotetext{
${ }^{40}$ Lower number indicates better ranking and therefore better quality.
} 
4.81. Serbia's per-km costs for routine road maintenance are among the highest in the region, suggesting potential for efficiency gains (Figure IV.22), in large part because maintenance contracts are not competitively bid. Incumbent companies with maintenance contracts continue to operate in their region (there are 26 regions) through annual extensions of contracts based on unit rates set by the PERS. Serbia can enhance the efficiency of road care by using performance-based maintenance contracts and monitorable SLAs for national road maintenance, and avoiding institutional duplication. Prudent use of PPPs could also significantly reduce the costs of operations and maintenance.

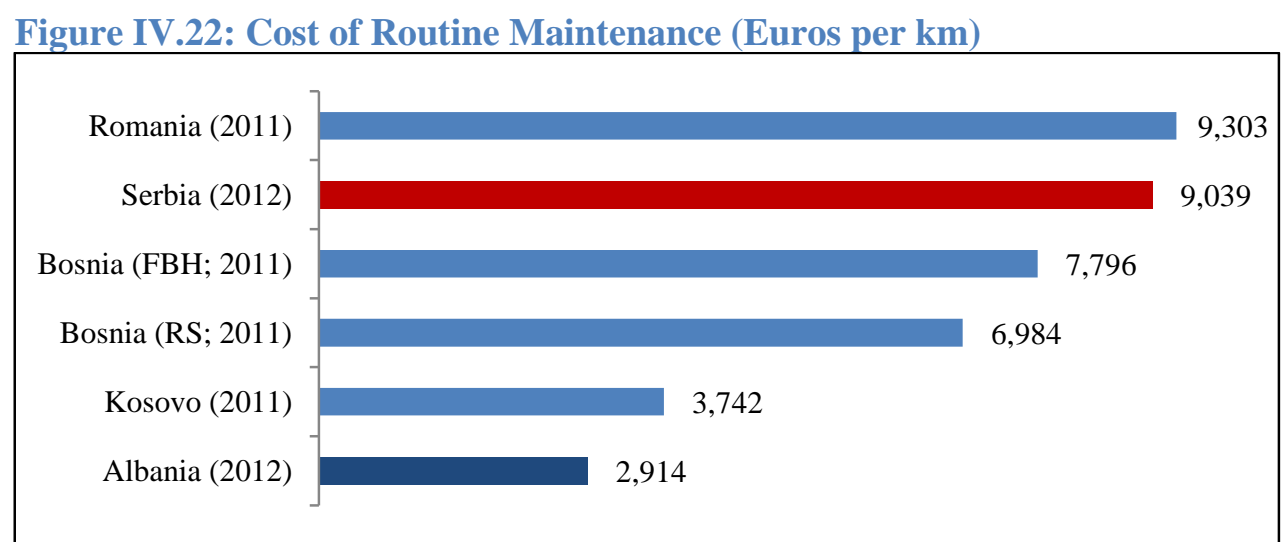

Source: Public Enterprise Roads of Serbia (PERS), World Bank Staff.

4.82. The reliability and comfort of rail passenger services are poor. Almost half of Serbia's tracks have not had a major overhaul for 40 years, and only about $200 \mathrm{~km}$ have been overhauled in the last 10 years. Thus the maintenance investment needs are significant. Line speeds do not exceed $60 \mathrm{~km} / \mathrm{hour}$ on about 50 percent of the network, although the average design speed is $94.5 \mathrm{~km} / \mathrm{hour}$. Particularly urgent is investment in rehabilitating the track along Corridor $\mathrm{X}$ and Route 4 connecting to the port of Bar in Montenegro. It would be more cost-effective to replace low-density lines with bus services. As discussed earlier, the scope for efficiency gains in railways is large given the low traffic intensity and labor productivity of ŽS (Figure IV.23).

Figure IV.23: How Serbian Railways Stack Up, 2013

Traffic Intensity

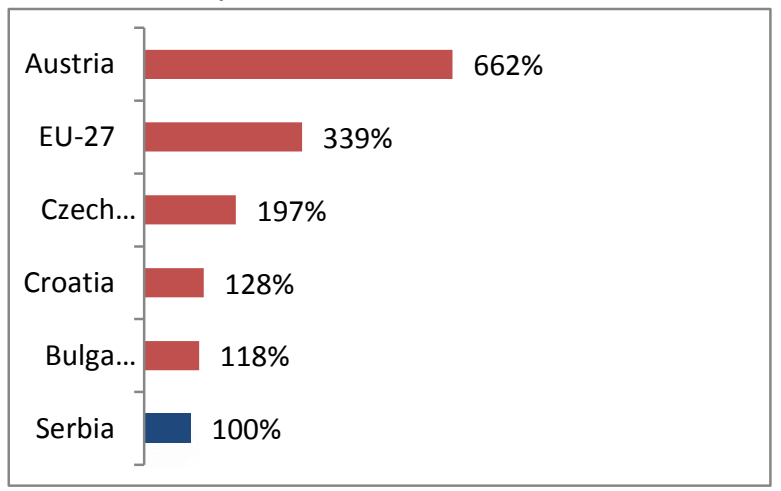

Source:Serbia Railways, World Bank Staff.
Labor Productivity

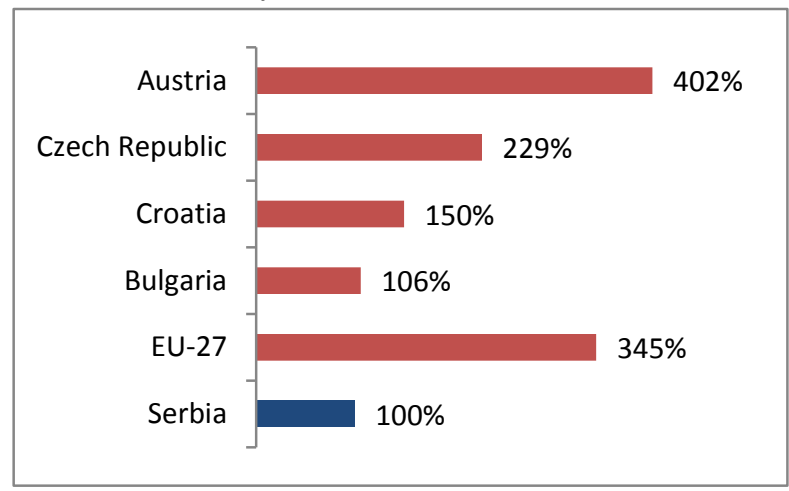


4.83. Coal, mostly low-energy lignite, accounts for over 54 percent of Serbia's total primary energy supply (TPES). Coal use is followed by oil and oil products (23 percent), natural gas (11 percent), renewable energy including biomass $(7$ percent), and hydro resources ( 5 percent). Net energy import dependence of coal, oil products, and natural gas was 27.7 percent in 2012, roughly half the EU average of 53 percent. In 2010, $\mathrm{CO}_{2}$ emissions were at 6.3 metric tons per capita, less than the EU average of 7.4, but higher than the Balkan average of 5.0. The predominance of domestic coal explains the country's low import dependency but also its relatively high $\mathrm{CO}_{2}$ emissions.

\subsection{Enhanced connectivity to the regional energy networks can boost Serbia's energy security and economic growth. With annual final consumption of about $28 \mathrm{TWh}$, Serbia is one of the largest power markets in South East Europe and its strategic geographic position at the heart of the Balkans gives it an important role in the power trade in South East Europe. Inter-connected to eight countries, the main regional trading pattern is a flow of electricity from the EU member states to its neighbors and within the region. In 2014, about 12 TWh flowed through Serbia, or about 44 percent of its own annual electricity consumption. Furthermore, a significant portion of the country's hydropower potential is from rivers that border neighboring countries. Decisions in managing water resources have domestic and regional implications for energy security, water quality, climate change mitigation and adaptation, and ecological protection, as recently seen during 2014 floods.}

4.85. However, for Serbia to capture the benefits of its assets and regional competitive advantage as an energy hub in south Eastern Europe, it will have to deepen the recently started reform process, including: i) its energy market opening process, whereas already about 40 percent of consumers (industry) already procure their electricity from the open market; ii) establishment of the Serbian-European Power Exchange (SEEPEX) and its coupling with four market couplings (Hungarian, Romania, Czech Republic, and Slovakia) to set-up a transparent spot and forward price signal to ensure efficient long-term contracts and signals for new investments in generation by regional investors; and iii) a gradual replacement of its aging power generation infrastructure in particular.

4.86. Energy intensity is comparable to that of countries in the region, but 1.89 times higher than the European average (Figure IV.24). Higher energy intensity is due partly to losses due to aging infrastructure, but also to very low efficiency in most households and industry. In fact, prices for residential consumers are the lowest in the region (Figure IV.25) and are estimated to be 30 percent below market prices, so consumers have few incentives to save energy. 
Figure IV.24: Energy Intensity, Selected

Countries, 2011, 2013

TPES/GDP (tonne of oil equivalent per thousand 2005 US\$ PPP)

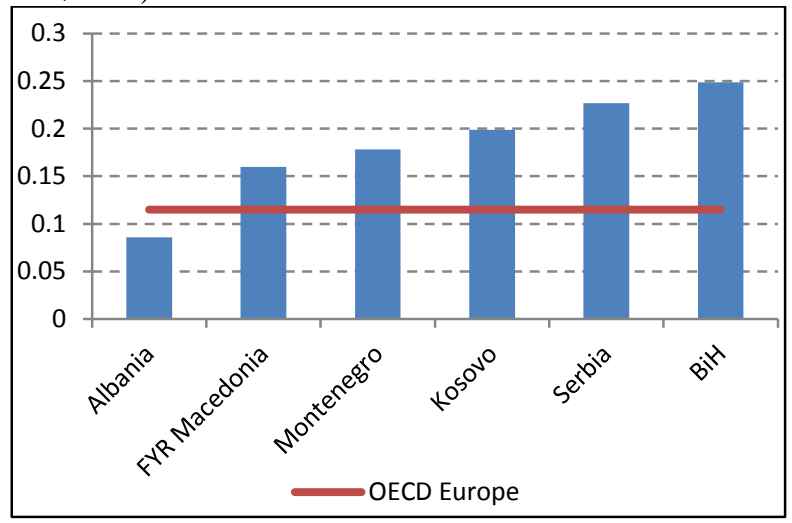

Source: IEA Energy Statistics.
Figure IV.25: Serbian Residential Electricity

Prices, 2013

Euro cents/Kwh

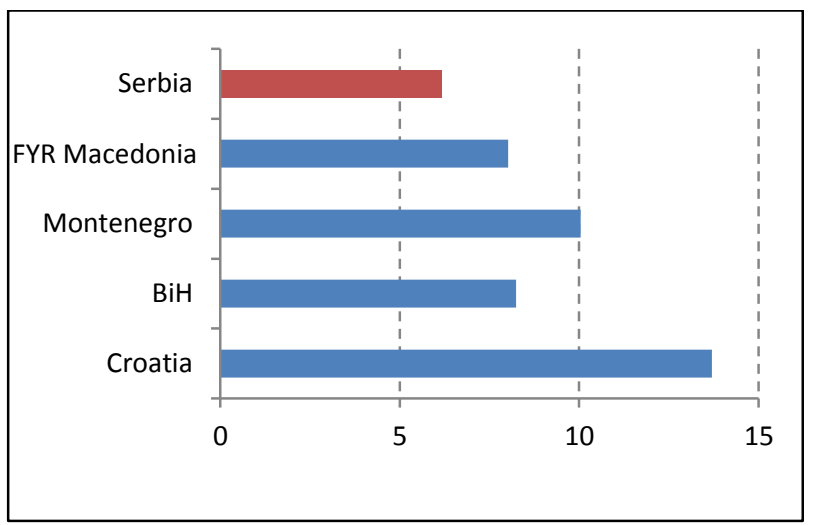

4.87. Policy, regulatory, financial, and operational challenges to the sector require urgent attention. Among these are below-cost pricing, low energy efficiency on both supply and demand sides, a need for large investment to replace aging infrastructure to ensure adequate and quality ${ }^{41}$ supply-demand balance and reduce pollution concerns, and an unfinished reform agenda to liberalize electricity and gas markets in line with EU accession requirements. Compounding the challenges, the devastating 2014 floods had a short- and medium-term impact: losses and damages in the sector are estimated at about $€ 480$ million. Water overflowing from the Kolubara River flooded open pit mines in the Kolubara coal basin (Tamnava West and Veliki Crljeni).

4.88. With more than 1,000 MW potentially idle due to lack of coal supplies, the supply-demand gap in electricity between June 2014 and April 2015 is estimated to be about 3,700 GWh, which has to be met by imports. Also damaged were mining equipment and the distribution network. Significant resources will be required to bridge the financing gap to cover the investments required to bring the sector back to pre-flood levels (see section on sustainability for more on this) and complement the Government's economic growth agenda.

4.89. Private sector participation can be considered as a way of mobilizing private investment and knowhow in infrastructure. A broad range of private sector participation arrangements - e.g. short term management contract; PPPs to help finance and implement projects; long term concessions for development and maintenance of existing infrastructure assets; sale of a minority stake; and privatization-- can be applied depending on the objectives of the Government vis-à-vis each of the utility companies. As per the Serbian PPP legislation, public utility companies can enter into joint ventures (so called "institutional PPPs") with the private partners for the development of new projects. This model could be particularly useful for implementation of new power generation facilities, considering that EPS has been facing difficulties in securing funding for its planned projects. Privatization has been successfully applied in other countries, for

${ }^{41}$ The time and cost of connecting to electricity remain excessively high compared to countries with similar power system size: 131 days in Serbia as compared to 38 days in Slovenia or 30 days in Chile, for example. 
example, in electricity and gas distribution networks, and railways rolling stock and operations. Long term concessions have similarly been successfully implemented in the management of railways sector.

\section{Information Communication Technology}

4.90. Serbia performs well in Internet and telephony competition, which is measured by a composite index of Internet, international long distance, and mobile telephone services. It has jumped up in the World Economic Forum's 2014 Network Readiness Index rankings ${ }^{42}$ For example, on number of applications for ICT-related patents filed under the Patent Cooperation Treaty, Serbia ascended from 96th in 2012 to 59th two years later.

4.91. Serbia's fixed and mobile broadband service penetration rates are among the highest among Western Balkan or Baltic peers (Figure IV.26), and international connectivity capacity per user is the highest in the SEE (Figure IV.27). High-speed connections (above 8Mbps), however, are limited in Serbia as in other SEE countries. The recent positive growth in fixed broadband subscriptions has been fuelled by more competition in the market. The growth of new subscribers, however, slowed from 46.2 percent in 2010 to 9.2 percent in 2013, which suggests that most urban areas are covered and expansion to less profitable areas is not easy.

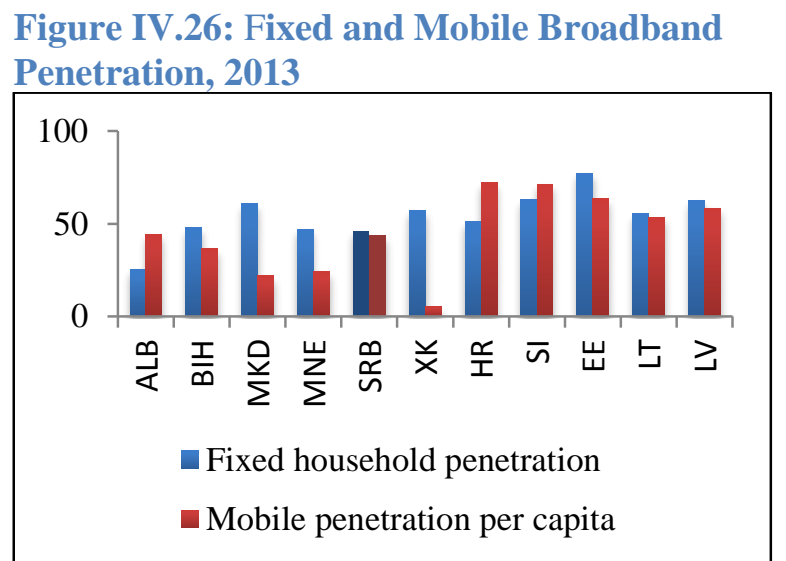

Source: Enlargement countries monitoring report 4, Cullen International, 2014.
Figure IV.27: International Internet Connectivity, Kbps, 2013

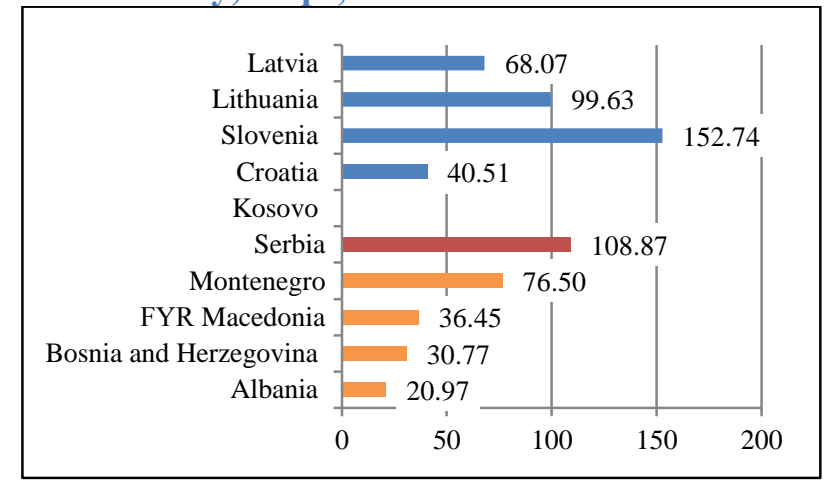

Source: ITU, 2013. Note: Data is not available for Kosovo.

4.92. Serbia's IT industry and ICT outsourcing contribute jobs and services exports in Serbia. Serbia's IT industry officially employs 15,000 workers ${ }^{43}$ and evidence suggests that Serbian IT developers are the best-paid workers in Serbia, competitive with EU counterparts. In their study of the Belgrade Service Sector, CEVES estimated that the productivity of ICT companies was more than three times higher than the Serbian average productivity. ${ }^{44}$ In 2011 , out of 1,704 active IT companies achieving revenue over $€ 10,000,104$ were outsourcing companies. Serbia outperforms its Western Balkan and Baltic peers both in

\footnotetext{
42 http://www3.weforum.org/docs/WEF_GlobalInformationTechnology_Report_2014.pdf

${ }^{43}$ DAAD, "ICT in Serbia 2013”. See also: Serbia Competitiveness Policy Note. Rebalancing Serbia's Economy: Improving Competitiveness, Strengthening the Private Sector, and Creating Jobs. June 2014. The World Bank Group. 44 "Understanding Belgrade Services Sector", CEVES, 2007
} 
terms of the number of online IT and programming freelancers and lifetime earnings per freelancer (USD1,242).

4.93. However, Serbia could lose its regional leadership unless it expands training and the supply of specialized IT and soft skills. In 2012, 35 Serbian higher education institutions offered ICT courses, with a total enrolment capacity of 8,619 students. Yet the total number of students enrolled in ICT academic programs (B.Sc, M.Sc, or Ph.D.) was only 5,523. IT companies that do less software outsourcing and more production of their own software and hardware products are likely to run into a particular shortage of highly qualified labor. IT companies also lack a supportive environment and professional support in the form of venture capital, incubators, accelerators, and other features that boost innovative companies.

4.94. Privatization of Telekom Srbija, the main provider of fixed line, mobile, Internet, and data services in Serbia, could enhance ICT competition and efficiency. Telekom Srbija was established in 1997 by PTT Serbia, OTE of Greece, and Telecom Italia (TI), but the Serbian state took full control in January 2012. As discussed above, the privatization agenda is now under implementation, with the Serbian government having confirmed in October 2014 that it is looking for an investment partner in Telekom Srbija. If successful, that could introduce more competition and add dynamism to the sector.

\section{Human Capital}

4.95. The knowledge, skills, and productivity of the Serbian workforce, together with the breadth and depth of labor market engagement, are important determinants of economic growth. Human capital is productive wealth embodied in labor, skills, and knowledge. The stock of human capital depends on the quality and equity of investments by the government and households in education, training, health, nutrition, and related services, as well as skills and experience gained through employment. The contribution of human capital to development and economic growth depends in turn on the extent of labor market engagement, opportunities for innovation and entrepreneurship, and the alignment between available skills and knowledge, on the one hand, and the demands of firms and the market on the other. This section will review available evidence on links between human capital and growth.

\section{Labor Market Engagement}

4.96. Low labor market engagement, including among women, youth, and older workers, constrains Serbia's growth potential, and contributes to fiscal constraints. As discussed above, overall employment rates in Serbia are low and have declined since the crisis, and are particularly low among young workers, women, older workers, and vulnerable groups such as Roma. Many of those employed are working in low productivity, informal sector jobs that do not generate fiscal revenues. As discussed in Chapter 5, the gender gap rate of female employment is estimated to result in a 16 percent loss in income per capita (Cuberes and Teignier, 2014). Early withdrawal of older workers from the workforce results in lost productivity, reduced fiscal revenues, and increased pension costs. Very low rates of youth employment have both short- and long-term consequences for growth and fiscal revenues. Conversely, equalizing labor market earnings in Serbia for Roma could generate economic benefits ranging from €252 million to $€ 1$ billion annual, and fiscal benefits up to $€ 257$ million annually (see Box IV.1). Labor market issues are discussed in further depth in Chapter V. 
4.97. Youth unemployment in Serbia ( 47 percent) is among the highest in the region, in part reflecting slow job creation, a stagnant labor market, and high unemployment overall. Youth unemployment persists despite relatively high levels of secondary educational attainment: in 2012, Serbia had a 102 percentage gross graduation rate ${ }^{45}$ at the lower secondary level. Like in other European countries, higher levels of education are accompanied by lower inactivity rates and higher levels of employment. While this symptom could be in part due to limited demand in a currently weak economy, key supply-side explanatory factors are: the large number of youth who are functionally illiterate, and an outdated vocational and training system that offers programs in occupations for which there is little employment (see below).

\section{Supply and demand for skills}

4.98. Skills are vital for increasing a country's productivity and growth, and demands for skills will evolve as the economy grows. ${ }^{46}$ The global market for goods, services, capital, and labor offers both countries and individuals opportunities and challenges as new jobs require diverse advanced skills. Skills encompass fundamental cognitive skills, such as math and reading, socio-emotional skills (such as perseverance), as well as job-related technical skills. In fact, non-routine cognitive tasks have become more important to work activities in many modern economies (Sondergaard \& Murthi 2012; Aedo, Hentschel, Luque, \& Moreno 2013). Countries in the region have found a shortage of human capital, particularly skills, to be a constraint on economic growth, despite adequate levels of educational attainment. (Sondergaard \& Murthi 2012). These constraints can change and become more acute as the economy grows and moves up the global value chain. As such, it is important to consider both the skills of the existing workforce, as well as the education and skills of current students, who will be joining the future workforce.

4.99. Existing evidence of the extent to which skills gaps constrain business and productivity in Serbia is limited and mixed, suggesting an important knowledge gap for further investigation. Direct measures of skills through skills surveys in Serbia and representative data of skills demand are not yet available. The analysis below will rely on a number of possible symptoms including education and health outcomes, unemployment rates, skills or education premium, and firms' perception of the skill constraint. The analysis is focused on the existing workforce, who has already completed its education (e.g., the current stock of labor).

4.100. Available estimates of the earnings premium show a stable trend from 2006 to 2010. A significant rising trend could be a sign that demand for higher education is outpacing supply. Estimations for Serbia of the returns to education using the 2006, 2008, and 2010 HBSs show that the returns have held

\footnotetext{
45 The Gross Enrolment Ratio is the "Number of students enrolled in a given level of education, regardless of age, expressed as a percentage of the official school-age population corresponding to the same level of education" (UNESCO, 2014).

${ }^{46}$ Skills, which describe what a learner can do after a period of learning, are an important learning outcome, but there are others, namely knowledge and competences (see e.g. European Qualifications Framework for Lifelong Learning: https://ec.europa.eu/ploteus/content/descriptors-page ). While the term 'skills' is often used as a synonym for learning outcomes; a graduate without knowledge of basic historical and societal facts would have little chance to succeed in a sophisticated working environment. 'Competences' are used in Europe to describe a set of complex (working and learning) attitudes and abilities (e.g. 'learning how to learn'; ability to work in teams). In what follows section, 'skills' is used so as to incorporate 'competences' according to European terminology.
} 
steady over time (Table IV.4), which suggests that skills shortages are not yet a serious constraint in Serbia. The values obtained are on the same order of magnitude as those reported by Montenegro and Patrinos (2014). Longer trend estimates are not available due to data limitations. At least for the period examined, there is no clear evidence that employers in Serbia have to pay increasingly more for higher education, though education does not necessarily equate to skills. The lack of a rising wage premium is not surprising, however, given current high rates of unemployment following the economic downturn.

Table IV.4: Serbia: Rate of Returns of Education, Percent (per year in each level)

\begin{tabular}{llllllllll}
\hline & \multicolumn{2}{c}{2006} & \multicolumn{4}{c}{$\mathbf{2 0 0 8}$} & \multicolumn{5}{c}{$\mathbf{2 0 1 0}$} \\
& All & Male & Female & All & Male & Female & All & Male & Female \\
\hline Primary complete & 1 & 0 & 3 & 1 & 1 & 2 & 2 & 3 & 0 \\
Secondary & 7 & 7 & 8 & 7 & 6 & 9 & 6 & 5 & 8 \\
Tertiary & 9 & 8 & 10 & 9 & 8 & 11 & 8 & 8 & 10 \\
\hline
\end{tabular}

Source: World Bank staff calculations.

Figure IV.28: Employment Rates by Education, 2012

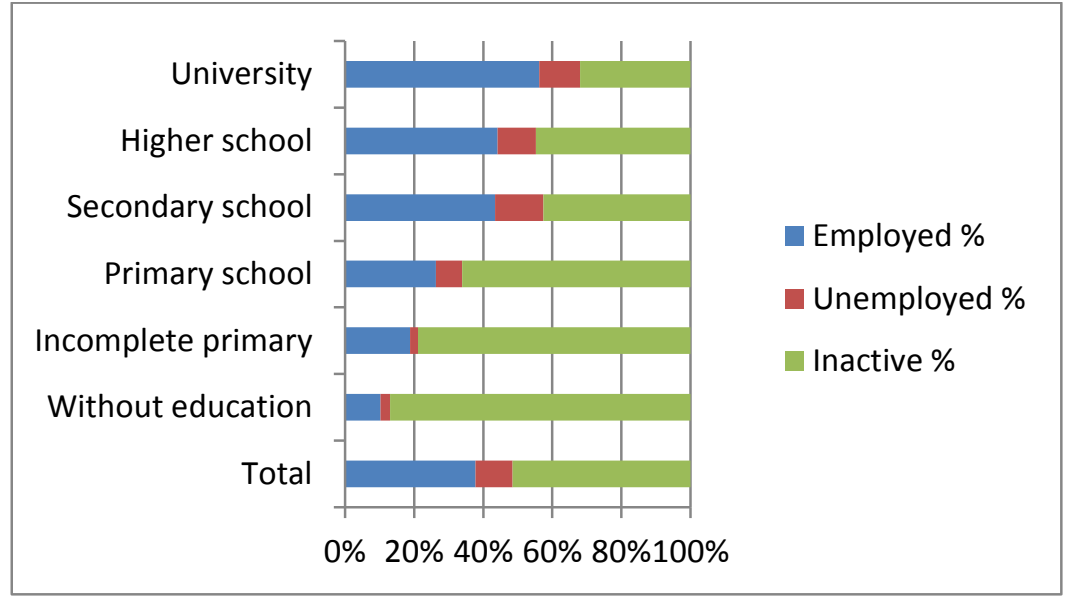

Source: Statistical Office of the Republic of Serbia, 2014.

4.101. Firms in Serbia report inadequately educated workforce as a constraint but not necessarily among the top issues for doing business in the current situation. According to the latest available BEEPs 2013, the percentage of firms citing this constraint as the top impediment to doing business is smaller than that for most other constraints (Figure IV.11 in Business Environment section). Still, just like in most of ECA, an inadequately educated workforce is among the top ten business climate constraints. In 2013, 16 percent of foreign firms and 18 percent of exporting firms identified an inadequately educated workforce as a major constraint compared to only 11 percent for domestic firms. This may be the case because foreign and exporting firms tend to use advanced technologies and ways of working that require adaptable (or transferable, 'soft') skills which Serbian graduates seem to be lacking. 24 percent of firms in Southern and Eastern Serbia report an inadequately educated workforce as a major constraint compared with only 3 percent of those in Sumagija and Western Serbia, and 8 percent of firms in Belgrade. In 2002 and 2009, 18 percent of Serbian exporters identified "inadequately educated workforce" as a "major" constraint," whereas this fell to 12 percent in 2013, concurrent with the economic downturn and increased unemployment (BEEPS 2002, 2009, 2013). The quality and relevance of skills and competences of the 
workforce are likely to re-emerge as a more significant constraint in Serbia once economic growth resumes, progress is made in addressing other constraints with respect to the business climate, and the country seeks to move up the value chain in manufacturing and exports. For example, in FYR Macedonia - which has made progress in business climate reforms and experienced positive growth in recent years -43 percent of exporting firms identified "inadequately educated workforce" as their biggest obstacle (BEEPS 2013).

\section{Education and Skills}

4.102. Despite relatively high levels of basic and secondary education attainment, Serbia has a large share of functionally illiterate youth, suggesting that quality and equity in the education system could be improved. Future growth and productivity of the Serbian economy will depend on a welleducated and adaptable workforce. A well-functioning education systemfrom early childhood development (ECD) programs, basic and higher levels of education, to a life-long learning system and through Figure IV.29: PISA Math Scores, Serbia, 2000-12

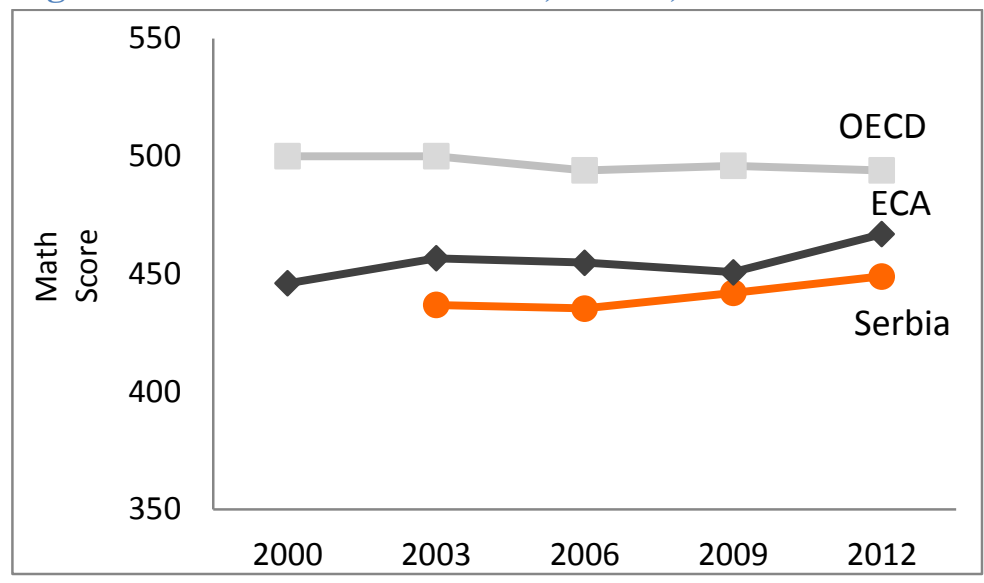

Source: OECD, Program for International Student Assessment, 2000, 2003, 2006, 2009, and 2012. assessing learning in students - is critical for a dynamic workforce (Quintini, 2011; Pierre, Sanchez Puerta, Valerio, and Rajadel, 2014). As discussed further in Chapter 5, primary and secondary school attainment is relatively high in Serbia, though pre-school education remains limited. Since much cognitive and socioemotional skills development takes place before the age of five, limited coverage of early child education has significant implications for education achievement as well as lifelong labor productivity (see Chapter V). However, despite improvements since 2000, PISA 2012 data show that about 40 percent of students are functionally innumerate in math and about 30 percent functionally illiterate in reading. Performance is uneven across groups, highlighting prevailing equity issues. For instance, students in urban areas perform much better than those in rural areas. Students whose families belong to the top 20 percent in income perform the equivalent of two school years better than students from the bottom 20 percent. While Serbia has marginally improved results since 2009, the gap between the ECA average and Serbia is the equivalent of half a year of schooling and between OECD and Serbia in mathematics a full year (Figure IV.29). These data suggest the need for policies and reforms to improve quality as well as equity and efficiency of the education sector.

4.103. While access to secondary education is high in Serbia, the TVET system, the most attended secondary program, faces challenges with the quality and relevance of training provided. Over 74 percent of secondary enrollment is in three- and four-year technical and vocational institutions, the latter giving access to higher education after students pass the State Matura exam. Comparatively more male than female students are enrolled in TVET (80 percent versus 72 percent). The TVET system, particularly the three-year programs, faces several challenges: TVET is typically under-funded and its profiles and curricula 
are obsolete: they do not correspond to skills demanded for modern jobs. Students study economy, law, and administration (13.24\%), followed by mechanical engineering (10.46\%), electrical engineering (9.88\%), trade, hospitality and tourism (9.35\%), and health (8.20\%; Banović 2013). Students do not have opportunities to practice on the job. In fact, employers have criticized the type and quality of skills students acquire, since the system tends to emphasize theoretical knowledge over technical and problem-solving skills and business expertise. Moreover, teachers are not adequately trained.

4.104. While Serbia's opportunities for sustainable economic growth are in agribusiness, manufacturing (textiles, metal industries, and automobiles), the pharmaceutical industry, and ICT, most higher education graduates come from the social sciences. The percentage of individuals with completed higher education is about 16 percent in Serbia, considerably below the EU average. Over 50 percent of higher education enrollment comes from students in education, humanities, social sciences, business, and law (Figure IV.30). A recent analysis of a graduate survey conducted in 2013 in Serbia, Bosnia and Herzegovina, and Montenegro shows that computing and mathematics had the highest share of graduates whose career started successfully without a period of unemployment, about 48 percent for those in computing and 46.4 percent for those in math. In contrast, five years after graduation, 21 percent of graduates in health and 24 percent of graduates in life sciences were unemployed and did not have work experience (Lažetić, Zivadinovic, Jaric, \& Radonjic, 2014). Thus, Serbia will need to further develop its higher education sector in the medium term while using policy tools at hand to support higher enrollment in mathematics, informatics, natural sciences, and technology (MINT) subjects.

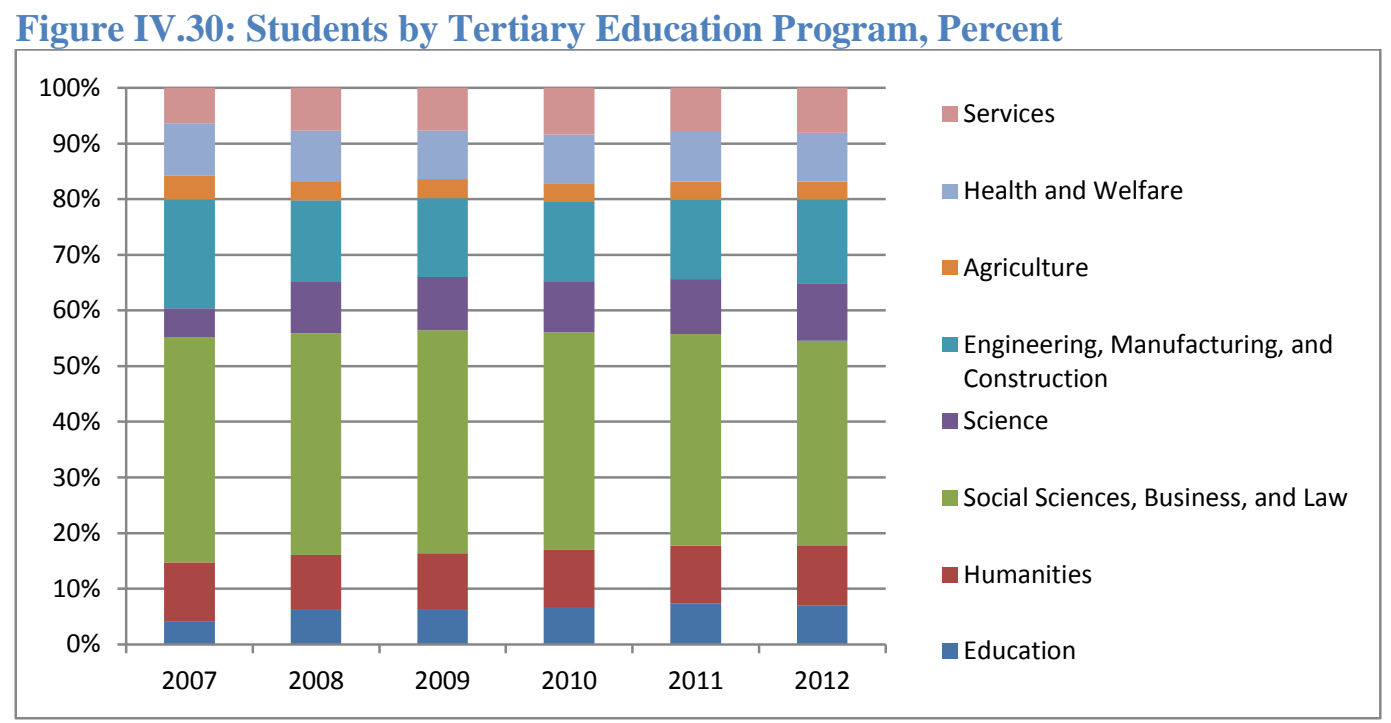

Source: UNESCO, UIS, 2014.

\section{Summary and Conclusions}

4.105. To generate broad-based and sustainable growth, Serbia will need to improve its governance and institutional capacity, restore fiscal sustainability and ensure macroeconomic stability, complete the first generation SOE reform, improve the business climate and remove the infrastructure constraints to exports and competitiveness. 
4.106. Serbia's ability to create the basic conditions for sustained and inclusive economic growth is hampered by weak governance and institutional capacity to implement reforms- namely, a lack of a robust accountability framework for results, limited technical capacity and a high turnover in senior staff and advisors during changes in Government. Weak overall management of the public service at large has led to a growing volume of politically-based appointments and a clogged decision making process throughout the system. The policy coordination and management system has effectively collapsed, leading to all decisions being pushed up to ministerial levels, and government sessions being overloaded with relatively trivial issues.

4.107. Serbia's growing public debt, if unchecked, is unsustainable. Public debt (including guarantees) has more than doubled, from 29 percent of GDP at the end of 2008 to over 70 percent of GDP at the end of 2014. A significant part of this increase came from guarantees issued on behalf of public enterprises (SOEs and public utilities) and local governments. With no reforms, public debt is unsustainable. The growing public debt not only absorbs a significant amount of resources in debt service (at 35 percent of total revenues) which could be used for productive purposes, it also poses a high roll-over risk. The fiscal and debt vulnerabilities make it critical that the government pursues a fiscal consolidation program to achieve debt sustainability and assure macroeconomic stability over the medium term.

4.108. Completing the first generation SOE reforms is fundamental to restoring growth and fiscal sustainability. SOE reforms will reduce the fiscal pressure on the state budget; level the playing field for the private sector; improve efficiency in resource allocation; and improve productivity and growth. These gains, however, are not costless as the transitional employment consequences of these reforms are significant. Although the exact estimates are difficult to make, potentially between 30,000 and 50,000 workers could be made redundant in this process, and cushioning and managing the social impacts of such layoffs and labor retrenchment - through appropriate severance packages, employment services, and active labor market policies to support transition to new jobs--is critical for the success of the reforms. A strong political commitment to see through these reforms is clearly critical.

4.109. Serbia needs to do much more to improve its business climate, attract investment, and support higher productivity and growth and opportunities for broad-based employment. Among reforms that will be important to all types and sizes of firms are: (a) reducing the time it takes to obtain construction permits; (b) making policy and regulation more predictable, and consistently enforcing laws and regulations through better administrative coordination and supervision; (c) continuing to restructure SOEs and reducing negative competition to formal sector businesses from the informal economy; and (d) improving contract enforcement and insolvency mechanisms. For SMEs, BEEPs data suggest that special attention to access to finance, including long-term finance, is warranted. For large and exporting enterprises, facilitating customs and trade seems particularly critical. All these measures are vital for Serbia to secure current investments and attract more; create broad-based growth and job opportunities; and increase exports and competitiveness. The bulk of low wage earners in Serbia work in the non-tradable service sector; they work for micro and small enterprises; they work in agriculture; and many of them are actually selfemployed. In order to boost employment for these groups, in addition to export-led growth, complementary policies focused on removing barriers for SMEs and self-employment as well as attract investments in the non-tradable service sector and agriculture is essential. 
4.110. While Serbia's quality of infrastructure is generally respectable, the quality of rail passenger services is particularly poor both in terms of reliability and comfort. Serbia's overall quality of roads is decent, although maintenance investment in the national roads network could be increased through competitive bidding, and the local road network expanded. A significant part of the agenda of improving the quality of infrastructure, particularly in transport and energy, relates to institutional and financial reforms in large public utilities to increase efficiency, illustrating again the centrality of SOE reforms to the growth and competitiveness agenda.

\subsection{Given current high rates of unemployment, education and skill gaps are not major binding} constraints to growth, but may emerge as major constraints if the economy recovers and other structural constraints to growth are addressed. Firms in Serbia report an inadequately educated workforce as a constraint but not necessarily among the top five constraints for doing business in the current situation (although inadequately educated workforce is among the top ten constraints). On the other hand, other indicators suggest that the type and quality of skills students acquire may not be most relevant to the modern economy: the education system produces a large share of functionally illiterate youth; TVET's profiles and curricula are obsolete; and most higher education graduates come from the social sciences while the demand of the economy seems to be in areas such agribusiness, manufacturing, ICT services. Reforming the training and education systems in the short to medium term is still necessary to help address future skill needs. 
Figure IV.31: The critical constraints on Serbia's growth performance

Governance and institutional capacity are weak, particularly in policy coordination...

Policy Coordination Metcalfe score 1-9 (stronger), 2006

Slovak Republic

Czech Republic

Hungary

Poland

Serbia

$$
1
$$

1-indepdent organizational



Weak economic activity and poor fiscal discipline resulted in rising deficits...

Fiscal deficit including amortization of called guarantees, $\%$ of $G D P$

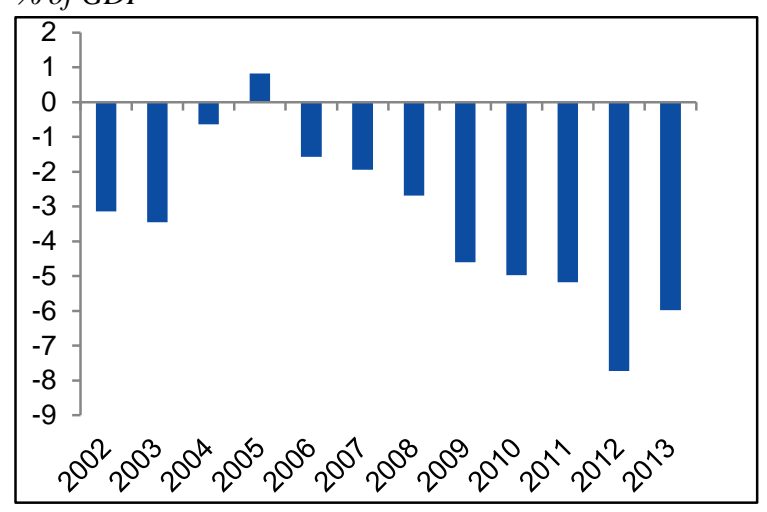

SOE reform is critical to the fiscal outlook... "Cash" transfers to public enterprises

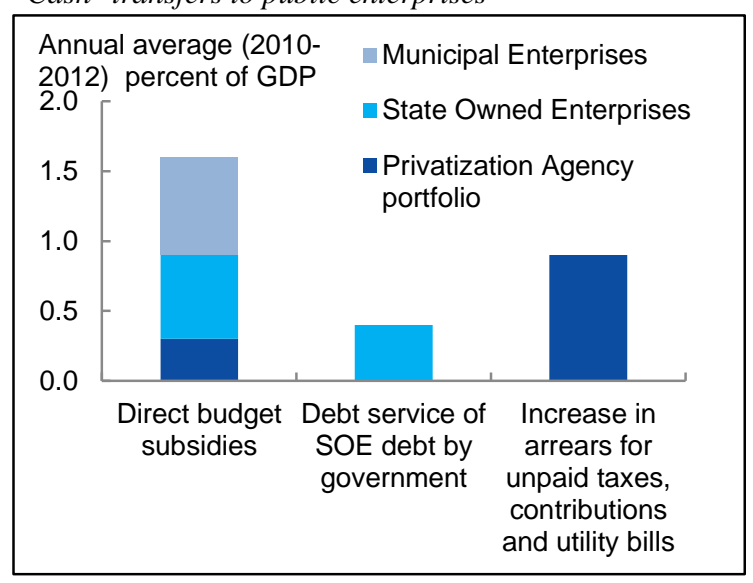

...and in HR management, impeding reform

implementation and service delivery

HR Sigma rating (1-7), 2006



... and increasing government debt which, if unchecked, risks macro-fiscal stability

Government debt to GDP, \%



....and can help improve infrastructure quality Infrastructure Quality Score 1-7 (best), 2014-15

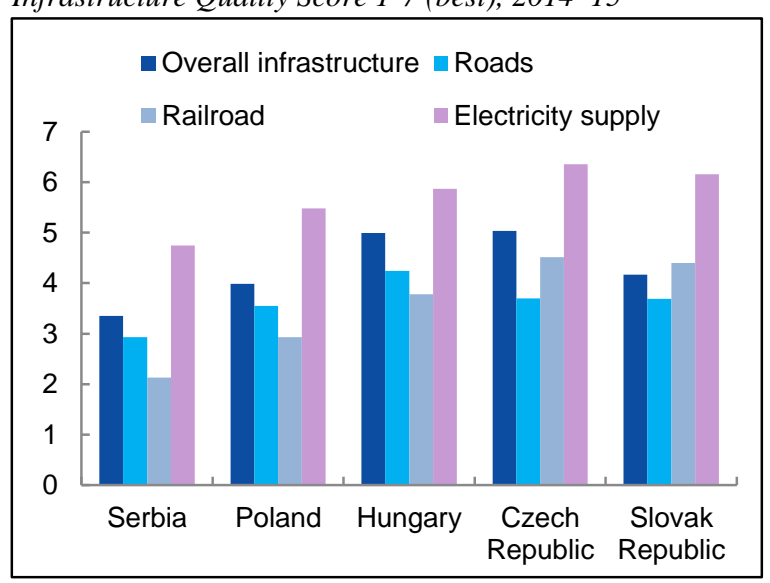




\section{Regulatory and political uncertainty are weakening the business climate}

Main business climate constraints on SMEs (\% of establishment)

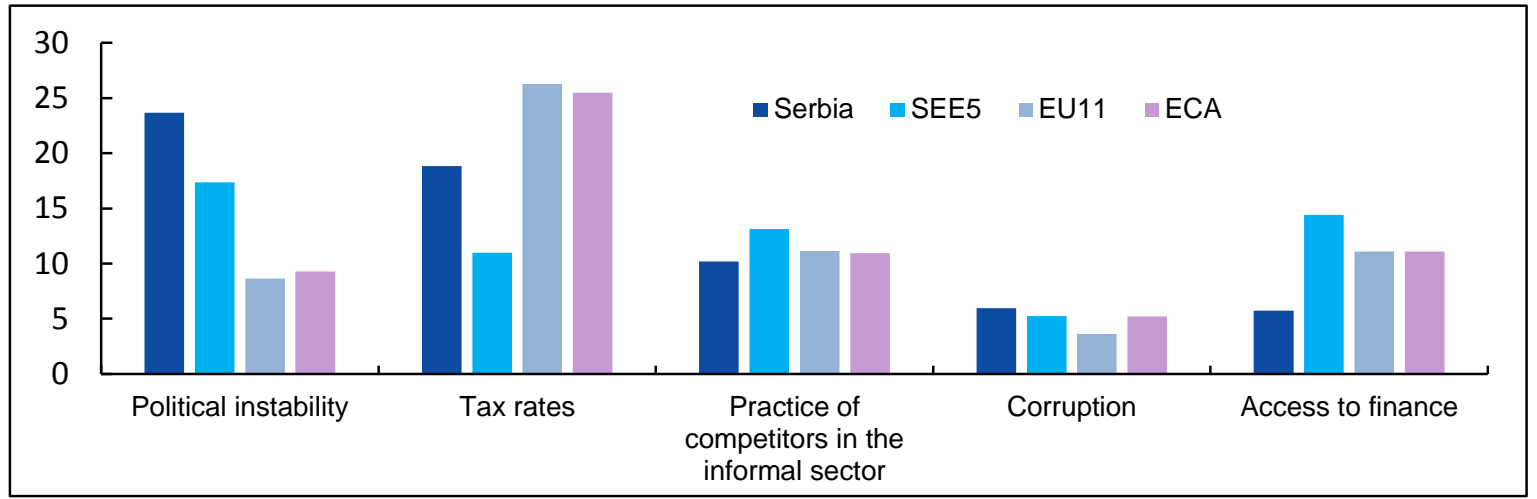

While relatively healthy, the banking sector has seen a weakening in credit quality and stagnation in credit growth

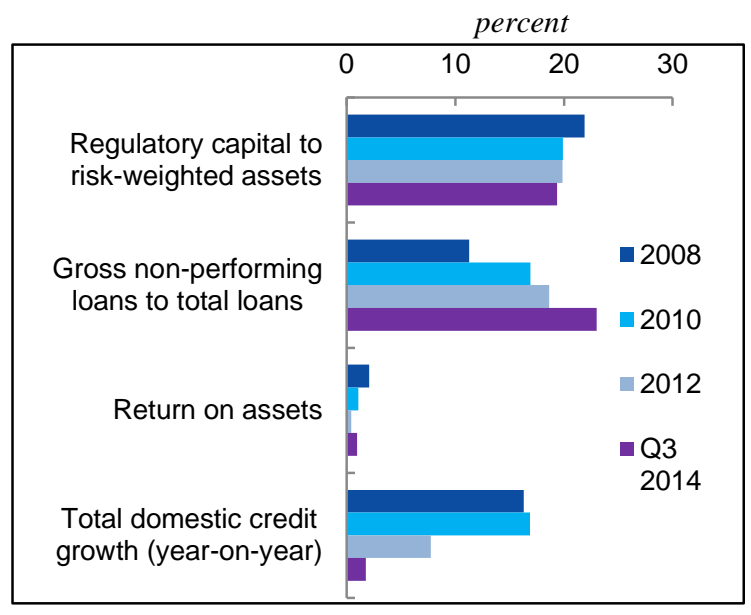

Investing in human capital is needed to ensure that future skills gaps do not become binding as growth recovers

PISA Math Scores

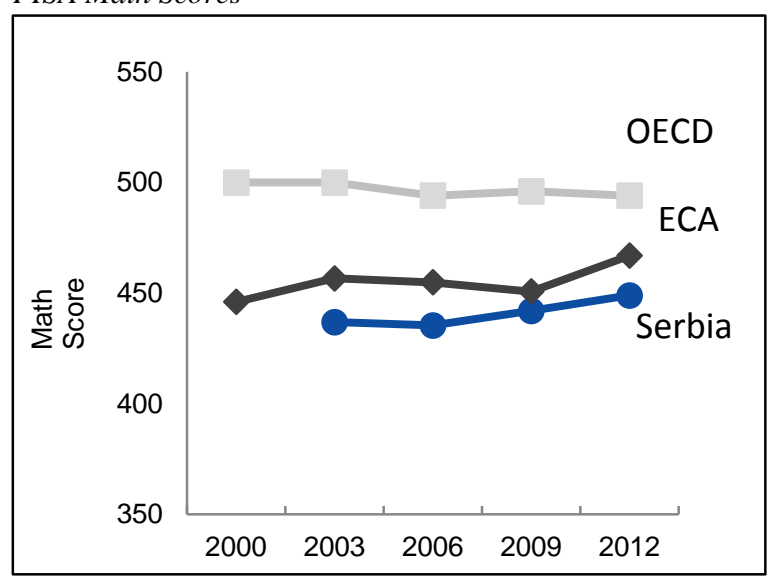




\section{DRIVERS AND CONSTRAINTS TO INCLUSION}

\subsection{While reinvigorating economic growth is essential, it is not sufficient to make progress toward}

inclusion and poverty reduction. Inclusion is achieved when, facilitated by markets and institutions, the less well-off and excluded groups, such as Roma people ${ }^{47}$, have equitable opportunities to build critical endowments and opportunities for sustained income generation. This section will first examine with an equity lens assets vital to income generation — such as health and education — and access to basic services and social protection, highlighting several spatial and socioeconomic differences. It will then examine the ability of individuals and households as workers, entrepreneurs, and farmers to acquire returns from these investments.

Figure V.1: The principal constraints on inclusion

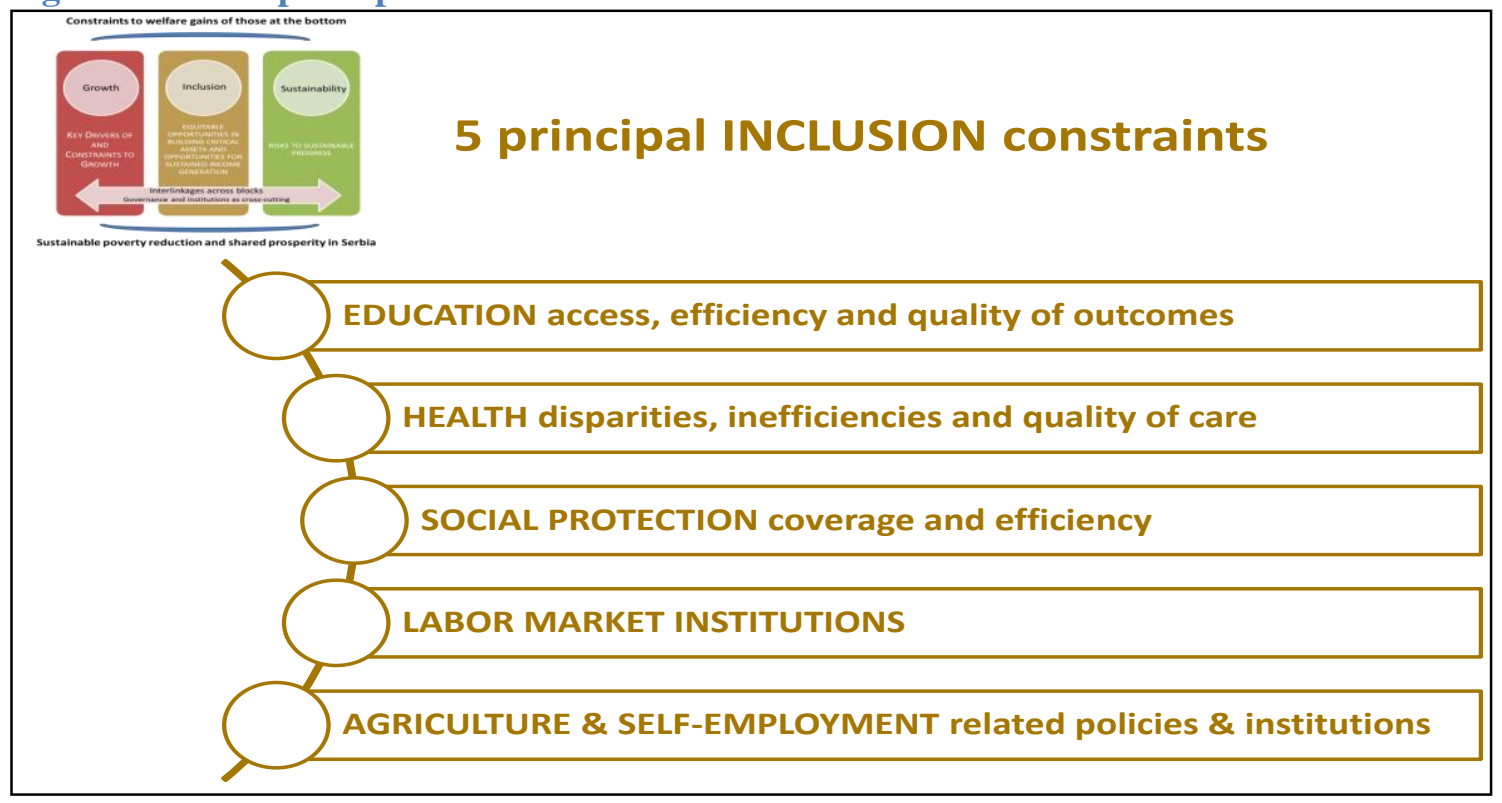

Source: World Bank staff.

5.2. Understanding the barriers to income-generating opportunities and to sustained improvements in rural poverty is necessary to identify drivers toward the twin goals. The welfare of those at the bottom has been closely associated with trends in employment, labor income, and rural poverty. Yet accessing gainful employment is a long-standing and mounting challenge in Serbia, exacerbated in the short run by potential redundancies caused by necessary SOE reforms, but limited broadly by the constraints on the whole economy for broad-based growth and private sector-led job creation, as discussed above. This section will analyze recent dynamics and disparities in health, education, and social protection. It will also analyze the recent labor market dynamics and the need for more effective labor markets and institutions to facilitate earnings opportunities for less well-off Serbians and help mitigate the consequences for those workers affected by economic restructuring. Analyzing constraints to agriculture productivity and income is also important for understanding the factors influencing rural welfare and poverty. The figure above provides a simple schematic outlining the structure for the chapter.

${ }^{47}$ Another group, though not of focus here due to lack of data, is the Albanian minority in Serbia. 


\section{Equitable and Sustainable Opportunities to Build Critical Assets}

5.3. There is a respectable degree of asset accumulation in Serbia. Yet there are concerns about both socioeconomic and spatial disparities as well as quality in acquiring human capital. There is evidence that these issues reflect inefficiency and inequity in certain public spending and service delivery.

\section{Basic Services}

\subsection{Serbia's human development indicators and access to basic services are generally good across} the country. Serbia performs better on the Human Development Index than other countries with similar income levels - including with respect to school enrollment rates, life expectancy, and infant and maternal mortality rates (Figure V.2). In the Human Opportunity Index, which reflects both coverage and equality of opportunity, Serbia performs well relative to other ECA countries in primary school completion and access to water, sanitation, and electricity. The coverage rate of electricity, adjusted for inequality due to predetermined circumstances, is nearly universal at 99.3 percent. $^{48}$

\subsection{Spatial differences in access to a number of basic services are small, except for Internet access.}

The most recent household data indicates that flush toilets and a bathroom within the dwelling are common, though thinly populated rural areas and the poorest quintile have a slightly lower coverage rate (Figure V.3). Telephone coverage is also universal, but access to the Internet is more unequal, with the coverage rate in thinly populated areas only half that in densely populated areas. Price analysis of the cheapest retail offerings indicates that for the average household in Serbia's bottom two quintiles broadband services are not affordable (because they exceed 5 percent of monthly disposable income). Access to piped water is high, 86 percent of the population, and service is generally good. ${ }^{49}$ However, wastewater management is behind EU standards, with only slightly over 50 percent of households connected to a sewer, and only about 14 percent of all wastewater produced actually treated, posing significant environmental and public health hazards. ${ }^{50}$ In terms of road access, setting aside issues with maintenance and road quality, the network of national and local roads covers all of Serbia. While Belgrade has the highest road densities per square km, the regions of Sumadija and Western Serbia and South and East Serbia have higher road densities per population than Belgrade and Vojvodina.

5.6. In Serbia water and wastewater services are the responsibility of local governments. As detailed in a recent World Bank report (Serbia Municipal Public Finance and Expenditure Review, 2013), There is considerable scope for making water utility companies more efficient. ${ }^{51}$ Many water utilities suffer operating losses of 20 to 50 percent of income before subsidies mainly due to high technical losses and overstaffing, ${ }^{52}$ which is a drain on municipal resources. For example, there are 5-6 staff per 1,000

\footnotetext{
${ }^{48}$ World Bank Group's Visualize Inequality Dashboard. http://www1.worldbank.org/poverty/visualizeinequality/index.html

${ }^{49}$ WHO/UNICEF Joint Monitoring Program, 2014 update (www.wssinfo.org)

${ }^{50}$ National environmental approximation strategy for the Republic of Serbia, Ministry of Environment, Mining and Spatial Planning, Belgrade, 2011

${ }^{51}$ Serbia: Municipal Public Finance and Expenditure Review I, World Bank, April 2013

52 "Cost Recovery of Water and Wastewater Utilities in Serbia", Srdjan Topalović, Aleksandar Đukić, Zorana Naunović, in Water Research and Management, Vol. 2, No. 4 (2012) 19-32
} 
connections, more than double regional good practices of $2-3 .{ }^{53}$ To offset worsening financial results, utility companies have resorted to tariff increases above inflation as well as decreasing investment and amortization $^{54}$, which puts service provision on an unsustainable path.

Figure V.2: Serbia's Human Development Indicators
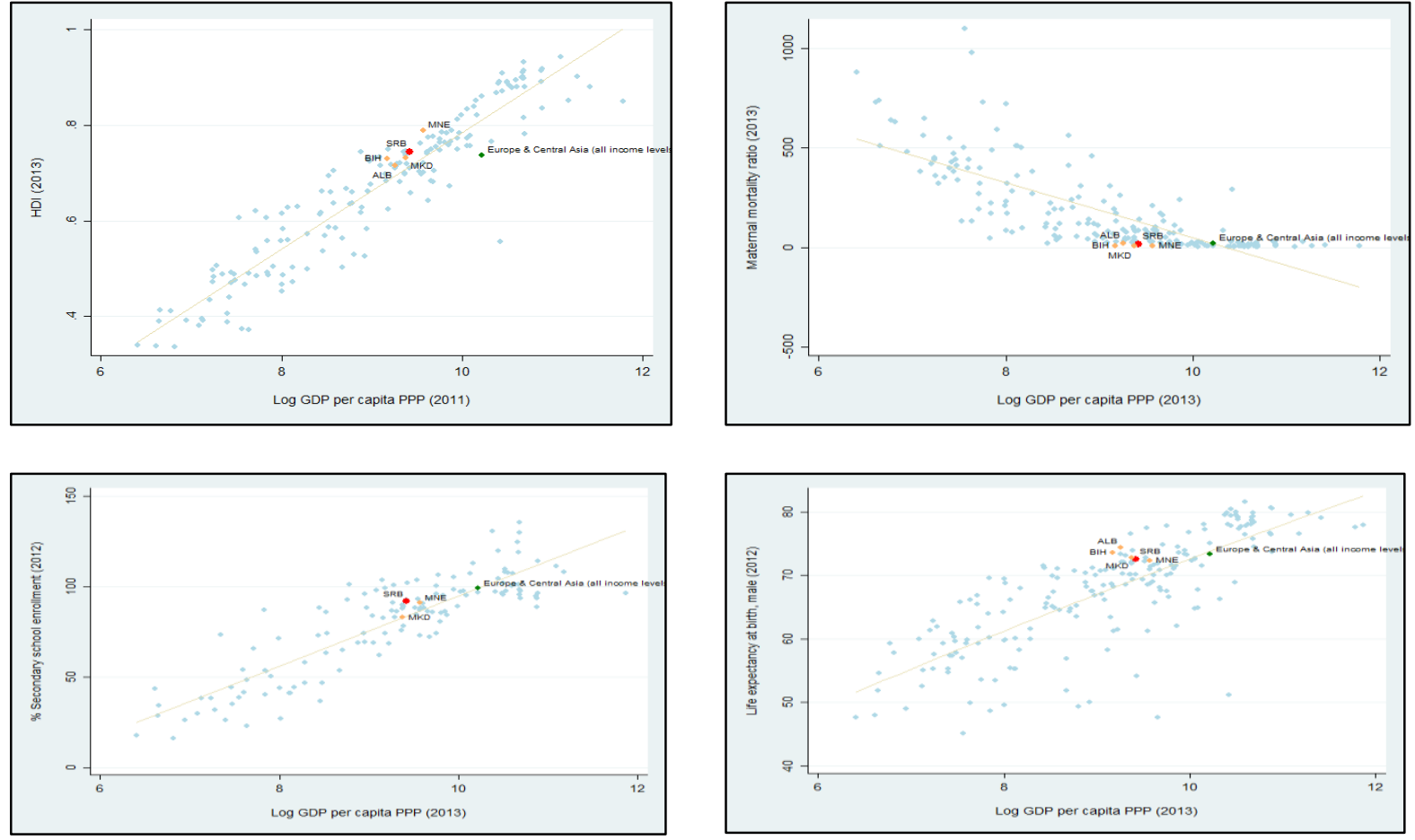

Source: WDI.

Figure V.3: Access to the Internet by Income Group and Urban-Rural Location $\%$ of population with access, by income quintile and region
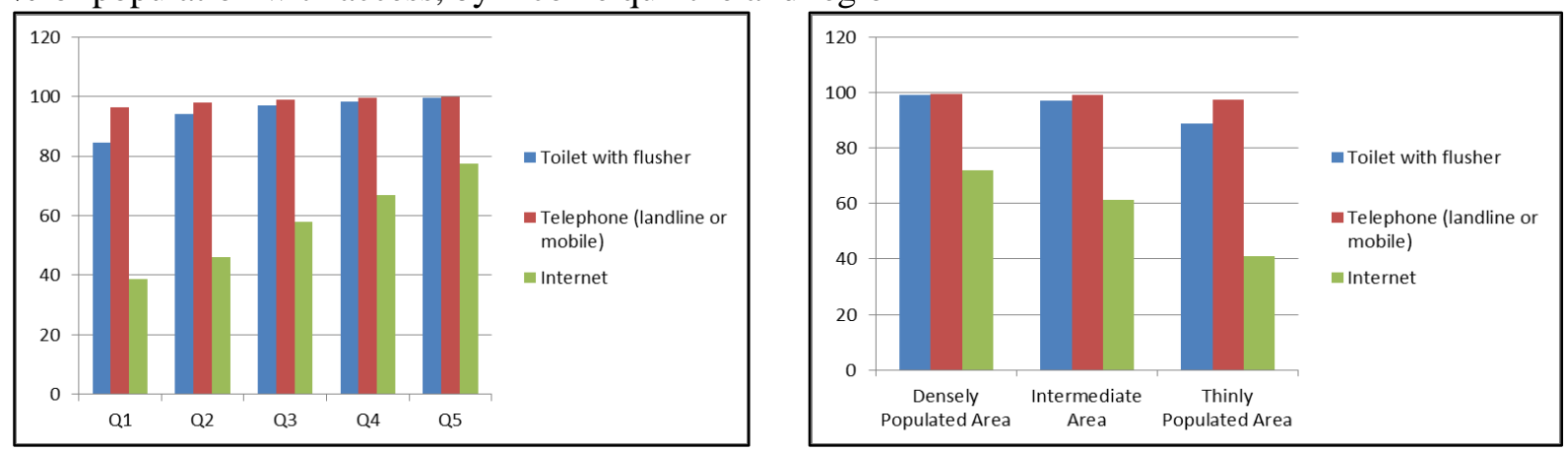

Source: Staff estimates based on SILC 2012.

${ }^{53}$ IB-Net / DANUBIS data, www.danubis.org, based on a limited sample of Serbian utilities.

${ }^{54}$ Municipal Public Finance Review - Options for Efficiency Gains, World Bank, 2014 


\section{Education}

5.7. As discussed above, an effective education system starts with ECD; although improving preschool education in Serbia is limited, particularly for marginalized groups. ${ }^{55}$ Socioeconomic differences in schooling are most stark at the preprimary level: only 8.6 percent of children aged 36-59 months in the poorest quintile and 6 percent of Roma children participate in ECD programs, compared to 82 percent of children in the wealthiest quintile (Figure V.4).

Figure V.4: Early Education ECD Participation by Welfare Quintile Early Child Development or Secondary School attendance (\%)

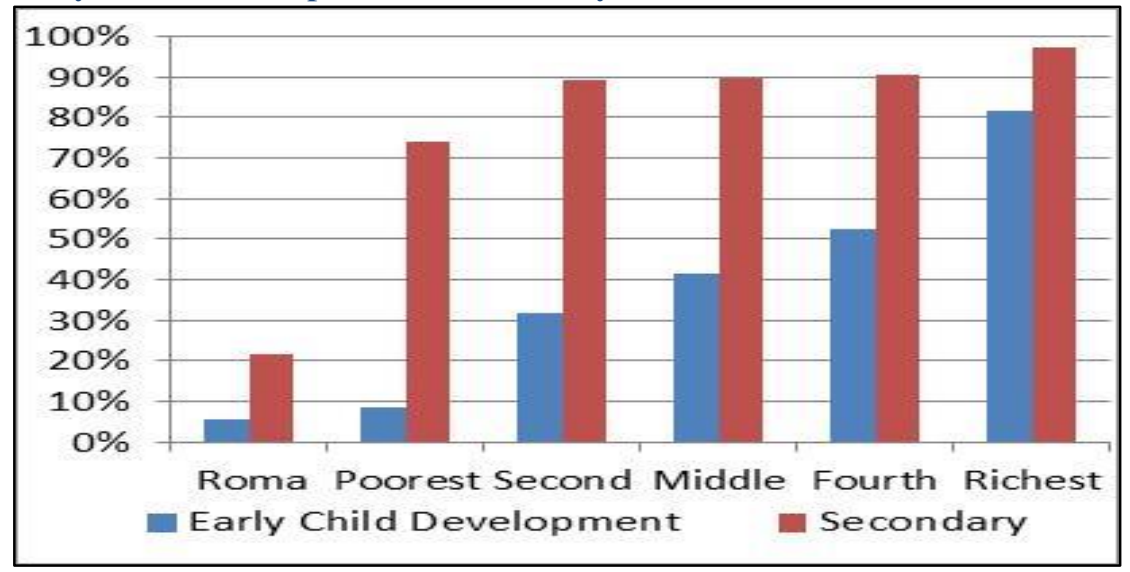

Source: MICS 2014.

5.8. Participation in education in Serbia is high for all levels, but socioeconomic disparities persist in both participation and attainment. As shown in Figure V.2, Serbia's enrollment rates in primary and secondary school are better than in other countries at similar income levels. However, according to the MICS 2014, secondary attendance is only about 70 percent among the poorest quintile and 20 percent among Roma, compared to 90 percent among the 2nd through 4th quintile, and 97 percent among the wealthiest (Figure V.4). Primary and secondary enrollment rates are on average similar for girls and boys, but the girls to boys ratio in secondary school net attendance is only 0.53 for Roma (MICS, 2014). In terms of school completion, lower income groups also have less educational attainment (Figure V.5); 52.4 percent of Serbians aged 15 and above in thinly populated areas compared to 83.1 percent in densely populated areas completed at least upper secondary school, and 95 percent of non-Roma children but less than 33 percent of Roma children complete elementary education. The secondary completion rate is 76 percent for non-Roma but less than 8 percent for Roma children (Republic of Serbia 2010). Roma women in Serbia have on average one less year of education than Roma men and only about half as many years (6) as nonRoma women (11) living in the same areas (UNDP/WB/EC Roma survey, 2011).

${ }^{55}$ UNICEF (2012). Investing in Early Childhood Education in Serbia; p. 9. http://www.romachildren.com/wpcontent/uploads/2013/02/RECI-Serbia-Report.ENG .pdf on 30 September 2014]. 
Figure V.5: Educational Attainment By Income Group

$\%$ of people in top and bottom income quintile, by highest education

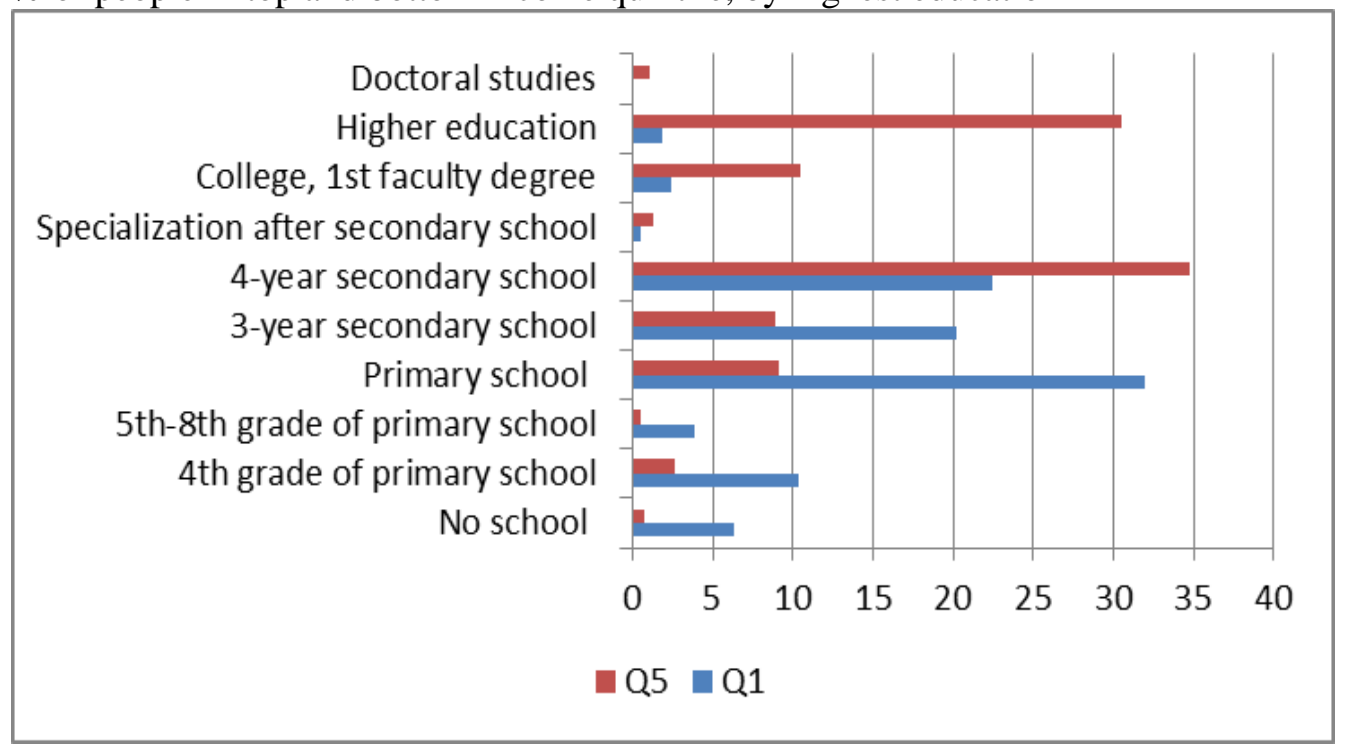

Source: Staff estimates based on SILC 2012.

5.9. Compared to EU-CESEE countries, there are significant socioeconomic and geographic disparities in learning outcomes, especially according to school location, size, and parental education. Serbia's performance in the 2012 PISA and the 2011 TIMSS (Trends in International Mathematics and Science Study) improved over earlier rounds, particularly in mathematics. Yet on the PISA Serbian students still score about 50 points below the OECD average in mathematics, reading, and science; 32.9 percent of Serbian 15-year-olds, compared to 23.5 percent in the EU-CESEE, are functionally illiterate - unable to locate or interpret information in the text. The share of functionally illiterate students is much higher in the poorest group of students, and ranges between 60 and 75 percent. On the national $8^{\text {th }}$ grade examination, administered in June 2011, students in urban schools, large schools, and schools with higher levels of maternal education scored consistently higher on the Serbian language and mathematics exams than students in rural schools, small schools, and schools with less parental education. The performance gap between large urban and small rural schools is about 66 points on the standardized exam scale. This difference exceeded even the gap between schools with students in the highest income quintile and those in the lowest. These disparities are likely to perpetuate the cycle of low education and intergenerational poverty, limiting opportunities for economic mobility.

\subsection{Inefficiency of resource allocation in education and teacher qualifications may be serious} constraints. Though the distribution of public education spending is both pro-rural and pro-poor, it does little to close the performance gap between poor rural and affluent urban students. How resources are allocated across schools matters more for student performance than the total amount spent. Schools that spent a larger share of their budgets on teaching and learning inputs, rather than on staff salaries - and, in particular, salaries of non-teaching staff - proved to have better student performance on the $8^{\text {th }}$ grade exam. Rural schools and schools in the least-developed municipalities also have fewer well-educated and experienced teachers. Though there is no rigorous causal evidence, descriptive evidence indicates that teacher qualifications and experience have a major role in determining Serbia's student learning outcomes. Evidence from the BOOST Analysis of Resource Allocation in Serbia shows that a 10 percent increase in 
the share of teachers who have a university degree correlates with an increase in exam scores of up to 0.20 standard deviations. While Serbia spends more on teacher salaries than many other countries, including the Netherlands, Poland, Spain, Italy, and Bulgaria, salaries are flat and there are few performance incentives for teachers.

\section{Health}

5.11. Serbia's key health outcomes, including life expectancy and infant and maternal mortality rates, have improved and are comparable to the ECA averages (Figure V.2), but problems of disparities, inefficiencies, and the quality of care remain. The B40, particularly the Roma, have worse health and nutrition outcomes (Figure V.6). For example, SILC 2013 data shows that among adults in the B40 percent, 25 percent report being in poor health but among the wealthiest quintile, only 12 percent do so. The prevalence of NCDs is higher among the poor. Delivery at health facilities is nearly universal although poor women and Roma are less likely to have four antenatal care visits (Figure V.7). Full child immunization is better for the poorest quintile than the wealthiest but lower for Roma (Figure V.7). Although infant mortality rates are relatively low for the overall population, they are

Figure V.6: Nutrition Outcomes of Poor and Roma Children under 5, Percent

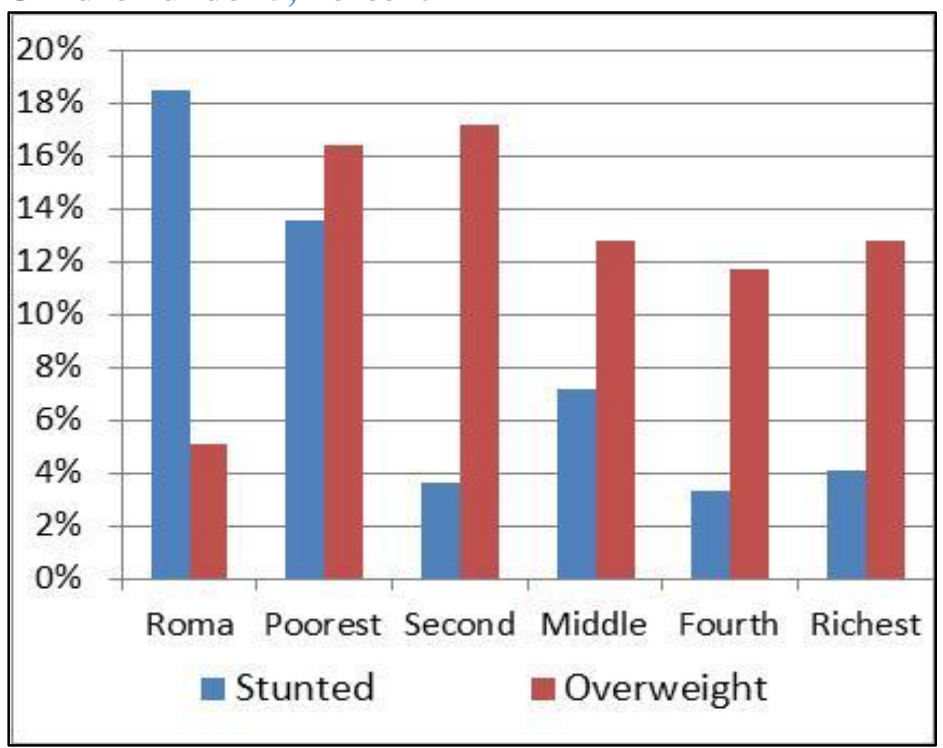

Source: MICS 2014. Note: Stunted is defined as less than two standard deviations of average height for age.

twice as high for Roma (13 deaths per 1,000 live births). Figure V.6 also shows a higher incidence of chronic malnutrition (stunting) among Roma children, despite recent improvements, with serious implications for their cognitive development and lifelong earning potential. Government programs such as the Roma health facilitators, which has reached 140,000 Roma since it began in 2006, have helped improve their access to health services for Roma, but gaps remain: the percentage of women aged 20-24 who have had at least one live birth before age 18 is 1 percent for Serbia and 38 percent for Roma settlements, which is likely to have implications for Roma women's education and labor market participation. Serbia's total fertility rate is 1.6 births per women but 3.1 among the Roma (MICS 2014). 
Figure V.7: Child Immunization and Antenatal Care, by Welfare Quintile*

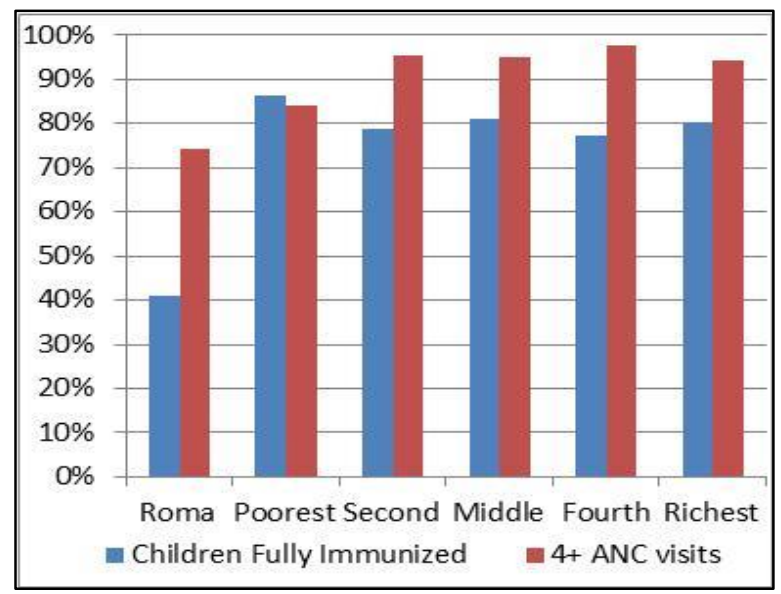

Source: MICS 2014

Note :* Percentage of children age 24-35 months who received all recommended vaccinations; $\%$ expectant mothers with 4 or more antenatal visits, by income quintile.
Figure V.8: Unmet Medical Needs and Insurance Coverage, by Income Quintile $\%$ of household

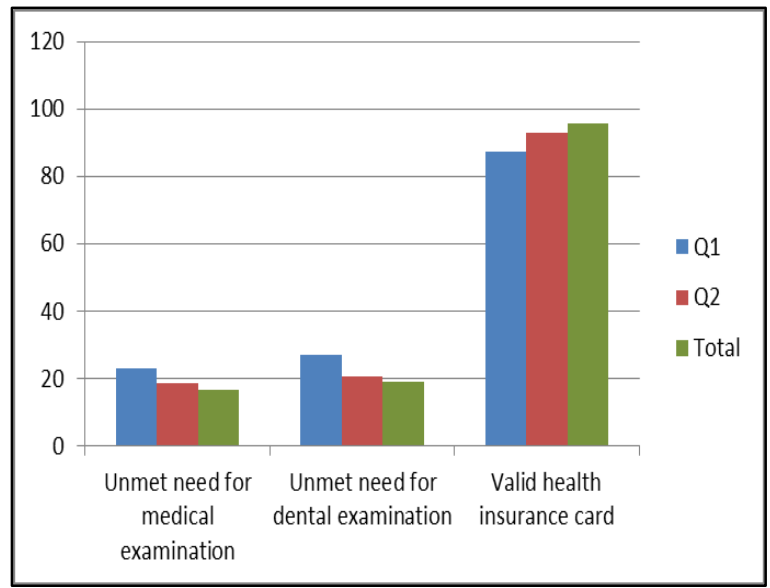

Source: Based on Statistical Office of Republic of Serbia's SILC data.

5.12. Non-communicable diseases pose a growing risk to health, productivity, and welfare. Because its population is aging, Serbia's disease burden is now weighted towards non-communicable diseases (NCDs) and external causes, such as injuries. The top three causes of premature death in 2010 were heart disease (19.9 percent), stroke (18.8 percent), and cancers (about 18 percent). In 2013, 54 percent of the population over 15 reported at least one $\mathrm{NCD}$, with the incidence increasing with age, and with higher rates among women (59 percent). Compared to 2000 and 2006, the incidence of hypertension, depression, diabetes, high cholesterol, and allergies is increasing (Figures V.9 and V.10).

Figure V.9: Self-reported Adult Hypertension by Income Quintile

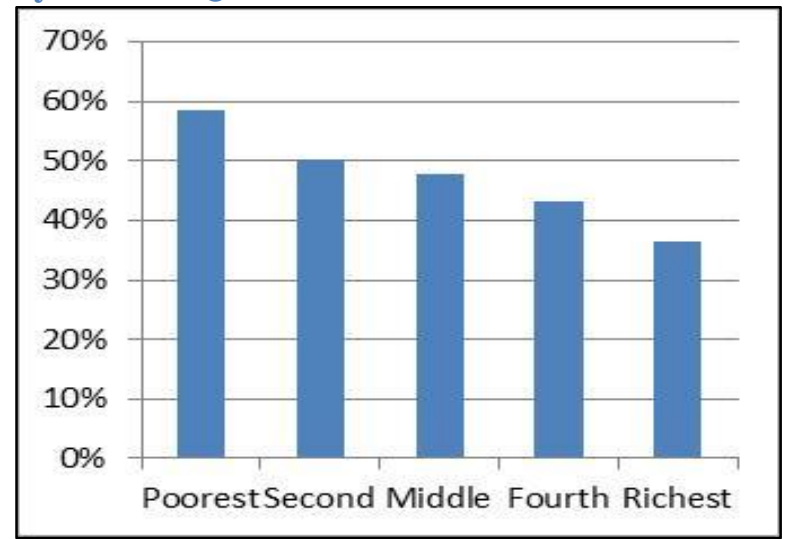

Source: National Institute of Public Health, National Health Survey 2013. Note: $\%$ of adults over age 15 with hypertension and potential hypertension based on selfreporting.
Figure V.10: Non-communicable Disease Incidence, 2000-13

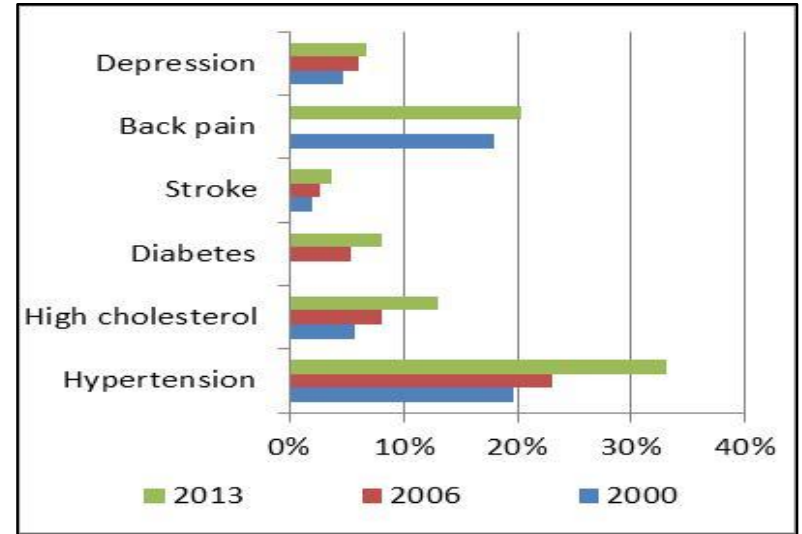

Source: National Health Surveys, 2000, 2006, 2013. Note: Depression includes chronic anxiety; stroke includes conditions related to stroke; hypertension based on measured blood pressure at time of survey. 
5.13. Chronic pain and mental health issues also compromise the quality of life and the productivity of Serbians. The 2013 National Health Survey identified 4 percent of the population who had symptoms of mild to severe depression, and 57 percent reported experiencing stress (up from 43 percent in 2006). Pain significantly impaired daily activities for 10 percent of the adult population. Premature mortality and morbidity reduce productivity, particularly for older workers, although the short-term impact on growth is likely mitigated by early retirement and high unemployment among older workers. Improved prevention and treatment of NCDs and mental illness should be a critical component of a medium- to longterm growth strategy, particularly since growth and the sustainability of the pension system will require keeping workers healthy and productive for longer.

\subsection{The formal health insurance system provides reasonably good financial protection, but with} gaps in coverage for vulnerable groups. Although 94 percent of the population has health insurance coverage, lower-income groups tend to have slightly higher unmet medical needs and lower insurance coverage (Figure V.8). Health insurance has helped reduce the burden of out-of-pocket spending for the poor. The wealthiest quintile spent 23 times more per capita on health than the poor and were more likely to incur "catastrophic expenditures," spending more than 25 percent or 40 percent of nonfood expenditure on health (HBS 2010). However, the poor are more likely to forego care: among the poorest quintile, 11 percent reported that they had not been able to access health services in the past year for financial reasons, compared to 1.5 percent of the richest quintile. In 2010, about 4 percent of poor households spent more than a quarter of non-food expenditures on health. With everything else unchanged, health spending pushed about 1 percent of near-poor households below the poverty line. This level of "impoverishment" due to health spending is higher than the EU average but comparable to EU new member states. Out-of- pocket health expenditures are a burden for the elderly, self-employed, and unemployed. Retirees-particularly single retirees, who are disproportionately women - face by far the highest rates of catastrophic expenditure due to worse health and the copayment costs for medicines, even though insurance coverage for pensioners is almost universal. The self-employed and unemployed face the next highest burden due to gaps in their insurance coverage.

5.15. Inefficient health spending, the poor quality of primary care, service rationing, and corruption make it harder to improve the health of disadvantaged groups and address NCDs. In 2013, one-third of adults surveyed were confirmed as having high blood pressure, but only a third of those hypertensive adults had been diagnosed by a physician (NHS 2013). Inefficiencies in health spending and the growing gap between the health benefit package and the resources available have contributed to explicit and implicit rationing of services and waiting lists. They also create opportunities for corruption. In Serbia, bribes or "gifts" often are solicited in consideration for better quality care (including for deliveries) or to reduce the waiting time for medical tests or surgery, which significantly compromises the quality and equity of health services. ${ }^{56}$ Serbia spends almost twice as much per capita than comparable countries to get similar health outcomes, and the costs for providing services vary significantly between primary care facilities and

\footnotetext{
${ }^{56}$ In June 2013, 11 percent of adults surveyed confirmed that they had given bribes of a gift or money in the past three months (a 3 percent decrease since December 2012), of which 48 percent went to doctors (up from 25 percent in December 2012). The average amount of bribes was $€ 250$, with a third of respondents stating that the bribe had put a significant strain on the household budget. In June 2013, 41 percent of respondents stated there is 'very much' corruption (up from 37 percent in 2012), 27 percent said there is 'a lot,' and 25 percent stated there is 'a little." Few thought bribes were necessary for primary care visits ( 8 percent), but a quarter thought they were needed to see a specialist or get admitted to a hospital (CeSID and UNDP 2013).
} 
hospitals, underscoring the need to make health care more efficient. Among reform options to be assessed are output-based financing, enhanced facility autonomy and accountability, increased share of medical staff in total health care staff, further reforms of pharmaceutical spending, and capital investment and maintenance of equipment and capital stock.

\section{Social Protection}

5.16. The B40 rely heavily on public transfers and are vulnerable to falling back into poverty during economic downturns as well as due to weather-related shocks. The sensitivity of poverty rates in recent periods in Serbia suggests there is a substantial vulnerable population slightly above the poverty line. Sustained progress toward the country's goals thus depends on institutions to protect the poor and vulnerable. A strong social protection system is important to support resilience and protect against shocks, promote equity, and broaden opportunities to build rather than erode critical human capital.

5.17. While the targeting of social safety nets in Serbia to the poorest quintile is respectable, coverage of the poor receiving assistance is small, and the last-resort social assistance program is not generous. Serbia spent about 2 percent of GDP on social assistance in 2009 (more than 15 percent of GDP on all social protection), in line with the ECA regional average. The share of the population receiving social assistance benefits was 10.6 percent in 2008, significantly lower than in EU-CESEE countries, and coverage of the poorest quintile, however, is smaller than in many other ECA countries (Figure V.11) ${ }^{57}$ Serbia's lastresort means-tested social assistance program, Financial Social Assistance (FSA), is relatively small in size, coverage, and generosity. Expenditures on the FSA represent about 0.25 percent of the country's GDP. The FSA program is very well targeted to the poor, with 75 percent of the benefit going to the poorest quintile and another 10.7 percent going to the second poorest quintile. However, the FSA covers only 5.7 percent of the population in the poorest quintile. The average transfer per person under the program is about 20 percent of the minimum wage, and the value of the FSA represents 19.6 percent of the pre-transfer consumption of the population in the poorest quintile. The FSA design contains certain built-in work disincentives, stemming from the means test and benefit formula. Although these work disincentives might not prevent beneficiaries to work in the informal sector, they are likely to represent a major barrier for formal employment. Efforts to expand targeted social assistance need also to go hand-in-hand with improvement of the benefit design to incentivize transition to formal work.

${ }^{57}$ World Bank 2011. "Social Safety Nets in the Western Balkans: Design, Implementation and Performance.” 
Figure V.11: Social Assistance Coverage of the Poor, Percent

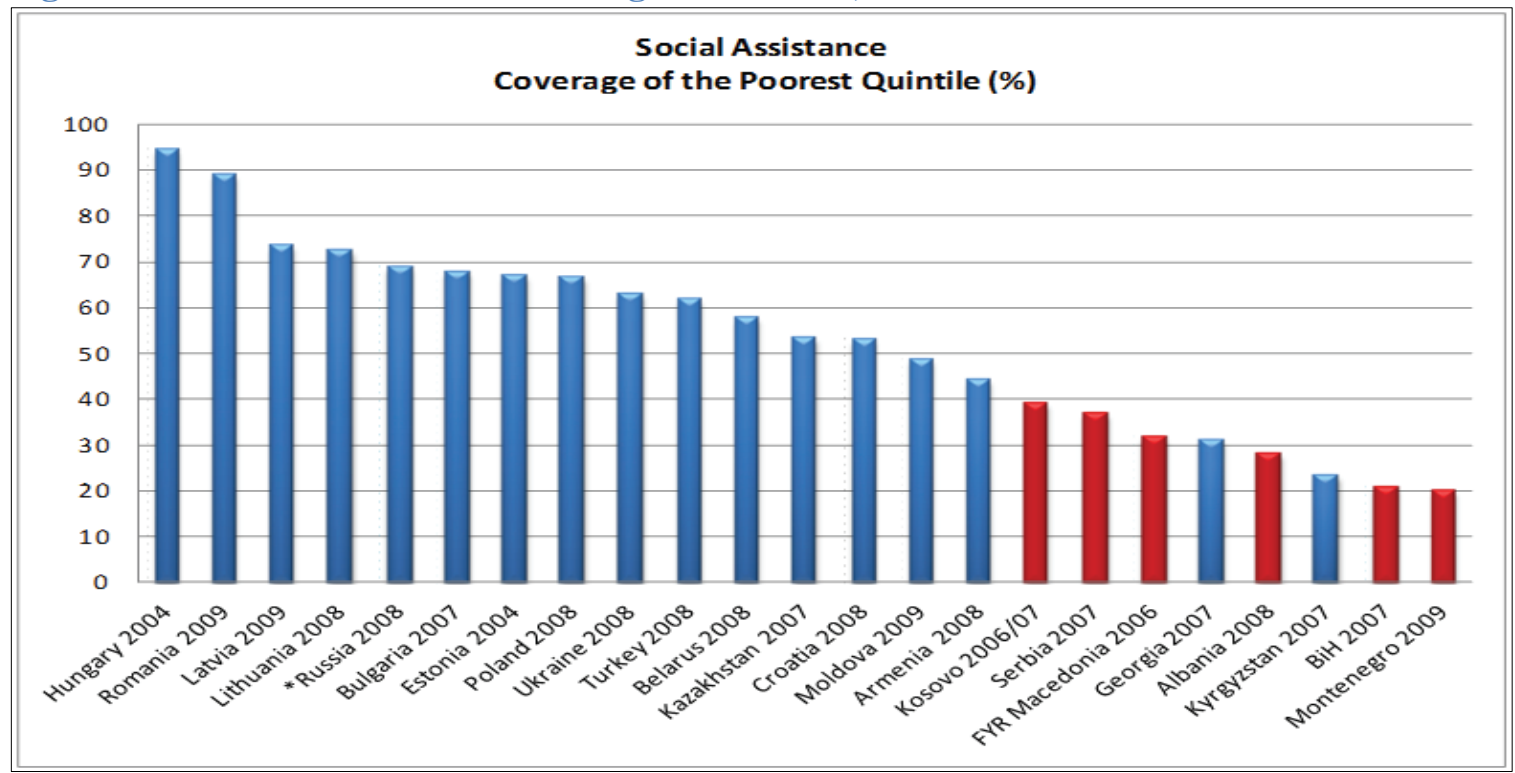

Source: World Bank 2011. "Social Safety Nets in the Western Balkans: Design, Implementation and Performance."

5.18. Improving coverage, generosity, and appropriate activation elements would allow Serbian social safety nets to better protect the poor and vulnerable and help to link them to formal jobs. The government has been making efforts to improve coverage of the poor by social assistance while retaining good targeting. Serbia has a management information system for administering social benefits, which could facilitate expansion of the currently well-targeted assistance programs, but it is not linked to other databases, such as employment services. The recent social protection law introduced incentives for activation for ableto-work beneficiaries (requirement to register with the NES and search for jobs), but few FSA recipients participate in ALMPs. The biggest shares are in training programs (4.16 percent), career guidance and counseling ( 2.66 percent), and public works ( 2.63 percent). Closer linkages between employment services and social welfare - through such positive incentives as income disregards and in-work benefits-would help protect vulnerable populations while minimizing their dependence on transfers and connecting them to productive income-generating opportunities.

5.19. Today pension programs provide reasonably generous protection for the elderly, but in the future, both the adequacy of benefits to prevent old age poverty and the coverage of the elderly are expected to fall short. As noted above in Box III.1 (and para. 4.19), the current pension system in Serbia provides generous benefits relative to the average wage in Serbia and covers the majority of the elderly. However, moving forward, the benefit levels, as legislated, are expected to drop dramatically, with future pensioners receiving as little as $30 \%$ of average wage in 2025 , from today's levels of between 60 and $70 \%$ of average wage. And benefit levels will continue to drop, leaving open the question of whether the benefits will be adequate to prevent poverty. Furthermore, as few as 55\% of the population aged 35-39, prime labor force ages, are currently contributing to the pension system, compared to close to $90 \%$ of that cohort in much of Western Europe, suggesting that almost half of the future elderly have not contributed to the pension system and will not have access to pension benefits when they retire. Given that the social assistance system is already having difficulty covering the poor, it is likely to be further strained when a 
substantial percentage of the increasing number of elderly have to rely solely on social assistance for survival.

\section{Opportunities for Sustained Income Generation}

5.20. Sustainable poverty reduction and shared prosperity require opportunities for less well-off populations to earn income as workers, entrepreneurs, and farmers. Yet accessing gainful employment has been difficult, and will be exacerbated by the short-run impacts of redundant workers as SOEs are reformed. Analyzing the recent dynamics and disparities - as well as the reasons for these-in Serbia's labor market and the constraints to entrepreneurship and agriculture is important for understanding factors that influence household income opportunities and rural welfare.

\section{The Labor Market}

5.21. Serbia's labor market has been in a difficult situation for several decades, with a large inactive population and high unemployment. Labor market trends (Figure V.12) reflect the country's incomplete transition to a modern market economy. During the first phase of major reforms, Serbia's labor market outcomes followed a typical transition pattern: between 2000 and 2006 activity rates came down from 57 percent to 51 percent, and employment rates dropped from 50 percent to 40 percent. Net job creation from 2002 through 2006 was negative, largely due to restructuring, leading to high unemployment and falling activity rates as many retrenched workers could not find jobs and dropped out from the labor force. The impact on employment of the reforms that Serbia embarked on in the early 2000s took a few years to set in. A reversal in the trend seems to have begun in 2006 but was soon halted by the financial crisis. Activity and employment rates hit bottom in 2012, when unemployment peaked at 24 percent. Between 2008 and today, employment in agriculture has contracted the most, followed by the wholesale sector, manufacturing, and construction, while employment in education, ICT, and professional activities has expanded (figure V.13). The slight recovery in the last two years has been in mixed types of jobs: employment to produce goods for own consumption has increased most, followed by employment in ICT, public administration, agriculture, and professional and scientific activities. In Q2 of 2014, the activity rate stood at 50 percent, the employment rate at 40 percent, and unemployment at 20 percent. For an aging society like Serbia with a rising old-age dependency ratio, it is all the more crucial to increase participation, tap the full potential of its labor force, and leverage the productive economic participation of all groups. 
Figure V.12: Serbia's Labor Market Indicators

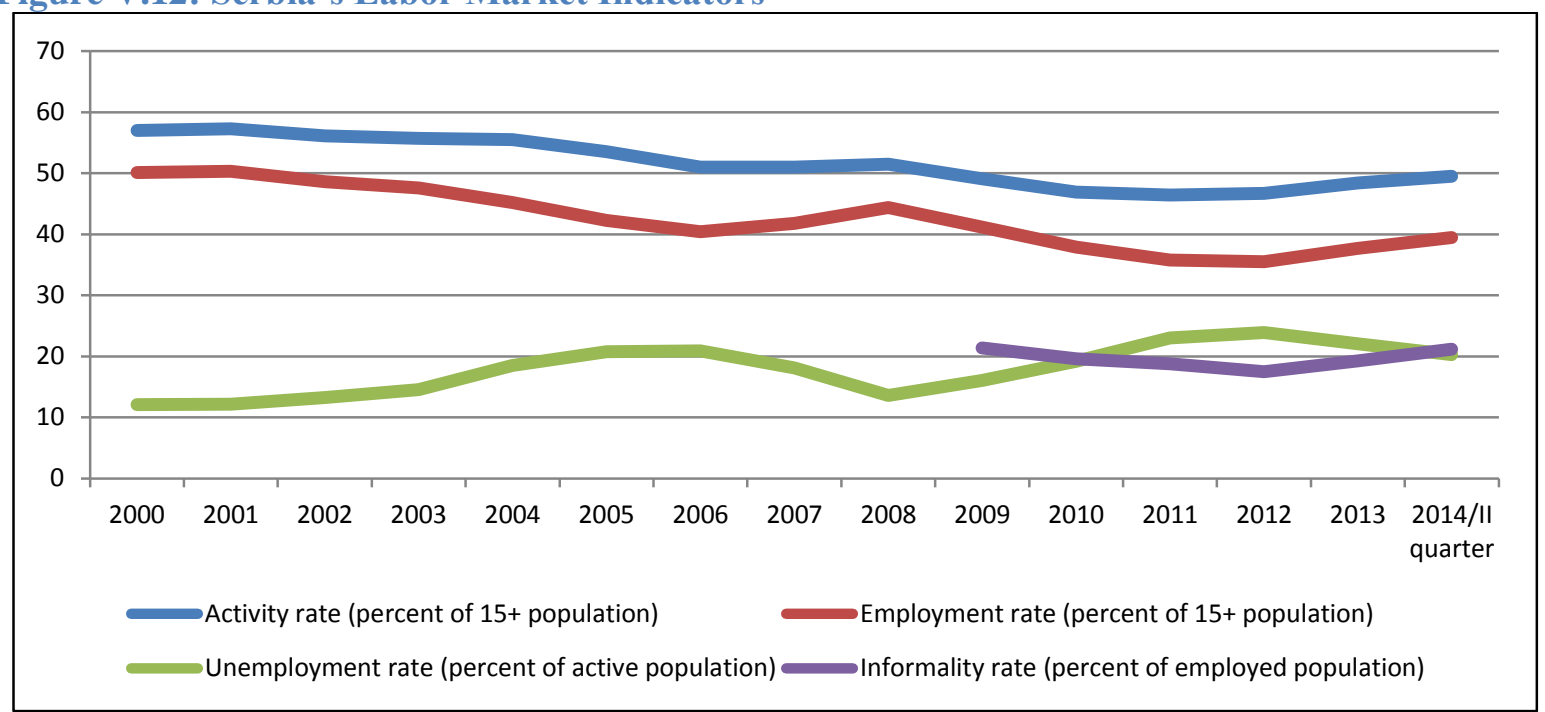

Source: SORS, on-line database.

Figure V.13: Net Employment Losses by Sector, 2008-14

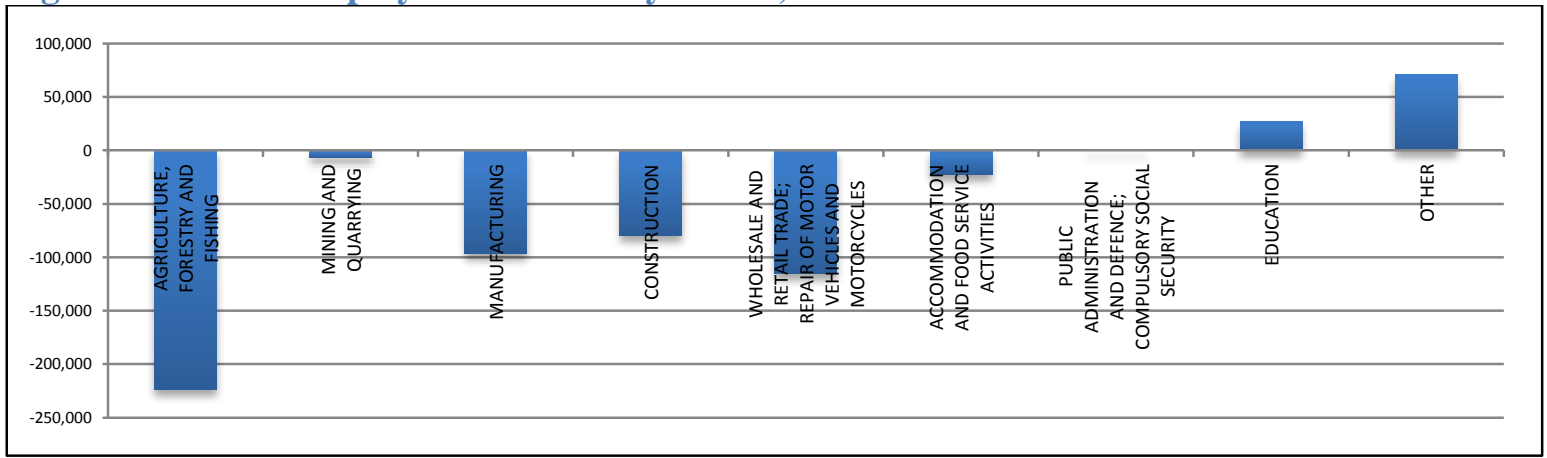

Source: Statistical Office of the Republic of Serbia, on-line database.

5.22. The formal employment rate in Serbia is low. Currently, about 21 percent of all jobs in Serbia are informal. ${ }^{58}$ Combined with the low employment rate, this means that in 2013, a mere 1.8 million people-700,000 of whom worked in the public sector-worked in the formal private economy. ${ }^{59}$ The private sector is not generating many formal jobs, and public employment is still abundant, accounting for more than one-third of formal employment. Even among the 1.1 million formal private jobs, a large portion - more than 200,000 - are sole proprietors. Part-time employment is more dominant in the informal sector - 30 to 40 percent, compared to 3 to 4 percent of part-time jobs in the formal sector-and is particularly high among women. Adjustments in employment due to changing economic conditions are mainly made on the informal sector, which contracts during recession and expands during booms (see figure V.14). Just as activity and employment rates picked up after 2012, so did informality, increasing from 17.5 percent in 2012 to 21.2 percent in 2014. It appears that Serbian employers see informal employment as the margin where employment can be adjusted: informal workers are the first to be laid off in bad times and the first to be hired in good times.

\footnotetext{
${ }^{58}$ Informality refers to (a) all employers, self-employed, and own-account workers of nonregistered enterprises; (b) unpaid family workers; and (c) all employees without written labor contracts.

${ }^{59}$ Based on calculations from the 2013 LFS.
} 
5.23. Net job creation recently has mostly been in the informal sector, particular in part-time work. Between October 2012 and the third quarter of 2014 the Serbian economy created about 176,000 jobs (Figure V.14). Although the number of formal full-time jobs actually decreased by about 18,000, informal full-time jobs expanded by about 65,000. Interestingly, the loss of formal full-time jobs was almost entirely borne by the transition generation of those aged 40 and older, while the younger generation actually experienced a slight expansion of formal full-time jobs, suggesting a substitution of older with younger workers in this important labor market segment. Overall, there was a clear trend towards irregular employment, either formal part-time or entirely informal. The largest number of jobs created, about 79,000, was part-time and informal, especially in agriculture, but also in construction and services. These are certainly not the best jobs, but a shift in policy to acknowledge this source of job creation - and an effort to bring them into the formal sector-is likely to improve their impact on household welfare.

Figure V.14: Structure of Net Job Creation, by Type and Age of Worker, 10/2012-9/2014

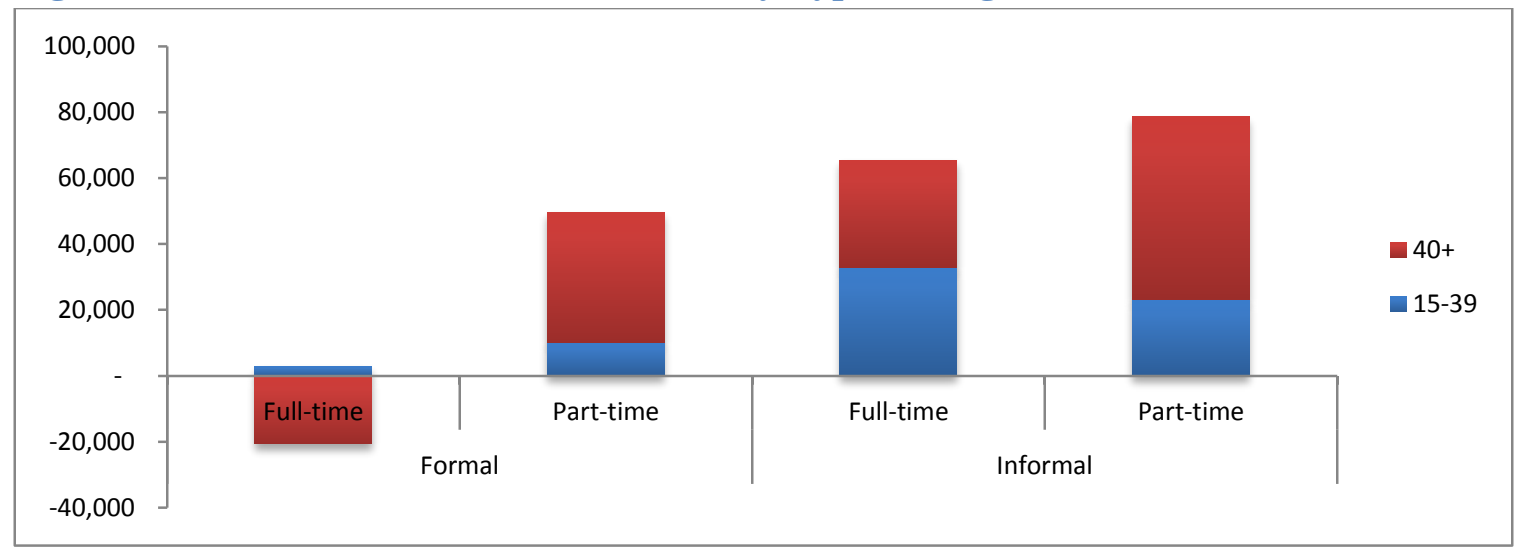

Source: SORS, labor force surveys (LFS) 2012 to 2014.

5.24. Young firms and small firms in Serbia have higher rates of employment growth, but since they start with fewer employees, their contribution to total job creation in the past three years trails that of large firms. The 2013 BEEPs collected self-reported firm data on net employment changes over 2010-13. Large and old firms still create most jobs (Figure V.15), but smaller and younger firms have higher rates of employment growth, in ECA in general and in Serbia specifically. Regression analysis found that, due to their low base, small-firm employment has grown at a higher rate over the period than larger firms after controlling for such factors as age, location, sector, and export status. The distinction between exporters and non-exporters in terms of employment growth and jobs created is relatively small. By sector, firms in manufacturing and retail and in wholesale trade reported the most jobs created. 
Figure V.15: Contribution to Job Creation by Firm Size and Age



Source: BEEPs 2013.

5.25. The spatial and socioeconomic disparities in labor market outcomes also limit the extent of inclusive welfare gains for Serbia's less well-off. As discussed earlier, the B40 have higher unemployment and self-employment rates than the rest of the population. Those that receive (mostly formal) salaries close to the minimum wage are also primarily employed in micro enterprises and in the service sector. Of those in the labor force, 29 percent in thinly populated rural areas are self-employed and 39.1 percent are in wage employment (2012 SILC data); in densely populated urban areas, 9.1 percent are self-employed and 61.5 percent in wage employment. Those at the bottom of the earning distribution also tend to be in the informal sector. In the SILC 2012 data, the average wage of the top quintile is 3.5 times that of the bottom quintile, and wages of the 90th percentile are 4 times those of the 10th percentile. As expected, wages are highest in Belgrade and are higher for professionals and senior officials and managers than for service workers and those in basic occupations.

5.26. For a number of reasons women in Serbia have less access to economic opportunities than men. The gender gap is estimated to result in a 16 percent loss in income per capita (Cuberes and Teignier, 2014). ${ }^{60}$ The female employment rate of 34 percent in Serbia trails that of men in Serbia by 13 percentage points and that of women in ECA and upper-middle-income countries by 19 percentage points - a pattern that was true even under the former Yugoslavia. In low-skill occupations, women earn at least 20 percent less than men. For those in the middle, the average hourly wage gap of 5 percent is highest for those with less than 10 years' experience (7.3 percent for 6-10 years). Gender wage gaps are minimal for higher-paid and more-educated women. While those working for the public sector do not experience significant wage gaps, in the private sector women earn 9 percent less than men. As in many other countries, gender differences in time use, limited child care enrollment, and skills profiles constrain women's ability to work

\footnotetext{
${ }^{60}$ The paper uses a general equilibrium occupational choice model where agents are endowed with a random entrepreneurship skill, based on which they decide to work as either employers, self-employed, or workers. The model assumes an underlying distribution of entrepreneurial talent in the population and studies the resulting allocation of productive factors across entrepreneurs as well as the size distribution of firms. The model also incorporates the exclusion of women from the work force, both as entrepreneurs and employees.
} 
and heighten employment segregation. Serbian women spend 2.5 times more hours a day on domestic work than men, even if they are employed. Labor force participation rates drop for women in childbearing years, and only 13 percent of Serbian children under the age of 3 were enrolled in child care centers in 2010 and 2011 (UNECE 2010). This situation is even worse among the Roma, where there is general agreement that a man should earn and a woman should look after the children and the household (World Bank 2010). Qualitative studies in Serbia have also found that the most common discrimination is related to a woman's right to be absent from work during pregnancy and maternity leave. It often happens that after returning from maternity leave, a woman is dismissed, and when they look for employment, women are often asked whether they plan to have a family (World Bank 2010). As in countries across the region, women and men also have different specializations in university, which contributes to the segregation seen in the labor market and the differences in labor market outcomes. Women constitute 89 percent of graduates in education, 75 percent in health, and 74 percent in humanities and the arts. However, they make up only 35 percent of graduates in engineering, manufacturing, and construction (GenderStats 2011).

\subsection{The Roma population faces poorer labor market outcomes and relies more on non-labor} income. The World Bank/UNDP/EC survey found lower activity and employment rates and higher unemployment and informality rates: about 49 percent of Roma are unemployed, compared to 27 percent among non-Roma living in the same neighborhoods (Figure V.16). Employment rates are only 13 percent for Roma women (2011), less than half of the rate for non-Roma women and a third of the rate for Roma men. Earnings from work represent only 38 percent of Roma household monthly income while in general close to 60 percent of total income comes from wages and self-employment. These differences may be partly explained by the very large education gap between Roma and non-Roma, especially among women, by their poor housing and living conditions, and other socio-economic characteristics. Box V.1 elaborates on the factors affecting social exclusion of the Roma and other groups and suggests a much-needed comprehensive approach for inclusion.

\subsection{Roma inclusion is not only a moral imperative but also smart economics for Serbia. According} to a World Bank estimate based on 2007 data, assuming an equal number of working-age Roma men and women and that average wages remain unchanged, equalizing labor market earnings in Serbia for Roma could result in potential economic benefits ranging from $€ 252$ million to $€ 1$ billion annually, and fiscal benefits ranging from $€ 62$ million to $€ 257$ million annually. ${ }^{61}$ These results illustrate the economic potential of closing the very large ethnic gap in labor market outcomes. Equalizing labor market opportunities could help counter the growth and fiscal implications of Serbia's aging population.

${ }^{61}$ World Bank, Roma Inclusion: An Economic Opportunity for Bulgaria, Czech Republic, Romania and Serbia (Washington, DC: World Bank, 2010). 
Figure V.16: Roma Employment Patterns

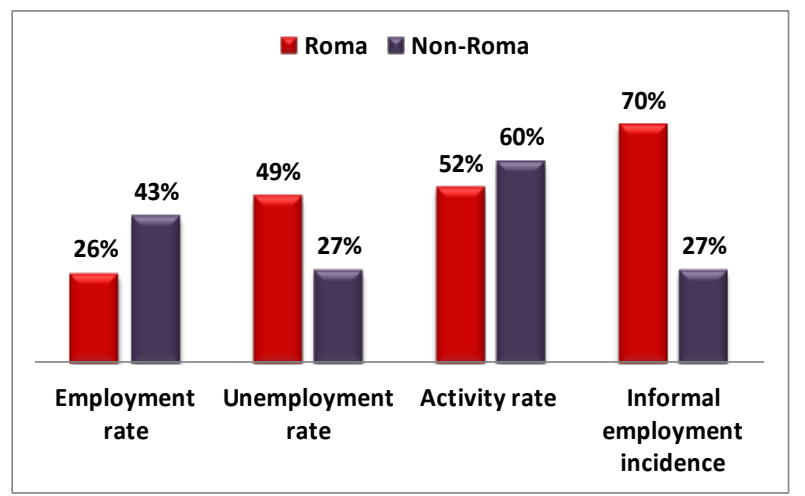

Source: UNDP/WB/EC Roma survey in Serbia.
Figure V.17: Employment Rates by Age, Percent

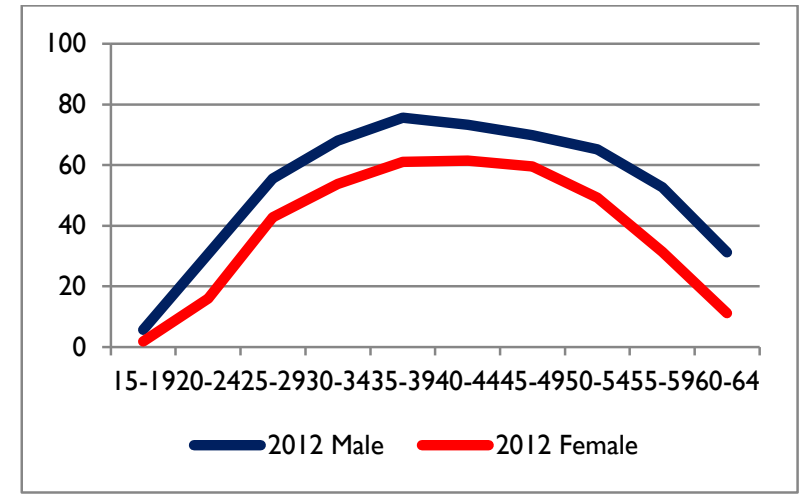

Source: World Bank Staff, based on Serbia LFS 2012.

\section{Box V.I: Policy Priorities for Roma Inclusion in Serbia}

Roma are one of the most vulnerable groups in Serbia. They include long-established residents, refugees or internally displaced persons from recent conflicts, returnees from Western countries, and seasonal workers. As in other countries in the region, Roma have been subjected to systematic discrimination and marginalization, with restrictions on birth registration, citizenship rights, and movement that limit livelihood opportunities and prevent social, political, and economic integration. In Serbia, the Roma population is poorer and faces multiple inter-related disadvantages in accessing basic opportunities in education, health, living conditions, and labor market opportunities. The government is taking steps to improve Roma well-being, including adoption (in 2013) of the Action Plan for 2012-14 for the Implementation of the Strategy for Advancing the Status of the Roma in the Republic of Serbia. Preparation of the baseline study for drafting the 2015-20 Strategy is underway. The following are key policy priorities for Roma inclusion:

\section{Anti-discrimination:}

- Serbia's anti-discrimination legislation is generally in line with international standards on combating racism and discrimination, however measures to ensure its full implementation are lacking. Special implementation effort is needed to reduce discrimination against Roma, as well as women, sexual minorities, and people with disabilities.

\section{Social protection and health care:}

- Ensure that the undocumented members of the Roma population achieve assistance in obtaining identification cards and thereby are able to claim health care and social protection services;

- Increase responsiveness of the health care system to the specific needs of vulnerable Roma communities, especially those living in remote settlements, including through introduction of mobile clinics, scaling up of the Roma health mediator program, and sensitizing the medical staff to specific health needs of Roma communities.

\section{Local government, citizen engagement \& social accountability}

- Provide targeted budgetary allocations at national and local levels for the inclusion of Roma, with participation of relevant stakeholders in defining priorities and monitoring implementation.

- Support local governments to develop strategies and monitor their efforts for improving the living conditions of Roma in their territories, including upgrading of Roma housing, identifying locations for social housing, implementation of the improvements to infrastructure in Roma settlements (e.g., roads, water supply, sewage and electricity) and enhanced connectivity to municipalities' social service networks.

\section{Housing/Land}

- Conduct mapping of settlements, housing and infrastructure conditions in informal settlements for their legalization. 
- Revise national regulations for resettlement of Roma communities to align with international standards for involuntary resettlement. At a minimum, timely consultation with affected communities, provision of alternative accommodation in proximity to jobs, and protection of property/objects of specific significance to the affected communities.

- Publish and disseminate guidelines on the legal framework related to legalization and provide legal support for those citizens that express interest to submit a legalization request.

- Allocate state funds for Roma housing to improve living conditions of Roma settlements.

Education

- Expand quality and coverage of ECD programs for Roma and other vulnerable groups, including ensuring both geographic and financial access.

- Develop early identification and drop-out prevention mechanisms for high-risk primary and secondary school pupils.

Labor market \& employment

- Support employment of Roma in public institutions, including setting and monitoring clearly defined minority employment targets.

- Strengthen capacity of National Employment Services to provide support to Roma job seekers, adapted to their specific employment needs.

Source: World Bank, Roma Inclusion: An Economic Opportunity for Bulgaria, Czech Republic, Romania and Serbia (Washington, DC: World Bank, 2010).

5.29. Employment for both the pre-transition generation of older workers and for youth is necessary, though difficult, to ensure an inclusive labor market and mitigate the social impacts of SOE reforms. Employment rates in Serbia currently peak at age 35 (Figure V.17), in stark contrast to other European countries, where peaks are at much older ages. The generation aged 40 and older received its education and first jobs before or during the transition, with possible long-lasting scarring effects. Their education and skills might be obsolete in terms of current labor market demand; and when they entered the labor market, the economy was dominated by the public sector. LFS data reveals a high share of inactive and long-term unemployed among those 45 and older, and even today many who are active still work in the public sector, including in SOEs. The employment rates in Serbia also drop quickly at older ages due to pension system incentives for shorter careers; even though as mentioned above the recent Pensions Law introduced some actuarial penalties for early retirement, many potential early retirees were exempted. The younger generation has significantly more education and may be in a better position than older workers to compete in modern sectors when Serbia can reinvigorate growth and private sector led job creation. Yet at the moment the youth unemployment rate, close to 50 percent, is twice that for Serbians of working age generally. About 22 percent of young people are neither in employment nor in training or education, among the highest youth NEET (Not in Education, Employment or Training) rates in the world, which means that Serbia runs the risk of another lost generation of workers.

\section{Improving Labor Market Outcomes}

5.30. Numerous factors account for Serbia's stagnant labor market outcomes, which are even worse for disadvantaged groups. During the first phase of major reforms in the early 2000 s, Serbia's labor market outcomes followed a typical transition pattern of initially declining employment. 
1. On the demand side, more recently slow or even negative growth and limited private sector job creation naturally reduced income-generating opportunities in the labor market. An incomplete transition, the large role of the state, and protected high public wages in Serbia crowd out efficient factor allocation, limit private sector jobs, perpetuate informal employment, and even discourage job seekers and push them into inactivity. The recent regional study on jobs (AriasDias \& Sanchez 2014) shows that advanced ECA reformer countries have better labor market outcomes than those whose economic transition has been slower (Arias Diaz, Omar S.; Sanchez, Carolina, 2014). Low growth and limited private sector job creation contributed to low labor force participation overall as well as that of women and Roma.

2. On the supply side, as discussed earlier, Serbia's key human development indicators are generally good, although there is evidence of issues with quality and the types of skills the education and TVET systems produce. Disparities in labor market outcomes are in part related to low human capital among disadvantaged groups. Lower education often translates into lower earnings: wage regressions using the SILC 2012 data show statistically significant returns to education starting with upper secondary school and becoming particularly high for tertiary education. Tackling the low labor force participation of women and Roma would require paying attention to the specific barriers they face.

3. Weak labor institutions also make it difficult to match labor and jobs efficiently. Serbia's labor regulations used to have restrictions on part-time work until the recent 2014 reform to allow for more flexible forms of work. However, a number of other constraints-ranging from poor public employment services to a high tax wedge for labor at low earnings to work disincentives in social welfare-persist and are discussed below.

5.31. The need to re-embark on the difficult path to privatization in Serbia adds urgency to addressing the sluggish labor market with social mitigation measures and a modern, proactive social protection and labor system to help support the difficult transitions ahead. The lack of productivity in the SOEs is of overwhelming importance for the Serbian economy and for the sustainability of public finances, as analyzed above. The labor market as is could not absorb a further inflow into unemployment of 30,000 to 50,000 workers from SOEs, most of them older and unskilled. If redundant workers, especially those over 40, find work at all, it is most likely to be informal, low-skilled, low-paid, casual, and part-time. Hence, many more people might become unemployed and eventually discouraged from looking for work at all. The challenge for Serbia's government is to manage the social impact of SOE reform by providing adequate financial compensation for redundant workers in the short run and ensuring that a modern social protection and labor system can mitigate impacts in the long run. In terms of severance payment, the government has recently embarked on reforms to ensure adequacy, equity between the private and the public sector, and fiscal sustainability. Among the three options for financial compensation for redundant workers from SOEs, Option 1 pays $€ 200$ per year of service, ensuring adequate compensation especially for low-wage earners with long work histories. Option 2 pays severance payment as would be paid to private sector employees under the regulations of the labor code, with subsequent access to unemployment benefits. This package is most likely to link redundant workers best to the services provided by the National 
Employment Service (NES) ${ }^{62}$ Experiences from previous privatization efforts show that in the long-run workers need not only cash in the form of severance pay but also employment services.

\subsection{In tackling these employment challenges, private sector-led creation of more jobs is clearly} important. Earnings opportunities for less well-off Serbians will hinge upon the economy's capacity to grow and demand labor from the population across the board. Completing the first-generation reforms of a post-transition economy and tackling governance, macroeconomic, and business climate issues, as already discussed at length should help Serbia to boost productivity, private investment, and external competitiveness. In the process, industry - including significant labor-intensive production-is likely to pick up and also contribute to growth and labor demand. Increasing labor productivity, which is currently much lower than in manufacturing in the new EU member states (see Chapter III), would typically translate into higher real wages and earnings for workers. Taking advantage of Serbia's prospects of accessing EU markets (for example, with manufacturing exports and agriculture and food products where Serbia has comparative advantages) should help to generate broad-based employment opportunities not only in the export sectors directly but also down the value chain.

\subsection{Aside from addressing constraints to broad-based growth and private-sector-led job creation, improving the functioning and inclusiveness of the labor market is necessary so that more Serbians} can access sustained income-generating opportunities. If the current demand is mostly for informal parttime jobs - which are also the best chances of employment for the B40, in particular for older workers of the transition generation and other excluded groups - getting these informal jobs to be done formally will require reform of Serbia's labor taxation. Germany's experience with its labor reforms in the early 2000s shows that the right flexible work contract arrangements and tax and benefit system can help create these "mini" and "midi" jobs. Yet Serbia is the only country in the region that still has a social security floor that is not adjusted by actual hours worked. This design makes any low-paying, part-time work completely unviable in the formal sector: if anyone working just a few hours a week has to pay as much social security as someone working full-time, no one will do the job formally. The tax wedge at lower wage levels in Serbia, 36.7 percent, is one of highest compared to OECD and neighboring countries. Reforming the minimum social security contribution would at least adjust it by actual hours worked (as currently done in FYR Macedonia), but a further study to identify a fiscally sustainable reform would be useful. As experience has shown, most recently in FYR Macedonia, considerably decreasing the minimum social security contribution has not caused revenue losses. The biggest concern could be that firms and workers start misreporting full-time work as part-time after the reform. Strengthening inspection services and tax audits, in particular for firms that report many part- time workers, could mitigate this concern.

5.34. Labor market institutions need to be built up. At the moment, more than half of the registered unemployed are not actually looking for work, leading to unsustainable high ratios of cases per case worker at the NES and keeping the agency from doing a proper job. In Serbia, the caseload is currently between 400 and 900; in more advanced European countries it does not exceed 80. Creating a list of active job seekers, removing incentives to register as unemployed, and increasing administrative capacity would help the NES reduce caseload. The NES currently offers a whole spectrum of ALMPs, which can be redesigned

\footnotetext{
${ }^{62}$ A third option pays a lump-sum payment to those with long work histories, but is irrelevant since almost all workers would receive higher payments under the other two options.
} 
to better connect job seekers to where the jobs are (including through relocation benefits), training for the young and older workers, and public works as a last resort. Better use of current data and gathering of new data to better monitor, evaluate, and research labor market conditions and programs in Serbia would also help improve the efficiency of public employment services. Lastly, better design of last-resort social assistance through in-work benefits would help overcome current disincentives for formal work in the form of losing social assistance benefits.

\section{Self-employment and Agriculture}

\subsection{Self-employment and agriculture also offer income-generating opportunities particularly for} the poor and less well-off in Serbia.

Figure II.11 shows that the B40 and those at risk of poverty derive more of their total income from selfemployment than the rest of the population, who gain more of their income from wage employment. Deficient access to financial capital (Figure V.18) and entrepreneurial skills may constrain self-employment and entrepreneurship, particularly for the less well-off. As discussed earlier, weak credit growth recently has hampered economic recovery, and the high rate of NPLs limits efficient

Figure V.18: Accounts at Financial Institutions by Income (Percent)

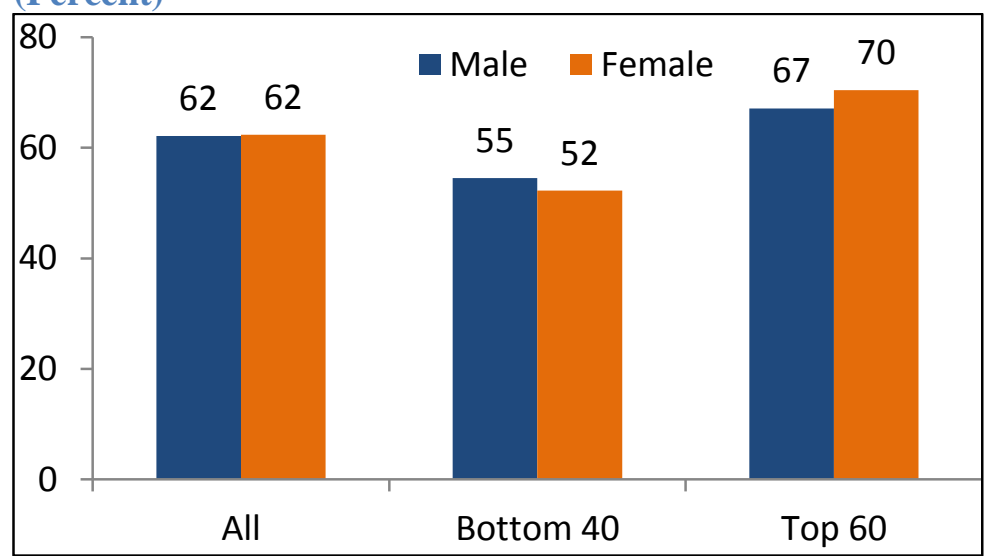

Source: Findex 2011. use of financial assets, as for entrepreneurial activities. Serbia's relatively high interest rate restricts access to credit for corporations and households, which is more of an issue for entrepreneurs and SMEs than for large enterprises. According to the 2013 BEEPS, most Serbian SMEs resort to internal sources, and the share using trade credit from suppliers rather than bank financing (which is most accessible to larger firms) has risen significantly in the last five years.

\subsection{Agriculture and rural development have been important for the employment and welfare} dynamics of the B40 and will probably continue to be, at least in the short term. Earlier analysis of poverty and shared prosperity trends in Serbia shows that they are sensitive to what happens to agriculture. According to the SILC 2012 data, 36 percent of the B40 and 46 percent of those at risk of poverty are employed mainly in agriculture and mining, dominating their presence in other sectors by a large margin (Figure V.19). In thinly populated areas 40.6 percent of employed individuals are in agriculture and mining, which in densely populated areas is true of only 1.7 percent (2012 SILC data). Off-farm employment opportunities are also important for rural welfare. As in most middle-income countries, income from agriculture is not the largest share of total household income: agriculture sales account for 11.9 percent of the total income of poor rural households and 13.9 percent of B40 households in rural areas - slightly less than half the share from nonfarm labor income (HBS 2010 data). The $2013 \mathrm{HBS}^{63}$ suggests that agriculture

\footnotetext{
${ }^{63}$ Available budget and individual consumption of households in the Republic of Serbia in 2013, Statistical Release No 077, Year LXIV, 31/03/2014, Statistical Office of the Republic of Serbia
} 
(sales and direct consumption combined) contributes 22.6 percent to total rural household income, compared to 2.3 percent for urban households. Geographically, (semi-) subsistence farmers are concentrated in the South, where poverty is also higher, with a smaller portion of income from the sale of food and a higher proportion in direct consumption. In Southern Serbia 79 percent of agricultural workers (full-time equivalent) are employed on holdings that yield below $€ 2,000$ in annual output but in Vojvodina in the North, over 75 percent of agricultural labor works on holdings yielding $€ 250,000$ or more. At least in the short term, agricultural growth, productivity, and income can therefore have a sizable impact on poverty reduction for those already employed. Over the long term, improved agricultural productivity holds the key to releasing labor from agriculture, improving rural-urban mobility of the poor, and facilitating structural transformation.

Figure V.19: Employment Breakdown by Sector, Percent



Source: Based on Statistical Office of Republic of Serbia's SILC data.

5.37. Land fragmentation, skewed incentives due to subsidies, and broad policy and institutions for agriculture support all affect agricultural productivity in Serbia. Both land productivity, especially fruit and vegetable crop yields, and labor productivity are below those of regional peers, such as the new member states, and EU countries generally (Figures V.20 and V.21). The older age profile of Serbian farmers makes them less amenable to technology adoption, land transactions for efficient reallocation, or mobility to non-farm activities. The average holder of a family farm is $59 ; 65$ percent of farmers are over 55 and 35 percent over 65. Land fragmentation and a desultory land market keep a large number of small farms producing many crops and livestock. Even though the number of medium to large farmers has risen in the last decade, workers on small family farms still constitute 96 percent of agricultural employment. The 2012 agricultural census recorded 628,552 family agricultural holdings and 3,000 agricultural enterprises, of which 386 are cooperatives. Farms smaller than 5 ha make up 78 percent of total farm holdings. Only 3.1 percent of farm households have more than 20 ha, but they represent 44 percent of total 
agricultural land utilization. While there are almost no restrictions on sale, purchase, or lease of agriculture land, transactions often take place unofficially without registration of transfer of rights, with no official records of the purchase and sale transactions or of land leases outside the formal records, to avoid the 20 percent lease tax paid by the landowner.

Figure V.20: Crop Yields, Serbia, FYR Macedonia, Turkey, and the EU (100 kg/ha, 2010-2012 average)

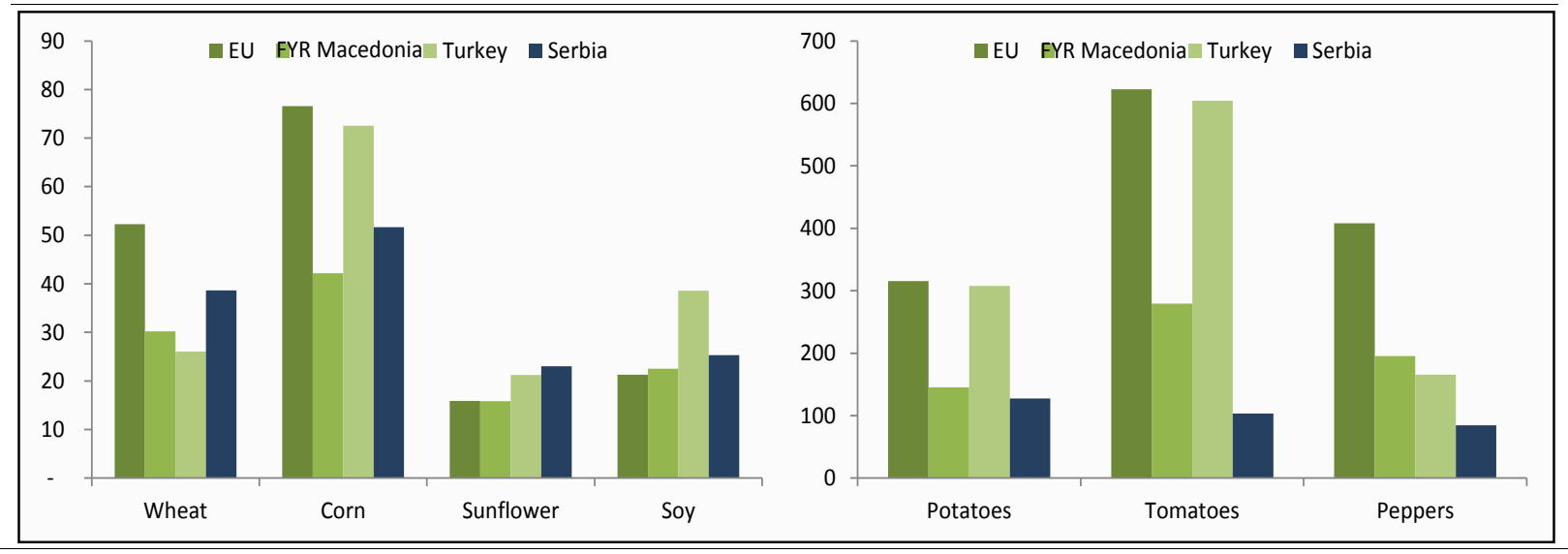

Source: Eurostat and Serbia National Office of Statistics.

Figure V.21: Agricultural Labor Productivity, Serbia and EU, 2004-12, €/person Employed,

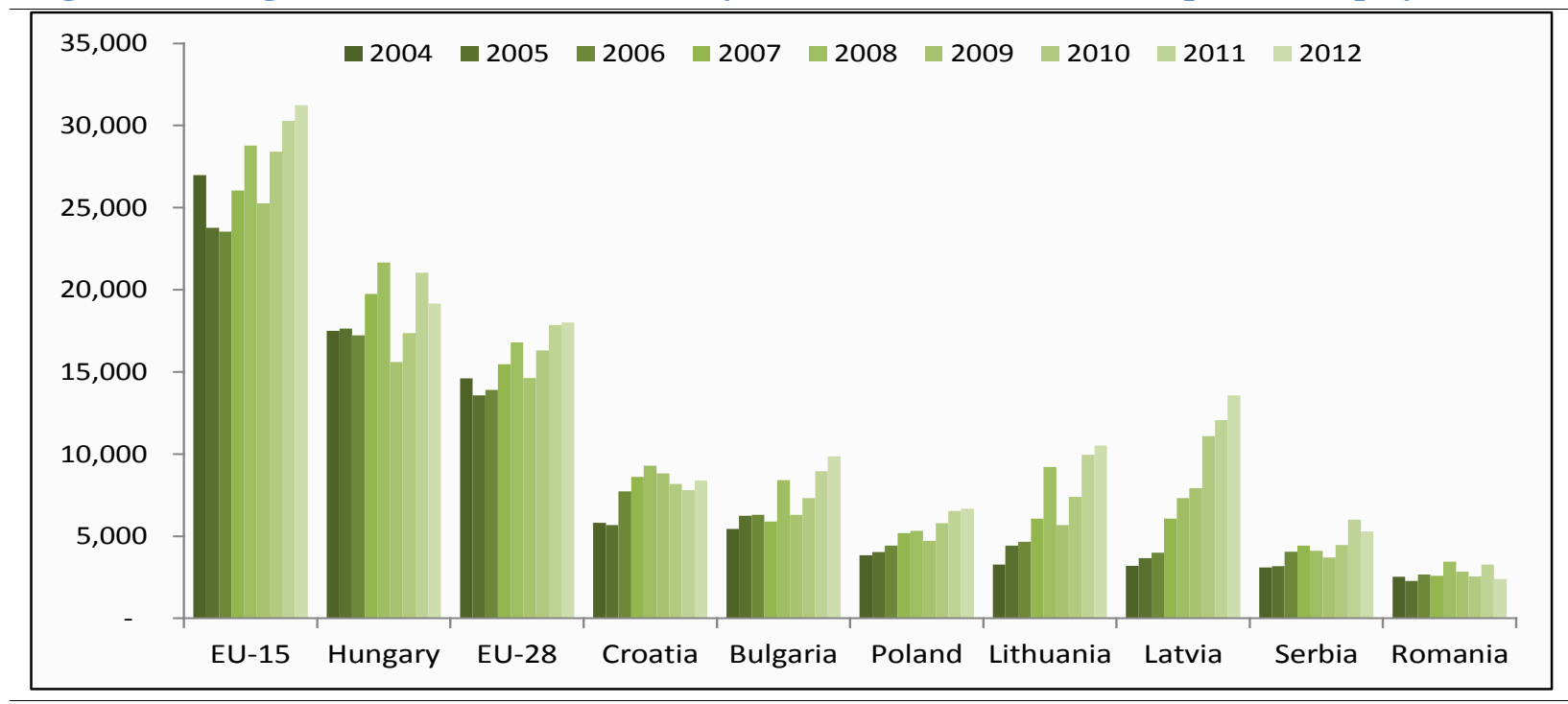

Source: Eurostat (Agriculture gross value added, NACE, and employment in agriculture, labor force survey).

\subsection{The design of area-based payments (subsidies related to land size) distorts efficient use of} land. Experience in western and central Europe shows that area payments inhibit farm restructuring. The current flat area payment program reduces incentives for farmers to increase productivity and heightens the likelihood that the transfer will be used to support household consumption rather than investment in the farm. With the subsidy, small and low-productivity farmers have less incentive to lease or sell their land to more progressive producers who have the ability and resources to increase productivity and compete in liberalized markets. Where feasible, eligibility for area payments should thus be conditional on farm-level 
initiatives to invest, improve product quality, or adopt sustainable environmental practices. Because landowners who lack the incentive to engage in these activities would be ineligible for direct support, they would be more likely to lease or sell their land to more progressive farmers. For older farmers, eligibility for area payments could also be conditional on lease of their land to younger farmers, provided the lease was formal and long-term. The credibility and effectiveness of such reforms will depend on Serbia's policy stability and its institutional capacity to follow through on the reforms.

5.39. An unsupportive policy environment and inadequate institutions pose another major barrier to agriculture productivity, prospects for growth and reaping benefits of EU integration, and contribution to household welfare. While improvements in access to water ${ }^{64}$ credit, extension services, technology, and markets would each be helpful reforms, the critical constraint is with the policy environment and institutional capacity. The volatility of budget support (for example, a 50 percent cut in budget allocation in 2009) creates disincentives for farm investment. Individual support programs change frequently. Even within programs, eligibility criteria and the amount of support can change more than once in a single season. Public support for agriculture has been dominated by direct payment subsidies (since 2012 mostly area or animal payments, followed by input and production subsidies) rather than extension services, diversification of farm income, irrigation and other improvements of infrastructure, and technology transfer. In the past two years the government has adopted a number of laws and regulations, but addressing the constraints still calls for reforms to facilitate farm restructuring, deepen land markets, rebalance support between direct payments and investment or structural support, strengthen supply chains, and modernize production systems; other priorities are also important for sustainable use of natural resources and rural development and welfare support.

5.40. Strengthening agribusiness - broadly defined as the manufacture and distribution of farm equipment and supplies, and the processing, storage, and distribution of farm commodities-can support shared prosperity and poverty reduction. The agribusiness subsector currently contributes more than $17 \%$ of the national GDP. With some 1.4 million farmers operating on 3.4 million ha of land, agribusiness also provides $21 \%$ of the total employment. The Serbian Government is committed to developing a strong and competitive agriculture and food processing industry for domestic, regional and EU markets. A number of investment incentives are being offered by the Government, including various tax and non-tax instruments to attract foreign investors and increase employment. The prospective EU and WTO membership with trade liberalization provide an important motivation for further sector development.

5.41. A considerable potential of the agribusiness sector is waiting to be unlocked. The agribusiness sector in Serbia is performing below its potential due to the low productivity in comparison with EU countries and Serbia's own performance in the past. One of the most important preconditions for improving productivity is the introduction of modern technologies and equipment in the agribusiness value chain. Mixed and public forms of enterprise ownership and lack of suitable financing instruments reduce opportunities for attracting private capital for modernization of the sector resulting in the lost opportunity for adding value. Despite the government's effort to stabilize agribusiness financing, the availability of commercial financing to the sector sharply contracted due to the global financial crisis. Credit facilitation programs do not appear to improve availability of capital to smallholder famers who represent the vast ${ }^{64}$ Only 3 percent of planted agricultural land is irrigated (Agriculture Census 2012), which is a serious problem given
weather volatility. 
majority of the farming units in Serbia and who are unable to access financial markets otherwise. Cross regional and 'large farm - small farm' divides are becoming deeper -- trade and investment opportunities and agriculture sector support appear to have disproportionately benefited few larger wealthier farmers in the north. Addressing these challenges and improving access to finance, particularly for smallholders, is critical to harness the agribusiness potential and help reduce poverty in the rural areas.

5.42. Finally, labor mobility could be an important force for access to economic opportunities and efficient use of factor endowments, given differentials in economic activities within Serbia and gradual integration into the EU factors markets. In terms of internal migration, statistics from the 2010 LITS suggest that 18 percent of adult Serbians had moved in the past 20 years. This is lower than the ECA average and lower than the reported intention to move (World Bank 2013 ECA Jobs report). In terms of cross-border migration, the number of Serbian emigrants was estimated in 2010 to be 196,000 (World Bank, Migration and Remittances Factbook, 2011), 2 percent of the population, although this could be an underestimate given the data problem of capturing such movements. Education levels of Serbian emigrants do not differ much from those who stay at home, unlike the case of migrants from Albania, Bosnia and Herzegovina, and FYR Macedonia. ${ }^{65}$ Remittances accounted for about 10 percent of Serbia's GDP in 2010, the average among Western Balkan countries, but their role at the individual household level is marginal; they account for 1.3 percent of urban household income and 2.2 percent of rural households ${ }^{66}$ (2013).

\section{Summary and Conclusions}

5.43. Opportunities for building critical assets and earning income are critical to include the less well-off in the growth process. While asset accumulation is respectable in Serbia, despite a number of disparities, heightening the returns on those assets to generate income, particularly in the labor market, is a major challenge. Addressing this difficult problem through effective labor markets and institutions; improving rural welfare, especially through agriculture; and making service delivery more efficient will be necessary to complement efforts to boost growth and job creation.

5.44. In Serbia today only $\mathbf{4 0}$ percent of the adult population has a job; even fewer have a formal job, and even fewer still a private-sector formal job. No country can sustainably grow with so little employment and participation. Not surprisingly, the B40 mostly consists of the jobless, and the lack of labor income is a major deterrent to escaping poverty. In other words, bringing these people back into jobs is the key to both economic growth and inclusion. They mostly represent two groups: (a) the pre-transition generation, aged 40 or more, who either lost their jobs during the transition and never found a proper new job, or entered the labor market as the transition was beginning and never gained a firm foothold; and (b) groups, especially minorities like the Roma and also women generally, who have never been strongly attached to the labor market. These groups now live either on public and private transfers or subsistence farming and are largely excluded from labor markets, especially formal jobs.

\footnotetext{
${ }^{65}$ South Eastern Europe Regular Economic Update 2014

${ }^{66}$ http://webrzs.stat.gov.rs/WebSite/repository/documents/00/01/57/24/Individual_consumption_2014.pdf - Statistical Office of the Republic of Serbia
} 
5.45. While heightening the engagement of these groups in the labor market can no doubt support growth, the vital question is how to generate jobs for the B40. Clearly, many of them will not have the skills they need to benefit from the high-productivity jobs that export-led growth could create. It appears that Serbia has only limited potential to considerably increase exports of low-skilled manufacturing products, for example. While there could be some potential in agricultural products, especially the fresh vegetables and fruits that are labor-intensive to harvest but require relatively little skill, the analysis found that most low-wage earners in Serbia work in the service and hence the non-tradable sector; they work for micro and small enterprises; they work in agriculture; and many of them are in fact self-employed.

5.46. To boost employment for the B40 and excluded groups, in addition to export-led growth, policy should be directed to removing barriers for SMEs and self-employment and attracting investments in agriculture and the non-tradable service sector. This principally means removing barriers to low-productivity jobs through flexible work arrangements; reforming the minimum social security contribution; redesigning the social benefit system to make it incentive-compatible; reforming labor market institutions like the NES to support efficient matchmaking between job-seekers and employers; and dismantling financial barriers in the SME sector. Combined, these reforms would constitute the crucial first step to engaging in the Serbian labor market those not previously part of it. In many Western countries low-paying formal part-time jobs make up a considerable part of the labor market. Making that happen in Serbia should help to bring into work both the 40+ generation and excluded groups. For women, whose contribution will be important, additional measures like providing care facilities for children and the elderly might be necessary to help them reconcile care duties with career goals.

5.47. While inclusion policies are desirable on their own, they also can contribute to sustainable growth, creating a virtuous cycle for faster progress toward the twin goals. Improved and more equal access to quality education and better health care services are essential to expand human capital and workforce productivity. ECD interventions, for example, especially among groups lagging behind in human capital accumulation such as the Roma, are critical not only for inclusion but also to build the skills and competencies necessary for future competitiveness and sustained growth; they lay the foundation for lifelong development of advanced generic skills and competencies. A more skilled labor force is also associated with higher labor market participation rates (see, e.g., World Bank, Europe 2020 Poland, 2011). Higher productivity and increased labor participation can in turn support higher growth, especially in countries like Serbia where labor's contribution to growth has been negative due to an aging population and a low labor force participation rate.

5.48. Over the medium to long term, Serbia's aging population and declining workforce make it all the more important that the Roma and other excluded groups become more active in the labor force, to support growth. In the medium term, the Serbian labor force is projected to shrink significantly due to demographic contraction. As it shrinks, it becomes imperative that the labor force become more productive, not only to sustain growth but also to finance such social services as health care and pensions for the old. Serbia can partly mitigate the adverse demographic impact by active policies that support increased labor participation and employment rates (e.g. through training unemployed and inactive workers) among the general population and excluded group, and family-friendly policies that can encourage 
birth rates. ${ }^{67}$ The Roma minority, with its demographic patterns of high fertility ${ }^{68}$ should be a focus of policy both in terms of human capital development and greater participation in the economy.

5.49. Greater economic and social participation of excluded groups allows not only for higher accumulation and better use of individual assets, such as human capital, but also enhances their contribution to the growth process. It is well-established that both inactivity and unemployment rates are particularly high among these groups. The costs of continuing to exclude people who are over 40, women, and Roma are large in terms both of the fiscal costs and transfers and of lost economic growth due to income and consumption foregone. Equalizing labor market earnings in Serbia for Roma could generate estimated annual economic benefits ranging from $€ 252$ million to $€ 1$ billion, and fiscal benefits of up to $€ 257$ million. Similarly, estimates suggests that the income loss associated with the gender gaps in labor force participation for wage earners, employers and self-employed in Serbia is significant at about 16 percent of income per capita (Cuberes and Teignier 2014).

5.50. Other aspects of inclusion could also affect economic growth. Mitigating risks for the most vulnerable Serbians through effective social protection programs can also limit reversals in the stock of endowments for generating income that individuals and households possess. Finally, inclusion can also promote greater government accountability due to a better educated, healthier, and more empowered population.

\footnotetext{
${ }^{67}$ A lot can be learned from European countries with positive birth rates, which have invested significantly in compulsory pre-school provision (for instance, as of age 4 in France and the Netherlands).

${ }^{68}$ MICS5 data suggest a fertility rate of 3.1 for Roma as compared to 1.6 for non-Roma. Taking the MICS5 and survey data as a basis and assuming that the current under-5 age cohort enters the labor market between the ages of 16 and 21, new labor market entrants of Roma descent would be expected to make up between 15 and 29 percent of total new labor market entrants in Serbia [World Bank estimate].
} 
Figure V.22: The critical constraints on the sharing of Serbia's prosperity

Asset accumulation is respectable, but disparities persist...

$\%$ of people in top and bottom income quintile, by highest education

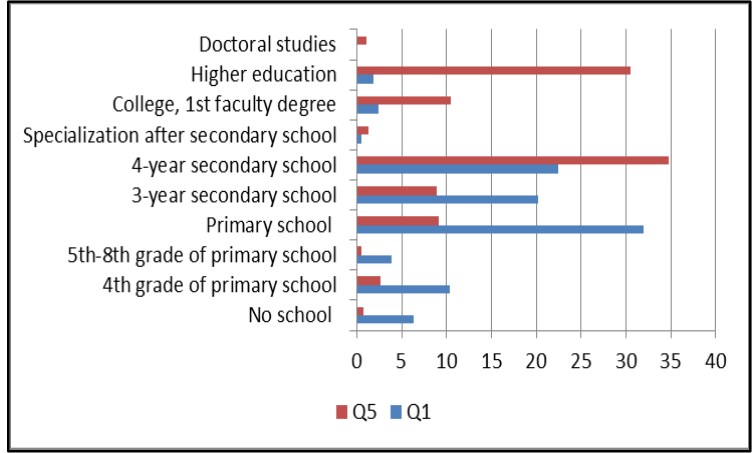

Targeting of social assistance is respectable but coverage of the poor is small

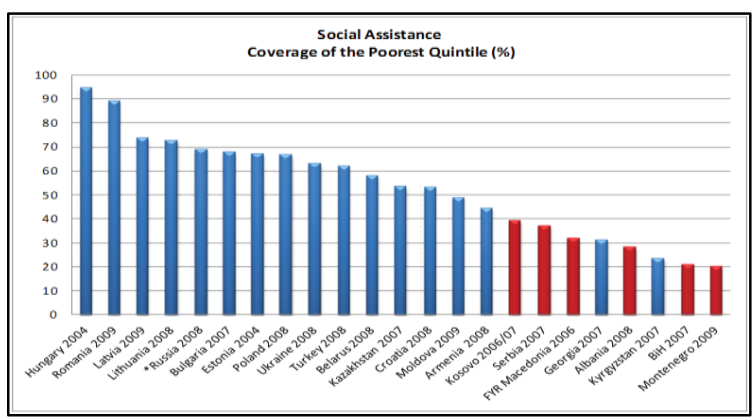

...and much of job creation has been informal and/or part-time

Figure IV.11: Structure of Net Job Creation, by Type and Age of Worker, 10/2012-9/2014

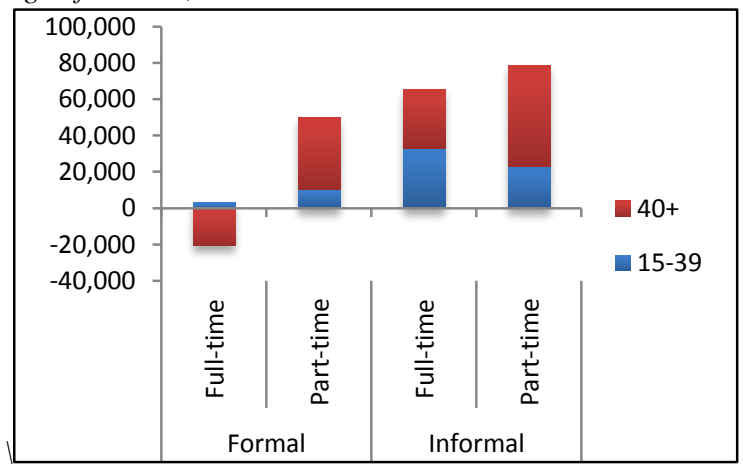

...including for marginalized groups in education and health coverage and delivery

Child Immunization \& Antenatal Care, by quintile*



Amid a challenging labor market, unemployment has risen...

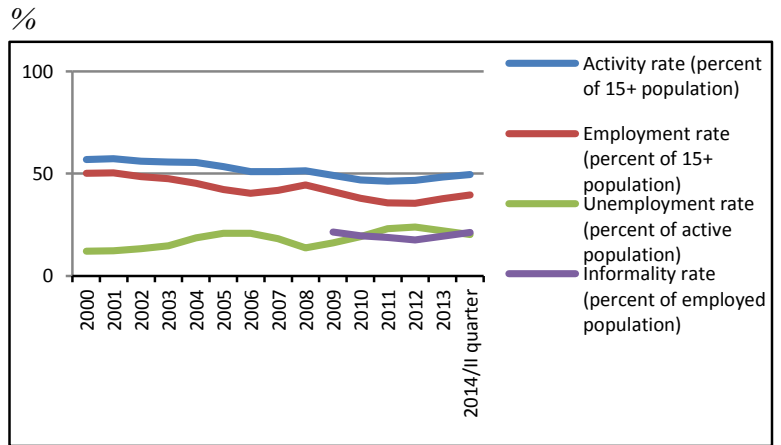

Improving returns from self-employment and agriculture can support the welfare of the bottom 40 percent

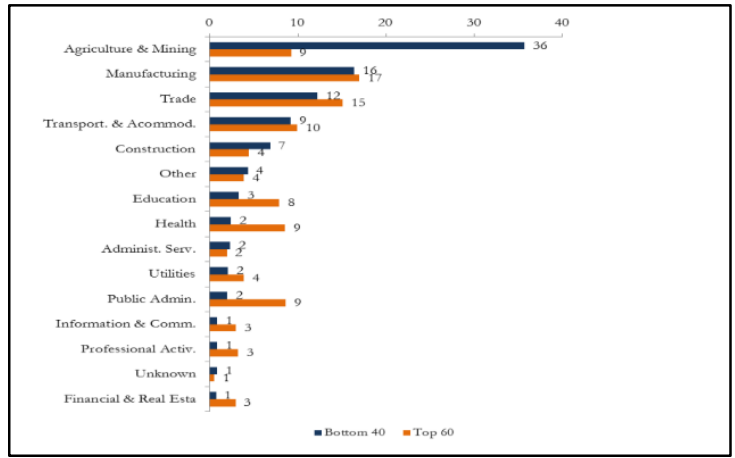

Source: Ministry of Finance and Statistical Office of the Republic of Serbia. Source: World Bank 2011. "Social Safety Nets in the Western Balkans: Design, Implementation and Performance". Job creation data from LFS. Employment by sector from SILC data. MICS 2014.

Note: $* \%$ of children age 24-35 months who received all recommended vaccinations; $\%$ expectant mothers with 4 or more antenatal visits, by income quintile. 


\section{RISKS TO SUSTAINABILITY}

\subsection{Serbia is confronted by threats to sustainable growth, shared prosperity and poverty}

reduction. The risks to sustainability span external, environmental risks, and social and political, all of which need to be managed carefully. With regard to external risks, Serbia's economy is closely linked with the economies of the Eurozone, and a protracted slowdown there could dampen expected growth and public finances, potentially jeopardizing macroeconomic stability, growth and shared prosperity. With respect to the environment, Serbia is prone to a series of natural risks, such as floods and droughts that could seriously damage the economy and the well-being especially of vulnerable populations; and the frequency and strength of such disasters is projected to increase with climate change. Serbia faces large needs in expanding and improving environmental infrastructure, particularly waste and wastewater management; and it is confronted with environmental liabilities of its large SOE sector. Finally, there are numerous social and political risks that could undermine the sustainability of shared prosperity. These relate to the large reform agenda with significant social implications and whether the government can maintain political support for these reforms; inertia and whether Serbia will be able to push through public sector reforms; the tension between Serbia's EU ambitions and its policy toward Russia and Serbia's ability to maintain a delicate balance between the two to preserve its economic relations and benefits.

Figure VI.1: The principal risks to sustainability

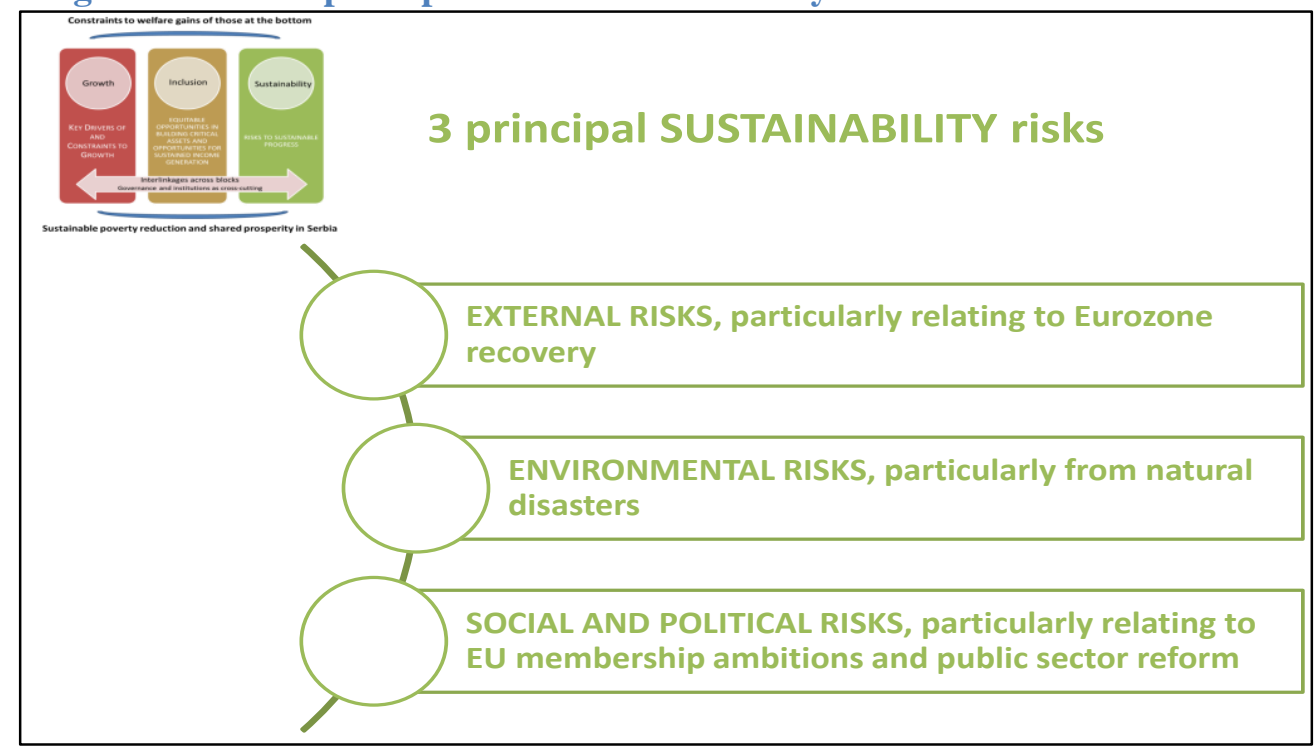

Source: World Bank staff.

\section{External Risks}

6.2. The main external risks relate to a slower-than-expected Eurozone economic recovery, which would affect Serbia's economic performance through exports, workers' remittances, and capital flows. In a nutshell, problems in the Eurozone could depress external demand for Serbia's exports, reduce inflow of remittances, and introduce even more caution into the banking sector, which is now much less willing to lend to the private sector compared to the pre-crisis. 
- Serbia has strong trade linkages with the Eurozone economies. Nearly 60 percent of Serbia's total trade is with the EU and the banking sector has close ties with the EU. Export growth has already weakened due to the slowdown in the Eurozone, a further stagnation of the Eurozone could mean low export growth and therefore the overall growth.

- Workers' remittances are an important part of national income in Serbia, ranging between 8-12 percent of GDP. The Eurozone economies account for 80 percent of remittances to Serbia, and a further weakening of growth prospects across the Eurozone would likely affect remittances more broadly and increase poverty in Serbia.

- Serbia's linked with the Eurozone through FDI and the banking sector. The EU accounts for about 80 percent of all FDIs in Serbia. A further deterioration of the Eurozone economies could lead to investors reducing their operations in or withdrawing from the region. While deleveraging by Western European banks has so far been steady and orderly, a potential worsening of the Eurozone crisis could accelerate further deleveraging, jeopardize credit recovery and undermine growth and its sustainability in Serbia.

6.3. External risks could also arise from changes in policies and economic conditions in other developed or emerging economies. Adverse shocks to capital inflows, for example, from normalization of U.S. interest rates or negative spillovers from other emerging economies, could also threaten economic growth and sustainability, given Serbia's large market-based financing needs and the burden of foreign currency debt. Both the weaker performance in the Eurozone and adverse shocks to interest rates and capital flows could reduce Serbia's growth. Beyond lowering growth, they would likely lead to deterioration in the fiscal and current account balances, and a widening of external financing gaps. They could also lead to increased unemployment and poverty rates, in an environment of already high unemployment a fiscally strapped government that may not be able to expand the coverage of social safety nets. Households already strained from the effects of the global economic crisis could find themselves in position of having even fewer coping possibilities.

6.4. Given these risks are exogenous, there is very little Serbia can do to control them, but it can put in place (indirect) mitigating measures to limit their adverse impact. These include: (i) Effective financial sector oversight and crisis management, including effective resolution mechanisms of failing banks; appropriate depositor protection to maintain confidence in the financial system; and reduction of non-performing loans through a variety of measures (such as loss recognition and the removal of tax impediments to debt restructuring); (ii) Fiscal reforms focused on longer-term sustainability, which address the high costs of pensions and wages as well as the high fiscal drain coming from SOEs. (iii) Structural reforms aimed at stimulating investment and improving private sector competitiveness and increasing labor force participation and employment rates through fiscal and labor market reforms; and (iv) Where fiscally affordable, expanding and strengthening the last resort social assistance programs to help protect the poor in the face of such external risks.

\section{Environmental and Climate-Related Risks}

6.5. While there is a lack of information on Serbia's total wealth (physical, human, and natural), available information from the World Bank Group's comprehensive wealth database indicates that its percapita natural capital has been increasing, particularly in recent years. Serbia's natural capital comprises 
primarily crops and pasture land and a smaller fraction in energy and minerals (Figure VI.2). Since natural capital is a significant proportion of the B40's 'wealth', its sustainable management is an imperative. For example, many of the land management and policy constraints identified above (Self Employment and Agriculture) should be a priority to encourage improvements in productivity.

Figure VI.2: Composition of Serbia's Natural Capital, 2010

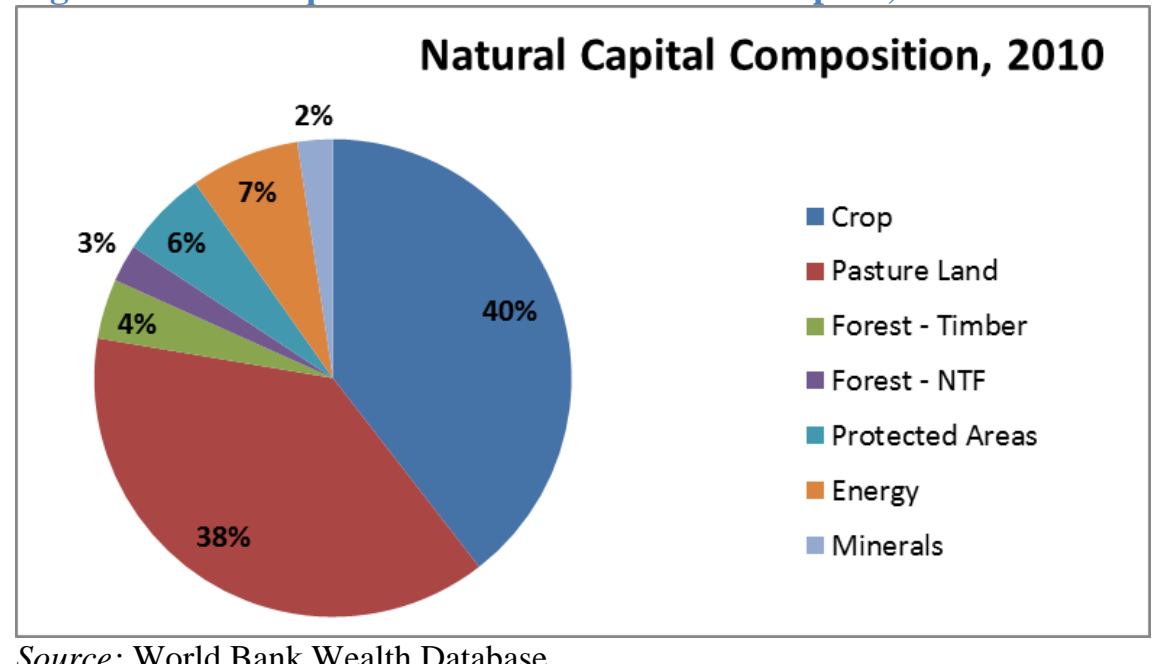

Source: World Bank Wealth Database.

6.6. Table VI.1 presents a number of environmental indicators for Serbia against relevant benchmarks - EU, ECA and upper middle income country averages. Serbia is performing better than comparators, including EU countries on average, in preventing deforestation and air quality measured by PM2.5, which is the main air pollutant of public health concern. At the same time, its water withdrawal rates are higher not only those in EU countries but also all ECA counties and all upper middle-income countries averages, pointing to the importance of water use efficiency. Serbia's energy intensity and $\mathrm{CO} 2$ emissions intensity per unit of GDP (in PPP terms) about twice those of the EU average, while CO2 emissions intensity of its energy sector is high by all comparisons, mainly due to a significant share of outdated power plants using low quality fuel. Serbia also lags behind many comparator countries in terms of protected areas.

Table VI.1: Serbia: Select Comparative Environmental Sustainability Indicators

\begin{tabular}{lrrrrr}
\hline & ECA & EU & UMIC & Serbia & Year \\
\hline Forest loss: \% lost in 2000-2012 & 1.1 & 1.8 & 1.9 & 0.4 & 2012 \\
Air quality: PM2.5/m3 & 37.1 & 28.7 & 45.5 & 14.0 & 2012 \\
Water withdrawals: \% of internal resources & 39.6 & 40.6 & 42.1 & 49.1 & 2013 \\
Energy intensity: kg oil eq./\$1 GDP & 0.4 & 0.1 & 0.3 & 0.2 & 2011 \\
Emission intensity: kg CO2/\$1 GDP & 0.6 & 0.3 & 0.5 & 0.5 & 2010 \\
Emission intensity of energy: t CO2/t oil eq. & 2.3 & 2.3 & 2.2 & 3.0 & 2010 \\
Protected areas as a \% of total area & 14.5 & 25.5 & 12.6 & 6.3 & 2012 \\
\hline
\end{tabular}

Source: World Development Indicators, Environmental Performance Index, various years.

6.7. Serbia faces major challenges - institutional and financial - in achieving compliance with EU environmental and climate directives, including the EU2030 energy and climate package, on its way to 
EU accession. As noted in chapter 5, waste water and waste management is behind EU standards. Only slightly over 50 percent of households connected to a sewer, and only about 14 percent of all wastewater produced actually treated, posing environmental and public health hazards. Industrial and municipal discharges into the Sava River have regional implications. An outsized and inefficient SOE sector has also contributed to the legacy problems of contamination and environmental liabilities. In addition to adverse environmental and health impacts, these liabilities can become an obstacle or/and reduce the potential value of several planned privations, and need to be assessed. In 2014 the Government slated enterprises for production and processing of coal, oil, gas and oil derivatives, ferrous and non-ferrous metals, non-metallic minerals, and chemical products, yarn and fabrics, and food and beverages and building of machines, vehicles and ships - all of which are associated with significant environmental pollution. The effective handling of environment liabilities in the privatization process through environment assessments and audits and incorporation of clear, time-bound environmental action plans in the privatization agreements is an urgent priority for reform to succeed. A serious impediment to assessing Serbia's environmental priorities is the lack of systematic information and data series, improving which is also an important priority for measuring and supporting environmental sustainability of country's economic progress and reforms.

6.8. Serbia is subject to a wide variety of natural hazards which affect both people and infrastructure in the short-term. Floods, landslides, droughts, earthquakes, and wildfires cause serious damage to the economy and the well-being of vulnerable populations. The predominance of old and dilapidated buildings and infrastructure, coupled with the concentration of population in urban areas, heightens the country's vulnerability to such hazards. Over the last 15 years, Serbia has been repeatedly affected by medium and major floods and landslides. There were floods in 1999, 2001, 2002, 2005, 2006, 2007, 2009, 2010, and - the biggest so far-in 2014. These floods resulted in the loss of lives, resettlements, severe damage to infrastructure, and adverse impacts on agriculture, energy, and other productive sectors.

6.9. In May 2014, record-breaking rainfall caused massive floods, which caused estimated damages equivalent to 2.7 percent of GDP and losses equivalent to 2 percent. These floods pushed the already tottering economy into recession. Using data from the 2013 SILC and estimated employment loss, it is estimated that the floods increased national poverty by 1.7 percentage points - equivalent to 125,000 people.

6.10. The catastrophic floods also brought forward a number of issues that must be addressed: (1) inadequate flood protection and drainage infrastructure and insufficient investment in new or upgraded facilities, maintenance, and rehabilitation; (2) institutional and management weaknesses, especially in terms of integrated planning for river basin management and flood prevention, asset management, and financing of new investments; and (3) lack of hydro-meteorological monitoring and analysis and preparedness and response initiatives. The restoration of critical sections of protection infrastructure, investment planning to enhance protection through rehabilitation of existing and construction of new infrastructure and integrated planning and flood management practices have now become urgent.

6.11. While floods and landslides are the biggest threats, earthquakes and wildfires have also inflicted damage. Prolonged periods of low precipitation and higher temperatures have often led to wildfires, which are widespread during the dry summer season, threatening 28 percent of Serbian forests, homes, and farmland. Between 1998 and 2008, 853 forest fires burned over 16,357 ha; in 2007 alone there 
were 258 fires, which caused damage of about $€ 40$ million and burned more than 5,200 ha. More recently, the 2010 earthquake damaged 5,967 structures, at a cost of about US\$150 million.

\subsection{Climate change is expected to increase the intensity and frequency of disaster events in Serbia} (Box VI.1). For instance, it is likely to intensify water extremes nationally, with more droughts in the summer and more floods in the winter and spring, which will have serious implications for agriculture, infrastructure, and the security of the population.

\section{Box VI.1I: Climate Change Scenarios for Serbia: Heat Waves, Droughts, and Floods}

- Mean annual temperature has increased almost everywhere in Serbia except the southeast: compared to $1961-90$, the period $1971-2000$ was warmer in most of the country by $0.7^{\circ} \mathrm{C}$. Mean annual precipitation over a large part of Serbia was lower in 1971-2000 than in 1961-90, though in some locations, especially in the west and north, precipitation was higher. Weather-related disasters have become more frequent: Serbia is particularly susceptible to floods and these have become more frequent, with major episodes in 1980, 1981, 1988, 1999, 2001, 2002, 2005, 2007, 2006, 2009, 2010, and 2014, the last being the most devastating so far. Droughts are most prevalent in the east and in the Pannonian Basin in the north; catastrophic droughts have struck Serbia three times in the last 20 years. Mean damages from drought, mainly to agricultural production, are estimated to have reached $€ 500$ million annually. In July and August 2007 there was a severe drought coupled with the longest registered wave of extremely high air temperatures (10-17 days with temperatures of 35-45 centigrade). Extreme heat waves have also been reported: there were four between 2000-11, causing five fatalities and injuring 70 people (WWF 2012, EM-DAT).

- The Western Balkans have emerged as warming hot spots, with more frequent heat waves, affecting 2540 percent of summer months in a $2 \mathrm{C}$ world and escalating to 80 percent of summer months in a $4 \mathrm{C}$ world.

- Water is expected to become considerably less available in the summer months through the 21st century: there could be a 20 percent increase in the number of drought days and river discharge could be reduced by up to $15-45$ percent in a $2 \mathrm{C}$ world and 50 percent or more in a $4 \mathrm{C}$ world.

- Winter and spring flood risk (>100 yr.) is expected to increase along the Danube, Savap, and Tiszap rivers.

Source: First National Communication to UNFCCC (2010), Turn Down the Heat III (World Bank, forthcoming), WWF (2012), Emergency Events Database (EM-DAT).

\subsection{Addressing these environmental risks will require a significant shift from the current approach of concentrating only on emergency response to a more comprehensive approach based on resilience and risk management. There needs to be a better understanding of the contingent liabilities caused by adverse natural events; proactive risk reduction activities; policies and actions to avoid exacerbating future risk; and more efficient ways to respond to disasters, such as risk financing instruments to manage liabilities. A coherent mechanism and institutional capacity to assess, plan for, and mitigate such risks will be critical to ensuring climate and disaster risk resilience.}

6.14. Agriculture, already on the frontline of the Serbian economy, is most vulnerable to weather hazards and climate change, with repercussions for growth (value-added and exports) and shared prosperity (B40 welfare). Increasingly frequent and intensive droughts in the past two decades have deeply damaged Serbian agriculture: it is estimated that droughts can reduce average crop yield by over 40 percent and this could worsen as the climate changes. The main findings from crop models of alternative climate change scenarios 
indicate that winter crops might benefit from a longer vegetation period but spring and summer crops may suffer from drier conditions as they grow.

6.15. There are a number of possible adaptation options for reducing risk (e.g., expand the share of winter crops, improve on-farm water management and water storage capacity (including in-soil)); rethink policy and financing (e.g., integrate climate change considerations and adaptation into the agriculture sector development plan; facilitate access to finance including long-term finance; pilot insurance schemes); build more knowledge and capacity (e.g., integrate assessment of adaptation options, raise awareness and skills on climate-smart practices by agro-ecological zone, etc.).

6.16. With respect to mitigation and green growth, Serbia can do more particularly in two areas, energy efficiency, clean energy and waste management and pollution control. Serbia's economy is the least-energy efficient in the Western Balkans (25 percent above the average). It is also among the most carbon-intensive, with some two-thirds of its electricity needs met by lignite power plants. While the country has embarked on a path to adapt its energy and climate policies to meet EU accession requirements and it is making progress in this direction, the energy sector remains vulnerable to climate change, as evidenced by disruptions to supply caused by extreme events. The provision of well-developed and properly equipped waste collection and disposal systems is less than satisfactory. Poorly managed wastes tend to release more greenhouse gas emissions (such as methane) and cause pollution. Hazardous waste is also a serious issue as it relates to the poor, who tend to reside in low-value lands that may be contaminated from previous production or hazardous waste acquired by scavenging old industrial sites to meet income needs. An efficient waste management system is vital for Serbia to enhance the welfare of the poor as well as align with the EU accession agenda.

\section{Social and Political Risks}

6.17. A review of Serbia's recent political economy ${ }^{69}$ suggests that progress on reforms has been limited by three principal constraints: lack of strong political will and leadership; weak institutions for reform implementation; and lack of popular demand and weak internal coalitions for reform. While the external incentives (e.g., EU) can provide a "nudge" and, perhaps, a "tipping point," Serbia's recent experience clearly demonstrates that external incentives alone are rarely sufficient for successful adoption and implementation of a reform program.

6.18. Public demands for market economy and economic reforms have generally been weak in Serbia. Nostalgia for "soft" socialism and self-governance of former Yugoslavia, both among politicians and their electorate, has limited the appetite for market reforms. Former Yugoslavia had remained prosperous under the socialist self-management system until 1980-well within the living memory of a large block of voters - where perceptions seem to persist among the populace that such a system was better with respect to equality, social mobility, and corruption. This perception seems to support the view that if wealth can again be redistributed more equitably and transparently, the citizens would be better off again. At the same time, aversions towards a market economy have further been solidified by nationalism, spurred

${ }^{69}$ See, for example, "Political Economy of Reform in Western Balkans: Are there Quick Wins?" by Jana Kunivoca and Zeljko Bogetic, 2013, World Bank. 
by the efforts of the international community to interfere with the national issues, such as the question of Kosovo for the Serbs.

6.19. As discussed earlier, Serbia's political fragmentation has contributed to a lack of a unified vision for reform. With no clear majority, Serbia's recent governments have been based on wide and heterogeneous post-election coalitions with substantial number of small parties, virtually all of them with substantial veto power. This situation has left recent governments in a state of permanent election campaign and cabinet reshuffling, thereby contributing to a lack of unified reform vision and weak reform implementation. In addition, the focus on territorial issues, ethnically-charged battles, regional reconciliation have dominated those political agendas that leave little room for comprehensive structural reforms.

6.20. Institutional weaknesses, in particular politicized appointments, have contributed to the slow progress in reform implementation. While Serbia's quality of institutions at the start of 1990s was high, due to Belgrade's status as the former capital of Yugoslavia, the quality of institutions has deteriorated over time both due to the Balkan wars and the exodus of the intellectual elites. A key factor contributing to institutional weaknesses and lower professionalism of the civil service has been the politicized recruitment, which has resulted high civil service turnover following the changes in the government, decreased efficiency and accountability of the civil service, and corruption, mainly in the public procurement.

6.21. The pro-reform voices have been muted while the status-quo groups have been able to exert considerable influence. Serbia's pro-reform alliances of companies, municipalities and NGOs united under NALED and the Foreign Investors Council monitor progress on the economic reforms and propose reform priorities from the point of view of investors. However, their influence has been limited due to low interest for deeper structural reforms both in government and among the public in general. On the other hand, pro-status quo groups such as trade unions, pensioners, civil servants and veterans -often in coalition with political groups who stand to gain rents from the status quo--have successfully managed to block any major social, labor market and economic reforms which have impact on them.

6.22. The large reform agenda means that Serbia faces broader risks to regenerating and maintaining the reform momentum. Serbia's experience to date suggests that, going forward, the main risk may be inertia - that the fundamental reforms may move slowly or not at all because of concentration of decision-making and the political unwillingness to suffer the short-term unpopularity that will inevitably come with reforms. Serbia's macroeconomic outlook is precarious and the economy is facing very serious challenges. Public debt levels are high and still increasing. Dealing with public debt will require addressing stubborn spending pressures, which in turn requires wide-ranging and deep structural reforms that won't be easy to implement. The SOE and public sector reforms involve significant layoffs which are politically unpopular.Although the fiscal consolidation efforts are underway, the challenges on the road ahead for Serbia are huge. This, combined with extremely low employment levels and a third recession in six years, would suggest significant social and political risks going forward. A strong political commitment to see through these reforms is critical.

6.23. A key social and political risk relates to the adverse employment effects of the reforms. Although the exact estimates are difficult to make, potentially between 30,000 and 50,000 workers could 
be made redundant in the process of SOE and public sector reforms. The labor market as is today could not absorb a further inflow into unemployment of these works, most of them older and unskilled. If redundant workers, especially those over 40, find work at all, it is most likely to be informal, low-skilled, low-paid, casual, and part-time. Hence, many more people might become unemployed and eventually discouraged from looking for work at all. Cushioning and managing the social impacts of such layoffs and labor retrenchment - through appropriate severance packages, employment services, active labor market policies, and a return to growth -are all indeed critical to support transition and the success of the reforms.

\subsection{Tackling the large unfinished public sector agenda also carries substantial social and political} risks, associated especially with significant employment retrenchment and adverse impacts on B40 welfare. The pro-growth reforms - including fiscal consolidation, SOE reforms - have distributional implications which will need to be managed and mitigated as appropriate. Some of the effects of reforms could be indirect as some of the households affected by, for example, fiscal consolidation and SOE measures may have relatively high income and consumption levels. However, some others may impact the welfare of the B40, where particular attention is needed to protect those at the bottom of the welfare distribution. In the short term, fiscal consolidation and structural reform imperatives combined with the recent adverse impact of floods on growth could negatively impact especially the B40. Inequality could worsen. Furthermore, as the public sector sheds employment in the short to medium term, private sector investment and job creation may not kick in fast enough to offset immediate public sector losses, in which case unemployment and shared prosperity could worsen before improving. This transition period will be longer if the structural reforms are not tackled decisively and Serbia resorts, as it has in recent years, to a muddle-through approach to reforms. How quickly the B40 can start to benefit from general economic reforms thus depends on the pace of both public sector reform and private sector response, in particular response in terms of investment. Given the potential for adverse effects on the poor, it will be important to have in place complementary policies - such as well-targeted social assistance, supportive employment services, and less stringent labor taxation to help the low-skilled find even casual jobs - that will mitigate distributional consequences and provide short-term protection to the vulnerable.

\subsection{Finally, Serbia's ability to manage its EU membership ambitions and its relationship with} Russia will be a decisive influence on its medium-term economic development trajectory. As it has been proceeding with the EU accession negotiations, Serbia has maintained a cordial relationship with Russia, especially in the energy sector but also in other vital economic areas. Serbia remains committed to fulfilling its obligations toward the European path while staying on good terms with non-EU actors - in particular Russia, China, and the UAE. This is a delicate balance to maintain. For instance, possible spillovers from evolving regional geopolitical tensions and any related disruptions to Serbia's natural gas supply could hurt the economy. How well Serbia manages its delicate political-economy relationships may affect its economic development and its success in boosting shared prosperity. 


\section{PRIORITIES FOR ACTION}

7.1. Poverty reduction and shared prosperity in Serbia have closely mirrored economic growth, with substantial progress achieved before the global financial crisis but with deterioration after it. When real GDP grew by 5.0 percent a year in 2001-08, poverty fell from 14 percent of the population in 2002 to 6.6 percent in 2007. Since then, however, not only has poverty gone up, the annual consumption of the B40 has fallen by 3.8 percent, compared to an average drop of 2.9 percent for all Serbians. Reinvigorating economic growth is therefore necessary - although not sufficient - to make progress toward the twin goals. A slowly improving external environment, particularly in the Eurozone, will no doubt help, but strong and sustained higher growth will hinge on structural reforms that tackle a broad set of governance, macroeconomic, and structural problems.

7.2. The effort to create higher and sustainable growth at the macro level must be complemented at the micro level by steps to remove barriers to participation and inclusion of the less well-off in the economic growth process. Chief among these is creating employment and income-generating opportunities for the less well-off. While in general Serbia does not suffer from a lack of asset accumulation, creating the conditions for individuals to earn adequate returns on their assets has been very difficult. Export-led growth and higher-productivity industries could lead the inclusion agenda but they may not generate enough jobs for low-skilled and low- productivity workers. As analyzed in detail in Chapter 5, many of the B40 do not have the skills they need to benefit from the high-productivity jobs that could be created from export-led growth. Indeed, the analysis shows that the bulk of low wage earners in Serbia work in the non-tradable sectors such as services; they work for micro and small enterprises; they work in agriculture; and many of them are actually self-employed. This means that, in addition to export-led growth, expanding lower-skilled formal sector jobs through complementary policies designed to remove barriers for SMEs, self-employment, and agriculture is critical. Lower-skilled formal jobs must be part of the solution.

7.3. Based on the evidence and analysis presented in this report, this chapter outlines a prioritization process and proposes priorities for action. This report has analyzed in detail, supported by evidence and data, a number of areas that constrain growth, shared prosperity, and poverty reduction in Serbia. Some of these - governance and institutional capacity, fiscal sustainability and macroeconomic stability, SOEs, the business climate, financial sector stability and access to finance, infrastructure, and human capital - relate to macro barriers to generating higher and sustainable growth to generate income and job opportunities in Serbia. Others-education, health, social protection, the labor market, and selfemployment and agriculture-relate to micro constraints to making growth inclusive. Ultimately, the analysis identifies 11 priority areas for policy actions to accelerate growth, reduce poverty and boost shared prosperity. Table VII.1 present these 11 areas, along with the medium-term policy goal for each area. 
Table VII.1: Serbia: Key Constraints and Desired Medium-Term Policy Goals

\begin{tabular}{|c|c|}
\hline $\begin{array}{l}\text { Constraints Identified in the } \\
\text { SCD }\end{array}$ & Medium-Term Policy Objective \\
\hline $\begin{array}{l}\text { Governance and institutional } \\
\text { capacity }\end{array}$ & $\begin{array}{l}\text { - Create an effective institutional mechanism within government for } \\
\text { coordinating, implementing, and monitor reforms. }\end{array}$ \\
\hline $\begin{array}{l}\text { Fiscal sustainability; financial } \\
\text { and macro stability }\end{array}$ & $\begin{array}{l}\text { - Restore debt sustainability and maintain macro and financial } \\
\text { stability. }\end{array}$ \\
\hline State-owned enterprises & $\begin{array}{l}\text { - Reduce the state's footprint in the economy and make the public } \\
\text { sector more efficient by privatizing commercially oriented } \\
\text { enterprises and restructuring large public utilities. }\end{array}$ \\
\hline Business climate & $\begin{array}{l}\text { - Create an environment conducive to private sector-led investment, } \\
\text { growth, and job creation. }\end{array}$ \\
\hline Infrastructure & $\begin{array}{l}\text { Enhance the quality of Serbia's public infrastructure to support } \\
\text { international, regional, and domestic connectivity, productivity, } \\
\text { and competitiveness. }\end{array}$ \\
\hline Water and sanitation & $\begin{array}{l}\text { - Enhance Serbia's water resource management, wastewater } \\
\text { treatment, and environmental sustainability }\end{array}$ \\
\hline Education and skills & $\begin{array}{l}\text { Expand access to education and improve its quality for all, in } \\
\text { particular marginalized groups; reduce inequity, and increase } \\
\text { workforce productivity through improved skills and learning } \\
\text { outcomes. }\end{array}$ \\
\hline Health & $\begin{array}{l}\text { Expand access to care for marginalized groups, reduce disparities, } \\
\text { improve the quality of care and health outcomes, and reduce the } \\
\text { fiscal risks related to personal spending on health. }\end{array}$ \\
\hline Social protection & $\begin{array}{l}\text { Improve the coverage, equity, efficiency, and fiscal sustainability } \\
\text { of pensions and the social assistance program. }\end{array}$ \\
\hline Labor market institutions & $\begin{array}{l}\text { - Create more effective institutions to facilitate formal employment, } \\
\text { create earnings opportunities for the less well-off, and help } \\
\text { mitigate the negative consequences of SOE reforms. }\end{array}$ \\
\hline Agriculture, self-employment & $\begin{array}{l}\text { - Raise agriculture productivity and rural incomes with impacts on } \\
\text { the welfare of the B40 and poverty reduction. }\end{array}$ \\
\hline
\end{tabular}

\section{Prioritization Process and Criteria}

7.4. The SCD prioritization relies on a thorough review of the evidence, a process of team discussion and scoring of priorities (see Box VII.1), and consultations with the government and other stakeholders in Serbia to identify the most important priorities for sustainable achievement of the twin goals in Serbia. The prioritization exercise uses evidence and analysis presented in the report to identify which constraints are most binding. The Serbia country team then uses the evidence presented in the report, along with their country knowledge and informed judgment, to establish a general rank-ordering of the impact of the 11 policy areas on achievement of the twin goals. This is a collective judgment of the country team, which has extensive knowledge about Serbia. Finally, the team consulted further with the authorities and other stakeholders in Serbia to validate these priorities. ${ }^{70}$

\footnotetext{
${ }^{70}$ Such consultations took place in March 2015. For results of SCD consultations are summarized in Annex 6.
} 
7.5. The main criterion for prioritization of the $\mathbf{1 1}$ policy areas is their impact on achieving the twin goals of reducing poverty and increasing shared prosperity. In judging impact, the approach identifies intermediate channels through which policy actions could also impact the twin goals (see Table VII.5 for these intermediate channels). In addition, the prioritization exercise factors in three other consideration. The first one is whether a priority is "foundational" or "an enabler" in that it would need to be tackled early so that other policy actions or reforms can be effective. The second consideration is whether a priority would act through multiple, cross-cutting channels in terms of its impact on the twin goals. An example is SOE reform, which through its impact on fiscal policy, private investment, the labor market, and the quality of infrastructure would have substantial positive spillovers and benefits on growth and shared prosperity. Finally, the time horizon of impacts is taken into consideration. While some policies can yield immediate results, others take time to bear fruit. In general, the impact of removing the principal constraints on the twin goals is assessed over the medium term (4-6 years), but all else being equal, the constraints with the most immediate impact on growth, shared prosperity, and poverty reduction are given priority in light of the urgency in Serbia of restoring growth and protecting the less well-off. This does not mean that policies or investments with long gestation periods, such as investments in education and health, are not important; rather they play a crucial supporting role in generating sustainable growth and shared prosperity over the long-term.

\section{Box VII.I: Prioritization method and Team Scoring of Priorities}

The SCD thoroughly analyzes 12 critical constraints on growth, shared prosperity, and poverty reduction in Serbia. These areas were further consolidated from 12 to 10 principal constraints, with financial stability integrated into macroeconomic stability and human capital into education and skills. However, water supply and sanitation was added back as a separate priority area from infrastructure given its importance to sustainability and the fact that it does not quite fit into the objective of connectivity that other types of infrastructure address. For each constraint, a medium- term policy objective was specified, along with the most important policy actions to help achieve the policy goal. The matrix of constraints was then circulated for rating by the SCD team (see Table XII.5). To help the team think through systematically how the constraints impact the twin goals, intermediate channels through which the desired policy objective might impact the goals were identified.

The SCD team consisted of sectoral experts, team leaders, and project managers who have extensive country knowledge in their respective sectors and thematic areas. Team members were asked to rate impact on economic growth (mean income); impact on shared prosperity (income of the b40); and overall ranking among the 11 constraints. The SCD team was requested to evaluate the potential impact on the twin goals of removing the constraints in each area and attaining the medium-term policy objective. A numerical rating with a scale of 1 to 5 was used to assess impact on the twin goals, with 5 as the highest and 1 as the least impact. For rating the 11 constraints, team members were asked to rank-order them as 1 through 11 , with 1 as the most binding constraint on the twin goals and 11 as the least binding.

These ratings were then consolidated into simple averages as the team's collective ranking about the relative importance of the constraints. These consolidated ratings were then used, along with the evidence and further incountry consultations, to arrive at the top priorities for Serbia. 


\section{Prioritization Results}

7.6. After a systematic review of the evidence and the SCD team's collective scoring of the relative impact of the eleven policy areas, the priorities were ranked as shown in Table VII.2 below:

Table VII.2: Constraints and their Impact on the Twin Goals

\begin{tabular}{|l|l|}
\hline Constraints/Medium Term Policy Objective & $\begin{array}{l}\text { Impact on the Twin } \\
\text { Goals }\end{array}$ \\
\hline Foundational Priorities & \\
\hline $\begin{array}{l}\text { Fiscal sustainability, financial and macro stability: Restore debt sustainability } \\
\text { and maintain macro and financial stability. }\end{array}$ & $\bullet$ High \\
\hline $\begin{array}{l}\text { Governance and institutional capacity: Create an effective institutional } \\
\text { mechanism within government to coordinate, implement, and monitor reforms. }\end{array}$ & $\bullet$ High \\
\hline Priorities with Highest Impact on Twin Goals & \\
\hline $\begin{array}{l}\text { SOE reform: Reduce the state's footprint in the economy and make the public } \\
\text { sector more efficient by privatizing commercially oriented enterprises and } \\
\text { restructuring large public utilities. }\end{array}$ & $\bullet$ High \\
\hline $\begin{array}{l}\text { Business climate reform: Create an environment conducive to private sector-led } \\
\text { investment, growth, and job creation. }\end{array}$ & $\bullet$ High \\
\hline $\begin{array}{l}\text { Labor market institutions: Strengthen these institutions to facilitate formal } \\
\text { employment, create earnings opportunities for the less well-off, and help mitigate } \\
\text { the negative consequences of SOE reforms. }\end{array}$ & $\bullet$ High \\
\hline $\begin{array}{l}\text { Agriculture, self-employment: Support higher agricultural productivity and rural } \\
\text { incomes to improve the welfare of the B40 and reduce poverty. }\end{array}$ & $\bullet$ High \\
\hline $\begin{array}{l}\text { Infrastructure: Enhance the quality of public infrastructure to better support } \\
\text { international, regional and domestic connectivity. }\end{array}$ & $\bullet$ Medium/High \\
\hline Other Supporting Priorities & \\
\hline $\begin{array}{l}\text { Water and sanitation: Enhance Serbia's water resource management, wastewater } \\
\text { treatment, and environmental sustainability }\end{array}$ & $\bullet$ Medium \\
\hline $\begin{array}{l}\text { Education and skills: Expand access to and the quality of education for all, in } \\
\text { particular marginalized groups; reduce inequity and increase workforce } \\
\text { productivity by improving skills and learning outcomes. }\end{array}$ & $\bullet$ Medium \\
\hline $\begin{array}{l}\text { Health: Expand access to care for marginalized groups, reduce disparities and } \\
\text { improve the quality of care and health outcomes, and reduce the fiscal risks related } \\
\text { to personal spending on health. }\end{array}$ & $\bullet$ Medium \\
\hline $\begin{array}{l}\text { Social protection: Improve the coverage, equity, efficiency, and fiscal } \\
\text { sustainability of pensions and the social assistance program. }\end{array}$ & $\bullet$ Medium \\
\hline
\end{tabular}

\section{Foundational Priorities}

Restore debt sustainability and maintain macro and financial stability.

7.7. If left unchecked, Serbia's growing public debt is unsustainable and jeopardizes macroeconomic stability. Since 2008 public debt, including guarantees, has more than doubled, to over 70 percent of GDP at the end of 2014. A significant part of this increase has been driven by high mandatory spending on wages and pensions and guarantees on behalf of public enterprises and local governments, many of which have been called. The growing public debt not only absorbs a significant amount of 
resources in debt service (35 percent of total revenues) that could be used for productive purposes, it also carries high roll-over risk. The fiscal and debt vulnerabilities make it critical that the government urgently pursue fiscal consolidation to achieve debt sustainability and keep the economy stable over the medium term.

7.8. Among the critical (though not exhaustive) policy actions needed to restore debt sustainability and assure macro and financial sector stability are reducing public sector wage bills and pension costs, reducing fiscal support to public enterprises, addressing vulnerabilities in the remaining state-owned banks, reinforcing governance and the oversight and bank resolution framework, and better managing the public finances. While the government has, with the support of the IMF, initiated fiscal consolidation and structural reforms to halt the rise in public debt (IMF, 2015), it is early in the process and the challenges of reforming the SOEs, in particular the large public utilities, is far from complete, though still paramount. Restoring debt sustainability and assuring macroeconomic and financial stability is central to protecting the income and wellbeing of the less well-off and creating the basic conditions for private investment, growth, and shared prosperity. No resumption of growth or shared prosperity can be expected without macroeconomic stability - and in that sense this is a foundational step that is necessary for other reforms to work.

Create an effective institutional mechanism within government to coordinate, implement, and monitor reforms.

7.9. Inadequate governance and institutional capacity to implement reforms - especially the lack of accountability for results, limited technical capacity, a growing number of politically-based appointments, and a high turnover in senior staff during changes in government-limit growth and service delivery through loss of continuity and institutional memory, a virtual collapse in policy coordination, and a clogged government decision-making process. The system for coordinating policy management has effectively collapsed. All decisions are being pushed up to ministerial levels, and government sessions are overloaded with relatively trivial issues. Rapid investment in putting in place strategic planning and performance management processes and an overhaul of the outdated and largely dysfunctional policy coordination mechanisms have become critical for Serbia.

7.10. Among key actions needed to move toward the policy objective of creating effective governance and government institutional capacity are to overhaul the largely dysfunctional policy coordination mechanisms; establish strategic planning and performance management processes; and put in place a professional human resource management system that can support staffing control and horizontal redeployment of staff within government. This is a cross-cutting issue with significant implications not only for growth but for service delivery and shared prosperity. It impacts the pace and quality of reforms, the quality of public sector performance and service delivery, and over the long term trust between government and citizens. Whatever Serbia's priorities, other reforms are unlikely to work unless this capacity is operational. 


\section{Priorities with highest impacts on the twin goals}

7.11. Beyond the foundational priorities, five priorities emerge as most critical with the highest payoffs for Serbia in terms of their impacts on the twin goals and sustainability. These are (1) reforming SOEs to reduce the state's footprint in the economy and increase public sector efficiency; (2) reforming the business climate to create the conditions for private sector-led investment, growth, and job creation; (3) strengthening labor market institutions to facilitate formal employment, mitigate the transitional impact of SOE reforms, and create better employment opportunities for the less well-off; (4) supporting higher agriculture productivity and increased rural income through policy and institutional support and incentives to improve the welfare of the B40 and reduce poverty; and (4) enhancing Serbia's quality of public infrastructure to support improved regional and domestic connectivity and external competitiveness. Table VII.3 lays out the key policy actions that would help achieve the medium-term policy objective in each area.

Table VII.3: Five Top Priorities with the Highest Impact on the Twin Goals

\begin{tabular}{|c|c|}
\hline $\begin{array}{l}\text { Medium-Term Policy } \\
\text { Objective }\end{array}$ & Priority Policy Actions \\
\hline $\begin{array}{l}\text { Reform SOEs: Reduce the } \\
\text { state's footprint in the } \\
\text { economy and make the } \\
\text { public sector more efficient } \\
\text { by privatizing commercially } \\
\text { oriented enterprises and } \\
\text { restructuring large public } \\
\text { utilities. }\end{array}$ & $\begin{array}{l}\text { - Privatize/ divest the } 502 \text { commercial companies in the PA } \\
\text { portfolio. } \\
\text { - Restructure and corporatize the four largest public utilities } \\
\text { (Srbijagas, EPS, Railways, Roads). } \\
\text { - Srbijagas: Resolve the debts of large SOEs to Srbijagas; amend } \\
\text { the RINO law to stop SOEs and budgetary institutions from } \\
\text { accumulating new debt; corporatize and financially consolidate the } \\
\text { company, with priority attention to debt workouts with commercial } \\
\text { banks and gas suppliers. } \\
\text { - EPS: Increase collections from SOEs and budgetary institutions; } \\
\text { commercialize EPS, starting with a tariff adjustment; reinforce the } \\
\text { independence and accountability of the supervisory board; put in } \\
\text { place social protection measures for the most vulnerable } \\
\text { consumers. } \\
\text { - Railways (ŽS): Appoint autonomous management free to make } \\
\text { business decisions; retrench excess labor; close lines and stations } \\
\text { that no longer make sense and dispose of assets } \\
\text { - Roads (PERS): Transform PEPS into an autonomous agency with } \\
\text { a guaranteed budget and accountability for results; improve public } \\
\text { investment management in terms of readiness and land and } \\
\text { property issues; monitor progress at a higher level of government. }\end{array}$ \\
\hline $\begin{array}{l}\text { Business climate reforms: } \\
\text { Create an environment } \\
\text { conducive to private sector- } \\
\text { led investment, growth, and } \\
\text { job creation, }\end{array}$ & $\begin{array}{l}\text { - Reduce state's footprint, level the playing field for private sector } \\
\text { participation } \\
\text { - Reduce the time it takes to obtain construction permits. } \\
\text { - Make policy and regulation more predictable, and consistently } \\
\text { enforce laws and regulations. } \\
\text { - Improve contract enforcement and insolvency mechanisms. }\end{array}$ \\
\hline
\end{tabular}


Table VII.3: Five Top Priorities with the Highest Impact on the Twin Goals

\begin{tabular}{|c|c|}
\hline Medium-Term Policy & Priority Policy Actions \\
\hline & $\begin{array}{l}\text { - Reduce the high NPLs and improve access to finance, including } \\
\text { long-term finance, particularly for SMEs, including long-term } \\
\text { financing } \\
\text { - Reduce the time it takes for customs clearance and border } \\
\text { inspection }\end{array}$ \\
\hline $\begin{array}{l}\text { - Labor market institutions: } \\
\text { Strengthen labor market } \\
\text { institutions to facilitate formal } \\
\text { employment, mitigate the } \\
\text { transitional impact of SOE } \\
\text { reforms, and create better } \\
\text { employment opportunities for } \\
\text { the less well-off. }\end{array}$ & $\begin{array}{l}\text { - Help mitigate the layoff/ unemployment impact of the SOE } \\
\text { reforms } \\
\text { - Strengthen the capacity and programs of the National Employment } \\
\text { Service (NES). } \\
\text { - Reform, as fiscal space opens, the minimum social security } \\
\text { contribution; and the design of the FSA program through in-work } \\
\text { benefits. } \\
\text { - Further reform the labor code to encourage work in the formal } \\
\text { sector, including part-time work. }\end{array}$ \\
\hline $\begin{array}{l}\text { - Agriculture, self- } \\
\text { employment: Support higher } \\
\text { agriculture productivity and } \\
\text { rural incomes to improve the } \\
\text { welfare of the B40 and reduce } \\
\text { poverty. }\end{array}$ & $\begin{array}{l}\text { - Reduce distortions in the design of subsidies, such as the area- } \\
\text { based payment. } \\
\text { - Support for capacity building and reform of the national } \\
\text { institutions providing public services for agriculture to improve } \\
\text { land markets, food safety and quality and to better alignment with } \\
\text { EU regulatory policy; } \\
\text { - Improve the predictability of policy; rebalance public support from } \\
\text { direct payments toward investment and extension services. }\end{array}$ \\
\hline $\begin{array}{l}\text { - Infrastructure: Enhance } \\
\text { Serbia's quality of public } \\
\text { infrastructure to support } \\
\text { improved regional and } \\
\text { domestic connectivity, } \\
\text { external competitiveness }\end{array}$ & $\begin{array}{l}\text { Transport: competitively bid maintenance contracts; promote } \\
\text { prudent PPPs where possible; reform Roads of Serbia and } \\
\text { Railways (see SOEs above); and invest, as fiscal space opens over } \\
\text { the medium term, more in maintenance of national and rural roads. } \\
\text { - Energy: create an organized market (power exchange); establish a } \\
\text { transparent price signal and facilitate regional power trade; reform } \\
\text { Srbijagas and EPS (see SOE above); and as fiscal space opens over } \\
\text { the medium term, invest in new/upgrading energy infrastructure to } \\
\text { reliably meet demand. } \\
\text { - ICT: Provide supportive environment (e.g. training, venture } \\
\text { capital, incubation) to boost innovation; privatize Telekom Srbija. }\end{array}$ \\
\hline
\end{tabular}

Reform SOEs to reduce the state's footprint in the economy and make the public sector more efficient.

7.12. Central to restoring growth and shared prosperity in Serbia is completing the unfinished first-generation SOE reforms. As thoroughly discussed above, SOE reforms will have multiple and significant benefits, such as reducing the fiscal pressure on the state budget; leveling the playing field for the private sector; helping improve the quality of infrastructure; and making resource allocation more efficient; and producing at least one-off productivity gains and growth.

7.13. Two actions are needed to achieve the medium-term policy objective of reducing the state's footprint and making the public sector more efficient: privatizing the 502 commercially-oriented SOEs 
and restructuring public energy and transport utilities (Srbijagas, EPS, Serbia Railways, and Roads of Serbia). Getting these done can contribute significantly to fiscal sustainability and macroeconomic stability; help open up space for private sector investment and participation in the economy; and help improve the quality of infrastructure by introducing greater operational efficiency for these utilities and enhancing their financial viability.

7.14. These gains, however, are not costless - the transitional employment consequences of these reforms may be significant. Although exact estimates are difficult to make, from 30,000 to 50,000 workers could be made redundant in the SOE reform process, and cushioning and managing the social impacts of such labor retrenchment - through severance packages, employment services, and active labor market policies to support transition to new jobs - are critical to success. While the employment consequences of SOE reform are clearly negative in the short term, reform is a necessary step that Serbia must take; meanwhile it must build up its labor market institutions to mitigate the adverse impact and create the conditions for increased formal jobs (see labor market institutions below). Decisive political commitment to see these reforms through is critical.

Create an environment conducive to private sector-led investment, growth, and job creation.

7.15. If space is not opened up for private sector-led growth and job creation, it is unlikely that Serbia will make significant headway on the twin goals. As already discussed, a major part of that effort must be to reduce the state's footprint in the economy and downsize its dominant role in economic areas that are commercial in nature and suitable for private sector participation. Beyond SOE reforms, however, Serbia's business climate needs work to remove fundamental barriers to private investment and participation in the economy.

7.16. Policy actions that are critical to improving the business climate and promoting private sector-led growth and job creation are (a) reducing the state's footprint in the economy, leveling the playing field and opening up space for the private sector; (b) reducing the time it takes to obtain construction permits; (c) making policy and regulation more predictable, and consistently enforcing laws and regulations through better administrative coordination and supervision; (d) combating the informal economy and continuing to restructure SOEs; and (e) improving contract enforcement and insolvency mechanisms. For SMEs, special attention would need to be paid to access to finance, including long-term finance; and for large and exporting firms, facilitating customs and trade is particularly critical. Removing these constraints will enable Serbia to secure current and attract more investments; create broad-based growth and job opportunities; and increase exports and competitiveness.

Strengthen labor market institutions to facilitate formal employment, create earnings opportunities for the less well-off, and mitigate the transitional impact of SOE reforms.

7.17. Pro-growth reforms in Serbia will have distributional and transitional impacts, particularly in terms of the adverse employment effects, complementary policies are of paramount importance in mitigating such impacts. Given the mounting challenge of low employment in Serbia, improving labor market institutions and interventions is central to job creation and sustained shared prosperity and poverty 
reduction. From the SCD evidence and analysis and the team scoring of priorities, a clear priority emerges of the need to create more effective labor markets and institutions.

7.18. Policy actions critical to creating more effective labor market institutions are three-fold: (a) Rethinking the minimum social security contribution: Serbia is the only country in the region that still has a social security floor that is not adjusted by actual hours worked. That means it has one of the highest tax wedges on labor at lower wage levels among OECD and neighboring countries. Adjusting the minimum social security contribution by actual hours worked - or removing it - would encourage more formal parttime jobs, which are the best chances of employment for older workers and redundant SOE workers. A further study that would generate new knowledge on a fiscally-viable way of reducing the high minimum social security contributions, currently a strong disincentive to accepting formal part-time work, could be useful. While the authorities recognize this hinders formal employment, there is concern about the underreporting of wages, implications for the health and pension funds and the fiscal sustainability of the reform overall. The study could build the evidence base to support this important reform. (b) Building up National Employment Service (NES) capacity and programs: The NES caseload is unsustainably high; creating a list of active job seekers, removing incentives to register as unemployed, and increasing administrative capacity would help reduce it. NES ALMPs can be redesigned to focus on connecting job seekers to where the jobs are (by providing relocation benefits), training for the young and older workers, and as a last resort public works. Better use of current data and gathering of new data to better monitor, evaluate, and research labor market conditions and programs in Serbia would also help make the NES more efficient. (c) Redesigning the last-resort FSA program: In-work benefits could help overcome the current disincentives for formal work in the form of losing social assistance benefits.

7.19. Combined, these measures can help mitigate the transition costs of SOE reforms; support employment opportunities in part-time formal sector jobs, which are most relevant for the older workers likely to be laid off from SOEs and the less well-off; provide safety nets and better incentives for transition to work, and help reduce poverty. These measures could in turn feedback greater employment opportunities and labor participation in the economy to higher and sustainable growth.

Support higher agriculture productivity and rural incomes to improve the welfare of the B40 and reduce poverty.

7.20. The sluggish labor market in Serbia will take time to recover and ultimately thrive; in the meantime, agriculture is a major player in determining economic gains for the B40 employed in the sector. As already analyzed, tackling a few constraints can help raise agriculture productivity and rural incomes, with sizable impacts on poverty reduction, labor mobility, and over the long term structural transformation.

\subsection{Policy actions needed to make progress toward the medium-term goal of increased} agricultural productivity and rural incomes are (a) reducing distortions in the design of subsidies, such as the area-based payment; (b) deepening the land market to facilitate farm restructuring, reduce land fragmentation, and improve farmers' incentives to raise productivity and on-farm investment; and (c) improving policy predictability and institutional support to agriculture to enhance the productivity and incomes of poorer households. With the current subsidy scheme, small and low-productivity farmers have 
less incentive to lease or sell their land to more progressive producers who have the ability and the resources to heighten productivity and compete in markets. Where feasible, eligibility for area payments should thus be conditional on farm-level initiatives to invest, improve product quality, and adopt sustainable environmental practices. Making policy and institutional support more predictable is also important. Budget support to agriculture has been volatile. Individual support programs change often, and even within programs, eligibility criteria and the amount of support can change more than once in a single season. While the government has made progress in improving the policy framework by adopting numerous laws and regulations in the past two years, more predictable policy would create a more favorable environment for farm investment and production. Finally, rebalancing public support between direct payments and investment or structural support would shift the dominance from direct subsidies to farmers to productivityenhancing support in terms of extension services, diversification of farm income, irrigation and improvements of infrastructure, and technology transfer. In sum, addressing the constraints calls for reforms to facilitate farm restructuring, deepen land markets, rebalance support between direct payments and investment or structural support, strengthen supply chains, and modernize production systems. Other priorities are sustainable use of natural resources and rural development and welfare support.

Enhance Serbia's quality of public infrastructure to support improved regional and domestic connectivity, external competitiveness

7.22. While Serbia's infrastructure is generally of respectable quality, further investment and institutional reforms could enhance connectivity, competitiveness and access to services. Rail passenger services are neither reliable nor comfortable. Not only is investment in maintaining the Serbian roads network (an estimated 9,500 km) low, but the per-km cost is among the highest in the region. That could be reduced through competitive bidding and performance contracts. Investment is also needed to upgrade the energy infrastructure to reliably meet demand, create a power exchange market, and establish a transparent price signal and facilitate regional power trade. Beyond investment, a significant part of the agenda for improving the quality of infrastructure, particularly in transport and energy, relates to institutional and financial reforms to make large public utilities more efficient - another illustration of the centrality of SOE reforms to the growth and competitiveness agenda. In ICT, providing a supportive environment (e.g. through training, venture capital, incubation) can boost innovation and maintain Serbia's comparative advantage in ICT service exports.

\section{Other Supporting Priorities}

7.23. Four priorities emerge as supporting priorities with medium impact on the twin goals and sustainability. These are: (1) education and skills; (2) water and sanitation; (3) health; and (4) social protection. Table VII.4 lays out the main policy priorities in each area over the medium-term. 
Table VII.4: Supporting Priorities

\begin{tabular}{|c|c|}
\hline $\begin{array}{l}\text { Medium Term Policy } \\
\text { objective }\end{array}$ & Top/Priority Policy Actions \\
\hline $\begin{array}{l}\text { Water supply and } \\
\text { sanitation: Enhance } \\
\text { Serbia's water resource } \\
\text { management, wastewater } \\
\text { treatment, and } \\
\text { environmental } \\
\text { sustainability }\end{array}$ & $\begin{array}{l}\text { - Increase the operational efficiency and financial viability of } \\
\text { municipal water utility; } \\
\text { - Invest in and expand wastewater treatment (currently only } 14 \\
\text { percent of wastewater treated) to reduce environmental and public } \\
\text { health hazard. } \\
\text { - Create opportunities for greater private sector participation in solid } \\
\text { waste management and environmental sustainability, including } \\
\text { through PPPs/concessions. }\end{array}$ \\
\hline $\begin{array}{l}\text { Education and skills: } \\
\text { Expand access to } \\
\text { education and improved } \\
\text { quality for all and in } \\
\text { particular marginalized } \\
\text { groups, reduced inequity } \\
\text { and increased workforce } \\
\text { productivity through } \\
\text { improved skills and } \\
\text { learning outcomes }\end{array}$ & $\begin{array}{l}\text { - Expand preschool education for entire age cohort and in particular } \\
\text { marginalized group } \\
\text { - Expand access to education for the Roma } \\
\text { - Improve efficiency of resource allocation } \\
\text { - Improve teachers training and qualification, teacher incentives for } \\
\text { performance } \\
\text { - Improve skills and learning outcomes, including through early } \\
\text { learning and reforming of higher education and TVET system }\end{array}$ \\
\hline $\begin{array}{l}\text { Health: Expand access to } \\
\text { care (for marginalized } \\
\text { groups), reduce disparity } \\
\text { and improve the quality } \\
\text { of care and health } \\
\text { outcomes, and reduce } \\
\text { fiscal risks from health } \\
\text { expenditures. }\end{array}$ & $\begin{array}{l}\text { - Reduce disparities and expand access to care for the Roma } \\
\text { - Increase spending efficiency and quality of care: Serbia spends } \\
\text { almost twice as much per capita than comparable countries to get } \\
\text { similar health outcomes } \\
\circ \text { Output-based financing, enhanced facility autonomy and } \\
\text { accountability, } \\
\circ \text { Increased share of medical staff in total health care staff, } \\
\circ \text { Further reforms of pharmaceutical spending, and } \\
\circ \text { Capital investment and maintenance of equipment and capital } \\
\text { stock. }\end{array}$ \\
\hline $\begin{array}{l}\text { Social protection: } \\
\text { Improve the coverage, } \\
\text { equity, efficiency, and } \\
\text { fiscal sustainability of } \\
\text { pensions and the social } \\
\text { assistance program }\end{array}$ & $\begin{array}{l}\text { - Expand coverage and generosity of the last-resort, means-tested } \\
\text { Financial Social Assistance } \\
\text { - Improve the benefit design to incentivize transition to work - for } \\
\text { example by requiring able-to-work beneficiaries to register with the } \\
\text { NES and search for jobs } \\
\text { - Strengthen the link between social assistance and employment } \\
\text { services } \\
\text { - Ensure fiscal sustainability and future adequacy of pension benefits }\end{array}$ \\
\hline
\end{tabular}

7.24. The four supporting priorities enhance the achievement of high-impact priorities especially in the longer-term. They improve the sustainability of reforms aimed at accelerating growth, and are an important and inherent element of the overall inclusion agenda. Some of these 'supporting priorities' are directly linked to the success of the high priority reforms; for example, strengthening the social protection system can reduce vulnerability of the less well-off to fiscal consolidation and public sector downsizing. Others will have more medium to long term payoffs for equity and growth (e.g. expanded ECD enrollment), but given the constrained fiscal environment, implementation may need to be phased overtime, with a focus in the short-term on efficiency and institutional reforms that don't require money and, as fiscal space opens, 
investment in expanding access to social services (in health, education and water and sanitation) and addressing social disparities over the long-term.

7.25. Finally, Serbia cannot end poverty and achieve shared prosperity without addressing the Roma inclusion agenda. As already discussed, the Roma population faces multiple interlocking challenges, ranging from identity, discrimination, lack of access to basic services and opportunities in education and health care, to consequently lower income opportunities and a higher incidence of poverty and deprivation. As detailed in Box IV.1, cross-cutting policy priorities for Roma inclusion include: expanding the quality and coverage of ECD programs for Roma and other vulnerable groups; ensuring that undocumented members of the Roma population obtain the identification cards needed to claim health care and social protection services; upgrading Roma housing, identifying locations for social housing, improving infrastructure in Roma settlements; and, supporting employment of Roma in public institutions by, e.g., setting and monitoring clearly defined minority employment targets; strengthen NES capacity to provide support to Roma job seekers adapted to their specific employment needs.

Sequencing of Reforms and Overall Impact on the Twin Goals

Sequencing of reforms

7.26. The sequencing of priorities could be informed by three considerations: the strategic importance and spillover effects of reforms, their fiscal impact, and political economy considerations. For example, given Serbia's tight fiscal situation and the ongoing fiscal consolidation program, it won't be possible to pursue priorities which will require significant public investment/spending in the short-term. Some of the priority reforms - in particular those related to strengthening labor market institutions, investment in infrastructure including in adaptation and disaster risk mitigation infrastructure, etc.- do indeed require additional fiscal expenditures which are currently not available. As such, they can only be implemented over the medium term as public debt sustainability is brought back to sustainability and fiscal space is created.

7.27. The foundational priorities take precedence over any other priorities as they are essential for other reforms to work. No resumption of growth or shared prosperity can be expected without macroeconomic stability; nor any progress on reforms without overhauling the largely dysfunctional policy coordination mechanism and creating a modicum of effective governance and government institutional capacity within government. In that sense, the foundational priorities are enablers without which other reforms are unlikely to work. Fiscal consolidation to reduce fiscal deficits and restore debt sustainability is already underway, but further progress on governance including improving the policy coordination mechanisms; establishing strategic planning and performance management processes; and putting in place a professional human resource management system that can support staffing control and horizontal redeployment of staff within government are very much needed.

7.28. As the foundational priorities are tackled, the SOE and business climate reforms could then follow given their strategic importance and their potential to unlock, or support the effectiveness of, many others. SOE reform, through its impact on fiscal policy, private investment, the labor market, and the quality of infrastructure would have substantial positive spillovers and benefits on growth and shared 
prosperity. Most immediately, it would help reduce the state's footprint in the economy, create a levelplaying field for greater private sector participation in the economy. The latter is essential to support private investment and enhance private sector-led growth and job creation in Serbia. The complementary business climate reforms could then help attract even more private investment and facilitate increased productivity and efficiency, and private sector-led growth and job creation. Given the serious concerns around the lack of growth and jobs in Serbia today, no other reforms are more strategic. However, undertaking the SOE reform involves a transitional fiscal and social cost as 30,000 to 50,000 workers could lose their jobs, most of them older and unskilled. The challenge for the government is to manage the social impact by providing adequate financial compensation for redundant workers in the short run and ensuring that a modern social protection and labor system can mitigate impacts in the long run.

7.29. Even in this very constrained fiscal environment, this means that resources have to be found for some critical priorities, most directly or indirectly linked to labor market institutions and employment generation (e.g. financing of severance pay for laid-off workers, strengthening of the national appointment services). Fortunately, for severance pay, not only has the government recently reformed the system to ensure the adequacy and equity between the private and the public sector; but it has also included in the 2015-16 budget the fiscal expenditures required for such compensation to those who could be laid off. Over the medium to long-run, laid off workers need, beyond severance pay, employment services which will need to be strengthened.

7.30. Other priority reforms - in particular those related to investments in infrastructure and investment in other supporting priorities — could only be implemented over the medium to long-term as fiscal space opens up. On the labor market side, reforming the minimum social security contribution and improving the design of the FSA program through in-work benefits would both have fiscal implications which will need to be carefully assessed before implementation. Similarly, in infrastructure, investment in maintenance of national and rural roads, in new energy infrastructure, and in adaptation and mitigation measures all require fiscal resources, which may not be available in short-term but rather only over the medium to long-term. Those reforms should therefore wait. However, even within the same two priority areas of labor market institutions and infrastructure, reforms that don't necessarily require fiscal expenditures (e.g. institutional reforms) could be pursued in the short-term.

Impact on the twin goals

7.31. How do the reform priorities as a package deliver on the twin goals? The package of priority reforms described above would help place Serbia on a significantly more rapid path of sustainable growth, shared prosperity and poverty reduction. We consider two possible macroeconomic scenarios-one under which the government strongly implements the reform priorities as identified in this report (Scenario 1) and another where there is unsatisfactory or little progress in implementing the priority actions in the short to medium term (Scenario 2). The scenarios are illustrative only ${ }^{71}$ and actual outcomes could fall somewhere between the two scenarios.

${ }^{71}$ The two scenarios are descriptive illustrations and not backed by full-fledged macroeconomic projections. 
7.32. Scenario I: Strong Implementation of the Priority Actions. Under this scenario, the government undertakes a fiscal consolidation program, which would help restore debt sustainability, enhance macroeconomic stability and boost confidence in the policy framework, thereby stimulating private investment. It would also implement privatization and enterprise restructuring, and business environment reforms, which would lead to greater confidence in the policy framework, a robust private sector response, a rapid increase in productivity and export performance, and a return, as the Eurozone recovers, of external inflows including significant FDI. Under such scenario, average real GDP growth can reach 4-5 percent per year over the medium term, consistent with the country's potential growth rate. This high growth combined with efforts targeted at strengthening labor market institutions and mitigating social and distributional impacts--would in turn be strongly supportive of Serbia's goal of greater shared prosperity and lower poverty. While there would be an initial reduction of consumption growth to allow investment to reach levels which can produce more rapid economic growth, there will be a subsequent rapid rebound in consumption growth, reflecting the benefits of deeper reforms.

7.33. Scenario II: Weak/Unsatisfactory Implementation of the Priority Actions. Under the second scenario, the government maintains the current fiscal policy, including high mandatory spending on wages and pensions and continued fiscal support to SOEs. The SOE and investment climate reforms will be weakly implemented or not at all. Total public expenditures would remain high, and a mixture of poor fiscal performance, low growth, and high interest rates would lead to an unsustainable path for public debt. As a result of the unfavorable debt sustainability outlook and limited program credibility, and the failure to reform the SOEs and the investment climate, private investments including FDI would be crowded out. Average GDP growth under this scenario would be near zero or negative over the medium term as a result of the unsatisfactory implementation of the priority actions - fiscal, SOE, business climate--all of which would also be associated with a disappointing productivity performance, export competitiveness and growth. The economy would be highly exposed to adverse shocks, and more prone to a financial crisis. Clearly, such a policy environment would not be conducive to boosting shared prosperity and reducing poverty in Serbia. Under this scenario, total consumption growth falls steadily, reaching negative rates over the medium term. As the public sector is not adjusting, the growth rate of private consumption declines even more rapidly, reflecting the combined effect of slower GDP growth and the reduced availability of foreign financing. These will result in worsening shared prosperity and increased poverty, similar to the trends seen during 2009-14 but perhaps on a much more pronounced scale.

\subsection{The two illustrative scenarios exhibit strikingly different economic growth paths, with Serbia} reaching much higher growth rates under the first scenario while remaining at a virtual standstill or further contraction under the second scenario. Similarly, the growth paths of consumption, the main determinant of shared prosperity and poverty levels, would remain very different under the two scenarios, with consumption declining temporarily but rapidly rebounding and growing over the medium term under the first scenario and declining by less initially but steadily declining over the medium term under the second scenario. These paths are illustrative of the difficult choices involved in the reform process. Delayed reforms can defer the pain, but only temporarily and at the cost of more painful adjustments in the future. All in all, the results suggest that the implementation of the priority package of reforms-fiscal adjustment, SOE and investment climate reforms-- directed at improving productivity and export performance are Serbia's most promising route to achieving more rapid and more sustainable growth. Unwavering commitment and a determined implementation of the program would also enable Serbia to lock in the 
virtuous cycle of higher investment, savings, productivity and growth, and - improved living standards. Deviation from this route--as was demonstrated by the second illustrative scenario--would not only leave the economy highly vulnerable to external and internal shocks, but would also have adverse welfare implications for the B40.

\section{Sustainability}

7.35. For sustainable progress on the twin goals, Serbia needs to manage the three principal risks identified in this report: external, environmental, and sociopolitical. While all are important, evidence points to the special importance of Serbia better managing disaster and climate-related risks. This is not only because Serbia in recent years has been subject to a wide variety of natural hazards - floods, landslides, droughts, earthquakes, and wildfires - much more often than to the other two risks, it is also because these shocks directly affect both people and infrastructure and have caused serious damage to the economy and the well-being of vulnerable populations. The frequency of such events in the last 15 years suggests that investment in resilience and disaster risk management is a critical priority: Serbia experienced major floods in 1999, 2001, 2002, 2005, 2006, 2007, 2009, 2010, and - the biggest so far-in 2014. These have caused loss of lives, resettlements, severe damage to infrastructure, and adverse impacts on agriculture, energy, and other productive sectors.

\subsection{Agriculture, already on the frontline of the Serbian economy, is most vulnerable to weather} hazards and climate change, with repercussions for growth (value-added and exports) and shared prosperity (B40 welfare). Increasingly frequent and intensive droughts in the past two decades have deeply damaged Serbian agriculture: it is estimated that droughts can reduce average crop yield by over 40 percent, which could worsen as the climate continues to change. While floods and landslides are the biggest threats, earthquakes and wildfires have also inflicted serious damage. Climate change is expected to increase the intensity and frequency of such disasters, with more droughts in the summer and more floods in the winter and spring. That will have serious implications for agriculture, infrastructure, and the security of the population.

\subsection{Addressing these environmental risks will require a significant shift from emergency} response to a more comprehensive approach based on resilience and risk management, including: (i) A better understanding of the contingent liabilities caused by adverse natural events; proactive risk reduction activities; policies and actions to minimize future risk; (ii) Adaptation measures to reduce risks (e.g., expand the share of winter crops, improve on-farm water management and water storage capacity); integrate climate change considerations and adaptation into the agriculture sector development plan; pilot insurance schemes; build more knowledge and capacity (e.g., raise awareness of climate-smart practices by agro-ecological zone and heighten the related skills); and (iii) Mitigation measures, in particular energy efficiency, clean energy, and waste management and pollution control. Serbia's economy uses 25 percent more energy than the average for the Western Balkans. It is also among the most carbon-intensive, with some two-thirds of its electricity needs met by lignite power plants. Investment in adaptation and mitigation, however, can only happen over the medium term as public debt is brought back to sustainability and Serbia's gradually creates the fiscal space needed for new public investments. 
7.38. The socio-political risks relate to the potential distributional and social impacts of reforms, as well as the government's ability to maintain broad support for reforms in the face of the large reform agenda. Serbia's macroeconomic outlook is precarious and the economy is facing very serious challenges. Public debt levels are high and rising. Addressing public debt will require tackling stubborn spending pressures, which in turn will force wide-ranging and deep structural reforms that won't be easy to implement. The SOE and public sector reforms involve significant layoffs--potentially between 30,000 and 50,000 workers -- which are politically unpopular. If, as the public sector sheds employment in the short to medium term, private sector investment and job creation do not kick in fast enough to offset immediate public sector losses and/or other social mitigations measures are not put in place, unemployment and shared prosperity could worsen and the government could lose socio-political support for reforms. Cushioning and managing the social impacts of such layoffs and labor retrenchment - through appropriate severance packages, employment services, active labor market policies, social safety nets, and a return to growth -are all therefore critical to support transition and the success of the reforms.

\section{Knowledge Gaps}

7.39. A number of serious knowledge gaps have emerged in the course of the SCD analysis: (a) Labor demand: Better firm-level data (firm census or panel data) and further analysis to understand the dynamics of labor demand, the impacts on labor market outcomes, and whether labor supply responds effectively; (b) Roma: The agenda to enhance Roma inclusion is not simple, and continuing to experiment, evaluate and learn is necessary to better inform what works best to address this challenge; (c) Skills: The extent to which skills gaps will constrain business and productivity in a growing Serbian economy is unclear, suggesting an important knowledge gap for further investigation; and (d) Fiscal implications of reforming the minimum social security contributions: A further study is needed to generate new knowledge on a fiscally-viable way of reducing the high minimum social security contributions, currently a strong disincentive to accepting formal part-time work. While the authorities recognize this hinders formal employment, there is concern about the under-reporting of wages, implications for the health and pension funds and the fiscal sustainability of the reform overall. The study could build the evidence base to support this important reform. 
Table VII.5: Serbia SCD Prioritization: Principal Constraints and their Impact on Twin Goals (Based on SCD Team Scoring)

\begin{tabular}{|c|c|c|c|c|}
\hline $\begin{array}{l}\text { Constraints } \\
\text { as discussed } \\
\text { in SCD }\end{array}$ & $\begin{array}{l}\text { Medium Term } \\
\text { Policy objective }\end{array}$ & Top/Priority Policy Actions & $\begin{array}{c}\text { Intermediate } \\
\text { Impact Channels }\end{array}$ & $\begin{array}{c}\text { SCD Team } \\
\text { Ranking of } \\
\text { Overall } \\
\text { Impact on the } \\
\text { Twin Goals * } \\
\end{array}$ \\
\hline $\begin{array}{l}\text { Governance } \\
\text { and } \\
\text { institutional } \\
\text { capacity }\end{array}$ & $\begin{array}{l}\text { - Create an effective } \\
\text { institutional } \\
\text { mechanism within } \\
\text { government for } \\
\text { coordination, } \\
\text { implementation, } \\
\text { and monitoring of } \\
\text { reforms }\end{array}$ & $\begin{array}{l}\text { - Overhaul the largely dysfunctional coordination } \\
\text { mechanisms } \\
\text { - Establish strategic planning and performance } \\
\text { management processes } \\
\text { - Put in place professional human resource } \\
\text { management that can support staffing control and } \\
\text { horizontal redeployment } \\
\text { - Reduce number of employees in the Public } \\
\text { Sector/Government employed in administration and } \\
\text { bureaucracy }\end{array}$ & $\begin{array}{l}\text { Impact through: } \\
\text { - Pace and quality of reform } \\
\text { implementation } \\
\text { - Public sector performance and } \\
\text { service delivery } \\
\text { - Reduced wage bill in the public } \\
\text { sector } \\
\text { - Monitoring, course correction, } \\
\text { evaluation } \\
\text { - Improved trust between } \\
\text { government and citizens }\end{array}$ & 2 \\
\hline $\begin{array}{l}\text { Fiscal } \\
\text { sustainability, } \\
\text { financial and } \\
\text { macro stability }\end{array}$ & $\begin{array}{l}\text { Restore debt } \\
\text { sustainability and } \\
\text { maintain macro } \\
\text { and financial } \\
\text { stability }\end{array}$ & $\begin{array}{l}\text { - Implement a fiscal consolidation program, } \\
\text { including reduction in mandatory spending such as } \\
\text { wage bill, pensions } \\
\text { - Implement structural reforms related to SOEs, in } \\
\text { particular public utilities, and reduce their fiscal } \\
\text { support } \\
\text { - Address vulnerabilities in the state-owned banks } \\
\text { - Strengthen governance and oversight, and } \\
\text { supervisory bank resolution framework } \\
\text { - Strengthen public financial management }\end{array}$ & $\begin{array}{l}\text { Impact through: } \\
\text { - } \quad \text { Macro stability } \\
\text { - } \quad \text { Financial stability }\end{array}$ & 1 \\
\hline $\begin{array}{l}\text { State owned } \\
\text { enterprises }\end{array}$ & $\begin{array}{l}\text { - Reduce state's } \\
\text { footprint in the } \\
\text { economy and } \\
\text { increase public } \\
\text { sector efficiency } \\
\text { through } \\
\text { privatizing the } \\
\text { commercially } \\
\end{array}$ & $\begin{array}{l}\text { - Privatize or liquidate the } 502 \text { companies in the PA } \\
\text { portfolio } \\
\text { - Restructure and corporatize the four large public } \\
\text { utilities (Serbia gas, EPS, Railways, Roads) } \\
\text { - Create opportunities for greater private sector } \\
\text { participation in infrastructure including through } \\
\text { concessions/PPPs. }\end{array}$ & $\begin{array}{l}\text { Impact through: } \\
\text { - Government fiscal balance, macro } \\
\text { stability } \\
\text { - Level playing field for the private } \\
\text { sector } \\
\text { - Labor market/ employment } \\
\text { (negative in the short run but }\end{array}$ & 4 \\
\hline
\end{tabular}


Table VII.5: Serbia SCD Prioritization: Principal Constraints and their Impact on Twin Goals (Based on SCD Team Scoring)

\begin{tabular}{|c|c|c|c|c|}
\hline $\begin{array}{l}\text { Constraints } \\
\text { as discussed } \\
\text { in } \mathrm{SCD}\end{array}$ & $\begin{array}{l}\text { Medium Term } \\
\text { Policy objective }\end{array}$ & Top/Priority Policy Actions & $\begin{array}{c}\text { Intermediate } \\
\text { Impact Channels }\end{array}$ & $\begin{array}{c}\text { SCD Team } \\
\text { Ranking of } \\
\text { Overall } \\
\text { Impact on the } \\
\text { Twin Goals * }\end{array}$ \\
\hline & $\begin{array}{l}\text { oriented } \\
\text { enterprises and } \\
\text { restructuring the } \\
\text { large public } \\
\text { utilities }\end{array}$ & $\begin{array}{l}\text { - Srbijagas: resolve debts of large SOEs toward } \\
\text { Srbijagas; amend the RINO law to stop SOEs and } \\
\text { budgetary institutions from accumulating new debt; } \\
\text { corporatize and financially consolidate, with } \\
\text { priority attention to debt workouts with } \\
\text { commercial banks and gas suppliers. } \\
\text { - EPS: Increase collections from SOEs and budgetary } \\
\text { institutions; commercialize EPS, centering on } \\
\text { improved performance, and reinforced } \\
\text { independence of the supervisory board; put in place } \\
\text { mechanisms to monitor management accountability; } \\
\text { implement a financial consolidation plan including } \\
\text { staff reductions and a path of tariff adjustments; put } \\
\text { in place social protection measures to make energy } \\
\text { services affordable for the most vulnerable } \\
\text { consumers. } \\
\text { - Railways: Appoint an autonomous ŽS } \\
\text { management free to make business decisions; } \\
\text { retrench excess labor; close lines and stations that } \\
\text { no longer make sense and dispose of assets } \\
\text { - Roads (PEPS): Transform PEPS into autonomous } \\
\text { agency with guaranteed budget and accountability } \\
\text { for results; improve public investment management } \\
\text { overall (readiness, land and property issues, } \\
\text { progress monitoring at higher level of government) } \\
\text { - Telecom Srbija: Privatize Telekom Srbija }\end{array}$ & $\begin{array}{l}\text { beneficial over the medium to long } \\
\text { term) } \\
\text { - Viability of the public utilities and } \\
\text { quality of infrastructure } \\
\text { - Resource reallocation, higher } \\
\text { productivity } \\
\text { - Loss of income and poverty, } \\
\text { possibly for those who will be laid } \\
\text { off }\end{array}$ & \\
\hline $\begin{array}{l}\text { Business } \\
\text { climate }\end{array}$ & $\begin{array}{l}\text { - Create an } \\
\text { environment } \\
\text { conductive to } \\
\text { private sector-led }\end{array}$ & $\begin{array}{l}\text { - Reduce the time it takes to obtain all types of } \\
\text { business permits and licensing, in particular } \\
\text { construction permits; }\end{array}$ & $\begin{array}{l}\text { Impact through: } \\
\text { - Private investment, including FDI } \\
\text { - Efficiency, reduced time cost and } \\
\text { red-tape for businesses }\end{array}$ & 3 \\
\hline
\end{tabular}


Table VII.5: Serbia SCD Prioritization: Principal Constraints and their Impact on Twin Goals (Based on SCD Team Scoring)

\begin{tabular}{|c|c|c|c|c|}
\hline $\begin{array}{l}\text { Constraints } \\
\text { as discussed } \\
\text { in SCD }\end{array}$ & $\begin{array}{l}\text { Medium Term } \\
\text { Policy objective }\end{array}$ & Top/Priority Policy Actions & $\begin{array}{c}\text { Intermediate } \\
\text { Impact Channels }\end{array}$ & $\begin{array}{c}\text { SCD Team } \\
\text { Ranking of } \\
\text { Overall } \\
\text { Impact on the } \\
\text { Twin Goals } \\
\end{array}$ \\
\hline & $\begin{array}{l}\text { investment, } \\
\text { growth and job } \\
\text { creation }\end{array}$ & $\begin{array}{l}\text { - Improve the speed, accuracy and reliability of } \\
\text { registering property rights } \\
\text { Make policy and regulation more predictable, and } \\
\text { consistently enforce laws and regulations through } \\
\text { better administrative coordination and supervision; } \\
\text { - Improve contract enforcement and insolvency } \\
\text { mechanisms laws, regulations and judicial practice. } \\
\text { Improve access to finance for both SMEs and } \\
\text { corporates, including through reducing the high } \\
\text { NPLs } \\
\text { Reduce the time it takes for customs clearance and } \\
\text { border inspection }\end{array}$ & $\begin{array}{l}\text { - Efficient real estate (mortgage) } \\
\text { markets } \\
\text { - Better access to finance, including } \\
\text { long-term finance } \\
\text { - Jobs and employment } \\
\text { opportunities both through FDI and } \\
\text { SMEs } \\
\text { - Exports, export competitiveness }\end{array}$ & \\
\hline Infrastructure & $\begin{array}{l}\text { - Enhance Serbia's } \\
\text { quality of public } \\
\text { infrastructure to } \\
\text { support improved } \\
\text { regional and } \\
\text { domestic } \\
\text { connectivity, } \\
\text { external } \\
\text { competitiveness }\end{array}$ & $\begin{array}{l}\text { Transport: competitively bid maintenance } \\
\text { contracts; promote prudent PPPs where possible; } \\
\text { reform Roads of Serbia and Railways (see SOEs } \\
\text { above); and invest, as fiscal space opens over the } \\
\text { medium term, more in maintenance of national } \\
\text { and rural roads. } \\
\text { Energy: create an organized market (power } \\
\text { exchange); establish a transparent price signal and } \\
\text { facilitate regional power trade; reform Srbijagas } \\
\text { and EPS (see SOE above); and as fiscal space } \\
\text { opens over the medium term, invest in } \\
\text { new/upgrading energy infrastructure to reliably } \\
\text { meet demand. } \\
\text { ICT: Provide supportive environment (e.g. } \\
\text { training, venture capital, incubation) to boost } \\
\text { innovation; privatize Telekom Srbija. }\end{array}$ & $\begin{array}{l}\text { Impact through: } \\
\text { - } \quad \text { Efficiency of resource use } \\
\text { - } \quad \text { Quality of infrastructure } \\
\text { - } \quad \text { Private investment and } \\
\text { participation in infrastructure } \\
\text { - Environmental and health risks } \\
\text { - } \quad \text { Exports of services }\end{array}$ & 7 \\
\hline
\end{tabular}


Table VII.5: Serbia SCD Prioritization: Principal Constraints and their Impact on Twin Goals (Based on SCD Team Scoring)

\begin{tabular}{|c|c|c|c|c|}
\hline $\begin{array}{l}\text { Constraints } \\
\text { as discussed } \\
\text { in } \mathrm{SCD}\end{array}$ & $\begin{array}{l}\text { Medium Term } \\
\text { Policy objective }\end{array}$ & Top/Priority Policy Actions & $\begin{array}{c}\text { Intermediate } \\
\text { Impact Channels }\end{array}$ & $\begin{array}{l}\text { SCD Team } \\
\text { Ranking of } \\
\text { Overall } \\
\text { Impact on the } \\
\text { Twin Goals * } \\
\end{array}$ \\
\hline $\begin{array}{l}\text { Water supply } \\
\text { and sanitation }\end{array}$ & $\begin{array}{l}\text { - Enhance Serbia's } \\
\text { water resource } \\
\text { management, } \\
\text { wastewater } \\
\text { treatment, and } \\
\text { environmental } \\
\text { sustainability }\end{array}$ & $\begin{array}{l}\text { - Increase the operational efficiency and financial } \\
\text { viability of municipal water utility; } \\
\text { - Invest in and expand wastewater treatment } \\
\text { (currently only } 14 \text { percent of wastewater treated) to } \\
\text { reduce environmental and public health hazard. } \\
\text { - Create opportunities for greater private sector } \\
\text { participation in solid waste management and } \\
\text { environmental sustainability, including through } \\
\text { PPPs/concessions. }\end{array}$ & $\begin{array}{ll}- & \text { Quality of water } \\
\text { - } & \text { Improved sanitation and } \\
& \text { wastewater treatment } \\
\text { - } & \text { Lower public health hazard }\end{array}$ & 9 \\
\hline $\begin{array}{l}\text { Education and } \\
\text { skills }\end{array}$ & $\begin{array}{l}\text { Expand access to } \\
\text { education and } \\
\text { improved quality } \\
\text { for all and in } \\
\text { particular } \\
\text { marginalized } \\
\text { groups, reduced } \\
\text { inequity and } \\
\text { increased } \\
\text { workforce } \\
\text { productivity } \\
\text { through improved } \\
\text { skills and learning } \\
\text { outcomes } \\
\end{array}$ & $\begin{array}{l}\text { - Expand preschool education for entire age cohort } \\
\text { and in particular marginalized group } \\
\text { - Expand access to education for the Roma } \\
\text { - Improve efficiency of resource allocation } \\
\text { - Improve teachers training and qualification, teacher } \\
\text { incentives for performance } \\
\text { - Improve skills and learning outcomes, including } \\
\text { through early learning and reforming of higher } \\
\text { education and TVET system }\end{array}$ & $\begin{array}{l}\text { Impact on: } \\
\text { - } \quad \text { Skills and education endowment } \\
\text { - Participation in economic activity } \\
\text { - } \quad \text { Prodinclusion } \\
\text { - }\end{array}$ & 8 \\
\hline Health & $\begin{array}{l}\text { Expand access to } \\
\text { care (for } \\
\text { marginalized } \\
\text { group), reduce } \\
\text { disparity and } \\
\text { improve the } \\
\text { quality of care and }\end{array}$ & $\begin{array}{l}\text { Reduce disparities and expand access to care for } \\
\text { the Roma } \\
\text { - Increase spending efficiency and quality of care: } \\
\text { Serbia spends almost twice as much per capita than } \\
\text { comparable countries to get similar health } \\
\text { outcomes }\end{array}$ & $\begin{array}{l}\text { Impact through: } \\
\text { Better health and wellbeing; } \\
\text { increased productivity and } \\
\text { competitiveness over the long } \\
\text { term } \\
\text { - Participation in economic } \\
\text { activity, inclusion }\end{array}$ & 11 \\
\hline
\end{tabular}


Table VII.5: Serbia SCD Prioritization: Principal Constraints and their Impact on Twin Goals (Based on SCD Team Scoring)

\begin{tabular}{|c|c|c|c|c|}
\hline $\begin{array}{l}\text { Constraints } \\
\text { as discussed } \\
\text { in SCD }\end{array}$ & $\begin{array}{l}\text { Medium Term } \\
\text { Policy objective }\end{array}$ & Top/Priority Policy Actions & $\begin{array}{c}\text { Intermediate } \\
\text { Impact Channels }\end{array}$ & $\begin{array}{c}\text { SCD Team } \\
\text { Ranking of } \\
\text { Overall } \\
\text { Impact on the } \\
\text { Twin Goals * }\end{array}$ \\
\hline & $\begin{array}{l}\text { health outcomes, } \\
\text { and reduce fiscal } \\
\text { risks from health } \\
\text { expenditures. }\end{array}$ & $\begin{array}{l}\begin{array}{l}\text { Output-based financing, enhanced facility } \\
\text { autonomy and accountability, }\end{array} \\
\text { Increased share of medical staff in total health } \\
\text { care staff, } \\
\circ \begin{array}{l}\text { Further reforms of pharmaceutical spending, } \\
\text { and }\end{array} \\
\text { Capital investment and maintenance of } \\
\text { equipment and capital stock. }\end{array}$ & $\begin{array}{l}\text { Sustainable health financing, } \\
\text { while providing protection from } \\
\text { impoverishing health } \\
\text { expenditures }\end{array}$ & \\
\hline $\begin{array}{l}\text { Social } \\
\text { protection }\end{array}$ & $\begin{array}{l}\text { - Improve the } \\
\text { coverage, equity, } \\
\text { efficiency, and } \\
\text { fiscal } \\
\text { sustainability of } \\
\text { pensions and the } \\
\text { social assistance } \\
\text { program }\end{array}$ & $\begin{array}{l}\text { - Expand coverage and generosity of the last-resort, } \\
\text { means-tested Financial Social Assistance } \\
\text { - Improve the benefit design to incentivize transition } \\
\text { to work - for example by requiring able-to-work } \\
\text { beneficiaries to register with the NES and search for } \\
\text { jobs } \\
\text { - Strengthen the link between social assistance and } \\
\text { employment services } \\
\text { - Ensure fiscal sustainability and future adequacy of } \\
\text { pension benefits }\end{array}$ & $\begin{array}{l}\text { Impact through: } \\
\text { Expanded coverage of the poor, } \\
\text { and higher income for } \\
\text { beneficiaries } \\
\text { - Lower poverty and reduce } \\
\text { vulnerable of poor and near-poor } \\
\text { to shocks } \\
\text { - Transition from safety nets to } \\
\text { work } \\
\text { - Fiscally sustainable pension } \\
\text { system with adequate benefits }\end{array}$ & 10 \\
\hline $\begin{array}{l}\text { Labor market } \\
\text { institutions }\end{array}$ & $\begin{array}{l}\text { - Strengthen labor } \\
\text { markets } \\
\text { institutions to } \\
\text { facilitate increased } \\
\text { formal } \\
\text { employment, } \\
\text { create earnings } \\
\text { opportunities for } \\
\text { the less well-off, } \\
\text { and help mitigate }\end{array}$ & $\begin{array}{l}\text { - Help mitigate the layoff/ unemployment impact of } \\
\text { the SOE reforms } \\
\text { - Strengthen the capacity and programs of the } \\
\text { National Employment Service (NES). } \\
\text { - Reform, as fiscal space opens, the minimum social } \\
\text { security contribution; and the design of the FSA } \\
\text { program through in-work benefits. } \\
\text { - Further reform the labor code to encourage work in } \\
\text { the formal sector, including part-time work. }\end{array}$ & $\begin{array}{l}\text { Impact through: } \\
\text { - } \quad \text { Mitigation of transition costs } \\
\text { - } \quad \text { Supporting employment } \\
\text { opportunities } \\
\text { - } \quad \text { Providing safety nets } \\
\text { - } \quad \text { Reducing poverty } \\
\text { - } \text { Feedback from greater } \\
\text { employment to growth }\end{array}$ & 5 \\
\hline
\end{tabular}


Table VII.5: Serbia SCD Prioritization: Principal Constraints and their Impact on Twin Goals (Based on SCD Team Scoring)

\begin{tabular}{|c|c|c|c|c|}
\hline $\begin{array}{l}\text { Constraints } \\
\text { as discussed } \\
\text { in SCD }\end{array}$ & $\begin{array}{l}\text { Medium Term } \\
\text { Policy objective }\end{array}$ & Top/Priority Policy Actions & $\begin{array}{c}\text { Intermediate } \\
\text { Impact Channels }\end{array}$ & $\begin{array}{c}\text { SCD Team } \\
\text { Ranking of } \\
\text { Overall } \\
\text { Impact on the } \\
\text { Twin Goals * }\end{array}$ \\
\hline & $\begin{array}{l}\text { the negative } \\
\text { consequences of } \\
\text { SOE reforms }\end{array}$ & & & \\
\hline $\begin{array}{l}\text { Agriculture, } \\
\text { self- } \\
\text { employment }\end{array}$ & $\begin{array}{l}\text { - Higher agriculture } \\
\text { productivity and } \\
\text { rural income to } \\
\text { improve the } \\
\text { welfare of b40 and } \\
\text { reduce poverty. }\end{array}$ & $\begin{array}{l}\text { - Reduce distortions in the design of subsidies (such } \\
\text { as such as the milk-subsidies) } \\
\text { - Support for capacity building and reform of the } \\
\text { national institutions providing public services for } \\
\text { agriculture to improve land markets, food safety } \\
\text { and quality and to better alignment with EU } \\
\text { regulatory policy; } \\
\text { - Improve predictability of policy and rebalance } \\
\text { public support from direct payments toward } \\
\text { investment and rural development, particularly for } \\
\text { Central and South Serbia }\end{array}$ & $\begin{array}{l}\text { Impact through: } \\
\text { - Higher rural income, direct } \\
\text { poverty reduction } \\
\text { - Labor mobility, structural } \\
\text { transformation (long-term) }\end{array}$ & 6 \\
\hline
\end{tabular}




\section{REFERENCES}

Arias Diaz, Omar S., Carolina Sanchez. 2014. "The jobs challenge in ECA: translating economic growth into strong employment creation".

Banovic, Gojko. 2013. "Current Situation in Secondary Vocational Education in Serbia” A Presentation at a TVET conference, http://www.tvetconference2013.org/eng/presentation/gojko-banovic.pdf

Bodewig, Christian and Joost de Laat. World Bank/UNDP/EC 2011 survey of Roma population: "Roma Inclusion: An Economic Opportunity for Bulgaria, Czech Republic, Romania and Serbia" World Bank.

Bussolo, M. and L.F. Lopez-Calva. 2014. Shared Prosperity: Paving the Way in Europe and Central Asia. World Bank.

CEVES. 2007. "Understanding Belgrade Services Sector".

Cristian Aedo, Jesko Hentschel, Javier Luque and Martin Moreno. 2013 from Occupations to Embedded Skills: A Cross-Country Comparison. Washington, DC: World Bank.

Cuberes, David and and Marc Teignier-Baqué. 2014. Aggregate Costs of Gender Gaps in the Labor Market: A Quantitative Estimate", UB Economics Working Papers 2014/308, Universitat de Barcelona, Facultat d'Economia i Empresa, UB Economics.

EBRD-World Bank. EBRD-World Bank Business Environment and Enterprise Performance Survey (BEEPS) 2013.

European Commission. 2013. Serbia Progress Report. Retrieved December 222014 from http://ec.europa.eu/enlargement/pdf/key_documents/2013/package/brochures/serbia_2013.pdf

Evans, Anne and Gord Evans, 2001, "Improving government decision-making systems in Lithuania and Latvia", Journal of European Public Policy, Volume 8, Issue 6.

Ghosh, Swati R., and Aart Kraay, 2000, "Measuring growth in total factor productivity: Worksheet to estimate total factor productivity" PREM Note 42.

Government of Serbia. 2014. Second national report on social inclusion and poverty reduction in the Republic of Serbia. Belgrade: Government of Serbia.

Government of Serbia. 2010. "Initial National Communication of the Republic of Serbia under the United Nations Framework Convention on Climate Change.” Belgrade: Government of Serbia.

Government of Serbia, Ministry of Environment, Mining and Spatial Planning. 2011. "National environmental approximation strategy for the republic of Serbia." Belgrade: Government of Serbia. 
IMF. 2015. Republic of Serbia: 2014 Article IV Consultation and Request for Stand-By Arrangement-Staff Report; Press Release; and Statement by the Executive Director for the Republic of Serbia Series: Country Report No. 15/50

IMF. 2013. Serbia- 2013 Article IV Consultation Concluding Statement of the Mission. Washington, DC.

Isik-Dikmelik, Aylin and Boryana Gotcheva. 2013. "Activation and social safety nets in Serbia" study.

Khwaja, Munawer. 2014. Revenue potential, tax space, and tax gap: a comparative analysis, Volume 1. Policy Research Working Paper; no. WPS 6868. Washington, DC: World Bank.

Koettle, Johannes. 2014. Labor market notes: "Serbia’s Jobs challenges”, Apolicy brief.

Koettle, Johannes. 2010. "Does formal work pay in Serbia", Atechnical note.

Kuddo, Arvo. 2013. Labor regulations in the Western Balkans WB technical note.

Kunivoca, Jana and Zeljko Bogetic. 2013. "Political Economy of Reform in Western Balkans: Are there Quick Wins?" World Bank.

Lažetić, P.; Zivadinovic, I.; Jaric, I.; Radonjic, O. 2014. From Student to Unemployed Professional. Findings from the First Graduate Survey in Serbia, Bosnia and Herzegovina, and Montenegro within the Tempus Project CONGRAD. Tempus.

Linden, T. and N. Arnhold with K. Vasiliev. 2008. From Fragmentation to Cooperation: Tertiary Education, Research and Development in South Eastern Europe. Washington, DC: World Bank.

OECD, Program for International Student Assessment (PISA), 2000, 2003, 2006, 2009, and 2012.

OECD. 2013. PISA 2012 Assessment and analytical framework. Mathematics, reading, science, problem solving and financial literacy. OECD Publishing.

OSF. 2010. Roma Children in "Special Education" in Serbia: Overrepresentation, Underachievement and Impact on Life.

Pierre, G., Sanchez Puerta, M., Valerio, A., and Rajadel, T. 2014. STEP Skills Measurement Surveys. Innovative tools for assessing skills. Social Protection and labor Discussion paper. Washington DC: World Bank.

Quintini, G. 2011. Overqualified or under-skilled: A review of existing literature. OECD Social, Employment, and migration working papers N. 121 OECD.

Reva, Anna. 2012. "Gender Inequality in the Labor Market in Serbia" Using 2008 \& 2009 LFS and 2009 BEEPS.

SABER. Country Reports for Serbia. Various Issues.

Serbia Statistical Office. Poverty release using 2010 SILC; Poverty Report using LSMS 2002-2007.

Serbia Statistical Office. 2013. Survey of Income and Living Conditions 2013-Cross-sectional Database. Belgrade. 
Sondergaard, L., Murthi, M. et al. 2012. Skills, Not Just Diplomas. Managing Education for Results in Eastern Europe and Central Asia. Washington, DC: World Bank.

Statistical Office of the Republic of Serbia. 2014. Unemployment indicators. Retrieved December 2014 from http://webrzs.stat.gov.rs/WebSite/public/ReportView.aspx

Topalović, Srdjan., Aleksandar Đukić and Zorana Naunović. "Cost Recovery of Water and Wastewater Utilities in Serbia", in Water Research and Management, Vol. 2, No. 4 (2012) 19-32.

UNDP Serbia. 2014. Attitudes of Serbian Citizens towards corruption. UNDP, 2013.

UNESCO Institute for Statistics. 2014. Retrieved January 22 from

http://www.uis.unesco.org/DataCentre/Pages/country-profile. aspx? code=SRB\&regioncode $=40530$

UNICEF. 2012. Investing in Early Childhood Education in Serbia; p. 9. http://www.romachildren.com/wpcontent/uploads/2013/02/RECI-Serbia-Report.ENG_.pdf

USAID. 2013. "The Shadow Economy in Serbia: New Findings and Recommendations for Reform", Belgrade.

WHO/UNICEF. 2014. Joint Monitoring Program, www.wssinfo.org.

World Bank. 2010. “Mapping Serbia’s Growth - Spatial Dimensions.” Washington, DC.

World Bank. 2010. "Serbia Rightsizing the Government Wage Bill”, Washington, DC.

World Bank. 2010. Stepping up Skills for More Jobs and Higher Productivity. Washington, DC.

World Bank. 2010. Roma Inclusion: An Economic Opportunity for Bulgaria, Czech Republic, Romania and Serbia. Washington, DC: World Bank.

World Bank. 2011. "Social Safety Nets in the Western Balkans: Design, Implementation and Performance."

World Bank. 2011. Migration and Remittances Fact Book. Washington DC.

World Bank. 2012. "Serbia Country Economic Memorandum”, Vols. 1 and 2, Washington DC.

World Bank. 2013. "Serbia: Municipal Public Finance and Expenditure Review I”. Washington, DC.

World Bank. 2013. Doing Business 2014: Understanding Regulation for Small and Medium Enterprises, Washington, DC.

World Bank. 2014. "Serbia Municipal Public Finance Review II - Options for Efficiency Gains", Washington, DC.

World Bank. 2014. "Serbia Judicial Functional Review”.

World Bank. 2014. "Connecting to Compete: Trade Logistics in the Global Economy-The Logistics Performance Index and Its Indicators." Washington, DC. 
World Bank. 2014. "Turn Down the Heat: Confronting the New Climate Normal” Report No. 3, November. Washington, DC.

World Bank. 2014. Doing Business 2015: Going Beyond Efficiency, A World Bank Group Flagship Report. Washington, DC.

World Bank. 2014. "Competitiveness Policy Note: Rebalancing Serbia's Economy: Improving Competitiveness, Strengthening the Private Sector, and Creating Jobs". Washington, DC.

World Bank. Visualize Inequality Dashboard.

http://www1.worldbank.org/poverty/visualizeinequality/index.html

World Economic Forum. "The Global Competitiveness Report 2014-15"

http://www.weforum.org/reports/global-competitiveness-report-2014-2015

World Bank. "Serbia Financial Sector Assessment Program (FSAP) Update.” Washington, DC.

World Bank. Serbia Poverty Updates for 2008-2009 and 2010.

World Bank. South East Europe Regular Economic Report. Various issues.

World Wide Fund for Nature. 2012. Living Planet Report. Washington, DC. 


\section{Annex 1: Additional Statistics on Poverty and Shared Prosperity}

Table 1: 2012 Population Distribution by Income Category and Poverty Rates by Population Area

\begin{tabular}{|c|c|c|c|c|c|}
\hline \multirow[b]{2}{*}{ Region } & \multicolumn{3}{|c|}{ Population Distribution across Regions by Income Category } & \multicolumn{2}{|c|}{ Poverty Rates by Population Area } \\
\hline & Poor (60\% Median Income) & $\begin{array}{l}\text { Bottom } \\
40 \%\end{array}$ & Overall Population & $\begin{array}{l}\text { Poverty } 60 \% \\
\text { Median Income }\end{array}$ & $\begin{array}{l}\text { Poverty } \$ 5 / \text { day } \\
\text { PPP }\end{array}$ \\
\hline Densely Populated Area & 20.2 & 23.7 & 36.1 & 13.8 & 7.3 \\
\hline Intermediate Area & 26.6 & 26.9 & 27.7 & 23.6 & 12.9 \\
\hline Thinly Populated Area & 53.2 & 49.4 & 36.2 & 36.2 & 21.6 \\
\hline Total & 100 & 100 & 100 & 24.6 & 14 \\
\hline
\end{tabular}

Source: World Bank staff calculations based on SILC 2013.

Figure 1: Distribution of labor market status, by poverty and income group

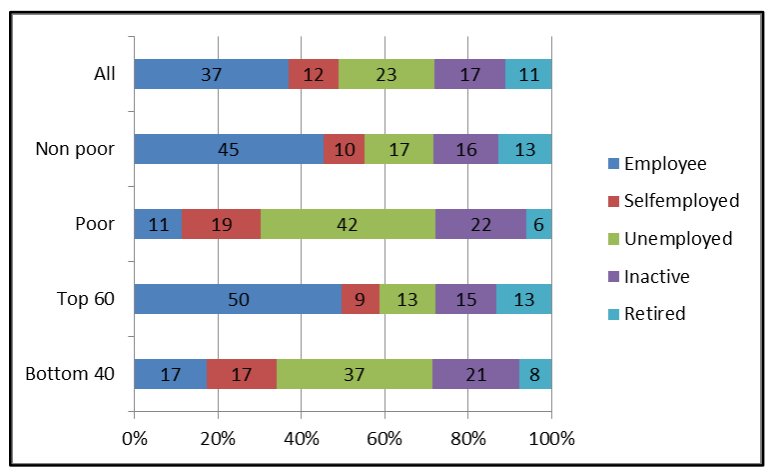

Source: Based on Statistical Office of Republic of Serbia's SILC data.

Note: "Poor" refers to at-risk-of poverty population (below 60 percent median income).
Figure 2: Following the crisis, loss in employment and labor income was the major contributor to poverty increase

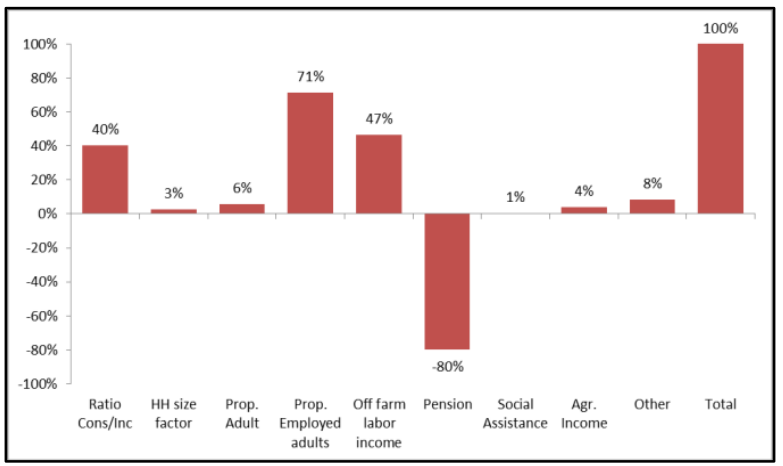

Note: Decomposition of poverty increase 2008-2010 by income component.

Table 2: Labor Force Statistics by income group (18-65)

\begin{tabular}{|c|c|c|c|c|c|}
\hline & \multicolumn{5}{|c|}{$60 \%$ Median Income } \\
\hline & All & Bottom 40\% & Top 60\% & Poor & Non Poor \\
\hline Labor Force Participation & 71.9 & 71.4 & 72.1 & 72.1 & 71.8 \\
\hline Unemployment & 31.7 & 52.1 & 18.6 & 58.2 & 23.0 \\
\hline Employment Rate & 49.0 & 34.2 & 58.7 & 30.2 & 55.3 \\
\hline Self-employment ( $\%$ of employed) & 24.7 & 49.3 & 15.4 & 62.1 & 18.0 \\
\hline Public Sector (\% of employed) & 32.8 & 14.6 & 39.7 & 9.6 & 37.0 \\
\hline
\end{tabular}

Source: Based on Statistical Office of Republic of Serbia's SILC data

Note: Labor forces statistics derived from household surveys can differ slightly from those derived from the Labor Force Surveys (designed specifically for measuring labor market data), but comparisons across income groups are expected to be reliable. 



\section{Annex 2: Serbia: Public Financial Management Challenges}

Serbia's budgeting process is not anchored by performance requirements. Strategic targets by line ministries are neither well-defined nor monitored regularly. Medium-term budgeting exists for a rolling three years, but in reality annual budgets are executed without careful consideration of the two following years. Planning and management of capital investments are not based on meaningful cost-benefit analysis that would enable efficient use of resources and yield better results. Sector strategies do not specify full costing of recurrent and investment spending.

Serbia lacks sound financial controls and spending management. While the Budget System Law established the Public Internal Financial Control (PIFC) framework, in practice internal audit and financial management and control (FMC) still need significant elaboration. Most public entities have adopted internal auditing but it is not yet fully effective. An FMC function has yet to be established in a large number of entities and even in those where there are written procedures, in practice they are not applied. The State Audit Institution (SAI) has made notable progress in staffing and coverage of public spending but the number of entities audited needs to be expanded and performance auditing introduced. The laws have recently been changed to improve budget execution and arrears through commitment control, but accrual accounting - which will allow for a more comprehensive understanding of the government financial position as well as more efficient management of assets and liabilities — is not yet in place.

Improved management of public finances will require a shift from an annual and incremental approach to a more strategic and forward-looking approach. The government has initiated programbudgeting and treasury modernization reforms, but as yet the changes have not been significant.

\section{Public procurement}

The Public Procurement Law enacted in 2013 was a notable effort to align with the EU Procurement Directives (2004/18). ${ }^{72}$ The intent of the law was at ensure efficiency and effectiveness, competition and transparency, and prevent corruption and other public procurement abuses. The law therefore provides, among other requirements, for publication of notices through the public procurement portal, introduction of mandatory procurement planning, creation of a register of bidders, involvement of the civil supervisor, prevention of corruption and conflicts of interest, and post-employment restrictions for procurement staff. The law similarly reflects good international practice in providing for a mechanism to review complaints, which is important for oversight and enforcement of the procurement legislation.

The Public Procurement Office (PPO), however, is finding it hard to fulfill its responsibilities due to lack of capacity and understaffing. One of its main responsibilities is to issue opinions on interpretation and application of the law. The PPO's report “Activities on the Law applications from April 1, 2013, until

\footnotetext{
${ }^{72} \mathrm{http}: / /$ ec.europa.eu/enlargement/pdf/serbia/key_document/saa_en.pdf (September 2013). To comply with the SAA Serbia is obliged to open up the award of public contracts on the basis of non-discrimination and reciprocity, following the WTO rules; gradually eliminate application of domestic preferences for local companies until they are completely removed; and take measures to enhance transparency and provide for effective judicial review of public procurement decisions.
} 
January 31, 2014" states that "940 written requests for opinions on interpretation and application of provisions of the Law were received during the reported period. Of those, 358 requests were answered in writing, while the rest remained unanswered due to lack of capacity within the Public Procurement Office." It has also not been able to deliver professional training and certification programs, which means that public procurement officers are not certified as the law requires.

Other problems with the law have emerged. For example, it defines sanctions policies and procedures for companies that use inappropriate practices during the procurement process. However, the procedure for giving "a negative reference" is so complex that no company has so far has been put on this "debarred list." Responsibility for investigating and obtaining proof for negative reference is mainly on the contracting authorities, who do not have the capacity to do this. Greater transparency and accountability could be achieved if there were a clear obligation in the law to publish procurement plans and reports on the PPO portal. Furthermore, while the law allows for use of electronic auction and even makes it mandatory in some cases, it fails to deal with security challenges and bottlenecks in the capacity of both bidders and contracting authorities. An e-procurement platform has not yet been set up to support these requirements. 


\section{Annex 3: Serbia Growth ACCOUnTing, 1990-2011}

GDP can be expressed as a function of physical capital and human capital as follows: ${ }^{73}$

$$
Y=A F(K, L)(1)
$$

where $Y$ is gross domestic product (GDP) in constant 2005 US\$; $A$ is total factor productivity; $K$ is gross domestic capital stock in constant 2005 US\$; $L$ is human-capital-adjusted labor input.

$L$ can be defined as a function of employment, $E$, and the average human capital per employed, $h c$.

$$
L=E h c
$$

Employment and average human capital per employed data are from the Penn World Table 8.0. The latter is calculated as a function of returns to education (Psacharopoulos, 1994) and average years of schooling (Barro/Lee, 2012).

We assume that the aggregate production function is Cobb-Douglas type with constant returns to scale, in which the parameter $\alpha$ is between 0 and 1 and measures the relative importance of capital ${ }^{74}$ :

$$
Y=A K^{\alpha} L^{1-\alpha}
$$

\section{$\underline{\text { Capital Stock }}$}

The real capital stock estimates are from the PWT8.0, and they ar based on the perpetual inventory method (PIM):

$$
K_{t}=(1-\delta) K_{t-1}+I_{t}
$$

where $I_{t}$ represents investment in period $\mathrm{t}$ and $\square$ is the depreciation rate. The PWT8.0 uses gross fixed capital formation to approximate investment, which is assumed to be made of six types of assets with different life spans (Table 1).

The PWT8.0 collects data from various sources including the national statistical offices to estimate investment by asset type. In the absence of this data, the PWT8.0 uses the commodity-flow method (CFM) to extrapolate. The CFM assumes that investment on an asset varies with the economy-wide supply (production + imports - exports) of that asset. Calculated with this methodology, the capital stock in Serbia has an average depreciation rate of 3.2 percent across time and assets. ${ }^{75}$ The capital stock is deflated by a

\footnotetext{
${ }^{73}$ This framework is based on Swati R. Ghosh and Aart Kraay, 2000, "Measuring growth in total factor productivity: Worksheet to estimate total factor productivity" PREM Note 42.

${ }^{74}$ For developing countries, reasonable values of alpha range from 0.3 to 0.5 .

${ }^{75}$ Reasonable values for the depreciation rate range from 0.04 to 0.08 .
} 
common investment deflator except for the ICT assets, whose deflator is assumed to follow the US price trend.

Table 1: PWT8.0 Asset Types

\begin{tabular}{lcc}
\hline Asset & Depreciation rate & Initial capital-output ratio \\
\hline Structures (residential and non-residential) & $2 \%$ & 2.2 \\
Transport equipment & $18.9 \%$ & 0.1 \\
Computers & $31.5 \%$ & 0 \\
Communication equipment & $11.5 \%$ & 0 \\
Software & $31.5 \%$ & 0 \\
Other machinery and assets & $12.6 \%$ & 0.3 \\
Total & & $\mathbf{2 . 6}$ \\
\hline
\end{tabular}

The PWT8.0 discusses two methods to estimate the initial capital stock $\left(K_{0}\right)$. The first, proposed by Harberger (1978) is based on the steady-state relationship from the Solow growth model:

$K_{0}=\frac{I_{0}}{g+\delta}$

where the initial capital stock is a function of the investment in the initial period, the rate of depreciation, and the steady-state growth rate of investment, $g$. The PWT8.0 finds that the steady-state assumption is problematic particularly for the transition countries, and as a result uses an alternative approach to estimate $K_{0}$.

The PWT8.0 estimates the initial capital stock by assuming an initial capital-output ratio based on the sample median (Table 1). This initial capital-output ratio, $k_{0}$, is 2.6. Table 3 shows the real capital stock and its evolution in Serbia calculated based on the assumptions explained above. The real capital stock shows a consistent decrease during the transition years and a rapid increase in the post-transition period. 
Table 2: Real Capital Stock, 1990-2011

\begin{tabular}{lccccc}
\hline & $\begin{array}{c}\text { Average rate } \\
\text { of depreciation }\end{array}$ & Real investment & $\begin{array}{c}\text { Real capital } \\
\text { stock }\end{array}$ & Real GDP & $\begin{array}{c}\text { Capital-output } \\
\text { ratio }\end{array}$ \\
\hline 1990 & & & 229,990 & 92,955 & 2.7 \\
1991 & 0.036 & 221,435 & 229,758 & 82,112 & 3.0 \\
1992 & 0.036 & 219,223 & 227,436 & 59,006 & 4.1 \\
1993 & 0.035 & 215,656 & 223,634 & 41,051 & 5.9 \\
1994 & 0.034 & 212,664 & 220,277 & 42,116 & 5.7 \\
1995 & 0.033 & 210,177 & 217,468 & 44,511 & 5.4 \\
1996 & 0.032 & 208,057 & 215,086 & 46,582 & 5.1 \\
1997 & 0.032 & 206,519 & 213,309 & 50,042 & 4.5 \\
1998 & 0.031 & 205,044 & 211,650 & 50,361 & 4.3 \\
1999 & 0.031 & 203,451 & 209,921 & 44,732 & 4.6 \\
2000 & 0.030 & 203,119 & 209,376 & 47,084 & 4.3 \\
2001 & 0.029 & 202,124 & 208,284 & 49,602 & 3.8 \\
2002 & 0.029 & 202,134 & 208,260 & 51,755 & 3.9 \\
2003 & 0.029 & 204,405 & 210,534 & 53,051 & 3.9 \\
2004 & 0.030 & 208,499 & 214,766 & 58,002 & 3.8 \\
2005 & 0.031 & 212,493 & 219,090 & 61,136 & 4.5 \\
2006 & 0.031 & 217,838 & 224,713 & 63,310 & 4.6 \\
2007 & 0.032 & 225,482 & 232,671 & 66,718 & 4.8 \\
2008 & 0.033 & 232,584 & 240,332 & 69,266 & 4.7 \\
2009 & 0.035 & 235,546 & 243,844 & 66,837 & 4.5 \\
2010 & 0.034 & 238,541 & 246,852 & 67,521 & 4.6 \\
2011 & 0.034 & 242,997 & 251,321 & 68,616 & \\
Average & $\mathbf{0 . 0 3 2}$ & & & & \\
\hline
\end{tabular}

\section{$\underline{\text { Labor share of output and human capital adjusted labor input }}$}

In the aggregate Cobb-Douglas production function, the marginal product of labor is given by the following:

$$
\frac{\partial Y}{\partial L}=A_{t}(1-\alpha) K_{t}^{\alpha} L_{t}^{-\alpha}=\frac{(1-\alpha) Y_{t}}{L_{t}}=w_{t}
$$

The PWT8.0 estimates the share of labor in GDP, $(1-\alpha)$, by adjusting the compensation of employees given in the national accounts statistics for the labor income of the self-employed. Depending on the country characteristics different adjustment methodologies are employed, which are explained in Inklaar and Timmer (2013). Table 3 shows the estimated labor shares of GDP for Serbia. The labor share shows a significant and abrupt decline during the transition, which may suggest a break in the series. 
Table 3: Labor Share of GDP, 1990-2011

\begin{tabular}{|c|c|c|c|c|c|c|}
\hline & Labor share & Real GDP & Employment & $\begin{array}{l}\text { Real earnings } \\
\text { per employed }\end{array}$ & $\begin{array}{c}\text { Average } \\
\text { human capital } \\
\text { per employed }\end{array}$ & $\begin{array}{c}\text { Human capital } \\
\text { adjusted labor } \\
\text { input }\end{array}$ \\
\hline 1990 & 0.78 & 92,955 & 3.1 & 23,505 & 2.5 & 7.9 \\
\hline 1991 & 0.78 & 82,112 & 2.9 & 22,575 & 2.6 & 7.3 \\
\hline 1992 & 0.78 & 59,006 & 2.9 & 16,160 & 2.6 & 7.4 \\
\hline 1993 & 0.78 & 41,051 & 2.9 & 11,154 & 2.6 & 7.5 \\
\hline 1994 & 0.78 & 42,116 & 2.9 & 11,340 & 2.6 & 7.6 \\
\hline 1995 & 0.78 & 44,511 & 2.9 & 11,851 & 2.6 & 7.8 \\
\hline 1996 & 0.78 & 46,582 & 2.9 & 12,450 & 2.7 & 7.8 \\
\hline 1997 & 0.78 & 50,042 & 2.8 & 13,856 & 2.7 & 7.6 \\
\hline 1998 & 0.67 & 50,361 & 2.9 & 11,736 & 2.7 & 7.7 \\
\hline 1999 & 0.64 & 44,732 & 2.8 & 10,169 & 2.7 & 7.6 \\
\hline 2000 & 0.61 & 47,084 & 2.8 & 10,223 & 2.7 & 7.6 \\
\hline 2001 & 0.65 & 49,602 & 2.8 & 11,315 & 2.7 & 7.7 \\
\hline 2002 & 0.69 & 51,755 & 2.7 & 12,962 & 2.7 & 7.5 \\
\hline 2003 & 0.71 & 53,051 & 2.7 & 14,098 & 2.7 & 7.3 \\
\hline 2004 & 0.67 & 58,002 & 2.7 & 14,499 & 2.7 & 7.3 \\
\hline 2005 & 0.65 & 61,136 & 2.5 & 15,900 & 2.7 & 6.9 \\
\hline 2006 & 0.65 & 63,310 & 2.4 & 17,104 & 2.7 & 6.6 \\
\hline 2007 & 0.65 & 66,718 & 2.4 & 17,861 & 2.8 & 6.7 \\
\hline 2008 & 0.64 & 69,266 & 2.6 & 17,086 & 2.8 & 7.2 \\
\hline 2009 & 0.63 & 66,837 & 2.7 & 15,681 & 2.8 & 7.5 \\
\hline 2010 & 0.63 & 67,521 & 2.5 & 17,203 & 2.8 & 6.9 \\
\hline 2011 & 0.63 & 68,616 & 2.3 & 18,505 & 2.8 & 6.5 \\
\hline Average & 0.70 & & & & 2.7 & \\
\hline
\end{tabular}

\section{Total factor productivity and growth accounting}

With data on $Y, K, E$, and $h c$, and an estimation and/or assumption of reasonable values for the parameters of the growth accounting equations, $\square$ and $\square$, it is straightforward to estimate $A$, the Total Factor Productivity (TFP). Using the fact that in continuous time, the instantaneous rate of growth of output equals the ratio of its derivative with respect to time and the value at which the derivative is evaluated, we differentiate both sides of (3) with respect to time, divide by $Y$, and rearrange:

$$
\frac{\dot{Y}}{Y}=\frac{\dot{A}}{A}+\alpha \frac{\dot{K}}{K}+(1-\alpha) \frac{\dot{L}}{L}
$$

Using a discrete version of equation (7), we estimate the growth rate of TFP as the difference between the growth rate of output and the weighted growth rates of factor inputs, the weights being their respective aggregate income shares. Typically, the growth rates are approximated by the first-differences in log levels of variables. However, this approximation may substantially underestimate large positive growth rates and overestimate negative ones. Considering that the Serbian economy experienced large contractions during the transition, we depart from this standard estimation techniques of equation (7) following Dolinskaya (2001) and use actual growth rates instead.

Table 4 shows the contributions of factor accumulation and total productivity growth to real GDP growth during 2000-11. 


$$
\frac{\Delta\left(Y_{t} / L_{t}\right)}{Y_{t} / L_{t}}=\frac{\Delta A_{t}}{A_{t}}+\bar{\alpha} \frac{\Delta\left(K_{t} / L_{t}\right)}{K_{t} / L_{t}}(8)
$$

Table 4: Growth Accounting, 1990-2011

\begin{tabular}{lllll}
\hline & Real GDP growth & $\begin{array}{c}\text { Contribution of } \\
\text { physical capital }\end{array}$ & $\begin{array}{l}\text { Contribution of } \\
\text { human capital }\end{array}$ & $\begin{array}{l}\text { Contribution of total } \\
\text { factor productivity } \\
\text { growth }\end{array}$ \\
\hline 1990 & & & & \\
1991 & $-11.7 \%$ & $0.0 \%$ & $-5.6 \%$ & $-6.0 \%$ \\
1992 & $-28.1 \%$ & $-0.2 \%$ & $0.9 \%$ & $-28.8 \%$ \\
1993 & $-30.4 \%$ & $-0.4 \%$ & $1.2 \%$ & $-31.3 \%$ \\
1994 & $2.6 \%$ & $-0.3 \%$ & $1.3 \%$ & $1.6 \%$ \\
1995 & $5.7 \%$ & $-0.3 \%$ & $1.4 \%$ & $4.5 \%$ \\
1996 & $4.7 \%$ & $-0.2 \%$ & $0.1 \%$ & $4.8 \%$ \\
1997 & $7.4 \%$ & $-0.2 \%$ & $-2.3 \%$ & $9.9 \%$ \\
1998 & $0.6 \%$ & $-0.2 \%$ & $1.5 \%$ & $-0.7 \%$ \\
1999 & $-11.2 \%$ & $-0.3 \%$ & $-1.2 \%$ & $-9.7 \%$ \\
2000 & $5.3 \%$ & $-0.1 \%$ & $0.4 \%$ & $5.0 \%$ \\
2001 & $5.3 \%$ & $-0.2 \%$ & $0.8 \%$ & $4.8 \%$ \\
2002 & $4.3 \%$ & $0.0 \%$ & $-2.1 \%$ & $6.4 \%$ \\
2003 & $2.5 \%$ & $0.3 \%$ & $-1.8 \%$ & $4.0 \%$ \\
2004 & $9.3 \%$ & $0.6 \%$ & $0.5 \%$ & $8.3 \%$ \\
2005 & $5.4 \%$ & $0.7 \%$ & $-4.3 \%$ & $9.0 \%$ \\
2006 & $3.6 \%$ & $0.9 \%$ & $-2.0 \%$ & $4.7 \%$ \\
2008 & $5.4 \%$ & $1.2 \%$ & $0.8 \%$ & $3.3 \%$ \\
2009 & $3.8 \%$ & $1.2 \%$ & $4.2 \%$ & $-1.6 \%$ \\
2010 & $-3.5 \%$ & $0.5 \%$ & $2.6 \%$ & $-6.6 \%$ \\
2011 & $1.0 \%$ & $0.5 \%$ & $-4.9 \%$ & $5.5 \%$ \\
$1991-2000$ & $1.6 \%$ & $0.7 \%$ & $-3.5 \%$ & $4.5 \%$ \\
$2001-08$ & $-5.5 \%$ & $-0.2 \%$ & $-0.2 \%$ & $-5.1 \%$ \\
$2009-10$ & $5.0 \%$ & $0.6 \%$ & $-0.5 \%$ & $4.9 \%$ \\
\hline & $-0.3 \%$ & $0.5 \%$ & $-2.0 \%$ & $1.1 \%$ \\
\hline
\end{tabular}





\section{AnneX 4: Serbia Governance Benchmarking ViS-À-VIS EU Member StateS}

Table 1: Serbia Governance and Institutional Capacity Benchmarking a/

\begin{tabular}{|c|c|c|c|c|c|c|c|c|}
\hline Area of Study & & POLICY & & & PEO & & & E-GOV \\
\hline Aspect of Study & $\begin{array}{l}\text { Performance } \\
\text { Management }\end{array}$ & $\begin{array}{l}\text { Strategic } \\
\text { Planning }\end{array}$ & $\begin{array}{c}\text { Policy } \\
\text { Coordination }\end{array}$ & $\begin{array}{c}\text { HR } \\
\text { Legislation }\end{array}$ & $\begin{array}{c}\text { HR } \\
\text { Horizontal } \\
\text { Management }\end{array}$ & $\begin{array}{l}\text { Political- } \\
\text { Admin } \\
\text { Relations }\end{array}$ & Incentives & E-Gov \\
\hline Scoring System & $\mathrm{CAF}$ & $\mathrm{CAF}$ & Metcalfe & SIGMA & SIGMA & SIGMA & SIGMA & \\
\hline Scoring Range & $0-5$ & $0-5$ & $1-9$ & $1-7$ & $1-7$ & $1-7$ & $1-7$ & $1-4$ \\
\hline Poland & 0.5 & 0.5 & 4 & $6 / 7$ & $6 / 7$ & 7 & 5 & 1 \\
\hline Hungary & 1 & 1.5 & 5 & 5 & 5 & 5 & -- & 1 \\
\hline Czech Republic & 1 & 1.5 & 3 & $6 / 7$ & $6 / 7$ & -- & -- & 2 \\
\hline Slovakia & 1 & 1.5 & 3 & $6 / 7$ & $6 / 7$ & 7 & -- & 2 \\
\hline Slovenia & 1 & 1.5 & -- & 5 & 5 & -- & -- & 1 \\
\hline Lithuania & 3 & 4 & 8 & 5 & 5 & 2 & 3 & 1 \\
\hline Latvia & 3 & 3.5 & 7 & 5 & 5 & 3 & 2 & 2 \\
\hline Estonia & 1 & 1.5 & -- & 5 & 5 & -- & - & 4 \\
\hline Serbia & 0.5 & 0.5 & 2 & 2 & 6 & 6 & 6 & 1 \\
\hline
\end{tabular}

Source: World Bank (2007), EU-8 Administrative Capacity in the New Member States: The Limits of Innovation?

Note: a/ See Annex 5 for more details on the rating methods.

The benchmarking systems are outlined below:

\section{CAF rating scale ${ }^{\mathbf{i}}$}

0-no evidence or only anecdotal evidence of an approach; 1-an approach is planned; 2-an approach is planned and implemented: 3-an approach is planned and implemented and reviewed; 4-an approach is planned and implemented and reviewed on the basis of benchmarking data and adjusted accordingly; 5- an approach is planned and implemented and reviewed on the basis of benchmarking data and adjusted accordingly and fully integrated into the organization.

\section{The Metcalfe scale}

9 Overall strategy

8 Establishing priorities

7 Setting parameters for action

6 Arbitration of policy differences

5 Search for agreement on policies

4 Avoiding divergences among organizations

3 Consultation with other organizations (feedback)

2 Communication to other organizations (information exchange)

1 Independent organizational decision-making

\section{SIGMA ratings}

1-standard achieved; 2-standard substantially achieved; 3-standard only partially achieved; 4-standard not yet achieved but progress being made; 5-standard not yet achieved; 6-standard not likely to be achieved in the medium term; 7-standard unlikely to be achieved under present arrangements.

\section{E-government capability ratings}

Stage 1-informational - one way communication of information

Stage 2-interactivity - two-way communication (e-mail, bulletin board etc.) 
Stage 3-transactional- internal and external transactions from request to fulfilment

Stage 4-transformational-e-democracy, e-voting, interoperability, seamless integration of government agencies and citizens 
Annex 5: Serbia: Key Macroeconomic Indicators And Projections

\begin{tabular}{|c|c|c|c|c|c|c|c|c|c|}
\hline & 2009 & 2010 & 2011 & 2012 & 2013 & 2014 & 2015 & 2016 & 2017 \\
\hline Real Economy & \multicolumn{9}{|c|}{ Annual percentage change, unless otherwise indicated } \\
\hline GDP (nominal,-local currency) & 4.9 & 6.5 & 11.1 & 5.2 & 8.2 & 0.0 & 2.2 & 5.7 & 6.2 \\
\hline Real GDP & -3.1 & 0.6 & 1.4 & -1.0 & 2.6 & -1.8 & -0.5 & 1.5 & 2.0 \\
\hline \multicolumn{10}{|l|}{ Contributions: } \\
\hline Consumption & -0.5 & -0.4 & 0.9 & -1.2 & -0.6 & -1.0 & -3.6 & -0.2 & 0.4 \\
\hline Investment & -11.5 & -1.3 & 2.6 & 0.6 & -0.6 & -0.7 & 0.9 & 1.1 & 1.1 \\
\hline Net Exports & 8.9 & 2.3 & -2.1 & -0.4 & 3.8 & -0.1 & 2.2 & 0.6 & 0.5 \\
\hline Exports & -2.1 & 4.3 & 1.6 & 0.3 & 7.4 & 1.6 & 1.4 & 2.2 & 3.1 \\
\hline Imports & -10.9 & 2.0 & 3.8 & 0.7 & 3.6 & 1.7 & -0.8 & 1.6 & 2.6 \\
\hline $\begin{array}{l}\text { Unemployment rate, average (av, ILO } \\
\text { definition) }\end{array}$ & 16.1 & 19.2 & 23.0 & 24.0 & 22.1 & 18.9 & 19.0 & 18.0 & 17.0 \\
\hline GDP deflator & 8.3 & 5.9 & 9.6 & 6.3 & 5.4 & 1.9 & 2.7 & 4.1 & 4.1 \\
\hline CPI (eop) & 6.6 & 10.2 & 7.0 & 12.2 & 2.2 & 1.7 & 4.2 & 4.0 & 4.0 \\
\hline Fiscal Accounts & \multicolumn{9}{|c|}{ Percent of GDP, unless otherwise indicated } \\
\hline Expenditures & 44.2 & 44.6 & 43.1 & 46.6 & 43.5 & 46.6 & 44.6 & 42.4 & 40.7 \\
\hline Revenues & 39.8 & 39.9 & 38.2 & 39.4 & 37.9 & 40.0 & 38.7 & 37.7 & 36.9 \\
\hline $\begin{array}{l}\text { General Government Balance (including } \\
\text { amortization of called guarantees) }\end{array}$ & -4.3 & -4.7 & -4.9 & -7.2 & -5.6 & -6.7 & -5.9 & -4.7 & -3.8 \\
\hline PPG debt (eop) & 36.0 & 43.7 & 46.6 & 58.3 & 61.4 & 71.0 & 77.1 & 78.6 & 78.1 \\
\hline Selected Monetary Accounts & \multicolumn{9}{|c|}{ Annual percentage change, unless otherwise indicated } \\
\hline Base Money & 7.2 & -2.0 & 15.8 & 5.2 & 25.9 & & & & \\
\hline Credit to non-government & 16.0 & 26.9 & 7.7 & 9.8 & -4.5 & & & & \\
\hline Interest (key policy interest rate) & 9.5 & 11.5 & 9.8 & 11.3 & 9.5 & 8.0 & & & \\
\hline Balance of Payments & \multicolumn{9}{|c|}{ Percent of GDP, unless otherwise indicated } \\
\hline Current Account Balance /a & -6.1 & -6.5 & -8.6 & -11.5 & -6.1 & -6.0 & -4.7 & -4.7 & -4.4 \\
\hline Imports & -37.5 & -42.4 & -43.2 & -44.2 & -42.9 & -44.6 & -45.0 & -43.9 & -43.9 \\
\hline Exports & 19.4 & 24.8 & 25.2 & 26.5 & 30.8 & 32.2 & 33.9 & 33.6 & 34.3 \\
\hline Foreign Direct Investment, net & 4.4 & 3.0 & 5.5 & 2.1 & 3.6 & 3.7 & 4.0 & 3.8 & 4.0 \\
\hline Gross Reserves (in US\$ bill, eop) & 15.2 & 13.3 & 15.6 & 14.4 & 15.4 & 12.0 & & & \\
\hline $\begin{array}{l}\text { In months of next year's } \\
\text { imports }\end{array}$ & 11.5 & 8.3 & 10.2 & 8.9 & 9.4 & 7.2 & & & \\
\hline Terms of Trade (change) & 0.8 & -0.6 & 3.5 & -0.9 & 1.0 & -0.1 & -0.3 & -0.2 & 0.1 \\
\hline Exchange Rate, USD (average) & 67.6 & 77.9 & 73.3 & 87.9 & 85.2 & 88.5 & & & \\
\hline \multicolumn{10}{|l|}{ Other memo items } \\
\hline GDP nominal in US\$ billion & 42.7 & 39.4 & 46.5 & 40.7 & 45.5 & 43.6 & & & \\
\hline
\end{tabular}

a) BoP data using BPM6 is available only as of 2012, for years 2009-2011data is based on the earlier BOP Manual.

Source: Ministry of Finance, NBS, IMF; WB staff estimates 


\section{Annex 6: Public Consultations and Citizen Engagement around the SCD}

The SCD was informed by discussions and consultations with stakeholders in Serbia about the diagnostic of the country's main development challenges. The Government of Serbia is aware of the preparation of the SCD as part of the World Bank Group's country engagement model. When the CN review was completed, the team proceeded with within-country presentations and dialogue with the government, donors, academics, the private business sector, and citizens group. The consultations were repeated after the full draft of the report was ready, including the prioritization of the reform agenda. The purpose of the SCD consultations was to build up the evidence base for the analysis, validate and contextualize the story emerging in the SCD, and to confirm whether the identified priorities were the right ones.

The team worked closely with the Belgrade country office and communications team in designing and conducting dialogues and consultations, including in regions outside Belgrade. Discussions within the country were enhanced by a similarly inclusive process of gathering evidence and feedback within the World Bank Group (see team composition below) and an internal review mechanism.

The consultations - both in Belgrade and outside Belgrade-- were lively and, as summarized below, covered a wide range of issues critical for growth, shared prosperity and poverty reduction in Serbia--most prominently issues of political economy, trust and social cohesion, the business climate, institutional capacity, contract enforcement and poor functioning of the insolvency regime, education, energy, Roma poverty, private investment, access to finance and NPLs. The discussions also offered insights on how, and areas where, the report could be strengthened -which the team found useful and took into account in the course of developing the full report and priorities for action.

\section{$\underline{\text { Summary of Key Issues Discussed/Points Made }}$}

\section{Political economy/Implementation challenges}

- A lot of the diagnoses discussed in the report - and what needs to be done -are known. Question is "what should we do if the patient is not taking the medicine?"

- Low trust and cohesion undermining progress in implementation; trust of citizens toward politicians low; inequality is also increasing in Serbia

- In some cases, political will for change lacking, need for change in mind-set

- There are also gaps between intentions and skills and expertise for implementation

- Civil servants fail to take personal responsibility in their day to day functions, fear decision making

- Instability and unpredictability of laws and regulations further feeds fear of decision making

- Institutional capacity and coordination is weak, better functioning of institutions critical for productivity

- Corruption, informal economy

- Social trust: Serbia comparative data might be obtained from EU SILC and "quality of life surveys".

- Government:

- Resistance to change, scrambled and fragmented decision making process, lack of clear lines of accountability have constrained implementation

- Report could more systematically cover key governance and institutional capacity issues which is not the case at the moment 


\section{Productivity, investment and growth}

- Growth narrative: could draw on "Altars of Geography report" and the concept of geographic centers of growth, i.e. the presence of a critical mass of networked companies over a certain geographic area

- Productivity:

○ better technology and investment critical for raising productivity

○ report could discuss more trends in investment, most of pre-crisis investment went into non-tradables

- Constraints to growth

- Long-run: quality of education, institutions, and infrastructure

- Medium and short-run: government investment in infrastructure; access to finance for SMEs $=>$ deal with NPLs, contract enforcement and credible collateral execution, efficient legal procedures including courts

- High quality education critical for competitiveness - reorient education to private sector demand

- SOE reform agenda critical for growth, emphasis should be placed on management and financing of these companies

- Importance of overvalued exchange rate on export competitiveness could be emphasized more

- Country risk still high - Serbia is still not yet a member of the WTO and this should be emphasized

- Savings and domestic resource mobilization:

- A key question should be how Serbia can increase savings to support growth. Options may be to focus on domestic resource mobilization for growth

- Remittances - it would be good if report can better capture this issue

- FDI, SMEs, access to finance and NPLs

- It is questionable how much Serbia can rely on FDI in the short term

- Serbia's financial sector is still fully bank-centric, SMEs have problems of access to finance, in particular long-term financing

- Capital market potentially a good source of equity finance for SMEs but government not helping (i.e. govt. focused only on debt market and not enough on capital market development)

- Most SME financing is short term, with long-term financing available. Why not consider setting up a development bank?

- High euroization with $2 / 3$ of the funds in euros - significant exchange rate risks

- High real interest rate at 6 percent - policy rate is still high at 8 percent

- High NPLs - 1/3 households, 2/3 corporate; absence of corporate restructuring main reason for not being able to reduce NPLs; collateral execution another problem

- No law on covered bonds in Serbia; factoring and reverse factoring not in place but should be introduced.

\section{Business climate issues}

- Business climate issues

- Annual "White Book" detailing the constraints to private investment in Serbia just published by the Council of Foreign Investors. Lots of similarities between this and the WB's list of constraints 
- Implementation does not work - poor governance, lack of predictability of rules and regulations

- Fiscal consolidation to ensure macro stability absolute priority

- Corporatization of SOEs and level-playing field with the private sector absolutely essential

- Reform the public administration - to raise quality and productivity

- Improve regulations; cut administrative barriers/ streamline current regulations; introduce the World Bank guillotine project again (last one was done in 2009);

- Tackle the inspection problem/ informal economy and the unfair competition it poses for the formal private sector

- Address the issues of construction permits, conversion of land use rights to ownership rights

- Remove foreign exchange restrictions (placed by the National Bank of Serbia)

- Skills per se no a constraint, but the quality of human capital overall—defined a skills plus costs - a constraint as quality is going down; soft skills lacking, adding to the cost of doing business

- Hilton case illustrates the difficulty of the business environment

$\circ$ Hilton has been trying to invest in Belgrade over the last several months, but a huge problem with city administration

- Sometimes hard to even identify what the problems are

- City administration staff unwilling to take decisions; sometimes expecting letter from above to resolve ordinary business issues; afraid of taking personal responsibility $\rightarrow$ for fear of consequences due to shifting rules and regulations

- Contract enforcement, courts

- Lack of clear legal procedures

- Lack of efficient contract adjudication, speedy court resolutions

Jobs, education, health and quality of human capital

- Education and vocational training

- Education, education, education over the long term

- Education should be more strongly highlighted in the report

- Current education curriculum does not teach citizenship

- Vocational training, soft skills lacking

○ Continuous learning virtually absent

- Problem of migration and brain drain - could be emphasized more in the report

- Health:

- Child mortality rates still high

- Large number of doctors to retire - so shouldn't rush to cut doctors in public admin reforms

○ Sill complex procurement system

- Jobs and labor market

○ High youth unemployment; NES supporting employability but does not guarantee employment

- It would be useful if the report could shade more light on dynamics of the labor market

- LFS quarterly survey available for the first time in Serbia

- Private sector not attractive for the unemployed

- Employment in informal sector seems to be increasing 
- Overstaffing in public sector:

- Need further analysis that confirms what the report claims, and count on the WBG to do that.

- No evidence that the non-SOE public administration in Serbia is oversized compared to other European countries

\section{Roma poverty}

- Criminalization of certain Roma activities needs to stop (e.g. settlement);

- Government development programs ethnically biased and exclude Roma;

- Not a single Roma project by the State over the last few years;

- Roma needs are ignored in laws and regulations

- How the government can help:

- Legalization of Roma settlements is one immediate step that the government can take to help the Roma, to help create jobs among the Roma community

- Creating education opportunities is critical

- Roma migration has been a natural response to criminalization of Roma settlements and lack of opportunities

\section{Energy}

- Energy poverty is high in Serbia $>60$ percent

- Serbia importing energy and investment decisions decades ago having an impact now (e.g. fossil energy, large infrastructure, etc.)

- Serbia energy/carbon intensity high

- Health and environmental impact of dirty energy through pollution significant- health cost estimated at RSD 4 billion

- $\quad$ Need to promote renewable energy through subsidies and guarantees

\section{Agriculture}

- Territorial and spatial dimension a huge issue! Report can pay more attention to this issue including lagging regions in Serbia

- Fragmented landholding problematic

\section{Prioritization}

- The discussion with government (of the full draft report with prioritized actions) confirmed the top priorities identified in the report are indeed the right ones- and the authorities requested in-depth discussions on how to address some of the priority areas such as governance and institutional capacity. 